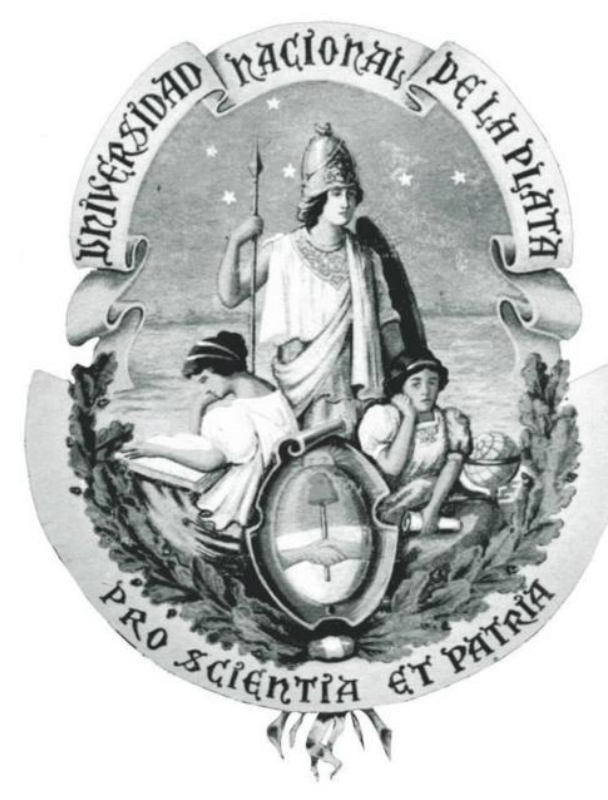

Facultad de Ciencias Naturales y Museo Universidad Nacional de La Plata

\title{
Caracterización genómico funcional de los neuropéptidos Allatotropina y Allatostatina-C y sus receptores en insectos vectores de la Enfermedad de Chagas
}

\author{
Licenciada María José Villalobos Sambucaro \\ 2017
}

Director: Dr. Jorge Rafael Ronderos

Co-director: Dr. Luis Aníbal Diambra

Cátedra de Histología y Embriología Animal de la Facultad de Ciencias Naturales y Museo - UNLP 


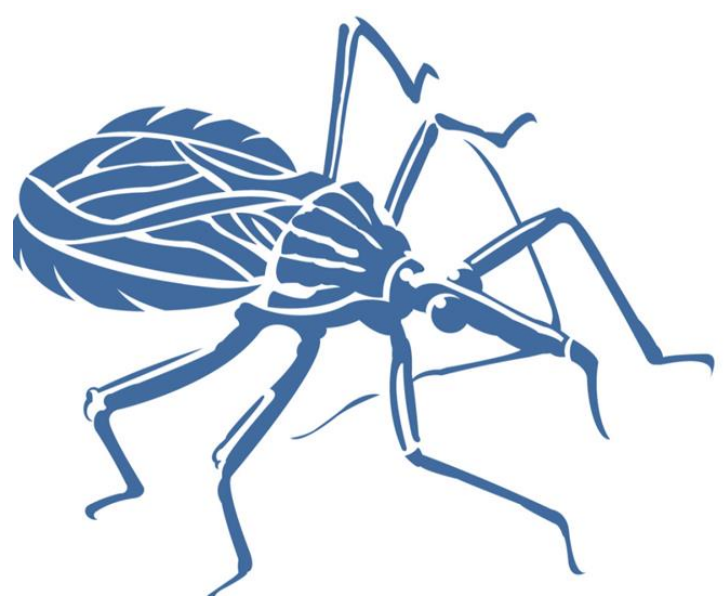

“...qué maravilla, Mi querida!!”

A mi queridísimo DIRECTOR, Dr. Jorge Rafael Ronderos

A mis PADRES, Marito y Chiche

A mi ABUCHA, con una sonrisa 


\section{AGRADECIMIENTOS}

Siempre digo que soy una persona afortunada, porque en esta profesión, donde deben ser protagonistas el compañerismo, la humildad y la generosidad entre las personas, he vivido todo eso y más. En esta etapa donde se forjan los primeros pasos como biólogo debo agradecer a varias personas el hecho de haber podido realizar mi trabajo de tesis con alegría y sin reproches en cuanto a mis logros.

En primer lugar a Mi querido Directorcin, Dr. Jorge Rafael Ronderos, maravilloso guía y persona excepcional. Generoso y paciente, que con su ejemplo me ha enseñado que trabajando con esmero y con honestidad, sobre todo con uno mismo, se llega a donde uno realmente quiere estar, a lo que uno de verdad quiere convertirse. Ronderín, no tengo palabras para expresar cuan orgullosa estoy de pertenecer a este laboratorio, y de lo feliz que me siento cuando entro a mi segunda casa. Gracias por haberme abierto las puertas, dejarme crecer en lo profesional y en lo personal, siempre entre risas y carcajadas, por dejarme jugar y hacer que todos los días se sientan como un viernes.

Agradezco al Dr. Luis A. Diambra, mi co-director, por atender mis consultas, la buena predisposición con la que siempre ha respondido mis preguntas, sin dejar pasar una palabra de aliento, de apoyo.

A mi querido, compañero, psicólogo, jefe (de cátedra) y AMIGO, el Dr. Fernando Riccillo, siempre dando la palabra justa. Precisamente las palabras son algo que te sobra, pero entre todas las que podés decir tenés las precisas. Gracias por la generosidad y la alegría que siempre brindás, esperando a cambio un rico mate.

A mi compañera de laboratorio y de viajes laborales, Dra. María Eugenia Alzugaray. Con vos y Jorgito, la perseverancia cobra vida, sin dudas. Te agradezco las conversaciones eternas, la amabilidad y el compañerismo. Sé que cuento con vos Euge.

Dr. Gustavo Calderón, mi gurú de la biología molecular, sos un personaje realmente asombroso. Tenés una bondad de la cual muchos deberían aprender, de la cual yo aprendo y trato de aplicar todos los días, en lo laboral, en la docencia, en la vida... Siempre atento a lo que un novato en ciertos temas puede necesitar, respondiendo a las preguntas más insólitas. Abriendo las puertas de tu laboratorio un sábado a las 10 AM o rotulando 50 tubos de PCR un 15 de enero, eso solo lo hacés vos!!!! Gracias!! 
Dra. María Cecilia Bruno, para mí La Reina del CREG 2013, siempre con una sonrisa, con esa personalidad admirable. Tu ayuda para aprender técnicas que para mí fueron nuevas y tediosas, me han alivianado la mochila en este trabajo. Tu compañía ha hecho que los viajes en el TALP y la subida por las escaleras, eternas, hasta llegar al cuarto piso sean divertidos. Sos valiosa y me alegra ser tu amiga.

Agradezco además, al Dr. Fernando Noriega, por invitarme a pasar buenos ratos, irrepetibles con él y con personas maravillosas, en lugares insólitos. Siempre ofreciendo posibilidades, facilidades, sabiduría, conocimientos, oportunidades. Sos ejemplo de que no hay que olvidarse de las raíces, y lo practicaré, siempre.

Sigo con las chicos del CREG y del INIBIOLP: GENIOS totales! Gracias por ayudarme y enseñarme una y otra vez todo, desde cómo prender una autoclave hasta cómo programar una termocicladora. Gracias por las recomendaciones en lo cotidiano del trabajo en el laboratorio, por los mates y la buena onda. Así se trabaja feliz muy fácilmente!! No voy a dejar de nombrarlos a todos: Lucila Traverso, Natalia Capriotti, Ivana Sierra, Naly (Natalia Cabrera), Lorena Caligiuri, Luciana Escobar, Cristina Mc Carthy, Débora Moriconi, Andrea Dulbeco, Belen, Carla, Marianela y Eli. Realmente me han hecho sentir siempre cómoda y como en mi casa cada vez que llegaba a sus laboratorios.

A mis Compañeros y AMIGOS de la mejor cátedra de la Facultad de Ciencias Naturales y Museo: Histología y Embriología Animal. Gracias a todos, los veintitantos docentes, a los de siempre y a los que han pasado por el aula B8. Con especial mención a Patricia Rey, Guillermo Panisse, Silvia Plaul, Juan Pablo Pilili, Matías Giglio, Laurita Genchi, Marianita Adami, Pilar Guimarey, Ceci Bruno, Gus Calderón: cómo me gusta crecer con ustedes! Siempre atentos a mis avances, en cada paso que doy en lo profesional, como investigadora y como docente. Realmente he sido favorecida por poder almacenar vivencias con personas maravillosas como ustedes.

Jamás imaginé que podría haber gente tan peculiar en la FCNyM que me cambiarían la vida. De esas personas que toman de la mano bien fuerte y siempre llegamos juntos a buen puerto. Mis AMIGOS BIOLÓGICOS: sus éxitos son los míos, su felicidad es la mía y sé que sienten lo mismo hacia mí. Angie, mi hermana y compañera de aventuras. No tengo palabras para describir lo que sos en mi vida, lo que fuiste en esta etapa de ocurrencias, a las cuales te he arrastrado. Por la sinceridad de siempre, por llevarme de la mano y alentarme en todo; Sole, yo soy tu bastón para sostenerte y vos sos el mío (aunque seas uno aberrante). Sonriendo empezamos juntas y sonriendo aún más terminamos de igual manera, juntas; Belucha, mi 
locaza, mi recreo, mi cuota diaria de buena onda y positividad que ni 1350 kilómetros pueden alejar; Fabi, mi amigo que todo hace mejor que nadie con humildad y grandeza. Juro que cuando crezca quiero ser como vos, tenaz, valiente, despojado de todo prejuicio, de otro planeta! Gracias por todo chicos, mis sucesos laborales solo puedo compartirlo con ustedes porque saben qué significan, porque somos los bichos raros de la sociedad y nadie los entiende. Vamos por todo, siempre juntos!!!

Gracias MAMÁ Y PAPÁ, por enseñarme que hay que amar lo que uno hace. Que el trabajo es una bendición y se hace todos los días con esmero, con paciencia, con inteligencia, que todos somos iguales y debemos respetarnos y cuidar el lugar de trabajo. A que no hay que bajar los brazos. Que siempre hay que saludar con una sonrisa y un "buen día", a decir "sí, como no", "por favor" y "gracias". Ciertamente, ser educado es la clave del éxito, sonreír para que el otro te sonría, eso me ha facilitado el camino recorrido hasta ahora. Gracias por enseñarme a pensar y decidir con libertad. Me han hecho especial, gracias por eso. LOS AMO!

Agradezco a mis hermanos, Pipi, Tincho y Ceci, y agrego a mi cuñado Luciano, que festejan cada cosa buena que me pasa como si fuera carnaval. Por confiarme a sus hijos, Brune, Isa, Joaqui, Emi y el bebé Francisco, corriendo el riesgo de que caigan en mis influencias biológicas. Creo que son muy fuertes, cuidado...

He aprendido a ser doctorando al mismo tiempo que he aprendido a ser parte de una familia nueva: la MIA. Nicolás, mi amor: te he apabullado cada cena contándote resultados, anécdotas, protocolos, trabajos científicos, experimentos, disecciones, horas de bioterio, proyectos, etc. etc. etc., y siempre me has escuchado, me has aconsejado y opinado con real interés, me has buscado y llevado a cualquier hora. Has hecho una mejor versión de mí. Vos con un mate, el Giuseppe moviendo su colita y la Michila ronroneando me han alegrado los días de mal humor, con cariño genuino. Tenemos un proyecto de vida juntos y como siempre te digo: nunca me sueltes la mano.

Por último, quiero recordar a mis abuelas Iris María Bollo de Villalobos y María Elena Bianchi, mejor conocidas como ABA y NONA. Dos personas distintas en carácter pero igual de sabias. La inteligencia era una cualidad sobresaliente en ellas. Gracias viejas amadas, porque con lo que han sido en esta vida me han enseñado que se puede combinar perfectamente el hecho de disfrutar de la vida mientras se trabaja responsablemente, dándolo todo, haciendo lo que uno realmente quiere y desea, sin importar nada ni nadie, sin prejuicios, sin sentimientos de envidias, mejorando cada día, siguiendo sueños! 
Gracias infinitas

Cocó 


\section{Índice}

RESUMEN

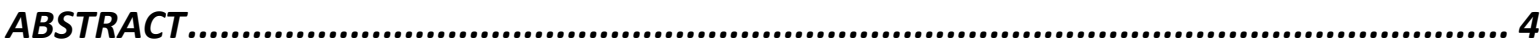

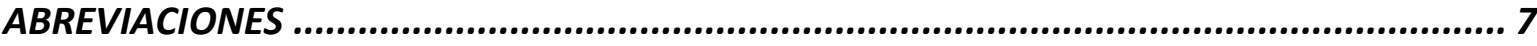

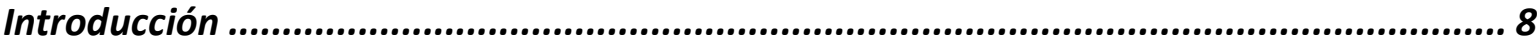

1.1 Rhodnius prolixus: GENERALIDADES SOBRE SU BIOLOGÍA E IMPORTANCIA SANITARIA ......... 9

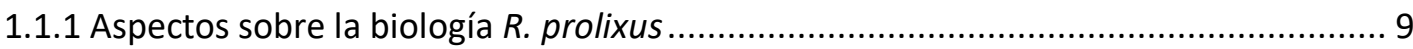

1.1.2 Importancia Sanitaria de los Insectos Triatominos .............................................. 10

1.2 ANATOMÍA Y FISIOLOGÍA DE LOS SISTEMAS DE ÓRGANOS DE R. prolixus DE INTERÉS EN

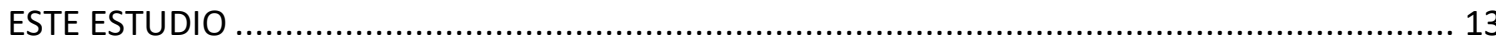

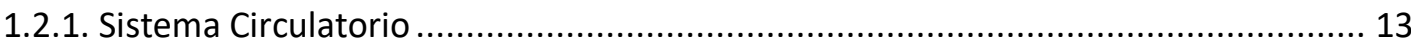

1.2.2. Fisiología de la Alimentación y Mecanismos de Control Durante la Diuresis............ 15

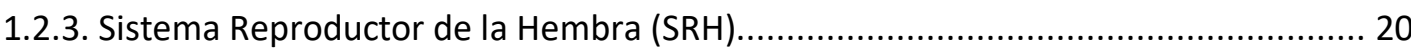

1.3 CONCEPTOS SOBRE LAS HORMONAS JUVENILES Y SU ROL EN EL PROCESO DE LA MUDA Y

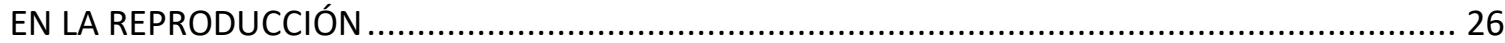

1.4 HORMONAS ALLATOTRÓPICAS: CARACTERÍSTICAS MOLECULARES, GENÓMICAS Y

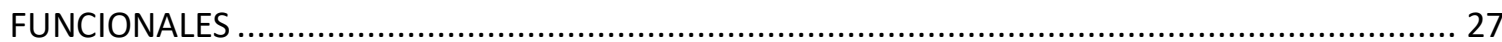

1.4.1. LA ALLATOTROPINA: Estructura Molecular y Funciones......................................... 27

1.4.2. LAS ALLATOSTATINAS: Diversidad y Funciones ....................................................... 30

1.5 RECEPTORES DE MEMBRANA ACOPLADOS A PROTEÍNA G (GPRC) ...................................... 34

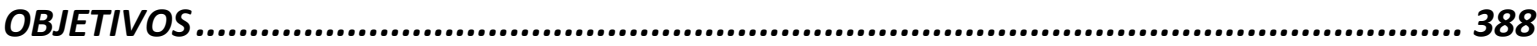

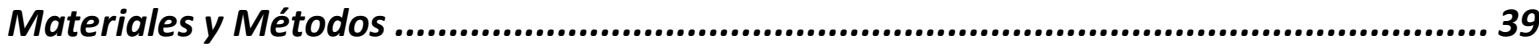

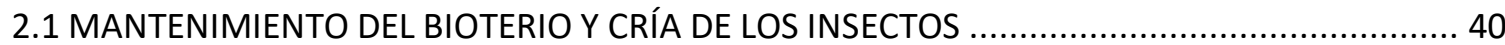

2.2 PÉPTIDOS Y ANTISUEROS UTILIZADOS EN LOS BIOENSAYOS: ALLATOTROPINA Y

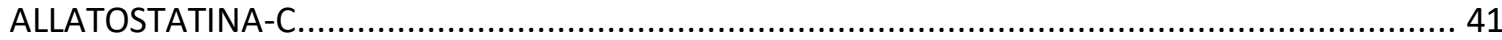

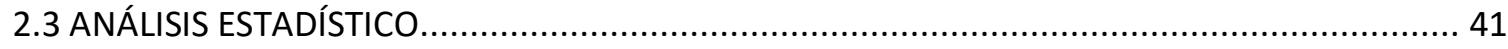

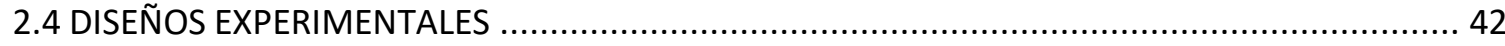

2.4.1 Experimentos en insectos machos adultos ...................................................... 42

2.4.2. Experimentos en insectos hembras adultas....................................................... 45

2.5 ESTUDIO DE LA PRESENCIA DE ALLATOSTATINA-C MEDIANTE MICROSCOPÍA LASER DE

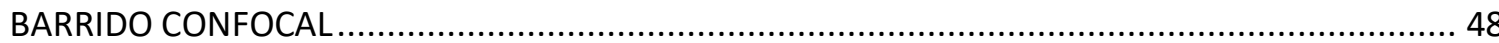

2.6 CARACTERIZACIÓN DE LOS RECEPTORES DE MEMBRANA DE ALLATOTROPINA (ATr) Y

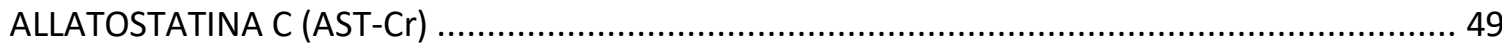

2.6.1 Búsqueda de las secuencias de los receptores en el genoma ................................ 49

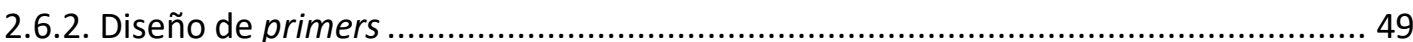


2.6.3. Extracción de RNA mensajero (mRNA) y síntesis de DNA complementario (cDNA) . 50

2.6.4 Análisis de la expresión de ATr y AST-Cr ................................................................ 50

2.6.5. Precipitación, purificación y secuenciación de productos de PCR ........................... 51

2.7 ANÁLISIS FILOGENÉTICOS DE LOS RECEPTORES DE MEMBRANA DE ALLATOTROPINA (ATr)

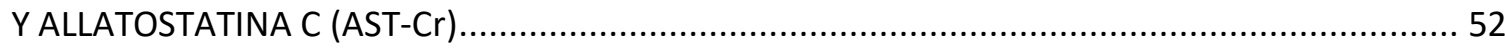

2.7.1. Búsqueda de secuencias homólogas en bases de datos ........................................ 52

2.7.2. Alineamientos múltiples y construcción de árboles filogenéticos............................ 52

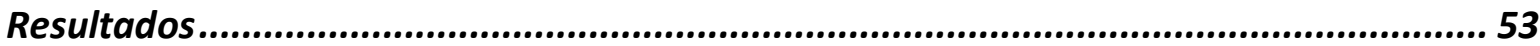

3.1 ANÁLISIS DE LA ACTIVIDAD MIO-REGULADORA DE AT Y AST-C SOBRE EL SISTEMA CIRCULATORIO Y DIGESTIVO DE MACHOS ADULTOS DE R. prolixus.......................................... 54

3.1.1 Análisis de la actividad de allatotropina y variaciones diarias en la frecuencia cardiaca basal en machos adultos ayunados.

3.1.2. Estudio del efecto mio-regulador de Allatotropina sobre la aorta y el digestivo medio anterior en presencia de serotonina en insectos ayunados.

3.1.3. Efecto de la administración a través de la ingesta de un antisuero anti-AT sobre la frecuencia de contracciones de la aorta y la tasa de ondas peristálticas del buche durante la diuresis post-prandial.

3.1.4 Estudio del efecto de Allatostatina-C sobre la actividad cardioaceleradora de serotonina/allatotropina en machos adultos sin alimentación previa

3.1.5 Estudio del efecto mioinhibidor de Allatostatina-C sobre la frecuencia de contracciones de la aorta y del digestivo medio anterior durante el periodo de diuresis post-prandial.

3.2 ¿DÓNDE SE PRODUCE EL PÉPTIDO QUE MODULA LA ACTIVIDAD DE LA AORTA Y EL BUCHE?: ANÁLISIS INMUNOHISTOQUÍMICO DE LA EXPRESIÓN DE ALLATOSTATINA-C MEDIANTE MICROSCOPÍA LASER DE BARRIDO CONFOCAL

3.3 PÉPTIDOS ALLATOREGULATORIOS COMO MIO-REGULADORES EN EL SISTEMA

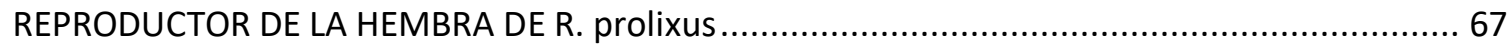

3.3.1 Evaluación del efecto dosis dependiente de Allatotropina sobre el SRH. .................67 67

3.3.2 Evaluación del efecto de Allatostatina-C sobre el SRH. ........................................ 72

3.4 CARACTERIZACIÓN GENÓMICA Y EXPRESIÓN DE LOS RECEPTORES DE MEMBRANA DE ALLATOTROPINA (RpATr) Y ALLATOSTATINA C (RpAST-Cr) .................................................... 74

3.4.1 Caracterización genómica y expresión de ATr..................................................... 74

3.4.2 Caracterización genómica y expresión de AST-Cr.................................................. 76

3.5 ANÁLISIS FILOGENÉTICOS DE LOS RECEPTORES DE ALLATOTROPINA Y ALLATOSTATINA-C .. 78

3.5.1 Búsqueda bioinformática de secuencias homólogas ........................................... 79

3.5.2 Construcción de los árboles filogenéticos ........................................................... 86

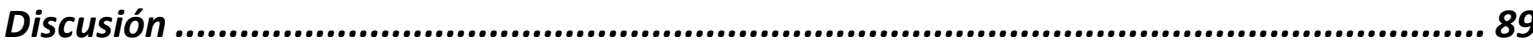




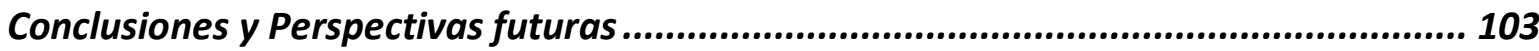

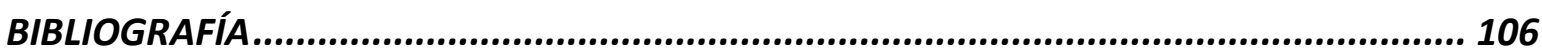

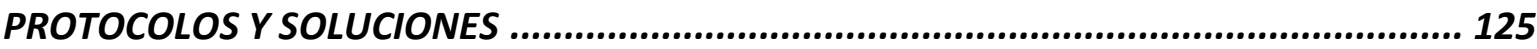

ANEXO 
Allatotropina (AT) y Allatostatina-C (AST-C), son neurohormonas de naturaleza proteica caracterizadas por su capacidad de estimular o inhibir la síntesis de hormonas juveniles en insectos, respectivamente. Estos péptidos han demostrado ser pleiotrópicos. AT cumple diferentes funciones a nivel del sistema nervioso central como neuromodulador además de controlar ritmos circadianos, estimula la síntesis de enzimas y controla el transporte de iones a nivel del tubo digestivo, intervienen en la actividad fagocítica de las células del sistema inmune, y se encuentra regulando la frecuencia de contracción de la musculatura asociada al tubo digestivo y del vaso dorsal. Por otro lado, la información sobre las funciones que desempeña AST-C es escasa. Se ha descripto que modula negativamente las contracciones de la musculatura visceral del intestino anterior en lepidópteros y del vaso dorsal de algunos dípteros.

Rhodnius prolixus (Hemiptera:Reduvidae), es un insecto hematófago vector del Mal de Chagas, enfermedad endémica de América, la cual provoca patologías coronarias y asociadas al tubo digestivo. El causante de esta enfermedad en el parásito Trypanosoma cruzi y la trasmisión del mismo ocurre cuando los insectos se alimentan. En ese momento se desencadena el proceso de diuresis post ingesta, generando la eliminación de grandes cantidades de orina y heces sobre el huésped. El parásito ingresa al mismo a través de estos desechos por la injuria provocada por el aparato sucto-picador. El proceso de diuresis es controlado por mecanismos neuroendocrinos, para reestablecer el desbalance hídrico-mineral provocado durante la ingesta. Nuestro laboratorio ha demostrado en la especie afín, Triatoma infestans, que AT interviene en la modulación de la frecuencia cardíaca y de la tasa de ondas peristálticas en el tubo digestivo durante este proceso, lo cual propicia la recirculación de la hemolinfa. Nos es relevante entonces, caracterizar la actividad de este péptido y analizar el efecto del péptido allatostático AST-C, así como la expresión de sus receptores en $R$. prolixus, en el sistema digestivo, circulatorio y reproductor durante momentos fisiológicos cruciales en la vida del insecto como lo son el proceso de diuresis post-prandial, la cópula y la oviposición en la hembra adulta.

Se evaluó la capacidad miomoduladora de AT y AST-C durante distintos momentos fisiológicos. AT demostró poseer la capacidad de sinergizar el efecto estimulador de la serotonina, incrementando la frecuencia de contracción de la aorta en insectos machos ayunados, mientras que AST-C antagonizó dicha actividad, disminuyendo significativamente la frecuencia de este órgano. Así mismo, este péptido disminuyo la actividad contráctil de 
manera dosis dependiente durante el proceso de diuresis post ingesta tanto en la aorta como en el buche.

Mediante el uso de microscopía de barrido laser confocal se demostró la presencia de AST-C en los ganglios nerviosos ventrales (órganos neurohemales), en la hemolinfa del interior del corazón, en los nefrocitos asociados a los músculos alares, y en las células secretoras del epitelio del buche.

El efecto miomodulador de AT y AST-C en el sistema reproductor de la hembra fue analizado en diferentes estados fisiológicos (hembras ayunadas, vírgenes y copuladas alimentadas y grávidas). Cada uno de los péptidos respondió de manera dosis dependiente. Los eventos de la cópula y la ingesta sanguínea demostraron ser condicionantes para que cada péptido desempeñe su actividad. Más aún, cada órgano que se encuentra conformando este sistema respondió de manera diferencial ante la presencia de los péptidos. AT demostró ser mioestimulador en ambos casos, mientras que no hubo respuesta sobre los órganos en hembras vírgenes que no habían recibido alimento. Por otro lado, AST-C provocó un descenso significativo en la frecuencia de contracción de los ovarios de las hembras grávidas.

Los receptores de ambos péptidos fueron clonados, secuenciados y registrados en el Genbank. Su expresión fue evidenciada en los órganos en estudios además de los tubos de Malpighi y recto. Los mismos pertenecen a la familia de los GPCRs (receptores de membrana acoplados a proteína G). Mediante el análisis genómico y bioinformática identificamos que las características propias de estos receptores se encuentran altamente conservadas entre las secuencias homólogas de insectos. Dichos análisis arrojaron como resultado que el receptor de AT de $R$. prolixus comparte características estructurales con los receptores de orexina de mamíferos, tales como la secuencia ubicada en el segundo dominio intracelular $\underline{D R W}$, mientras que el receptor de AST-C es homólogo con aquellas secuencias que se encuentran relacionadas evolutivamente con los receptores de somatostatina de mamíferos, ya que poseen no solo la secuencia de $\underline{D R Y}$, característica de la familia de los GPCR, sino que además presenta el motivo secuencial YSNSAMNPILYA, altamente conservado en los receptores tipo somatostatina.

En conclusión, utilizando diferentes disciplinas y metodologías, el presente trabajo de investigación cuenta con el primer reporte en cuanto a la relación funcional de péptidos allatotrópicos como moduladores del a musculatura visceral. Se ha profundizado en el entendimiento de las funciones mioestimuladoras que cumple AT, mientras que se ha descripto por primera vez el efecto antagónico de AST-C sobre el mismo. Se demuestra, además, su distribución en insectos triatominos explicando su probable fuente de síntesis y 
acción. Siendo el genoma de esta especie accesible llevamos a cabo la caracterización genómica de ambos receptores, cuya familia a la que pertenecen es de sumo interés ya que podrían ser utilizadas como potenciales alternativas para el desarrollo de nuevos agentes selectivos para el control de plagas. 
Allatotropin (AT) and Allatostatin-C (AST-C) are neuropeptides characterized by their ability to stimulate or inhibit the juvenile hormones synthesis in insects, respectively. They are pleiotropic too: AT performs different functions at the level of the central nervous system as a neuromodulator and as a controller of circadian rhythms. Also, AT stimulates the synthesis of enzymes and regulate the transport of ions at the level of the digestive tract ; it is implicated in the phagocytic activity in the cells of the immune system, and stimulates the frequency of contraction of the wall muscles of the gut and dorsal vessel. On the other hand, little is known about functions that AST-C could perfom. It acts as a myoinhibitory peptide on the spontaneous contractions of the anterior gut in lepidopterous and in the heart in dipterous.

The Chagas disease vector, Rhodnius prolixus (Hemiptera: Reduvidae), is a haematophagous insect useful to design physiological experiments to increase the knowledge about the biology of this insect with health importance. This illness is endemic of America and is caused by the parasite Trypanosoma cruzi, which provoke coronary and gut pathologies. The transmission occurs when the insect feeds on blood. At that moment the process of diuresis post prandial starts, provoking the elimination of large amounts of urine and feces on the host. The parasite enters through these wastes by the injury caused by the insect when its feeds. During the diuresis process, the mineral hydric balance is altered and controlled by neuroendocrine mechanisms. Our laboratory has shown in the related specie, Triatoma infestans, that AT is involved as miomodulator in the aorta's frequency and peristaltic wave's rate of the gut during the diuresis process. The movements of the wall of these organs cause the re-circulation of the haemolymph during this process. The aim of this research is to increase de knowledge about the functional characterization of the neuropeptides AT and AST$\mathrm{C}$ as well as the expression of their receptors in R. prolixus, in the digestive, circulatory and reproductive system during the crucial physiological events in the life cycle of the insects like diuresis process, the mate and oviposition in the adult female.

The ability of AT and AST-C to modulate the visceral muscles was evaluated during different physiological states. AT synergizes the stimulatory effect of serotonin, increasing the frequency of contraction of the aorta in unfed male insects, whereas AST-C antagonized this effect, reducing significantly the frequency of this organ. AST-C inhibitory effect was also evaluated over the frequency of peristaltic waves of the crop as well as the aorta during the diuresis process. 
Images of confocal laser scanning microscopy showed the presence of AST-C in the ventral nerves ganglions (neurohaemals organs), in the haemolymph inside the heart, in the nephrocytes associated with the allary muscles, and in the secretory cells of the crop epithelium.

The myomodulatory effect of AT and AST-C on the female reproductive system was evaluated at different physiological states, both of them acted as dose dependent way. Mating and feeding events are factors that modulate the activity of both peptides. Moreover, each organ of this system showed to be affected on different way when the peptides had been applied. Myostimulatory effect of AT was carry out in mated unfed females as well as on gravid ones, whereas there was no response on the organs in unfed virgin females. On the other hand, AST-C caused a significative decrease in the frequency of contraction of gravid ovaries.

AT and AST-C receptors were sequenced and annotated in Genbank. They belong to the GPCRs family (G protein coupled receptors). The genomic and bioinformatic analysis let us identify that the structure characteristics of these receptors are highly conserved among the homologous insects sequences. $R$. prolixus AT receptor shares structural features with mammalian orexin receptors, such as the aminoacid sequence $\underline{D R W}$ located in the second intracellular domain, whereas the AST-C receptor seems to be homologous with those sequences which are found to be related to mammalian somatostatin receptors, because they possess not only the $\underline{D R Y}$ sequence, characteristic of the GPCR family, but also presents the sequential motif YSNSAMNPILYA, highly conserved in somatostatin like receptors.

In summary, by the use of different methods and disciplines, this research has the first report on the functional relationship of allatotropic peptides as myoregulators over the aorta, crop and the reproductive female system. We deepen the understanding of the myostimulatory functions of AT, while the antagonistic effect of AST-C over the AT activity has been described for the first time. Couse the genome of this insect is available, we carry out the genomic characterization of both receptors. Nowadays, GPCR family to which they belong has a great interest because they just could be use as new selective agents for pest control.

In summary, by the use of different methods and disciplines, this research work has the first report on the functional relationship of allatotropic peptides as myoregulators over de aorta, crop and the reproductive female system. We deepen the understanding of the myostimulatory functions of AT, while the antagonistic effect of AST-C over the AT activity it has been described for the first time. It is also demonstrated that the distribution of this peptide in triatomine insects that explain its probable source of synthesis and activity on the 
studied organs. Couse the genome of this insect is available, we carry out the genomic characterization of both receptors. Nowadays, GPCR family to which they belong has a great interest because they just could be use as new selective agents for pest control. 


\section{ABREVIACIONES}

3TM: $3^{\circ}$ dominio transmembrana

7TM: $7^{\circ}$ dominio transmembrana

AST-Cr: receptor de Allatostatina-C

ATr: receptor de Allatotropina

BSA: albúmina de suero bovino

CA: Corpora Allata

Calcio: $\mathrm{Ca}^{+2}$

CC: Corpora Cardiaca

cDNA: DNA complementario

DNA: del inglés deoxyribonucleic acid

dNTP: Trifosfato deoxiribonucleotido

GPCR: del inglés $G$ proteine couple receptor, Receptores acoplados a proteína $\mathrm{G}$

HC: Hembras ayunadas copuladas

HG: Hembras alimentadas copuladas grávidas

HJ: Hormona Juvenil

HJs: Hormonas Juveniles

HV: Hembras ayunadas vírgenes

LSCM: Microscopía Laser de Barrido Confocal

M: Molar.

$\mathrm{mM}$ : milimolar.

$\mu \mathrm{M}$ : micromolar.

$\mu \mathrm{l}$ : microlitros.

mRNA: RNA mensajero

N4: larva de $4^{\circ}$ estadio

ORF: del inglés Open Reading Frame

$\mathrm{Pb}$ : pares de bases

PBS: del inglés Phosphate Buffered Saline

solución buffer fosfato

PBS-T: PBS-Tween (0,05\%)

PCR: del inglés Polymerase Chain Reaction, Reacción en cadena de la Polimerasa

RNA: del inglés ryribonucleic acid

Rp-AST-Cr: receptor de Allatostatina-C de $R$. prolixus

$\mathrm{Rp}-\mathrm{ATr}$ : receptor de Allatotropina de $R$. prolixus

SNC: sistema nervioso central

SRH: sistema reproductor de la hembra

TG: Tapsigargina

TMs: tubos de Malpighi

VD: vaso dorsal 
Introducción 


\subsection{Rhodnius prolixus: GENERALIDADES SOBRE SU BIOLOGÍA E}

\section{IMPORTANCIA SANITARIA}

\subsubsection{ASPECTOS SOBRE LA BIOLOGÍA R. prolixus}

Sir Vincent Wigglesworth (1899-1994), padre de la neuroendocrinología, fundó sus conocimientos realizando experimentos fisiológicos sobre el insecto hematófago Rhodnius prolixus (Stal, 1859) (Hemiptera: Reduvidae), organismo de importancia sanitaria ya que actúa como vector de la Enfermedad de Chagas. Sus trabajos científicos, pioneros en el conocimiento sobre la fisiología de insectos, se basaron en experimentos exhaustivos y minuciosos, que hoy siguen teniendo peso científico y son tomados como punto de partida para postular nuevas hipótesis de investigación.

Con respecto a R. prolixus, Buxton en el año 1930 publicó un trabajo titulado The Biology of a Blood-sucking Bug, Rhodnius prolixus, donde al inicio del mismo enunció:

"Son tan fáciles de criar y mantener en el laboratorio, y tan grandes, lo que los hace seguros de ser utilizados para estudiar los procesos de la digestión de la sangre, y en la fisiología de un insecto hematófago; pero esto no puede hacerse hasta que se hayan publicado datos cuantitativos cuidadosos relacionados con su ciclo de vida normal".

Es así que describió en detalle el ciclo de vida de este insecto hemimetábolo:

- Consta de cinco estadios larvales previos al estado adulto (Fig. 1A).

- Pueden ser criados en un rango de temperaturas de $24-30^{\circ} \mathrm{C}$.

- Cada estadio es hematófago obligado.

- El volumen de sangre que ingieren los insectos debe ser óptimo para que sea desencadenado en proceso de muda.

- Las larvas pasan al siguiente estadio al cabo de 12-15 días luego de haberse alimentado ad libitum.

- Tanto los machos como las hembras también requieren de un estado nutricio adecuado para que se desencadene la maduración de los órganos reproductores. La producción y el desarrollo de los huevos dependen del control neuroendocrino y de la cascada de señales producida por la ingesta.

- La oviposición comienza luego de 12-15 días después de la ingesta. 
Posteriormente se describió, también, el fenómeno de autogenia en tres especies de triatominos, entre ellas R. prolixus (Noriega, 1992). Este fenómeno se define como la capacidad que poseen las hembras de algunos insectos de producir huevos sin haberse alimentado durante el estado adulto, ya que las reservas nutricias almacenadas durante los estadios larvales han sido suficientes para desencadenar el desarrollo de huevos viables.

Los triatominos, se alimentan de sangre de aves y mamíferos. Estos insectos habitan una variedad de ambientes, desde hábitats silvestres hasta hábitats domiciliarios y peridomiciliarios. Siendo versátiles, pueden adaptarse a una variedad de climas aunque sus poblaciones se distribuyen principalmente en zonas intertropicales (Medone et al., 2015; de la Vega et al., 2015). También llegan a regiones templadas con estación invernal marcada como la Patagonia y centro de Estados Unidos. Las poblaciones de R. prolixus se ubican en un rango geográfico que se extiende entre los $18^{\circ}$ latitud norte y $3^{\circ}$ latitud sur, comprendiendo las regiones de América Central y el extremo norte del Cono Sur, aunque estudios de predicción de distribución poblacional estiman que ese rango geográfico se ampliaría por el incremento de la temperatura a causa del calentamiento global (Medone et al., 2015; de la Vega et al., 2015). Más allá de esta información, se asegura que gracias a distintos mecanismos de control se habrían eliminado las poblaciones de este insecto en países como Costa Rica, El Salvador y Guatemala, declarando así la región de Mesoamérica libre de la enfermedad de Chagas (Hashimoto \& Schofield, 2012).

\subsubsection{IMPORTANCIA SANITARIA DE LOS INSECTOS TRIATOMINOS}

El Mal de Chagas en una enfermedad endémica de América Latina, causada por el parásito flagelado Trypanosoma cruzi. Puede provocar en un 30\% de las personas afectadas trastornos cardiacos y hasta un 10\% presentan alteraciones digestivas (típicamente, agrandamiento del esófago o del colon), neurológicas o mixtas. Con el paso de los años, la infección puede causar muerte súbita por arritmias o insuficiencia cardiaca progresiva por destrucción del músculo cardiaco y sus inervaciones (www.who.int). Varias especies de triatominos son vectores de esta enfermedad, entre las más importantes se encuentran Triatoma infestans (principal vector en nuestra región) y R. prolixus. Los datos epidemiológicos relevados por la Organización Mundial de la Salud (OMS) en el año 2013 estimaron un total de entre siete y ocho millones de personas infectadas en América Latina (www.who.int). En el contexto de la globalización económica y cultural de las últimas décadas, las migraciones humanas se han incrementado, haciendo cada vez más frecuente la posibilidad de que las personas habiten en lugares diferentes a su sitio natal. En este marco, los escenarios epidemiológicos de las enfermedades infecciosas se vuelven 
cambiantes y dinámicos, y comienzan a emerger enfermedades tradicionalmente restringidas a una zona, en áreas originalmente no endémicas. El Mal de Chagas no queda al margen de esta situación y presenta nuevos desafíos para la comunidad internacional que debe visibilizarlo como una problemática de salud concreta y compleja, que no solo se restringe a parajes rurales de áreas endémicas sino que se ha convertido en una realidad tangible en ciudades. De hecho, en los últimos años la OMS ha reconocido al Chagas como una de las enfermedades más relevantes en América Latina y el mundo. Solo en Estados Unidos el sistema de salud estima que existen entre 80.000 y 120.000 personas infectadas por el T. cruzi. De igual manera se estima que aproximadamente 100.000 personas se encuentran infectadas en Europa, Canadá, Australia y Japón (Sanmartino et al., 2015). Según informa el Programa Nacional de Chagas del Ministerio de Salud de la Nación Argentina, en nuestro país se calcula que un 1.500 .000 personas tienen Chagas, es decir, un $4 \%$ de la población. Este valor coloca a la enfermedad como uno de los principales problemas de salud pública, habiendo personas con Chagas en todo el país debido a que además de la transmisión vectorial, las migraciones humanas y la existencia de otras vías de transmisión distribuye la enfermedad a lo largo de todo el territorio (www.msal.gob.ar/chagas/index.php/informacion-para-ciudadanos/el-chagas-en-el-pais-yamerica-latina).

La transmisión del parásito $T$. cruzi se produce principalmente por contacto con las heces y orina de insectos infectados en el momento en que se están alimentando. Por lo general, estos viven en las grietas y huecos de las paredes y los tejados de casas precarias en zonas rurales y suburbanas. Normalmente permanecen ocultos durante el día y por la noche entran en actividad alimentándose de sangre humana y de los animales domésticos. Los parásitos penetran en el organismo cuando la persona picada se frota instintivamente acercando las heces y la orina hacia la picadura, los ojos, la boca o alguna lesión cutánea. La trasmisión también puede ocurrir por consumo de alimentos contaminados con T. cruzi, por la transfusión de sangre infectada, por la transmisión de la madre infectada a su hijo durante el embarazo o el parto, por el trasplante de órganos provenientes de una persona infectada y por accidentes de laboratorio (www.who.int) (Fig. 1B). 
Figura 1: A: esquema que explica el ciclo de vida de la especie de vinchuca Rhodnius prolixus. B: Ciclo de transmisión de la enfermedad de Chagas. 1:La vinchuca pica a una persona o animal y contrae el parásito Trypanosoma curzi. 2: dentro del tracto digestivo del insecto se desarrolla parte del ciclo de vida del parásito. Cuando éste vuelve a alimentarse, infecta a una nueva persona o animal. 3: Al alimentarse, comienza el periodo de diuresis post ingesta, donde el insecto defeca sobre la piel, cerca de la injuria que provocó su aparato suctor. 4: Por allí, pueden ingresan los parásitos y continuan su ciclo dentro del hospedador. Extraído de hablamosdechagas.com.ar

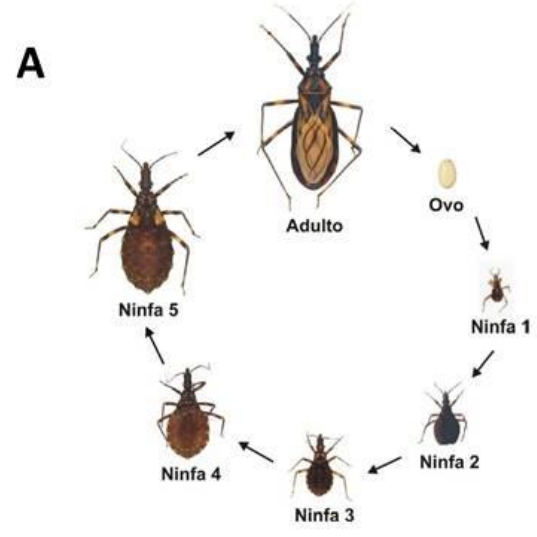

B

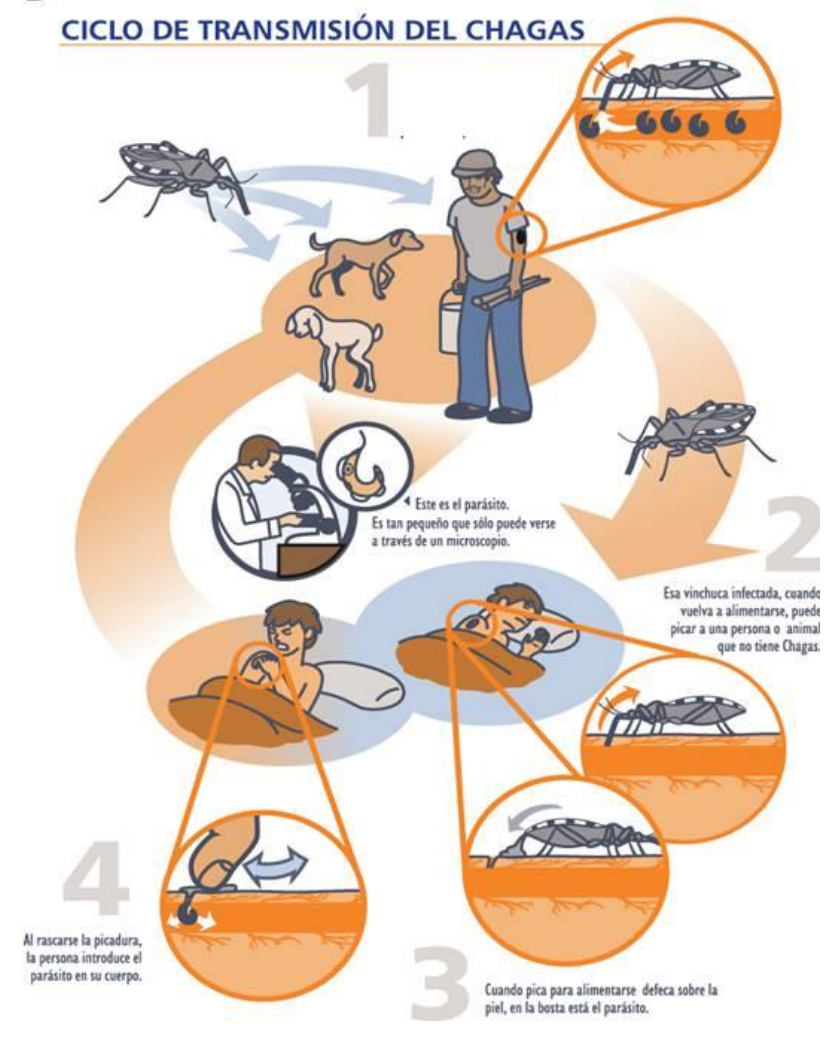

Debido a su importancia sanitaria, profundizar en el conocimiento de los distintos aspectos que hacen a la fisiología de los insectos triatominos resulta de interés para el desarrollo de nuevos métodos de control de las poblaciones, alternativos a los clásicos insecticidas. Desde el punto de vista experimental, el hecho de contar con información sobre el genoma de la especie $R$. prolixus (Mesquita et al., 2015), sumado a los conocimientos sobre su fisiología se conjugan para generar y responder nuevas preguntas genómico funcionales que pueden ser luego extrapoladas a otras especies de importancia regional.

Como hemos señalado anteriormente, la fuente de contagio más importante está relacionada con el intenso proceso de diuresis que se produce luego de la ingesta sanguínea, y que comienza instantes después de que el insecto inicia el proceso de alimentación, generando la eliminación de grandes cantidades de orina y heces sobre el huésped. Si bien los aspectos endocrinos que regulan la actividad de los túbulos de Malpighi (TMs) (principal órgano excretor en insectos) durante este proceso han sido ampliamente estudiados (ver Orchard, 2009), los aspectos asociados a los mecanismos que regulan la velocidad de recirculación de la hemolinfa, que permiten el normal funcionamiento de los TMs, y la eliminación de la orina durante el proceso, han sido en buena parte dejados de lado. Respecto 
a este punto, nuestro laboratorio ha demostrado que el neuropéptido Allatotropina (AT) interviene en la modulación de la frecuencia cardíaca y de la tasa de ondas peristálticas en el tubo digestivo de la especie emparentada T. infestans (Santini \& Ronderos, 2007, Sterkel et al., 2010). Nos es relevante entonces, caracterizar ahora la actividad de este péptido así como la expresión de su receptor en $R$. prolixus, y analizar el efecto del péptido allatostático Allatostatina-C (AST-C) en el sistema digestivo, circulatorio y reproductor durante momentos fisiológicos cruciales en la vida del insecto como lo son el proceso de diuresis post-prandial, la cópula y la oviposición en la hembra adulta.

\subsection{ANATOMÍA Y FISIOLOGÍA DE LOS SISTEMAS DE ÓRGANOS DE R. prolixus DE INTERÉS EN ESTE ESTUDIO}

\subsubsection{SISTEMA CIRCULATORIO}

Los insectos poseen un sistema circulatorio de tipo abierto, donde la hemolinfa baña los órganos de forma directa, facilitando el intercambio de nutrientes, desechos y hormonas, y participando además en la termo-regulación. La hemolinfa es impulsada por una bomba contráctil, el corazón, ubicada dorsalmente a lo largo de la línea media del abdomen, que se continúa con un conducto muscular denominado aorta que recorre el tórax y la cabeza (Hertel \& Pass, 2002; Klowden, 2013).

El sistema circulatorio de los triatominos presenta algunas modificaciones morfológicas, respecto al plan general presente en otros insectos. El corazón pulsátil se localiza en el extremo posterior del abdomen ocupando los segmentos VI, VII y VIII. A partir de esta estructura se extiende hacia el extremo cefálico la aorta, que recorre la línea media dorsal del abdomen (Fig. 2). A nivel del mesotórax desciende y lo recorre por debajo de los músculos del vuelo para volver a tomar posición dorsal en el protórax. Finalmente, se abre en un gran seno justo detrás del cerebro. En conjunto el corazón y la aorta reciben el nombre de vaso dorsal (VD) (Chiang et al., 1990; Insausti, 1994). 


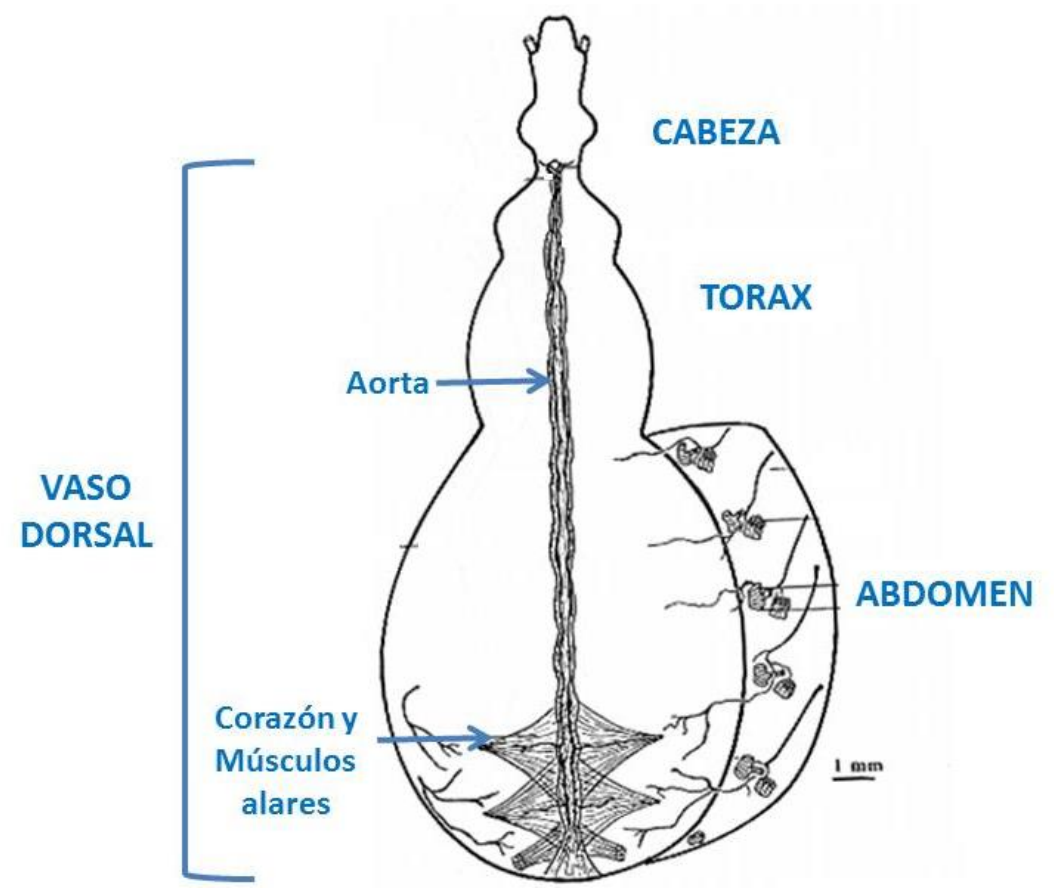

Figura 2: esquema de la morfología del vaso dorsal, donde se observan el corazón y los músculos alares asociados, ubicados en el sector posterior del abdomen, y el recorrido de la aorta dorsal. Tomado de Insausti 1994.

La circulación en dirección postero-anterior de la hemolinfa es provocada por el bombeo del corazón. La misma ingresa al corazón por 4 pares de ostia laterales cuando los músculos alares, que fijan el corazón a la pared dorsal del cuerpo, se contraen. La hemolinfa recorre la aorta y es volcada en el seno cefálico para luego retornar hacia la porción posterior del abdomen ayudada por los movimientos del sistema digestivo, en particular del intestino medio anterior (Maddrell, 1964b). El corazón está constituido por fibras de musculatura estriada que se orientan en forma espiralada. Por fuera se reconocen siete pares de músculos alares, que se extienden desde la pared externa del corazón hacia la pared del cuerpo. Los correspondientes a los segmentos abdominales VI y VII son de mayor tamaño respecto a los que se encuentran en los segmentos VIII, IX y X (Fig. 3). Sobre la superficie externa de los músculos alares se asocian células pericárdicas (Chiang et al., 1990). En la superficie ventrolateral del corazón y de la aorta abdominal transcurren dos grupos de fibras musculares longitudinales. Estos grupos de fibras se van fusionando y reduciendo a lo largo del recorrido de la aorta hacia el extremo anterior. La histología de este vaso describe la presencia de un miocardio -un anillo de elementos contráctiles- entre una capa adventicia externa y una delgada túnica interna de tejido conectivo (Chiang et al., 1990). 


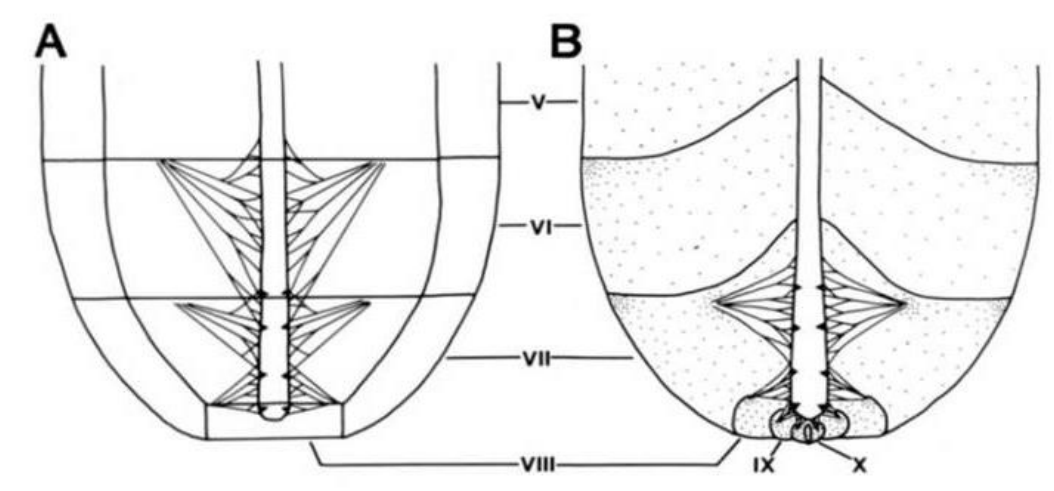

Figura 3: esquema de la morfología del corazón y de los músculos alares asociados. A: vista dorsal. B: vista ventral. Tomado de Chiang et al., 1990.

\section{Regulación nerviosa y hormonal del sistema circulatorio}

El VD está inervado por el nervio abdominal V (Insausti, 1994), y es estimulado por neurotransmisores como la serotonina y la allatotropina (Chiang et al., 1992; Sterkel et al., 2010). Además, su frecuencia de contracción está regulada por secreciones peptídicas que son liberadas a la hemolinfa desde, sitios neurohemales, modulando de manera positiva o negativa la actividad del tejido muscular (Lee \& Lange, 2011; Lee et al., 2012; Zandawala \& Orchard, 2013; Patel et al., 2014). El ritmo de contracción varía dependiendo del estado fisiológico del insecto, aumentando de manera significativa en el momento de la diuresis post-prandial, con el propósito de favorecer la recirculación de la hemolinfa para que rápidamente sea reestablecida la homeostasis hídrica y mineral que se ve alterada al momento de la ingesta sanguínea (Maddrell, 1964b; Santini \& Ronderos, 2007; Santini \& Ronderos, 2009a).

\subsubsection{FISIOLOGÍA DE LA ALIMENTACIÓN Y MECANISMOS DE CONTROL DURANTE LA DIURESIS}

En todos los organismos, el proceso de digestión tiene la finalidad de degradar los nutrientes para obtener energía y así llevar a cabo las funciones vitales. Los hidratos de carbono, proteínas y lípidos ingeridos son degradados por acción enzimática, asimilados por células epiteliales especializadas y luego distribuidos hacia el resto de las células.

Planteando un esquema general, el sistema digestivo de los insectos se compone de una cavidad bucal rodeada de apéndices modificados y adaptados según la dieta. Luego, comienza el tubo digestivo, en el cual pueden reconocerse tres sectores en base a su origen embrionario y a sus funciones fisiológicas: el tubo digestivo anterior, originado a partir del 
estomodeo, el tubo digestivo medio, de origen endodérmico y el tubo digestivo posterior, derivado del proctodeo. Dependiendo del tipo de alimentación, de sus características y de cómo debe ser procesado el alimento, los sectores del tubo digestivo adquieren características especiales, tales como esclerotizaciones de la superficie interna del proventrículo, divertículos que se evaginan desde el esófago, secreciones proteicas especiales de las glándulas salivares, bolsas gástricas, etc. (Audsley \& Weaver, 2009a; Klowden, 2013).

Haremos hincapié en la descripción funcional del tubo digestivo medio, sector que, en los insectos triatominos, posee la tarea de recibir el alimento, almacenarlo y concentrarlo, además de degradar y asimilar los nutrientes. En los triatominos se conforma de dos secciones con funciones diferentes, el intestino medio anterior y el intestino medio posterior (Fig. 4). El primero, denominado comúnmente buche, consiste en un saco que ocupa gran parte de la cavidad abdominal, el cual contiene, almacena y realiza un primer procesamiento del alimento. La capacidad de almacenamiento es muy grande y, de hecho, una larva de $R$. prolixus puede ingerir hasta 12.5 veces su peso en una única alimentación (Buxton, 1930). El epitelio de este órgano no presenta membrana peritrófica tal como se la conoce en otros insectos. Ha sido propuesto que en hemípteros hematófagos como R. prolixus, presenta una membrana de fosfolípidos denominada membrana perimicrovillar, que cumple la función de aislar el alimento ingerido para que se produzcan los procesos de degradación (Terra, 2001; Ribeiro et al., 2014; Burgos \& Gutiérrez, 1976). El transcriptoma del intestino medio ha revelado la expresión de numerosas enzimas que degradan hidratos de carbono, proteínas y lípidos (Ribeiro et al., 2014). En el buche ocurren procesos de digestión de azucares, detoxificación y neutralización de productos que pueden favorecer procesos oxidativos, o de aquellos que pueden ser tóxicos como el grupo heme, derivado de la degradación de la hemoglobina. Para evitar esto, en el buche el grupo heme es secuestrado por cristales formando un compuesto conocido como hemozina (Oliveira et al., 2000). En R. prolixus los compuestos derivados de los pigmentos sanguíneos son posteriormente reutilizados por el organismo, acumulados en las glándulas salivares dando su característico color e incorporados al vitelo de los huevos, también de color rojizo (Wigglesworth, 1943). En cuanto a la degradación de lípidos y proteínas, si bien se ha identificado la expresión de lipasas y proteasas en el buche, las enzimas son activas en el intestino medio posterior, donde se da el proceso de asimilación de los nutrientes (Ribeiro et al., 2014). 


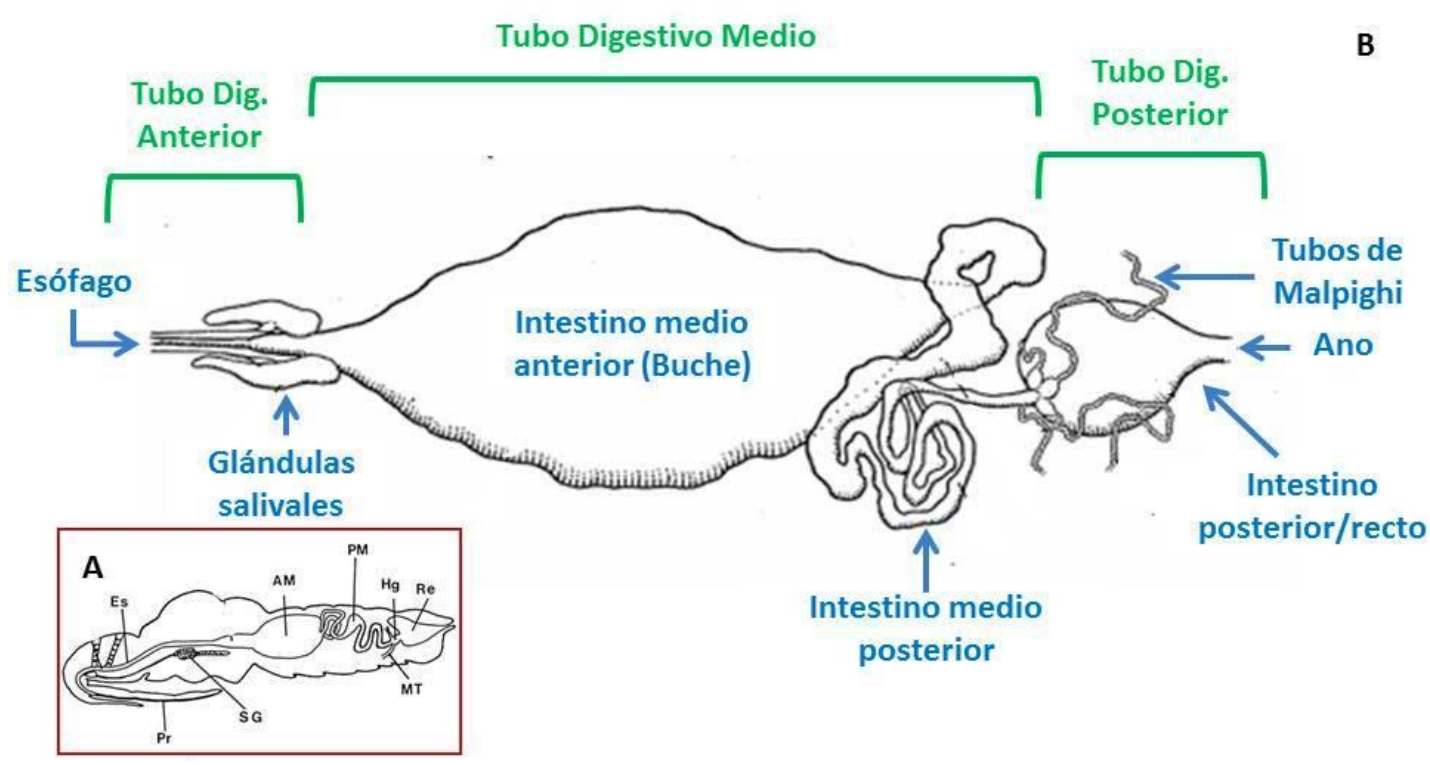

Figura 4: Órganos del tracto digestivo de triatominos A: Pr: proboscis, Es: esófago, SG: glándulas salivales, AM: intestino medio anterior, PM: intestino medio posterior, MT: tubos de Malpighi, Hg: intestino posterior, Re: recto. B: En la parte superior del gráfico se señalan los tres sectores principales: el tubo digestivo anterior, medio y posterior. A su vez, el intestino medio se compone de un sector anterior y otro posterior. También, se observan las glándulas salivales asociadas al esófago y los TMs, comunicados con el extremo terminal del intestino medio posterior. Por último, se señalan el intestino posterior/recto.

Pocos minutos después de iniciarse la ingesta de sangre, se desencadena el proceso de diuresis, crucial en la vida de estos insectos hematófagos. Es durante este proceso donde el sistema reestablece la homeostasis luego de someterse a un desbalance hídrico-mineral provocado por el transporte de iones y agua, desde la luz del buche hacia la hemolinfa (Barrett, 1982). Para regular este shock osmótico, son liberadas hacia la hemolinfa hormonas diuréticas como la serotonina que estimulan la actividad de los TMs interviniendo en la regulación del transporte de sales y agua que deben ser eliminadas en grandes cantidades en forma de orina con el fin de disminuir el peso y restaurar el equilibrio hídrico-mineral (Maddrell, 1963; Maddrell, 1964; O’Donnell \& Spring, 2000). Como hemos señalado, los TMs, son los órganos encargados de reestablecer la homeostasis hídrica y mineral mediante la producción de orina (Wigglesworth, 1931; Maddrell, 1969; Maddrell \& Phillips, 1975; Maddrell, 1978; O’Donnell \& Spring, 2000). Durante el proceso de diuresis, intervienen también el VD y el buche, provocando un aumento en la recirculación de la hemolinfa al incrementar su frecuencia de contracción y el número de ondas peristálticas, respectivamente (Maddrell, 1964). Esto es controlado, en parte, por el sistema neuroendocrino. Se ha observado que en la especie $T$. infestans, afín a $R$. prolixus, el péptido allatatotropina, modula positivamente las 
contracciones peristálticas del recto, buche y del VD (Santini \& Ronderos, 2007; Santini \& Ronderos, 2009a; Sterkel et al., 2010). Más aún, en esta especie se estudió la presencia del péptido en células de los TMs, y mediante experimentos fisiológicos, se observó que el recto incrementaba sus contracciones en presencia de los mismos, sugiriendo que la fuente de secreción de esta hormona son los TMs. A raíz de estos estudios se propuso que los mismos no sólo están circunscriptos a la formación de orina, si no que actúan como órganos endocrinos en insectos (Santini \& Ronderos, 2007; Santini \& Ronderos, 2009b).

La serotonina (5-hidroxitriptamina o 5-HT) es una monoamina biogénica ampliamente distribuida en la naturaleza. Este compuesto, que deriva de un aminoácido aromático, funciona como neurotransmisor y neuromodulador en el sistema nervioso central y como neurohormona (Vleugels et al., 2015). La serotonina ha demostrado cumplir múltiples funciones en los insectos: se encuentra involucrada en el control circadiano y en el control del apetito en Drosophila melanogaster (Yuan et al., 2005; Neckameyer, 2010); estimula también, la secreción de las glándulas salivales en Aedes aegypti, Calliphora vicina y Periplaneta americana. (Vleugels et al., 2015); tiene la capacidad de modular positivamente la actividad contráctil del corazón y la aorta en Anopheles gambiae, D. melanogaster y en $T$. infestans (Nichols, 2006; Sterkel et al., 2010; Hillyer et al., 2015). Recientemente, se observó que la serotonina se encuentra implicada en el aprendizaje y la memoria en larvas de Drosophila sp. a través de sensores olfativos y gustativos (Huser et al., 2017). La función como hormona diurética se dedujo a partir de los estudios realizados por Maddrell (Maddrell et al., 1993) durante el proceso de diuresis post-ingesta en $R$. prolixus. La misma es liberada en las terminales axónicas de la pared del buche minutos después del inicio de la alimentación, dado por el estímulo de estiramiento de la pared de este órgano. Además, las células de la mucosa también son secretoras de serotonina. La presencia de esta hormona produce un incremento de la tasa de transporte de iones y agua a través del epitelio del buche hacia la hemolinfa y por parte de las células de los TMs hacia su luz, para propiciar el restablecimiento hídrico-mineral (Maddrell, 1964a y b; Maddrell, 1966a y b). Asimismo, en el momento de la ingesta suceden numerosos eventos integrados que tienen que ver con el papel que cumple la serotonina al participar del aumento de la plasticidad de la cutícula del abdomen, modular la actividad de la musculatura visceral, aumentar la frecuencia de contracción en las glándulas salivales, buche, recto y corazón, lo que conjuntamente favorece el movimiento de la hemolinfa (Orchard, 2006; Sterkel et al., 2010).

Dada la importancia de los mecanismos de regulación que controlan los movimientos de contracción de la pared del buche durante la ingesta, la diuresis y la digestión, se han 
desarrollado estudios donde se han evaluado los posibles roles que cumplen algunos de los neuropéptidos conocidos hasta el momento. La histología del buche de la especie relacionada T. infestans, muestra que la pared de este órgano está constituida por un epitelio cilíndrico simple, apoyado sobre una membrana basal gruesa, rodeada por una túnica de tejido muscular incompleta, cuyas fibras se disponen en dos capas: una de ellas de orientación longitudinal interna, mientras que la otra se ubica de manera trasversal externa. Las fibras musculares cubren la membrana basal con excepción de las regiones donde penetran las tráqueas y traqueolas (Burgos \& Gutierrez, 1978; Te Brugge et al., 2009). La actividad de las fibras musculares provoca los movimientos peristálticos que a su vez son controlados por neurotransmisores que llegan por vía axónica (Audsley \& Weaver, 2009). Péptidos como la allatotropina y las allatostatinas también intervienen modulando la peristalsis del sistema digestivo. Se observó en larvas y adultos de $T$. infestans células secretoras de tipo abierto productoras de allatotropina en la mucosa del intestino medio anterior. Las mismas actuarían de forma paracrina detectando cambios en la luz del órgano, y regulando la actividad contráctil durante el consumo de sangre y la diuresis post-prandial (Sterkel et al., 2010). También se han encontrado células endocrinas secretoras de allatostatina-A en el intestino medio posterior de larvas de R. prolixus (Sarkar et al., 2003).

El tubo digestivo anterior y medio se encuentra inervado por el sistema nervioso estomatogástrico, el cual comprende al ganglio frontal y al ganglio hipocerebral. En los triatominos, el buche está inervado por el nervio recurrente que se origina justamente desde el ganglio frontal (Insausti, 1994; Audsley \& Weaver, 2009). Las neuronas que se encuentran en este ganglio sintetizan los neuropéptidos que modulan la actividad contráctil del buche, los cuales pueden estimular o inhibir las contracciones peristálticas del mismo (Audsley \& Weaver, 2009) así como lo hacen otros neurotransmisores como la serotonina (Orchard, 2006). Específicamente en $R$. prolixus, experimentos desarrollados in vitro en ninfas de $V$ estadio sugieren que los neuropéptidos kinina, proctolina, péptido simil factor de liberación de corticotropina (CRF-like $D H$ ) y el péptido simil corticotropina (CT-like $D H)$ poseen capacidad de estimular la frecuencia de contracción del buche. Por otro lado, aquellos que han sido evaluados como mioinhibidores son FMRF-amida (myosupresin peptide) y FGL-amida (Allatostatina-A) (Zandawala \& Orchard, 2013). Estudios realizados en grupos de insectos como ortópteros, dípteros y lepidópteros, se ha observado además de los neuropéptidos mencionados, así como otros, también modulan la actividad contráctil del intestino medio (Audsley \& Weaver, 2009). 
Si bien se conocen las posibles fuentes de síntesis y secreción de moléculas estimuladoras del tejido muscular como allatotropina y serotonina en triatominos y lepidópteros (Duve et al., 2000; Santini \& Ronderos, 2007; Sterkel et al., 2011) y otras que actúan inhibiendo la actividad del mismo como la allatostatina-C en dípteros y lepidópteros (Price et al., 2002; Duve et al., 2000), no se reportó aún la existencia de este tipo de fenómenos miomoduladores como mecanismos de regulación de la actividad de los músculos viscerales en $R$. prolixus.

\subsubsection{SISTEMA REPRODUCTOR DE LA HEMBRA (SRH)}

Las diversas estrategias que los insectos han desarrollado para perpetuarse los han llevado a ser uno de los grupos de organismos más diverso en la Tierra. Uno de los motivos importantes de este éxito ha sido sin duda los diversos recursos de su biología reproductiva, brindado un enorme potencial adaptativo a la hora de dejar descendencia. Los insectos recurren a una gran variedad de estrategias para conquistar prácticamente todos los hábitats mediante increíbles comportamientos durante el cortejo, la cópula, así como la cuantiosa producción de huevos. Se pueden citar numerosos ejemplos como las masivas e impresionantes producciones de huevos de los insectos sociales donde una abeja reina, que vive hasta 5 años, puede producir hasta 2000 huevos por día; las termitas reinas pueden producir 6000 huevos al día durante su vida útil de 15-50 años; durante un período reproductivo de 10 semanas, una mosca del género Drosophila sp. puede producir huevos equivalentes a 30 veces su peso corporal.

El sistema reproductor de la hembra de $R$. prolixus sigue el organización general que puede encontrarse en la mayoría de los insectos, donde se reconoce una porción productora de huevos, los ovarios, y una porción conductora, donde los mismos son movilizados hasta el momento de la oviposición. Los ovarios se unen al segmento anterior de la pared del abdomen a través de una estructura denominada ligamento o filamento. Tanto los ovarios como el ligamento se originan a partir del mesodermo esplácnico durante el desarrollo embrionario. Cada ovario se compone de siete unidades funcionales y estructurales denominadas ovariolas, donde se desarrollan las células germinales y aquellas que acompañan su desarrollo, como las células foliculares. La porción conductora comienza con los oviductos laterales, los cuales se conectan a los ovarios en sus extremos posteriores y comunican a éstos con el oviducto común o útero que se continúa a su vez con una cámara posterior, la bursa o vagina. Estas últimas porciones derivan del ectodermo embrionario, y de hecho la pared interna de la bursa se encuentra recubierta por cutícula. En la porción terminal del útero desembocan un par de órganos tubulares, las espermatecas, que además de tener la función de almacenar los 
espermatozoides que ingresan luego de la cópula poseen una porción glandular, y sus secreciones brindan un ambiente propicio para la supervivencia de las gametas masculinas. En el momento de la oviposición, los huevos son adheridos a la superficie elegida mediante una secreción proteica producida por la glándula de cemento, bien desarrollada en esta especie, que desemboca a través de un conducto en la superficie dorsal y posterior de la bursa (Fig. 5A) (Lococo \& Huebner, 1980; Chiang et al., 2012; Klowden, 2013; Atella et al., 2005).

Los ovarios son los órganos donde se desarrollan y se llevan a cabo los procesos de crecimiento y maduración de los ovocitos. En la hembra de R. prolixus las ovariolas son del tipo meroístico telotrófico. Se define como un ovario meroístico a aquellos donde las células madre, los ovocitos primarios, el tejido prefollicular y las denominadas células nodrizas o trofocitos están contenidos dentro del germario, la porción más proximal de las ovariolas. La condición de ser telotrófico se debe al hecho de que las células nodrizas son las que proporcionan al ovocito RNA, proteínas y ribosomas a través de cordones nutricios mientras que éste desciende a través del vitelario, la porción distal de cada ovariola (Huebner \& Anderson, 1972; Klowden 2013). En los hemípteros se reconocen tres etapas de desarrollo de los ovocitos: fase pre-vitelogénica (la cual ocurre en el sector anterior de cada ovariola denominado trofario), fase de vitelogénesis y fase de coriogénesis (que se dan en el sector posterior de cada ovariola conocido como vitelario) (Atella et al., 2005).

La maduración de los ovarios se produce si la cantidad y calidad de nutrientes es la indicada para que se desencadene una respuesta hormonal. La síntesis y secreción de dos hormonas, la ecdisona y la hormona juvenil son necesarias para que la vitelogénesis y la ovogénesis comiencen (Davey, 1993; Cardinal-Aucoin et al., 2013; Villalobos-Sambucaro et al., 2015b; Belles \& Piulachs, 2015). El estímulo de la ingesta sanguínea en las hembras de $R$. prolixus desencadena una cascada de señales que provoca la activación de los ovocitos a los 34 días, lo cual conlleva a la producción de huevos de manera continua hasta que los recursos nutritivos se agotan (Davey et al., 1986). Lutz \& Huebner (1980) describieron la injerencia que tienen dos hechos relevantes en la fisiología reproductiva de estos insectos en el desarrollo de los huevos: la cópula y la ingesta sanguínea. Además, estudios realizados por Davey \& Singleton (1989) plantearon que la cantidad de alimento, la calidad de éste, la distención del abdomen al alimentarse y la cópula son factores que actúan de manera conjunta sobre las diferencias que observaron al estudiar la producción y desarrollo de los huevos. Aquellas hembras a las cuales no se les había ofrecido alimento y fueron copuladas, produjeron en promedio 7 huevos por hembra mientras que, aquellas que eran vírgenes y no habían sido alimentadas produjeron promedio de 4,7 huevos por hembra. Más aún, la ingesta sanguínea y 
la cópula en conjunto modificaron la capacidad de maduración de los ovocitos, incrementando el número de huevos puestos en un rango de treinta y cincuenta, durante 2 a 3 semanas luego de la alimentación.

\section{La cópula induce cambios en la fisiología del SRH}

Durante la cópula, el macho introduce el espermatóforo y con él ingresan sustancias sintetizadas por las glándulas accesorias de su sistema reproductor, que modificarían la fisiología reproductiva de la hembra. En insectos machos de $R$. prolixus, la síntesis de estos productos es regulada por la hormona juvenil (Gold \& Davey, 1989). Se han estudiado los posibles cambios que producen estos compuesto a nivel del sistema neuroendocrino en $R$. prolixus, en cuanto a la producción de huevos (Davey, 1967), la migración de los espermatozoides hacia las espermatecas (Davey, 1958) y la actividad muscular del SRH (Davey \& Kriger 1985; Kuster \& Davey, 1986). Más aún, se ha propuesto que estos compuestos podrían atravesar la pared de la bursa y de las espermatecas hacia la hemolinfa en especies como Melanoplus sangunipes y en D. melanogaster (Friedel \& Gillott, 1976; Lung \& Wolfner, 1999). Las células diana que se verían afectadas por estos compuestos se encontrarían en el cerebro, las cuales serían estimuladas a secretar péptidos que modulan la ovogénesis y las contracciones del SRH, es decir que intervienen modificando la fisiología y el comportamiento de las hembras. Estos cambios incluyen pérdida de receptividad de apareamiento, aumento de la ovogénesis y oviposición, aumento de la actividad alimentaria y del reposo, inducción de respuestas inmunes y disminución de la longevidad (Baldini et al., 2012). En la mosca de la fruta $D$. melanogaster, se observó que las secreciones introducidas durante la cópula activan la remodelación del tejido epitelial y muscular de los oviductos así como también favorecen el incremento de terminales nerviosas que llegan a estos órganos (Kapelnikov et al., 2008). Varios de estos péptidos fueron identificados genómica, molecular y funcionalmente en algunas especies de dípteros, lepidópteros, himenópteros y coleópteros. A los componentes proteicos que conforman el líquido seminal se los denominó "proteínas de las glándulas accesorias" (ACP) (Gillott, 2003; Avila et al., 2011), pero también se ha identificado la presencia de otros compuestos como hormona juvenil, carbohidratos, prostaglandinas, etc., que también son introducidos en la hembra durante la cópula (Gillott, 2003).

La actividad de la musculatura del SRH, así como sucede en otros sistemas de órganos, se encuentra modulada por el sistema neuroendocrino. Se ha documentado en especies como Locusta migratoria, Musca domestica, Leptoglossus occidentalis y Tribolium castaneum que ciertos neuropéptidos regulan la coordinación de los procesos involucrados en la puesta de 
huevos (Paemen et al., 1991; Wagner et al., 1993; Lange, 2009; Chiang, 2010; Audsley et al., 2013). El SRH es inervado por nervios pares que surgen directamente del ganglio mesotorácico (GMT), denominados nervios mediales abdominales (abV). A medida que cada uno de los abV se extiende desde el GMT hasta los órganos genitales de la hembra, da lugar a ramas ipsilaterales que inervan a los segmentos abdominales V, VI y VII. La rama de abV recorre ventralmente los oviductos hasta la altura del segmento VII, donde se extiende una rama dorsal al útero, que inerva finalmente el extremo posterior del abdomen. A partir de esta rama se extienden pequeños y delgados nervios que alcanzan la bursa, el útero, las espermatecas y los oviductos (Fig. 5C) (Chiang \& O’Donnell, 2009).

Las diferentes estructuras del SRH muestran movimientos espontáneos antes o después de ser aislados del sistema nervioso central (SNC). De hecho, los ovarios, los oviductos, el útero, las espermatecas y la bursa son capaces de contraerse independientemente (Davey \& Webster, 1967; Davey, 1982; Sedra \& Lange, 2014 ). La frecuencia de contracción de estos órganos es dependiente del momento del ciclo gonadotrófico en el que se encuentre el insecto. Por ejemplo, las espermatecas se contraen con mayor frecuencia en hembras alimentadas y copuladas que en aquellas vírgenes, y de hecho, ese aumento en la actividad contráctil estaría controlado por neurosecreciones (Kuster \& Davey, 1986). La distribución espacial de las fibras musculares de la bursa es compleja y fue descripta por Davey (1959) y por Chiang \& O’Donnell (2009). Estos investigadores reconocieron la existencia de dos grupos de fascículos musculares orientados a lo largo del eje anterior-posterior del cuerpo, y que cubren los lados derecho e izquierdo; y un único paquete muscular que se extiende sobre la superficie dorsal, el cual se continúa hacia los lados, cubriendo parcialmente los músculos laterales. En sus extremos anteriores, los músculos laterales derecho e izquierdo convergen sobre un apodema situado en el borde medio posterior del esternito $\mathrm{VI}$, en el extremo anterior del útero. A partir de este apodema los músculos divergen y rodean la base del útero hasta sus apodemas posteriores localizados lateralmente en las porciones derecha e izquierda del esternito VIII (Fig. 5B). Chiang \& O'Donnell (2009) han descripto que los movimientos del útero y de la bursa suelen estar sincronizados con episodios de actividad que ocurren hasta siete veces por minuto, una sincronía que se produce con o sin conexiones al SNC. Cuando las espermatecas laterales están activas, muestran una acción de torsión aguda tal como ha sido descripto previamente en detalle por Kuster \& Davey (1986). Estas torsiones son más rápidas que los movimientos de los oviductos, útero y bursa, y suelen coincidir con el primer movimiento del útero. Por lo tanto, un conjunto completo de contracciones coordinadas comienza con una contracción de las 
espermatecas laterales, seguida rápidamente por la constricción del útero y una onda peristáltica rápida de los oviductos laterales. Este conjunto de contracciones coordinadas termina con una constricción gradual prolongada de los músculos de la bursa. Cuando las contracciones de este órgano son prominentes, pareciera que se moviliza en su totalidad hacia adelante, en dirección hacia la base del útero, estirándose en su extremo posterior. Se han descripto, además, movimientos de ésta cámara que van de lado a lado. Los ovarios experimentan movimientos peristálticos, pero no afectan a los movimientos del resto de los órganos (Chiang \& O’Donnell, 2009).

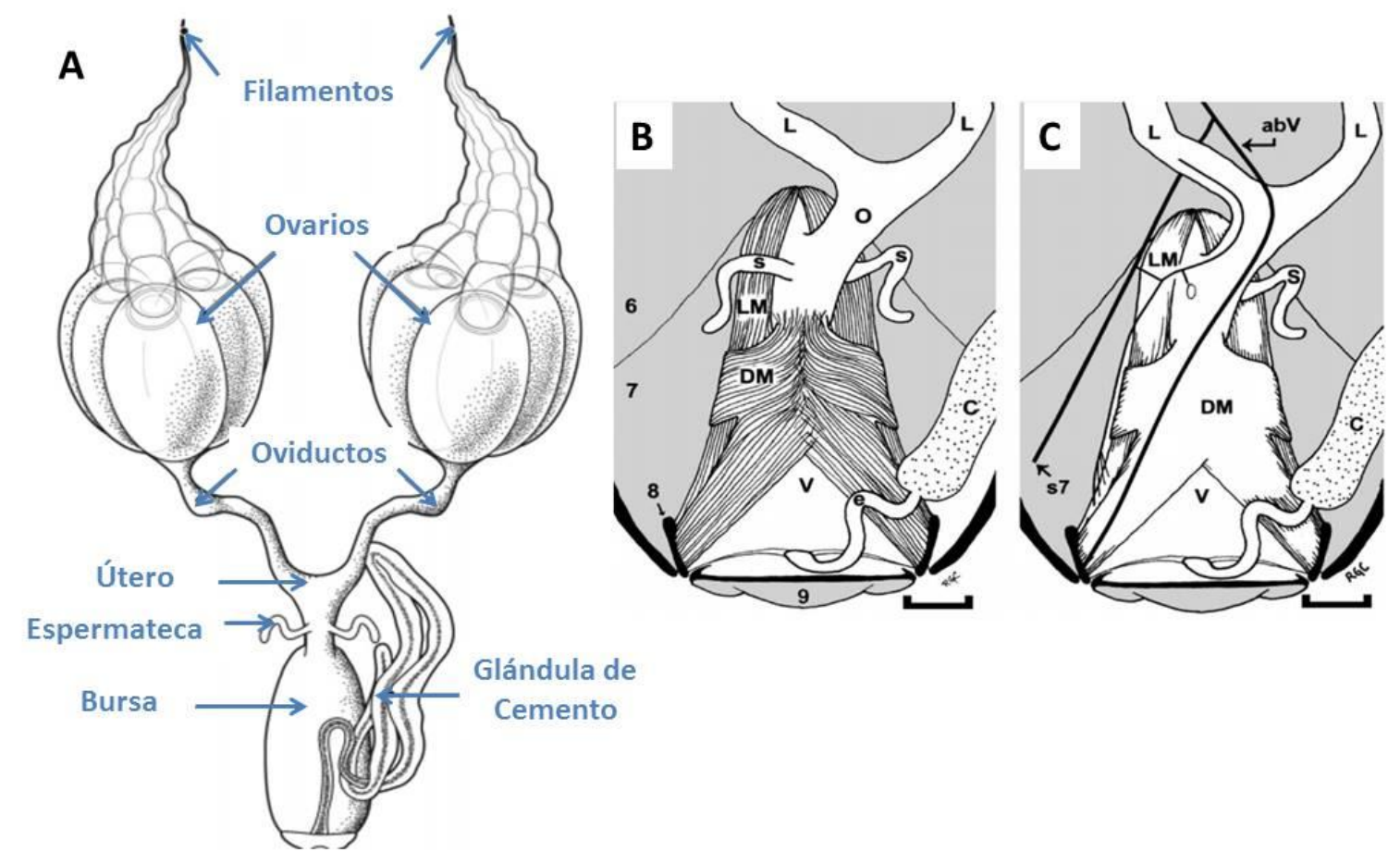

Figura 5: A: esquema de la morfología del sistema reproductor de la hembra. Tomado de Sedra \& Lange, 2014. B: detalle del sector dorsal y posterior del sistema reproductor de la hembra, donde se observa la disposición de los fascículos musculares que cubren dorsalmente la vagina o bursa (V). C: esquema donde se muestra con una línea continua de trazo grueso como se ramifica e inerva los distintos órganos el nervio abdominal V. L: oviductos laterales, CO: útero/oviducto común, S: espermatecas, C: glándula de cemento, e: conducto excretor, LM: músculo lateral, DM: Músculo dorsal. Tomado de Chiang y O’Donell 2009.

La cópula y la ingesta sanguínea no solo modifican la fisiología de la reproducción, sino también la actividad contráctil de la musculatura de todos los órganos del sistema reproductor de la hembra. Davey (2007) publicó una revisión donde analiza la información de sus estudios previos y la relación que se establece ante estos dos eventos. Previamente, Krieger \& Davey 
(1982) se cuestionaron lo siguiente: “¿Existen contracciones de los músculos ováricos in situ que se correlacionan con los períodos de ovulación y oviposición? ¿Estas contracciones dependen de un sistema neuro-secretor cerebral intacto?". Estas preguntas las resolvieron mediante experimentos realizados sobre hembras a lo largo de los 14 días que dura el ciclo gonadotrófico. Observaron en hembras copuladas un aumento en la frecuencia de las contracciones peristálticas de los ovarios durante lo que ellos reconocen como los dos episodios principales del ciclo, la ovulación y la oviposición. Este aumento de la motilidad está ausente en hembras vírgenes y en aquellas hembras copuladas a las cuales se les habían extirpado un grupo de células neurosecretoras del cerebro. A estas neuronas se les adjudicó la función de secretar la hormona miotrópica de la ovulación (Myotropic ovulation hormone), que más tarde fue identificada como FMRF-peptide (Sevala et al., 1992). Posteriormente se observó in vitro, mediante estudios de electrofisiología, que esta hormona modificaba la actividad contráctil de los ovarios, oviductos y bursa de manera dosis dependiente incrementando el tono basal (Sedra \& Lange, 2014). Por otro lado, se identificó la presencia de un neuropéptido denominado proctolina, el cual se encuentra presente en axones que inervan los oviductos, el útero, bursa y las espermatecas. Este compuesto tiene la propiedad de incrementar de manera dosis dependiente el tono basal, la amplitud y la frecuencia de contracciones fásicas de los oviductos, además de aumentar las contracciones rítmicas de las espermatecas (Lange, 1990; Orchard et al., 2011). Cabe aclarar que en estos estudios no se especificaron las condiciones fisiológicas en las cuales se encontraban las hembras al momento de realizarse los experimentos. De manera similar, se estudiaron los efectos mioinhibitorios que presentan dos neuropéptidos ampliamente distribuidos en los insectos: la GLa/AST o Allatostatina A y el denominado péptido mioinhibidor (MIP)/AST o Allatostatina B. Estos experimentos realizados sobre los oviductos, in vitro, respondieron de manera dosis dependiente disminuyendo las contracciones basales en hembras vírgenes ayunadas (Sedra et al., 2015).

Los péptidos miomoduladores podrían ser sintetizados por el macho y ser introducidos durante la cópula. Esto se ha sugerido, por ejemplo, en L. migratoria, donde un neuropéptido simil-Allatotropina fue obtenido a partir de homogenatos de glándulas accesorias de insectos machos. Al aplicarse ese extracto sobre oviductos aislados, estos respondieron incrementando la actividad contráctil (Paemen et al., 1991).

Hasta el momento no hay estudios experimentales realizados in vivo que pretendan explicar cómo cambia la configuración de la actividad muscular en el SRH en el marco de los diferentes estados fisiológicos ante diferentes compuestos reguladores peptídicos. 


\subsection{CONCEPTOS SOBRE LAS HORMONAS JUVENILES Y SU ROL EN EL PROCESO DE LA MUDA Y EN LA REPRODUCCIÓN}

Los insectos holometábolos y hemimetábolos, atraviesan distintos estados desde el huevo hasta el adulto sexualmente maduro, pasando por un número variable de estadios larvales y la pupa. Tanto la muda, la metamorfosis, como la maduración de las gónadas son dependientes del balance de la actividad de dos grupos de hormonas lipídicas, las hormonas juveniles (HJs) y los ecdiesteroides (Dubrovsky, 2005). La 20-hidroxiecdisona (20E), es la hormona de la muda más ampliamente distribuida y es sintetizada principalmente por la glándula protorácica. Las HJs son moléculas lipídicas pertenecientes a la familia de los sesquiterpenoides acíclicos. Son sintetizadas y liberadas a la hemolinfa por la corpora allata (CA), una glándula endocrina de origen par asociada al sistema nervioso; que se encuentra fusionada en triatominos (Tobe \& Stay, 1985). Se han identificado ocho formas diferentes de HJs, siendo la de mayor distribución la HJ III (Goodman \& Cusson, 2012). Las HJs no solo intervienen en los procesos de muda y metamorfosis sino también en los fenómenos involucrados en el desarrollo y maduración de las gónadas y de los ovocitos.

Desde principios de siglo XX se ha estudiado en numerosas especies de insectos las probables vías de modulación de la síntesis de HJs en la CA. La existencia de un control de la secreción, síntesis y liberación de las HJs a partir de neurosecreciones ya había sido observado por Wigglesworth $(1934 ; 1936)$ y por Berta Scharrer (Stay, 2000). Actualmente se ha reconocido en algunas especies la probable actividad allato-estimulante de la 20E, de la Ecdysis Triggering Hormone (ETH) y de péptidos similares a insulina, así como la acción inhibidora del neuropéptido F (Noriega, 2014; Zhu \& Noriega, 2016). Sin embargo, las primeras moléculas en ser identificadas por cumplir estas funciones fueron los neuropéptidos denominados Allatotropina (AT) y Allatostatinas (AST). AT está involucrada en la biosíntesis de las HJs modulando positivamente la actividad de enzimas que intervienen en la formación de la HJ (Li et al., 2003). En cuanto a los neuropéptidos allatostáticos, el mecanismo de acción de AST-C ha sido estudiado en profundidad A. aegypti por Nouzova y colaboradores (2015). Ellos realizaron experimentos in vitro donde revelaron que AST-C inhibe fuertemente la síntesis de HJ III mediante la inactivación de la proteína transportadora de citrato la cual se encuentra en la membrana de las mitocondrias, impidiendo la movilización de esta molécula esencial hacia el 
citoplasma y obstruyendo la producción citoplasmática del Acetil-CoA, molécula necesaria para la síntesis de HJs.

\subsection{HORMONAS ALLATOTRÓPICAS: CARACTERÍSTICAS MOLECULARES, GENÓMICAS Y FUNCIONALES}

\subsubsection{LA ALLATOTROPINA: ESTRUCTURA MOLECULAR Y FUNCIONES}

Allatotropina es un neuropéptido caracterizado en base a su capacidad de activar la síntesis de la HJ en la especie Manduca sexta (Kataoka et al., 1989). Estos investigadores lograron caracterizar la composición de este péptido el cual se constituye de los siguientes aminoácidos: H-Gly-Phe-Lys-Asn-Val-Glu-Met-Met-Thr-Ala-Arg-Gly-Phe-NH2, siendo la secuencia con actividad biológica el octapéptido H-Glu-Met-Met-Thr-Ala-Arg-Gly-Phe-NH2, demostrando además que la amida del carboxilo terminal es esencial para su actividad.

Estudios sobre la expresión del gen en $M$. sexta revelaron que pueden diferenciarse tres mRNA como resultado de mecanismos de splicing alternativo. A partir de ellos, se predicen tres prohormonas distintas, cada una de las cuales contiene la secuencia de AT (Taylor et al., 1996). La tasa de identificación de nuevos péptidos relacionados con AT ha aumentado rápidamente a medida que se están adquiriendo nuevos datos genómicos y bases de datos de secuencias de mRNA clonadas (EST: expressed sequence tag). Hasta el año 2013, se han determinado o predicho 34 secuencias para esta familia y el número continúa incrementándose (Kastin, 2013). Sin embargo, no en todos los insectos se ha podido identificar y verificar la expresión génica de AT. Esto se observó, por ejemplo, en D. melanogaster, Apis mellifera y Nasonia vitripennis, lo cual podría deberse a que el gen de este neuropéptido se haya perdido en estas especies (Hewes \& Taghert, 2001; Hummon et al., 2006; Hauser et al., 2010; Horodyski et al., 2011). Respecto a la presencia o ausencia del péptido en himenópteros, se ha identificado la expresión del mismo en sitios neurohemales del cordón nervioso ventral de abejas obreras de la especie $A$. mellifera y en adultos Bombus terrestris. El hecho de que no se encuentre el transcripto en estas especies podría deberse justamente a la baja concentración en que se sintetizaría el péptido por haber perdido su principal función en castas obrera (Veenstra et al., 2012). 
La caracterización genómica de AT así como de su precursor en $R$. prolixus fue presentada por Masood \& Orchard (2014). La secuencia de aminoácidos predicha coincide con la descripta previamente por Ons y colaboradores (2011) basada en análisis peptidómicos. Estos autores reportaron además que el péptido fue expresado únicamente en el SNC y en el cuerpo graso de larvas de quinto estadio, machos y hembras, estando ausente en otros cDNA (vaso dorsal, sistema digestivo, tubos de Malpighi, y órganos sexuales inmaduros). Además, determinaron el alto nivel de conservación del patrón de secuencia TARGF-amida mediante alineamientos múltiples de secuencias pertenecientes a otros grupos de insectos.

La acción allatotrópica de AT no solo fue identificada en $M$. sexta, sino también en $A$. aegypti (Rachinsky \& Feldlaufer, 2000; Audsley et al., 2000; Li et al. 2003; Sheng et al., 2007). Aunque no se ha reportado hasta el momento que AT realmente cumple esta función en insectos triatominos, si se ha registrado en larvas de IV estadio de $T$. infestans, la existencia de una posible relación funcional entre el péptido y su presencia en la CA (Riccillo \& Ronderos, 2010). La existencia de neuronas allatotropas en la región posterior del protocerebro, así como también la presencia de inmunorreactividad a nivel de la Corpora Cardiaca (CC) y CA sugiere que AT actuaría sobre la glándula. No sólo se observó marcación específica en la CA, sino también que la intensidad de la fluorescencia fue mayor en los primeros días del ciclo de muda, cuando la actividad de la glándula es máxima, disminuyendo en los días 7-8 y siendo casi indistinguible a los 12 días luego de la ingesta sanguínea (Ronderos, 2009; Riccillo \& Ronderos, 2010).

A nivel del SNC, AT no solo actuaría modulando la actividad de la CA. En efecto, se detectó la presencia del péptido en zonas del cerebro, más allá de aquellas neuronas que inervan la CA y CC. Analizando imágenes con inmunofluorescencia del cerebro de la cucaracha Periplaneta americana se interpretó que la colocalización de AT y otro neuropéptido, takinina, junto con los neurotransmisores GABA y acetilcolina, en interneuronas del lóbulo antenal, podrían estar actuando como cotransmisores o neuromoduladores en la fisiología del olfato. (Fusca et al., 2015). Se ha planteado también, que AT está involucrada en el control de ritmos circadianos por hallarse en la médula accesoria del cerebro y en las neuronas del lóbulo óptico de Leucophaea maderae (Petri et al., 2002; Homberg et al., 2003) S. gregaria (Wurden \& Homberg, 1995) y T. infestans (Riccillo \& Ronderos, 2010).

Al profundizar la caracterización funcional de AT, se ha demostrado que se trata de un compuesto pleiotrópico, desempeñando funciones en diferentes sistemas de órganos. Lwalaba y colaboradores (2010) observaron que el péptido actúa a nivel del tubo digestivo estimulando 
la secreción de enzimas digestivas como la amilasa y la tripsina en Spodoptera frugiperda. Por otro lado, en larvas de $V$ estadio de $M$. sexta AT inhibe de manera dosis dependiente el transporte de iones en el tubo digestivo medio posterior, pero no así en otros lepidópteros (Hyalophora cecropia y B. mori), lo que sugiere una función especie-específica (Lee et al., 1998).

Recientemente se ha planteado que AT participa de la respuesta de tipo inmune en mosquitos de las especies An. albimanus y A. aegypti (Hernández-Martínez et al., 2017). A través de evidencia experimental se documentó que AT provoca cambios morfológicos y aumento de la actividad fagocítica de hemocitos y líneas celulares inmunocompetentes en ambas especies. Dichos autores observaron también efectos diferenciales entre las especies estudiadas. La actividad de compuestos liberados durante la respuesta inmunológica, como la fenoloxidasa en hemolinfa, aumentó en presencia del péptido en A. aegypti, pero no así en An. albimanus; en individuos de esta última especie, los niveles de óxido nítrico y la expresión de genes de péptidos antimicrobianos se incrementaron después del tratamiento con AT (Hernández-Martínez et al., 2017).

Es conocido el papel que cumple AT como modulador de la actividad de las células musculares. La función mioestimuladora del péptido ha sido estudiada previamente en diferentes especies de lepidópteros y cucarachas, donde se observó un incremento de la frecuencia de contracción a nivel del sistema digestivo y del vaso dorsal (Veenstra et al., 1994; Duve et al., 1999; Duve et al., 2000; Rudwall et al., 2000; Koladich et al., 2002). Nuestro laboratorio ha demostrado que AT posee actividad cardio y mio-reguladora en $T$. infestans, induciendo un aumento de la frecuencia de contracciones de la aorta (Sterkel et al., 2010) y modulando positivamente la tasa de ondas peristálticas en el buche y recto (Santini \& Ronderos, 2007; Sterkel et al., 2010), mediante un efecto sinérgico sobre la actividad estimuladora de serotonina. Se identificó además, una acción diferencial entre hembras y machos, alcanzando los machos una mayor frecuencia de contracción con respecto a las hembras. Se observó también que las hembras poseen una amplitud de contracción mayor que no varía significativamente con la aplicación de AT (Sterkel et al., 2010).

La localización del péptido en estas especies de triatominos se estudió mediante inmunohistoquímica y microscopia de barrido confocal. AT se encontró presente en el SNC y nervios periféricos, intestino medio posterior y recto, y en glándulas salivales en larvas de $\mathrm{V}$ estadio de R. prolixus (Masood \& Orchard, 2014). En insectos de IV estadio de T. infestans se encontró inmunomarcación en el complejo retrocerebral (CA y CC) y TMs; a su vez, en este 
estadio y en adultos se observó la presencia del péptido en el SNC, células secretoras del epitelio del intestino medio anterior (células open type) y en procesos nerviosos en la aorta (Santini \& Ronderos, 2009b; Riccillo \& Ronderos, 2010; Sterkel et al., 2010).

Dada las numerosas funciones descriptas para AT, se ha propuesto que la actividad del péptido sobre la CA es una función derivada, característica de los insectos. De hecho, el péptido no sólo ha sido identificado y caracterizado en insectos a través de estudios genómicos, peptidómicos y/o fisiológicos, sino también en otros grupos de organismos como crustáceos (Christie, 2014), cnidarios (Alzugaray et al., 2013), platelmintos (Adami et al., 2011; Adami et al., 2012), nematodes (Koziol et al., 2016) y moluscos (Ahn et al., 2017). Su actividad estimuladora sobre las contractibilidad de las células fue documentada, por ejemplo, en Hydra sp., donde se propuso, que el péptido estaría involucrado en la alimentación, siendo la función ancestral del mismo facilitar la ingesta de alimento (Alzugaray et al., 2013)

\subsubsection{LAS ALLATOSTATINAS: DIVERSIDAD Y FUNCIONES}

Se conocen tres familias de péptidos denominadas allatostatinas, que así como otros péptidos en insectos, son neurohormonas pleiotrópicas. Sin embargo, se han aislado y caracterizado, en primera instancia, por su capacidad de inhibir la síntesis de HJ en la CA, aunque las estructuras moleculares de estos péptidos no están relacionadas químicamente. Dentro de las allatostatinas se incluyen:

- Allatostatina A (AST-A o FGLamida-ASTs): es una familia de péptidos cuya secuencia Cterminal se encuentra conservada entre los diferentes grupos y se caracteriza por contener los siguientes aminoácidos: Y/FXFGL-NH2 (Tyr/PheXaaPheGlyLeu/lle- amide).También es conocida como Dipu AST, lo cual hace referencia la especie de cucaracha de la cual se la aisló por primera vez, Diploptera punctata (Woodhead et al., 1989). Su actividad sobre la CA, aparentemente, está restringida a cucarachas, grillos, y termitas, conociéndose al menos 13 isoformas de esta neurohormona. Éstas han sido aisladas y caracterizadas en numerosos órdenes de insectos y crustáceos (Stay \& Tobe, 2007) siendo fuente de estudios genómicos, bioinformáticos y fisiológicos en distintos grupos. En cuanto a su receptor, al caracterizarlo se lo ha relacionado como homólogo al receptor de galanina de mamíferos (Bendena et al., 1999; Bendena \& Tobe, 2012; ). En R. prolixus, siete de las trece isoformas se han detectado en diferentes órganos (células neurosecretoras del SNC y en ganglios ventrales, en el sistema digestivo medio anterior y posterior, TMs y ovarios). En esta especie, las AST-A no presentarían actividad allatostática pero si se han realizado bioensayos in vitro, demostrando ser mioinhibitoria a nivel del intestino medio, posterior y 
recto, sobre la frecuencia cardiaca (Sarkar et al., 2003; Zandawala \& Orchard, 2012) y a nivel de la actividad basal de los oviductos en el SRH (Sedra et al., 2015).

- Allatostatina B o Péptido Mioinhibidor (AST-B/MIP): esta familia de péptidos se caracteriza por presentar la siguiente secuencia conservada en el extremo carboxilo terminal: $\mathbf{W}(\mathbf{X} \mathbf{6} \mathbf{6} \mathbf{W}-\mathbf{N H 2}$. Está ampliamente distribuida a lo largo de los protostomados, pero fue identificada por primera vez como el péptido mioinhibidor de L. migratoria (LomMIP) la cual se purificó a partir de cerebro, CC, CA y ganglios subesofágicos (Schoofs et al., 1991). Experimentos in vitro demostraron que el péptido disminuye las contracciones espontáneas del intestino posterior y el oviducto en esta especie, así como del intestino posterior de L. maderae. Más tarde, se purificaron cuatro isoformas a partir de la especie de grillo Gryllus bimaculatus, las cuales presentaron actividad allatostática en esta especie y en el escarabajo Tenebrio molitor. Además, esta familia de péptidos está químicamente relacionada con los denominados "sex peptide" (Bendena et al., 1999; Bendena \& Tobe 2012; Kastin, 2013 a y b). En R. prolixus el gen de AST- B, o RhoprMIP, codifica once neuropéptidos maduros putativos, ocho de los cuales son péptidos nucleares. AST B/MIP se encontró presente en células del cerebro y en los ganglios del SNC, CC, en procesos que inervan las glándulas salivales, en el tubo digestivo, en el sistema reproductor masculino y femenino. En cuanto a sus receptores, se caracterizaron dos isoformas y su expresión se encontró principalmente en el SNC, en las glándulas salivales y en las gónadas. La actividad biológica como miohinibidor de AST-B/MIP se observó sobre los oviductos y el intestino posterior (Lange et al., 2012; Sedra et al., 2015).

- $\quad$ Allatostatina C (AST-C/PISCF): en esta tercera familia de péptidos allatostáticos pondremos mayor énfasis en brindar la información que se conoce al respecto, ya que es uno de los péptidos que se analiza en el presente trabajo. Al igual que AT, AST-C se aisló por primera vez a partir de extractos de cerebros de mariposas adultas de la especie $M$. sexta. A partir de ello se determinó que la estructura primaria se compone de 15 residuos de aminoácidos: pGlu-Val-Arg-Phe-Arg-Gln-Cys-Tyr-Phe-Asn-Pro-Ile-Ser-Cys-Phe-OH, donde pGlu corresponde a piroglutamato (Kramer et al., 1991). A raíz de su secuencia motif, que se encuentra conservada en distintos grupos, a este péptido también se lo conoce como PISCF-AST. Estudios posteriores, más exhaustivos, determinaron que la molécula posee un puente de cisteína que genera un anillo que abarca los seis aminoácidos del extremo N-terminal (Kastin, 2013) (Fig. 6). Se demostró la importancia de este enlace disulfuro al modificar el péptido sintético, sustituyendo los residuos de cisteina por alanina. Con esta modificación estructural, el puente disulfuro que determina la 
formación del anillo funcional, no se forma dando como resultado la pérdida de la actividad, en este caso miomoduladora (Matthews et al., 2006). Más tarde, AST-C fue identificada en Pseudoletia unipuncta (Jansons et al., 1996), D. melanogaster (Williamson et al., 2001a), S. frugiperda (Abdel-Latief et al., 2003), L. migratoria (Clynen et al., 2006), A. aegypti (Li et al., 2006), Samia cynthia ricini (Sheng et al., 2007) y T. castaneum (Li et al., 2008).

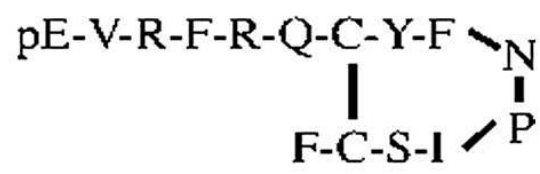

Figura 6: estructura molecular de AST-C de Manduca sexta. Tomado de Audsley \& Weaver, 2009.

El análisis genómico y transcriptómico realizado a partir de numerosas secuencias de varios grupos de artrópodos predice la existencia de dos genes que codifican un péptido tipo AST-C, uno de ellos denominado AST-CC, parálogo de AST-C. Ambos se encuentran en arácnidos (Ixodes scapularis), dípteros, lepidópteros, coleópteros, áfidos, y ptirápteros (Veenstra, 2009). Respecto del parálogo AST-CC, el mismo se expresaría en varias especies incluyendo a $D$. melanogaster, $B$. mori y $R$. prolixus. A raíz de estos estudios, sumados a la caracterización genómica del cDNA de la mosca de la fruta (D. melanogaster), se cree que los precursores de AST-CC tienen una segunda secuencia de péptidos conservada, lo que sugiere que podrían producir dos péptidos biológicamente activos, dependiendo del lugar donde se produzca la escisión de la proteína. Estudios bioinformáticos evidenciaron la similitud entre los receptores de ASTC / ASTCC y somatostatina (neuropéptido con actividad inhibidora por excelencia) de vertebrados, sugiriendo que los mismos poseen un ancestro común en su origen (Veenstra, 2009).

El gen que codifica para AST-C, así como también el péptido maduro fueron detectados a partir de extractos del SNC en R. prolixus (Sterkel et al., 2011).

Así como ocurrió con la caracterización funcional de la familia de las AST-A, el péptido AST-C se estudió por primera vez en base a su capacidad de inhibir la síntesis de HJs en la CA de larvas de $V$ estadio y hembras adultas de la mariposa del tabaco, $M$. sexta y también en hembras adultas de Heliothis virescens. Sin embargo, no hubo resultados al experimentar sobre otras especies como $T$. molitor, $M$. sanguinipes y $P$. americana 
(Kramer et al., 1991). Posteriormente, se reconoció esta misma función en $P$. unipuntata (Abdel-Latief et al., 2003), A. aegypti (Li et al., 2006), An. gambiae (Li et al., 2004) y S. cynthia ricini (Sheng et al., 2007). Más aún, el estudio mediante microscopia de barrido confocal de la distribución que presenta AST-C a nivel del SNC en dos especies de mosquitos, A. aegypti y An. albimanus mostró la asociación de las neuronas secretoras del neuropéptido ubicadas en el protocerebro con la CA (Hernández-Martínez et al., 2005).

AST-C no sólo cumple funciones como inhibidor de la síntesis de HJ sino que además, posee la capacidad de inhibir la actividad contráctil de la musculatura visceral. Esto se ha estudiado en el lepidóptero Lacanobia oleracea, donde el péptido presentó un efecto mioinhibidor a nivel del tubo digestivo anterior (Duve et al., 2000; Matthews et al., 2007). Incluso, en esta especie de lepidópteros se describió la existencia de un posible efecto antagónico de AST-C sobre la actividad mioestimuladora de AT sobre las contracciones espontáneas en larvas ayunadas (Matthews et al., 2007). En la especie D. melanogaster se observó que el péptido modula negativamente la actividad del corazón (Price et al., 2002). A pesar de haberse identificado la presencia de AST-C en nuestro modelo de estudio, no hay datos sobre el patrón de expresión del mismo ni del rol que lleva a cabo en la fisiología de estos insectos.

La actividad miomoduladora de AST-C no solo fue estudiada en insectos, sino también en otros organismos como en Hydra sp., perteneciente al phylum Cnidaria, grupo basal de los Metazoa. Recientemente, en base a experimentos fisiológicos in vivo, se propuso que al igual que otros péptidos, la función ancestral de AST-C podría estar asociada a la regulación de movimientos durante la alimentación, ya que este neuropéptido indujo cambios en la forma y longitud de los tentáculos, en el pedúnculo y en la cavidad gastrovascular (Alzugaray et al., 2016). Durante la alimentación, estos organismos poseen comportamientos específicos como la extrusión del hipostoma. Esta estructura puede ser estimulada en presencia de alimento o de AT, mientras que AST-C inhibe dicho efecto, evidenciando su actividad antagonista (Alzugaray et al., 2013; Alzugaray \& Ronderos, 2017). Estudios más exhaustivos sugirieron que ambos sistemas participan en los mecanismos reguladores asociados al calcio $\left(\mathrm{Ca}^{+2}\right)$ (Alzugaray \& Ronderos, 2017). 


\subsection{RECEPTORES DE MEMBRANA ACOPLADOS A PROTEÍNA G} (GPRC)

Los receptores de membrana acoplados a proteína G (GPCRs) son una familia numerosa de proteínas de transmembrana que median numerosas respuestas hormonales y de neurotransmisores. Su estructura cuaternaria se caracteriza por la presencia de siete dominios de transmembrana (TM), tipo $\alpha$ hélice, alternados por dominios intra y extracelulares. Los GPCR están entre los nodos esenciales de la comunicación entre los entornos internos y externos de las células. El papel clásico es acoplar la unión de agonistas a la activación de proteínas heterotriméricas $\mathrm{G}$ específicas, lo que conduce a la modulación de las proteínas efectoras. Estos receptores se dividen clásicamente en cinco familias en base a su estructura: receptores tipo rodopsina (Familia A), receptores tipo secretina (Familia B), receptores tipo glutamato (Familia C), receptores de adhesión y receptores Frizzled/Taste2. La familia tipo rodopsina es la más numerosa y diversa, caracterizándose entre sí por el alto grado de conservación en ciertos sectores de su secuencia. En el sector citoplasmático asociado al dominio 3TM se encuentra altamente conservado el patrón de aminoácidos $E / D R$ y un residuo del aminoácido glutamato en 6TM. Estos aminoácidos forman una red de interacciones polares que unen las dos hélices TM, estabilizando la conformación del estado inactivo del receptor. Otra identidad estructural y funcionalmente conservada, se encuentra en la cadena citoplasmática asociada al dominio 7TM donde se ubica un motivo de aminoácidos dado por NPXXY. Este sector participa en los cambios conformacionales asociados con la activación del GPCR. La prolina en este motivo causa una distorsión en la estructura hélice $\alpha$ y la tirosina se enfrenta en un bolsillo formado por los dominios 2TM, 3TM, 6TM y 7TM (Rosenbaum et al., 2009). El sector $\mathrm{N}$-terminal de estas proteínas está localizado en el dominio extracelular y posee a menudo varios sitios de glicosilación. El sector C-terminal, por otro lado, está orientado hacia el citoplasma y ofrece algunos sitios potenciales de fosforilación. Los dominios extracelulares están implicados en la unión específica para los ligandos, mientras que los dominios intracelulares interactúan con la proteína unida a GTP (proteína G) (Fig. 7). Los ligandos o agonistas pueden ser de diferente naturaleza química como por ejemplo fotones, aminoácidos, iones, aminas biogénicas, péptidos, etc. La proteína $\mathrm{G}$ consiste en tres subunidades $\alpha-, \beta-$ y $\gamma$. Cuando un GPCR se activa por su ligando, la señal extracelular será transducida en respuestas fisiológicas intracelulares. Un receptor activado experimentará un cambio conformacional, que a su vez conduce a la activación de la proteína $\mathrm{G}$ asociada. Esto provoca una cascada de señales intracelulares que tiene por finalidad la movilización de iones 
$\mathrm{Ca}^{+2}$ almacenados en el retículo endoplasmático hacia el citoplasma o la activación o inhibición de la enzima adenilato ciclasa, con el consiguiente aumento o disminución de la concentración de AMPc (adenosina monofosfato cíclica)(Caers et al., 2012) (Fig. 8).

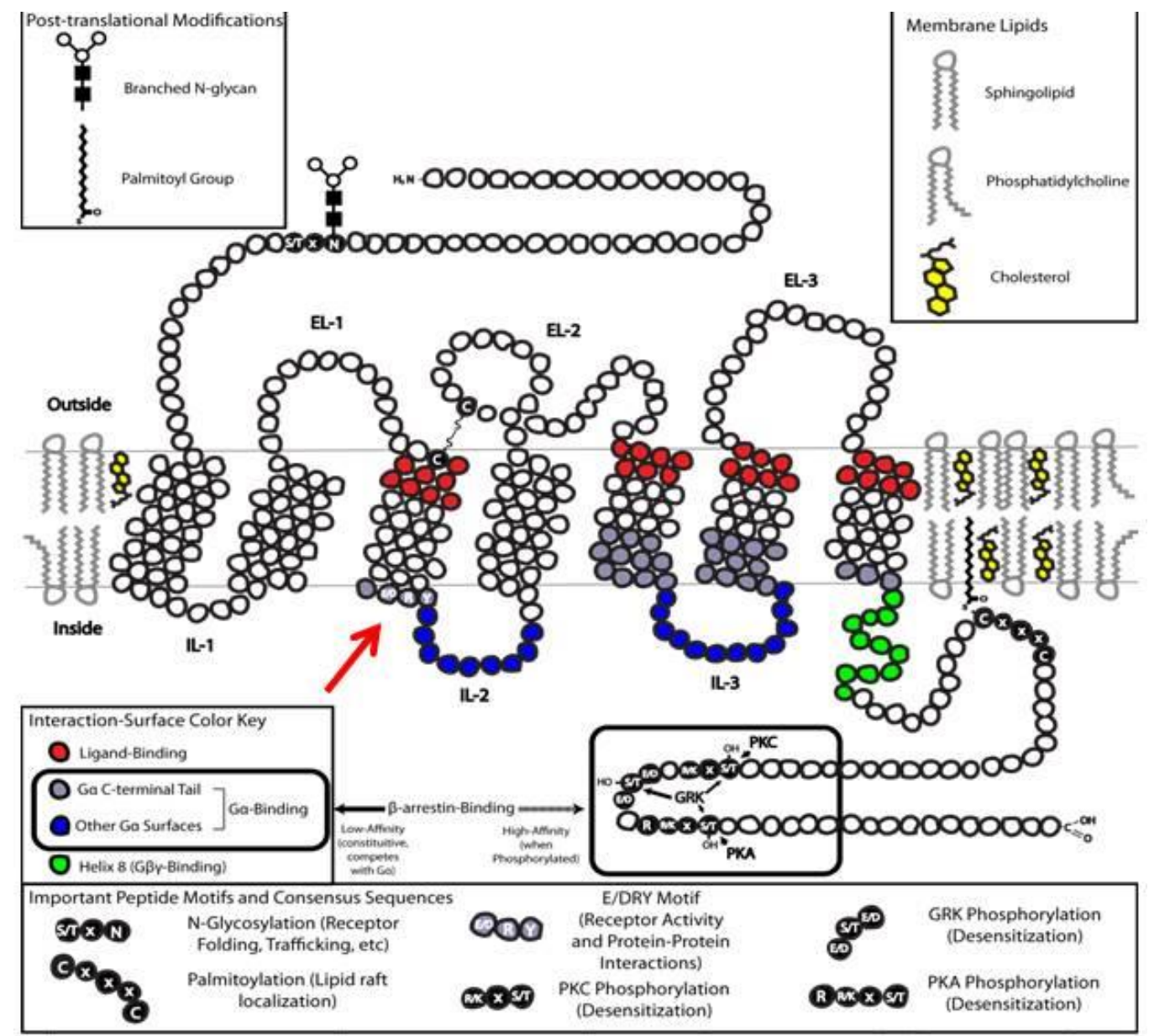

Figura 7: esquema de un receptor de membrana acoplado a proteína G. La secuencia E/DRY característica de GPCR se ubica en el extremo terminal del dominio 3TM, (flecha roja). Los sitios de unión con el ligando están representados en color rojo, los sitios intracelulares de unión con la proteína $\mathrm{G}$ se representan en color gris y azul. Tomado de Wikipedia. 


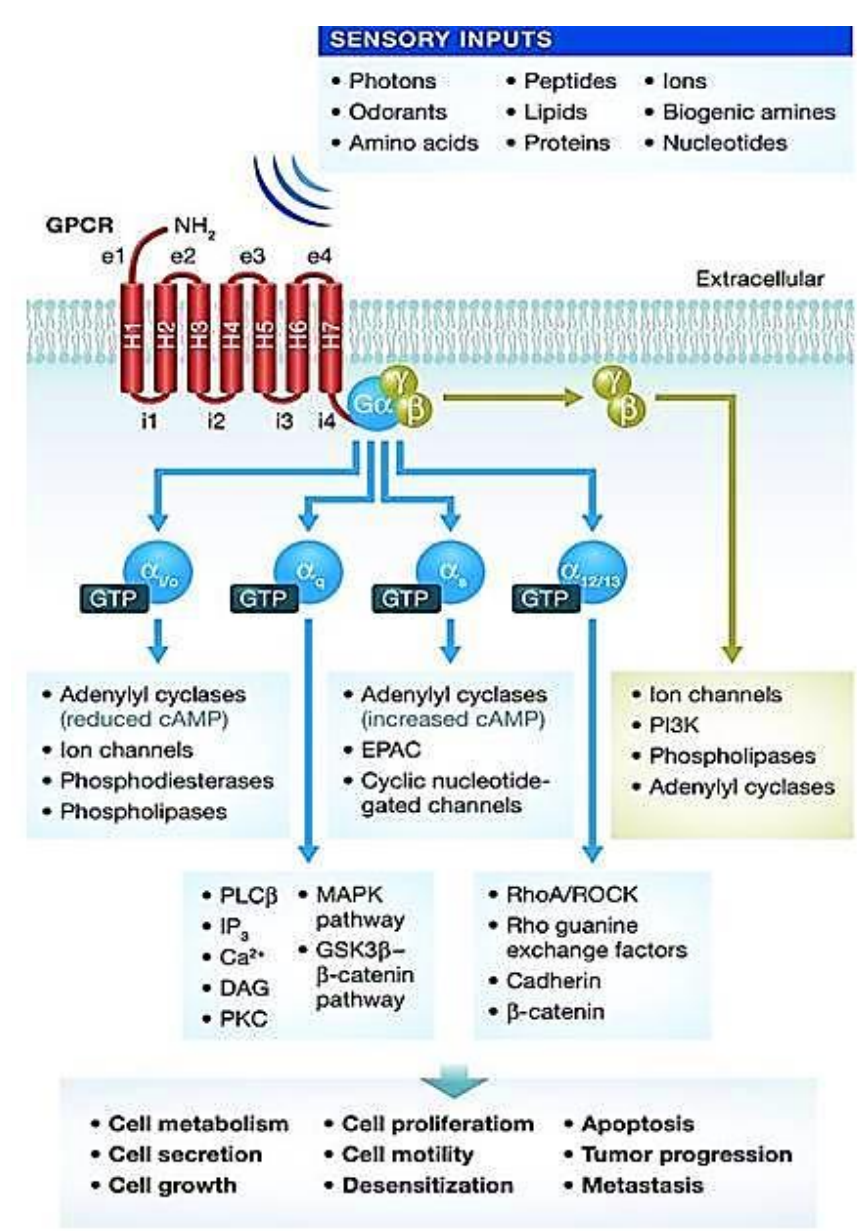

Figura 9: esquema donde se resume las vías de señalización que se desencadenan al ser activado por un ligando una proteína GPCR. Tomado de Schou et al., 2015.

En los últimos años se han incrementado los estudios referentes a la caracterización genómica de secuencias proteicas, como las GPCRs, gracias al libre acceso que se tiene a las bases de datos, como el Genbank. Estas investigaciones pueden orientarse a la generación de conocimiento referido a los cambios evolutivos, funcionales y estructurales, así como las relaciones filogenéticas que pueden presentarse entre estas proteínas encargadas de la comunicación entre las células. Los receptores de las hormonas peptídicas que hemos descripto, AT y AST-C, pertenecen a la familia tipo A de las GPCRs.

El receptor de AT (ATr) ha sido caracterizado genómica y funcionalmente por su alto grado de similitud con el receptor de orexina de vertebrados, en diferentes especies de insectos como B. mori, T. castaneum, M. sexta, A. aegypti, B. terrestres, S. gregaria (Yamanaka et al., 2008; Vuerinckx et al., 2011; Horodyski et al., 2011; Nouzova et al., 2012; Verlinden et al., 2013; Lismont et al., 2015) y su presencia ha sido predicha también en $R$. prolixus 
(Alzugaray et al., 2013). La expresión del mRNA se ha confirmado en órganos reproductores, en el SNC y en el complejo CC-CA y sistema digestivo, todos ellos órganos blanco de la acción del péptido (Verlinden et al., 2015). ATr presenta las características moleculares de las GPCRs, aunque posee un motivo DRW en lugar de DRY en el extremo citoplasmático del 3TM y una sustitución conservativa Y en lugar de W en el 6TM (Verlinden et al., 2015).

La caracterización genómica y funcional del receptor de AST-C (AST-Cr) se ha llevado a cabo en insectos como D. melanogaster, B. mori, A. aegypti, T. castaneum y se ha demostrado su estrecha relación estructural con los receptores de somatostatina de vertebrados, los cuales también pertenecen la familia A de GPCRs (Yamanaka et al., 2008; Kreienkamp et al., 2002; Mayoral et al., 2010; Audsley et al., 2013). En dípteros se han encontrado dos isoformas para AST-Cr dado por eventos de duplicación de este gen. Aunque no es clara la razón fisiológica de este hecho, los investigadores estiman que estos receptores hayan tomado una nueva función en estos insectos y de hecho estas isoformas se encuentran presentes en tejidos que desempeñan funciones diferentes (Mayoral et al., 2010; Kreienkamp et al., 2002).

Dada la amplia distribución en la naturaleza y las numerosas funciones a las que se asocian, resulta de interés profundizar en la caracterización genómico-funcional de este tipo de receptores, los que de hecho, han sido propuestos en los últimos años como potenciales alternativas para el desarrollo de nuevos agentes selectivos para el control de plagas (Verlinden et al., 2014). Se ha demostrado que la interrupción o la sobre-activación de los GPCR (o sus vías) que median funciones biológicas vitales puede conducir a una mortalidad dramática, a la detención del desarrollo, a defectos en el crecimiento y la reproducción y a la disminución de la aptitud de las plagas de insectos. Además, los ligandos de naturaleza proteica y sus receptores están sujetos a procesos de co-evolución, haciéndolos a menudo especie-específicos (Verlinden et al., 2014). 


\section{OBJETIVOS}

Es claro que la actividad de la musculatura visceral cumple un papel fundamental en momentos cruciales de la vida de estos insectos hematófagos. En cualquier estadio de su ciclo de vida, la recirculación de la hemolinfa, durante el periodo de diuresis post-ingesta, es favorecida por las contracciones no solo del vaso dorsal, sino también por los movimientos peristálticos de la pared del tubo digestivo. La actividad muscular regula, además, los eventos que tienen lugar durante la cópula y durante la oviposición en las hembras, clave para perpetuar la especie. Dada la relevancia de comprender la fisiología de estos procesos y de entender como estarían involucrados en ellos dos neuropéptidos pleiotrópicos como los son AT y AST-C en insectos, nos hemos propuesto llevar a cabo este trabajo de investigación integrando diversas metodologías, con el propósito de resolver los siguientes objetivos:

\section{OBJETIVO GENERAL}

Profundizar la caracterización funcional de los neuropéptidos Allatotropina y Allatostatina-C y llevar a cabo la caracterización genómica y funcional de sus probables receptores en la especie Rhodnius prolixus.

\section{OBJETIVOS PARTICULARES}

- Analizar el posible efecto miomodulador de los péptidos AT y AST-C sobre la frecuencia de contracción del sistema digestivo y circulatorio en insectos machos y en el sistema reproductor de las hembras, en diferentes momentos fisiológicos.

- Analizar la probable relación entre la cópula y el momento de la oviposición sobre la actividad contráctil de los órganos del sistema reproductor de la hembra ante la presencia de los péptidos.

- Estudiar probables mecanismos de regulación de la contracción por parte de AST-C.

- Analizar las probables fuentes de síntesis de AST-C mediante microscopía de barrido laser confocal.

- Caracterizar las secuencias del mRNA maduro y de los genes del receptor de AT y de AST-C, y analizar la expresión de ambos receptores en diferentes tejidos larvales y del adulto, en función de corroborar la funcionalidad de los mismos.

- Analizar las relaciones filogenéticas de cada receptor con receptores homólogos de la clase Insecta. 
Materiales y Métodos 


\subsection{MANTENIMIENTO DEL BIOTERIO Y CRÍA DE LOS INSECTOS}

Se utilizaron insectos provenientes de una colonia de vinchucas de la especie Rhodnius prolixus (Hemiptera: Reduviidae) establecida en el año 2012 en el bioterio de la Cátedra de Histología y Embriología Animal de la Facultad de Ciencias Naturales y Museo de la Universidad Nacional de La Plata (FCNyM-UNLP). Los insectos son mantenidos a una temperatura $30 \pm 2^{\circ} \mathrm{C}$ y $30 \%$ de humedad relativa y un fotoperíodo de 12:12 horas luz/oscuridad. Dado que las aves son refractarias a la infección con T. cruzi (Kierszenbaum et al., 1981) los insectos son alimentados con sangre de estos animales (gallina).

Los insectos son separados según su estadio y mantenidos en frascos de plástico a los cuales se les coloca una malla de licra ajustada con banditas elásticas. A través de ésta malla los insectos pueden traspasar su órgano sucto-picador para alimentarse.

Los diferentes diseños experimentales fueron realizados con individuos adultos (machos y hembras). Para lograr una mayor estandarización en las condiciones experimentales los insectos fueron seleccionados según el sexo durante el quinto estadio larval. La selección se realizó bajo lupa estereoscópica observando ventralmente los últimos segmentos abdominales. En la figura 1 se observan las características diferenciales a nivel de los segmentos que darán origen a la genitalia en el adulto y que permiten el reconocimiento del sexo de la larva durante este estadio (Chiang et al., 2013).
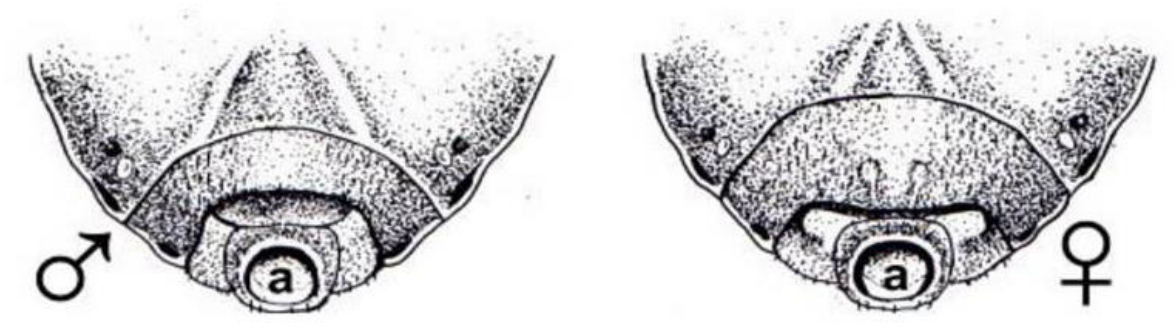

Figura 1: Vista ventral y posterior de insectos del V estadio larval de $R$. prolixus mostrando las características morfológicas que permiten la diferenciación entre sexos (tomado de Chiang et al., 2013).

Luego de haber sido separados según el sexo, los insectos son ayunados por un período no menor a 15 días antes de brindarles acceso a la fuente de alimento ad libitum. Solo los insectos que logran una alimentación a repleción, lo que garantiza el proceso de muda, son seleccionados. Aquellos individuos que no alcanzan una alimentación a repleción son 
separados y devueltos a la colonia. La selección previa de machos y hembras evita la cópula obteniendo un mayor control del estado fisiológico de las hembras luego de la eclosión de los individuos adultos (Davey, 2007).

\subsection{PÉPTIDOS Y ANTISUEROS UTILIZADOS EN LOS BIOENSAYOS:}

\section{ALLATOTROPINA Y ALLATOSTATINA-C}

Los péptidos utilizados durante los experimentos fueron sintetizados en base a la secuencia de aminoácidos correspondiente a Allatotropina (Center for Biotechnology Research, Kansas State University, USA) (Li et al., 2003) y Allatostatina-C (Alpha Diagnostic International, San Antonio, TX, USA) (Li et al., 2004) del mosquito A. aegypti. Para los experimentos realizados con alimentación artificial se utilizó un antisuero anti-Allatotropina de A. aegypti (Genemed Synthesis, San Francisco, Calif., USA) (Hernández-Martínez et al., 2005). Ambos péptidos y el antisuero fueron gentilmente cedidos por el Dr. Fernando G. Noriega (Florida International University, Florida-USA).

La actividad y presencia del péptido Allatotropina de $A$. aegypti en insectos triatominos fue previamente demostrada por nuestro laboratorio (Santini \& Ronderos, 2007, 2009a y 2009b; Riccillo \& Ronderos, 2010; Sterkel et al., 2010).

\subsection{ANÁLISIS ESTADÍSTICO}

Los resultados obtenidos fueron analizados mediante Análisis de la Varianza Multifactorial o Análisis de la Varianza de Medidas Repetidas. En la sección "Anexos" se encuentran las tablas de Análisis de la Varianza correspondientes a cada uno de los análisis.

Las comparaciones post-hoc se llevaron a cabo mediante la prueba de LSD (Least Significant Difference) o mediante la prueba de Tuckey, según el análisis. Los datos fueron transformados a logaritmo cuando fue necesario. Sólo se consideraron significativas aquellas diferencias con una probabilidad igual o inferior a 0,05 . Los datos se expresan como media \pm error estándar. 


\subsection{DISEÑOS EXPERIMENTALES}

\subsubsection{Experimentos en insectos machos adultos}

Preparación de los insectos: Todos los experimentos se llevaron a cabo in vivo, bajo microscopio estereoscópico Olympus a temperatura ambiente $\left(20 \pm 2^{\circ} \mathrm{C}\right)$. Para el conteo de las contracciones de la aorta y del buche, los individuos experimentales fueron colocados bajo microscopio estereoscópico sobre una placa de Petri con parafina, e inmovilizados colocando plastilina sobre sus patas. Dada la condición translucida de la cutícula dorsal del adulto, una vez seccionadas las alas, tanto la aorta como el buche pueden ser fácilmente visualizados a través de la cutícula (Fig. 2).

Los diferentes tratamientos fueron aplicados con jeringa Hamilton ( $5 \mu \mathrm{l}$ ) a través de una pequeña incisión realizada en el conexivo del segmento II del abdomen (Fig. 2). Para disminuir el efecto causado por el estrés de la manipulación, una vez establecidos en la placa, los insectos fueron mantenidos en reposo durante 30 minutos, permitiendo de este modo que la frecuencia cardíaca y la tasa de ondas peristálticas retornen a los valores basales.

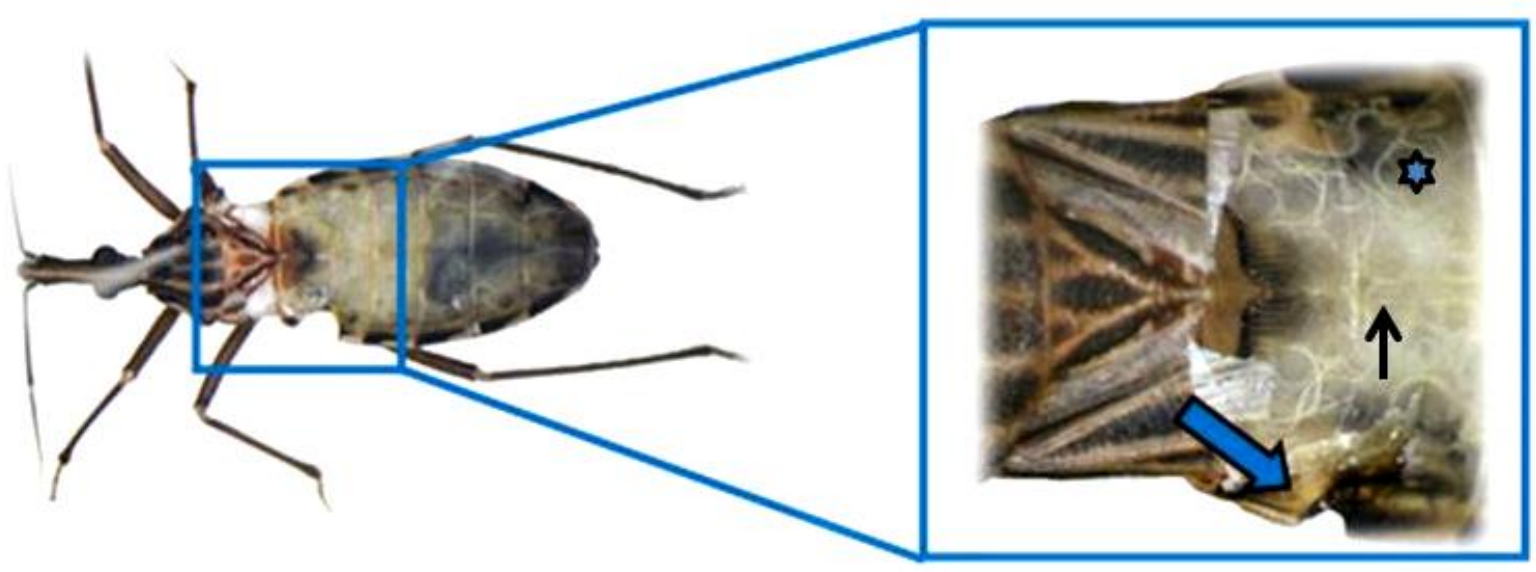

Figura 2: Vista panorámica y detalle dorsal de un macho sin alimentar al cual se le han seccionado las alas mostrando la incisión realizada en el conexivo para la aplicación de los distintos tratamientos (Flecha celeste). Se observa además la aorta (flecha negra) y el buche (estrella).

El número de contracciones de la aorta y de las ondas peristálticas del buche fueron contabilizadas a nivel de los segmentos III y IV del abdomen por un período de 3 minutos, a los 5, 15 y 30 minutos luego de comenzado el tratamiento. En ambos casos, las contracciones 
locales no fueron tenidas en cuenta. La frecuencia cardíaca y la tasa de contracciones peristálticas se expresa como Número de Contracciones/Minuto.

En el caso de experimentos que involucran ensayos de dosis-respuesta y, dado que las distintas dosis son analizadas en un mismo individuo, entre el ensayo de una dosis y la siguiente se permitió que el insecto retorne a la frecuencia basal, evitando un probable efecto acumulativo de las dosis.

En todos los casos se utilizaron insectos que no habían recibido alimentación previa en el estado adulto, ayunados por un período de entre 15 y 20 días luego de la eclosión. Luego del ayuno y en caso de que el diseño experimental lo requiriera, se les ofreció acceso a la fuente de alimento. En el caso de insectos alimentados, solo aquellos individuos que alcanzaron una alimentación a repleción fueron seleccionados.

\section{Análisis del efecto mio-regulador de Allatotropina sobre la aorta y digestivo medio anterior} en insectos ayunados: Hemos demostrado previamente en la especie emparentada $T$. infestans, que AT posee un efecto estimulador a nivel de la frecuencia de contracciones de la aorta, de la tasa de contracciones peristálticas del tubo digestivo medio anterior (buche) y el digestivo posterior (Santini \& Ronderos, 2007; Sterkel et al., 2010). En el caso de la frecuencia cardíaca hemos demostrado además que en individuos que no habían recibido alimentación previa durante el estado adulto, el efecto cardiorregulador de AT es dependiente de la presencia de serotonina (Sterkel et al., 2010). Masood \& Orchard (2014), desarrollando experimentos in vitro en larvas en condición basal, proponen que AT no posee actividad mioreguladora en $R$. prolixus, sugiriendo que el péptido se comporta de modo diferencial en ambas especies. Con el fin de corroborar la existencia de un efecto similar al descripto en $T$. infestans, decidimos reproducir en $R$. prolixus el sistema previamente analizado.

Se realizaron los siguientes experimentos:

- Análisis de la frecuencia cardíaca y efecto de AT en insectos ayunados $(N=6)$.

- Análisis de variaciones diurnas en la frecuencia cardíaca basal $(\mathrm{N}=6)$.

- Análisis de variaciones diurnas en el efecto de AT $(N=6)$.

- Efecto sinérgico de serotonina y AT sobre la frecuencia cardíaca y tasa de ondas peristálticas del buche $(\mathrm{N}=6)$.

Efecto de la administración de un antisuero anti-Allatotropina con la ingesta: Nuestro laboratorio ha demostrado previamente que AT posee actividad mio-reguladora sobre las 
contracciones peristálticas del digestivo posterior de $T$. infestans, facilitando la mezcla de orina y heces durante la diuresis post-prandial (Santini \& Ronderos, 2007). Hemos demostrado además que la inyección previa a la ingesta en el hemocele de larvas del IV estadio de un antisuero específico anti-AT, inhibe ese efecto disminuyendo de manera significativa la cantidad de orina eliminada por el insecto durante las primeras horas posteriores a la ingesta (Santini \& Ronderos, 2007). Hemos demostrado recientemente en larvas del IV estadio de $R$. prolixus, que el antisuero genera un efecto similar cuando es administrado a través de la ingesta (Villalobos-Sambucaro et al., 2015a).

Dado que la principal vía natural de contagio de la enfermedad de Chagas es la eliminación de orina y heces mientras que el insecto se encuentra sobre el huésped, el retraso en el proceso de diuresis, podría resultar una medida alternativa de utilidad en el control de la transmisión de la enfermedad (Santini \& Ronderos, 2007; Villalobos Sambucaro et al., 2015a).

Los insectos fueron alimentados en un alimentador artificial (Núñez \& Lazzari, 1990) con una solución de antisuero anti-AT en PBS (1/100) o solo PBS (control) (Solución Buffer Fosfato, PBS, ver protocolos). La especificidad del antisuero mediante la preadsorción del mismo con el péptido de origen fue previamente testeada (Santini \& Ronderos, 2007; 2009a, Villalobos-Sambucaro et al., 2015a) por lo que en este experimento dicho control no fue incluido. Los insectos fueron expuestos a la fuente de alimento por un período de 15 minutos y solo aquellos individuos que alcanzaron una alimentación a repleción fueron seleccionados. Una vez alimentados, los insectos fueron preparados para la evaluación de la frecuencia de contracciones de la aorta y tasa de contracciones peristálticas del buche según se describió previamente. La frecuencia cardíaca y tasa de ondas peristálticas se evaluó durante el período de máxima producción de orina (Maddrell, 1964b) a los 15, 30, 45, 60, 90, 120 y 240 minutos, y se compararon los valores correspondientes al grupo control (PBS) $(N=6)$ con el grupo que recibió el antisuero (PBS + anti-AT) $(\mathrm{N}=6)$.

\section{Análisis del efecto antagonista de Allatostatina-C sobre la actividad de Allatotropina en la}

\section{frecuencia de contracciones de la aorta y de ondas peristálticas en el digestivo medio}

anterior (buche): AST-C fue originalmente caracterizada en base a su actividad inhibitoria sobre la síntesis y secreción de HJs en la mariposa $M$. sexta y se ha propuesto que posee un efecto cardioinhibidor en D. melanogaster (Price et al., 2002). Teniendo en cuenta que ambos péptidos han demostrado tener un efecto opuesto sobre la actividad de síntesis de HJs en la CA, decidimos analizar la probable existencia de un efecto mioinhibidor de AST-C en $R$. 
prolixus. Con este fin se llevaron a cabo los diseños experimentales que se detallan a continuación:

- Análisis de la actividad mio-reguladora de AST-C sobre la frecuencia cardíaca y ondas peristálticas del buche en insectos ayunados previamente estimulados con Serotonina y $\operatorname{AT}(\mathrm{N}=6)$.

- Análisis de la actividad mio-reguladora de AST-C sobre la frecuencia cardíaca y ondas peristálticas del buche en insectos ayunados previamente estimulados solo con Serotonina $(\mathrm{N}=7)$.

- Análisis de la actividad mio-reguladora de AST-C sobre la frecuencia cardíaca y ondas peristálticas del buche en insectos recién alimentados (diuresis post-prandial) ( $N=7)$.

- Análisis de la actividad mio-reguladora de AST-C sobre la frecuencia cardíaca y ondas peristálticas del buche en insectos recién alimentados (diuresis post-prandial) en presencia de Thapsigargina (Inhibidor de la actividad de la Calcio-ATPasa del retículo sarcoplásmico) $(\mathrm{N}=8)$.

\subsubsection{Experimentos en insectos hembras adultas}

Estados fisiológicos a evaluar: Teniendo en cuenta que hay dos eventos importantes que modulan la fisiología de la hembra, la ingesta sanguínea y la cópula, se decidió evaluar los efectos de AT y AST-C como péptidos mio-reguladores en diferentes estados fisiológicos asociados a estos factores.

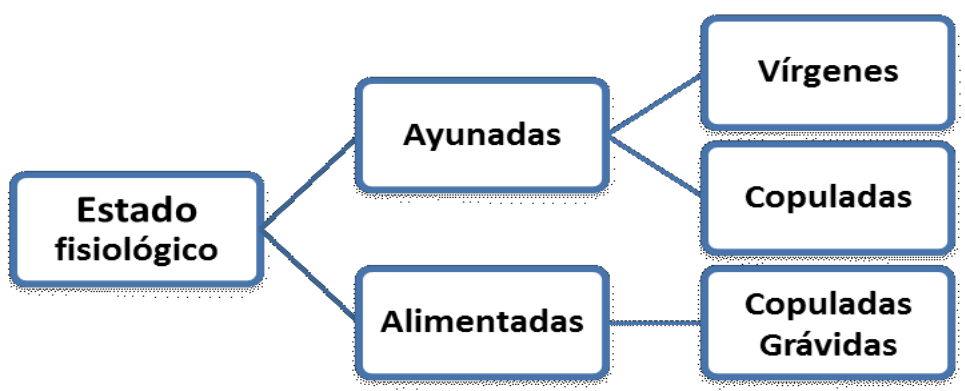

- Hembras ayunadas vírgenes (HV): hembras adultas recién emergidas separadas durante el quinto estadio larval, ayunadas durante 20 días antes de realizar los experimentos.

- Hembras ayunadas copuladas (HC): hembras adultas recién emergidas separadas durante el quinto estadio larval que fueron ayunadas durante 20 días. A los 15 días post muda se colocaron en frascos individuales una hembra ayunada con un macho 
alimentado ad libitum. Luego de 5-6 días se certifica que ha ocurrido la cópula tras encontrarse en el fondo del frasco el espermatóforo expulsado por la hembra (Fig. 3)

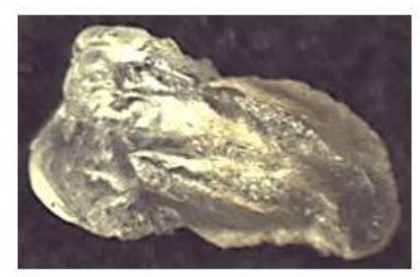

Figura 3: imagen de un espermatófo expulsado por una hembra. Estas estructuras son las que se encuentran en el fondo de los frascos que contienen a los insectos y con ello se confirma que la cópula se ha llevado a cabo.

- Hembras alimentadas copuladas grávidas (HG): hembras adultas recién emergidas separadas durante el quinto estadio larval que fueron ayunadas durante 15 días. En ese momento se colocaron en frascos individuales una hembra y un macho alimentados ad libitum. Luego de 5-6 días se certifica que ha ocurrido la cópula tras encontrarse en el fondo del frasco el espermatóforo expulsado por la hembra. El macho es retirado para que no se produzca una nueva cópula. Los experimentos se llevaron a cabo ni bien se inició la puesta de huevos (entre 12 y 15 días luego de la alimentación).

Preparación de los insectos: Todos los experimentos se llevaron a cabo in vivo, bajo lupa estereoscópica Olympus, a temperatura ambiente. Cada insecto fue disecado sobre una placa de Petri con parafina y sus patas fueron inmovilizadas con plastilina. Para poder visualizar el $\mathrm{SRH}$, los terguitos, la aorta, el cuerpo graso, y la totalidad del sistema digestivo fueron retirados. Para evitar la deshidratación de los órganos la cavidad abdominal fue bañada con 20 $\mu \mathrm{l}$ de solución salina de $R$. prolixus. Los tratamientos comienzan luego de 20 minutos de reposo con el propósito de que el sistema se estabilice luego del estrés provocado por la manipulación.

La frecuencia de contracción de la musculatura de ovarios (OV), oviductos (OVI), útero (UT), espermatecas (ESP) y bursa (B) (Fig. 4) fueron registradas de manera simultánea. 


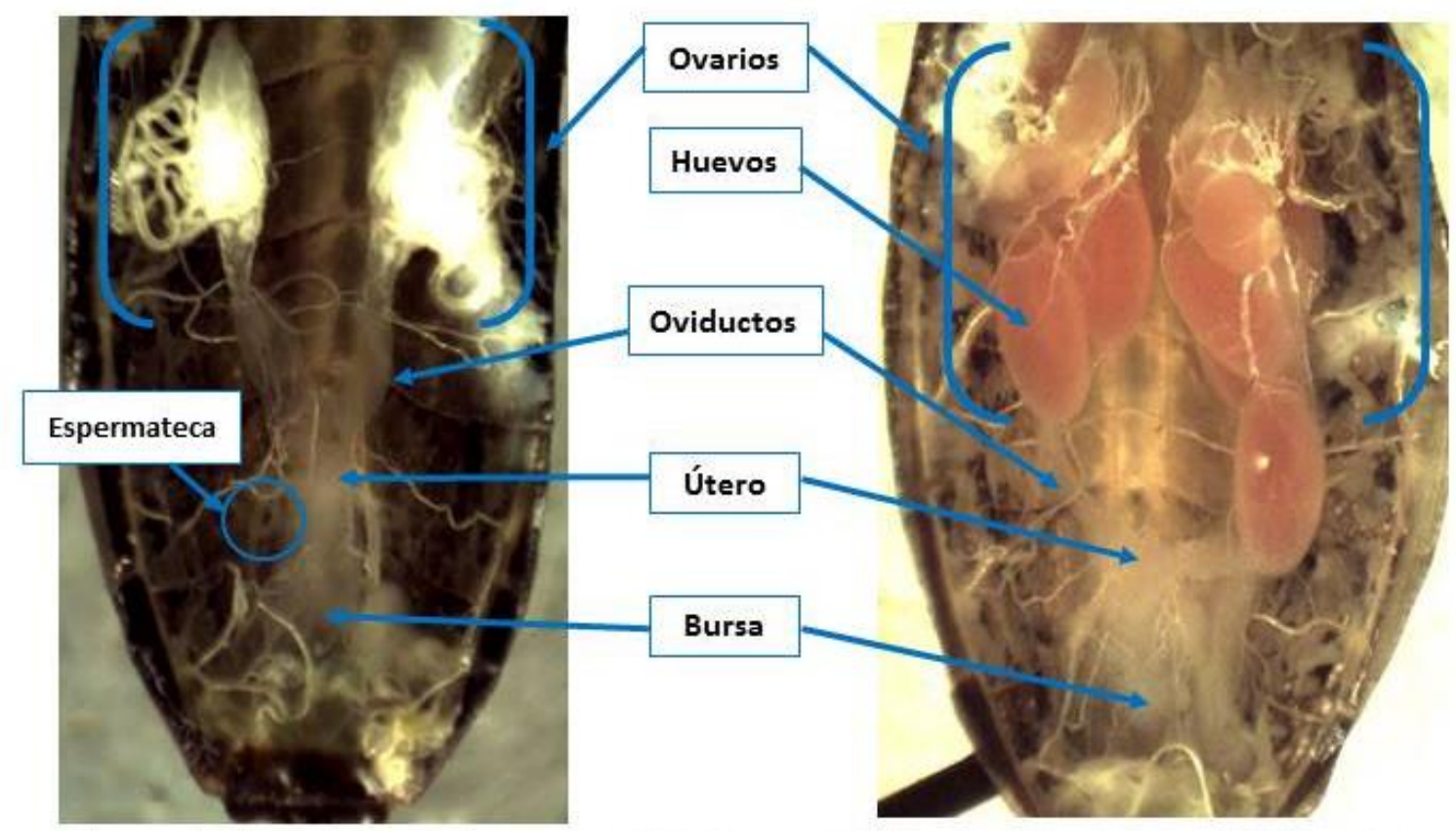

Figura 4: Vista de la anatomía del SRH de una hembra copulada (HC) (izquierda) y de una hembra grávida (HG) (derecha), donde se indica cada uno de los órganos. Únicamente se señala la espermateca izquierda en la imagen correspondiente a $\mathrm{HC}$, ya que las otras se encuentran plegadas, dificultando denotar su forma.

La frecuencia se calculó mediante el registro de imágenes realizado con una cámara acoplada a la lupa (Fig. 5). Durante cada tratamiento se tomaron un total de 150 fotografías (una por segundo), con una magnificación de 1.5X, cubriendo un total de 3 minutos por cada tratamiento. Las fotografías fueron editadas mediante el software Movie Maker para generar videos de tipo time-lapse y registrar el número de contracciones para cada órgano. Los resultados se expresaron como número de contracciones/minuto.

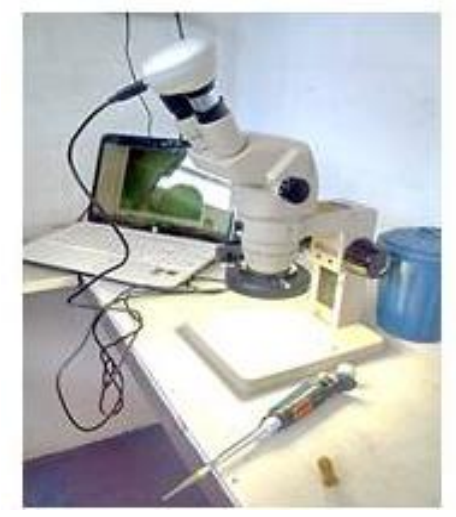

Figura 5: lupa de disección con cámara adosada al ocular. 
Evaluación del efecto dosis dependiente de Allatotropina sobre el SRH: con el propósito de estudiar la actividad mio-reguladora de AT sobre el SRH se realizaron tres experimentos en los tres estados fisiológicos detallados anteriormente: $\mathrm{HV}(\mathrm{N}=9), \mathrm{HC}(\mathrm{N}=6), \mathrm{HG}(\mathrm{N}=6)$. Se evaluaron cinco concentraciones crecientes de $A T\left(10^{-14} \mathrm{M}, 10^{-12} \mathrm{M}, 10^{-10} \mathrm{M}, 10^{-8} \mathrm{M}\right.$ y $\left.10^{-6} \mathrm{M}\right)$. La frecuencia basal, correspondiente a individuos que recibieron salina fue considerada como control. Para el registro de la frecuencia de contracción muscular en las distintas porciones que conforman el SRH la cámara acoplada al microscopio binocular fue programada para la toma de 1 imagen/segundo (150 cuadros). Los registros se realizaron a los 5, 15 y 30 minutos luego de aplicada cada dosis a evaluar.

Evaluación del efecto dosis dependiente de Allatostatina-C sobre el SRH: teniendo en cuenta la probable actividad mio-reguladora de AST-C, se decidió evaluar la actividad del péptido sobre el SRH en HG (N=6). Para ello, se ensayaron dosis crecientes del péptido $\left(10^{-14} \mathrm{M}, 10^{-12} \mathrm{M}\right.$, $10^{-10} \mathrm{M}, 10^{-8} \mathrm{M}$ y $10^{-6} \mathrm{M}$ ) que fueron aplicadas consecutivamente con una micropipeta automática $(20 \mu \mathrm{l})$, una vez transcurridos los 20 minutos post manipulación. La cámara fue programada para que tome 1 fotografía por segundo (150 cuadros) a los 5, 15 y 30 minutos luego de aplicada cada dosis.

\subsection{ESTUDIO DE LA PRESENCIA DE ALLATOSTATINA-C MEDIANTE MICROSCOPÍA LASER DE BARRIDO CONFOCAL}

Con el propósito de investigar las posibles fuentes de secreción del neuropéptido ASTC se procesaron el buche, el vaso dorsal (corazón y aorta) y los ganglios nerviosos ventrales (ganglios protorácico y metatorácico) de insectos machos ayunados durante 7 días luego de la eclosión. Los tejidos se diseccionaron bajo microscopio binocular y se fijaron en una solución de formaldehıdo-fosfato (PBS) (4\%) a $4^{\circ} \mathrm{C}$ durante 12 horas. Las muestras se lavaron en PBSTween (0,05\%) (PBS-T) (Tween 20-Bio-Rad Laboratories, Inc. CA 94547), se permeabilizaron con Triton (1\%) (24 horas a $4^{\circ} \mathrm{C}$ ) (TritonX-100- Bio-Rad Laboratories, Inc. CA 161-0407) y después se bloquearon con albúmina de suero bovino (BSA) al 3\% durante 2 horas a temperatura ambiente. Posteriormente, los tejidos fueron incubados durante la noche a $4^{\circ} \mathrm{C}$ con un antisuero contra $A$. aegypti AST-C (1/500 en BSA al 3\% diluido en PBS-T); y posteriormente se incubaron con un anticuerpo secundario de cabra anti-conejo marcado con FITC (Santa cruz Byotechnology) (1/200 en blocking buffer) durante 3 horas a temperatura ambiente. Para 
visualizar la disposición de las células musculares, las muestras se co-incubaron con una solución de rodamina-faloidina (Sigma-Aldrich) (1/1000). Después de cada paso, los tejidos se lavaron (3 veces $\mathrm{x} 20$ minutos) con PBS-T (0,05\%). Los órganos así procesados fueron montados en porta objetos a los que se les realizó un reborde con esmalte transparente para darle profundidad y se montaron en Vectashield, cuidando que no quedan burbujas que puedan interferir en la toma de las imágenes. Los bordes del mismo también fueron sellados con esmalte transparente. Una vez finalizado este procedimiento se mantuvieron en oscuridad a $4^{\circ} \mathrm{C}$ hasta el momento de ser observados. En el preparado control de anticuerpos secundarios, la incubación de anticuerpos primarios se sustituyó por PBS. Las muestras se analizaron en dos equipos de microscopía de barrido laser confocal diferentes: Zeiss LSM 510 Meta y Leica TCS SP5.

\subsection{CARACTERIZACIÓN DE LOS RECEPTORES DE MEMBRANA DE}

\section{ALLATOTROPINA (ATr) Y ALLATOSTATINA C (AST-Cr)}

\subsubsection{Búsqueda de las secuencias de los receptores en el genoma}

La identificación de ATr y AST-Cr en el genoma de $R$. prolixus se realizó utilizando herramientas bioinformáticas de acceso libre. Dichas secuencias fueron rastreadas utilizando el banco de datos Vector base (https://www.vectorbase.org). Dos secuencias ya identificadas genómicamente de ambos receptores fueron seleccionadas para realizar la búsqueda por similitud utilizando el algoritmo BLASTP (https://blast.ncbi.nlm.nih.gov/Blast.cgi). Las secuencias utilizadas fueron las pertenecientes al receptor de AT de la especie $M$. sexta (ADX66344.1) y al receptor de AST-C de la especie T. castaneum (XP_971178.2). Las estructuras de ambos genes fueron predichas utilizando el software http://augustus.gobics.de. Los dominios de transmembrana fueron predichos con el software online TMHMM (http://www.cbs.dtu.dk/services/TMHMM/).

\subsubsection{Diseño de primers}

Una vez identificadas las secuencias genómicas y con el propósito de evaluar la expresión y realizar la secuenciación parcial de ambos receptores, se diseñaron primers específicos utilizando el software GENERUNNER 3.05. Los correspondientes primers utilizados fueron sintetizados por la empresa EUROFIN y se detallan a continuación. 


\begin{tabular}{cl}
\hline ATr primers 900pb & $\begin{array}{l}\text { Forward 5'-ATGTCCGATGAAGACTATCTG-3' } \\
\text { Reverse 5'-TGTAGATAAGAGGATTAGTGGC-3' }\end{array}$ \\
\hline ATr primers 294pb & $\begin{array}{l}\text { Forward 5'-ATGTCCGATGAAGACTATCTG-3' } \\
\text { Reverse 5'-GTAGAGCACTAATTTGCAGAG-3' }\end{array}$ \\
AST-Cr primers 577pb & $\begin{array}{l}\text { Forward 5'-AATCTAAGCGGCCAGACAGCG -3' } \\
\text { Reverse 5'-TAGATGTGAGCGCCGTTGTGG -3' }\end{array}$ \\
\hline AST-Cr primers 195pb & $\begin{array}{l}\text { Forward 5'-AAGCGTGCACTTGTGCTGCTGG -3' } \\
\text { Reverse 5'-A TGTGAGCGCCGTTGTGGAATG-3' }\end{array}$ \\
\hline
\end{tabular}

\subsubsection{Extracción de RNA mensajero (mRNA) y síntesis de DNA complementario (cDNA)}

Para la síntesis de cDNA se extrajo mRNA de hembras adultas y de larvas de IV estadio (N4). Un pool de hembras de R. prolixus, en diferentes condiciones fisiológicas (ayunadas, alimentadas, grávidas) fueron disecadas, extrayendo el vaso dorsal (VD), tubo digestivo medio (DM), recto (R), SRH y TMs. Cada uno de ellos fue colocado por separado en tubos Eppendorf conteniendo RNAlater (ver Soluciones) con el propósito de evitar la degradación del RNA. Del mismo modo, un pool de larvas de IV estadio en diferentes condiciones fisiológicas fueron disecadas y la totalidad de sus órganos fueron extraídos y conservados en RNAlater. Todas las muestras fueron mantenidas a $4^{\circ} \mathrm{C}$ hasta su procesamiento.

La extracción de RNA se realizó siguiendo el protocolo del kit comercial RNEASY Plant Mini Kit (Qiagen) y se guardó en ultra-freezer $\left(-80^{\circ} \mathrm{C}\right)$. Una vez obtenido el mRNA, se realizó la síntesis de cDNA utilizando el kit Revert Aid First Strand (Fermentas, EE.UU.). Durante los procesos de extracción de RNA y síntesis de cDNA, las superficies donde se trabajó, los instrumentos de disección, las micropipetas, material plástico descartable y material de vidrio fueron cuidadosamente lavados con inhibidores de RNAasas (RNAsa ZAP- AMBION cat: AM9780).

\subsubsection{Análisis de la expresión de ATr y AST-Cr}

A partir de los diferentes cDNA obtenidos y con los primers diseñados para lograr evidenciar la expresión de éstos receptores se aplicó la técnica PCR (ver protocolos). En primer lugar, se pusieron a punto los primers diseñados planificando un gradiente de temperaturas de 
Annealing (Termociclador: MBS 0.2G Thermo Hybaid) para verificar cuál era la de mayor eficiencia en la reacción. Utilizamos los siguientes programas de termociclado empleando el cDNA de N4 como molde:

\begin{tabular}{ll}
\hline Programa ATr & Desnaturalización Inicial: 1 ciclo; $94^{\circ} \mathrm{C}-5^{\prime}$. \\
& Síntesis: 35 ciclos; Desnaturalización $94^{\circ} \mathrm{C}-$ \\
& $35 / 45^{\prime \prime} ;$ Annealing $53^{\circ} \mathrm{C}-35 / 50^{\prime \prime} ;$ Elongación \\
& $72^{\circ} \mathrm{C}-35 / 90^{\prime \prime}$. \\
& Elongación Final: 1 ciclo; $72^{\circ} \mathrm{C}-5^{\prime}$. \\
\hline Programa AST-Cr & Desnaturalización Inicial: 1 ciclo; $94^{\circ}{\mathrm{C}-5^{\prime} .}^{\circ}$ \\
& Síntesis: 35 ciclos; Desnaturalización $94^{\circ} \mathrm{C}-$ \\
& $35 / 40^{\prime \prime} ;$ Annealing $60^{\circ} \mathrm{C}-35 / 40^{\prime \prime} ;$ Elongación \\
& $72^{\circ} \mathrm{C}-35 / 60^{\prime \prime}$. \\
& Elongación Final: 1 ciclo; $72^{\circ} \mathrm{C}-5^{\prime}$. \\
\hline
\end{tabular}

Una vez establecidos los patrones de PCR, y con el objetivo de estudiar si ambos receptores se expresaban en todos los CDNA obtenidos, se realizaron PCR por cada uno de ellos como molde en cada reacción (Termociclador: MBS 0.2G Thermo Hybaid). La expresión se verificó mediante electroforesis de geles de agarosa $3 \%$ sembrando cada producto de PCR y revelándolos posteriormente en un transiluminador (ver protocolo).

\subsubsection{Precipitación, purificación y secuenciación de productos de PCR}

Con el propósito de verificar que las bandas obtenidas en los geles revelados corresponden a los receptores de interés, se realizó la precipitación y purificación del DNA, producto de las PCR y con el mismo llevar a cabo la secuenciación del cDNA. Las purificaciones de DNA de ATr y AST-Cr se realizaron mediante diferentes técnicas dependiendo de si el producto a purificar era directo desde el producto de PCR o sembrando la cantidad necesaria en un gel de agarosa 3\% en caso de encontrar bandas inespecíficas que puedan afectar la secuenciación (ver protocolo).

Finalmente, los DNA purificados fueron enviados para su secuenciación por electroforesis capilar según el protocolo requerido por el servicio de Unidad de Genómica Instituto de Biotecnología - CICVyA - CNIA - INTA. Una vez obtenidas las secuencias de ATr y AST-Cr y corroborando mediante alineamientos y búsquedas de similitud se procedió con la anotación de las mismas Genbank (https://www.ncbi.nlm.nih.gov/genbank/). 


\subsection{ANÁLISIS FILOGENÉTICOS DE LOS RECEPTORES DE MEMBRANA}

DE ALLATOTROPINA (ATr) Y ALLATOSTATINA C (AST-Cr)

\subsubsection{Búsqueda de secuencias homólogas en bases de datos}

Como se detalló previamente, tanto ATr como AST-Cr pertenecen a los GPCR, siendo éste un grupo de proteínas muy conservado en el Reino Animal. Con el propósito de inferir a cerca de la filogenia de estos dos receptores en la clase Insecta se analizaron varias secuencias homólogas de insectos. En primer lugar utilizando de "muestra" a la secuencia completa de aminoácidos correspondiente a ATr de M. sexta (ADX66344.1) y a AST-Cr de T. castaneum (D6X173_TRICA), se realizaron búsquedas de homólogos mediante el algoritmo BLAST y la matriz BLOSUM 62 (Henikoff \& Henikoff, 1992), seleccionándose para realizar los análisis filogenéticos únicamente aquellas secuencias que se encontraban completas, incluyendo los 7 dominios transmembrana característicos de los GPCR.

\subsubsection{Alineamientos múltiples y construcción de árboles filogenéticos}

El análisis filogenético de cada receptor se realizó mediante alineamientos múltiples utilizando ClustalW (http://www.ebi.ac.uk/Tools/msa/clustalw2) y el software JalView 2.7 (Waterhouse et al., 2009). Finalmente, el análisis de las probables relaciones filogenéticas entre secuencias se realizó utilizando el método de máxima verosimilitud (Maximum likelyhood-ML) basado en el modelo de corrección de Poisson, incluyendo un análisis de 1000 repeticiones de bootstrap, mediante el uso del software Mega 6.06 (Tamura et al., 2013). 
Resultados 


\subsection{ANÁLISIS DE LA ACTIVIDAD MIO-REGULADORA DE AT Y AST-C \\ SOBRE EL SISTEMA CIRCULATORIO Y DIGESTIVO DE MACHOS \\ ADULTOS DE R. prolixus.}

\subsubsection{Análisis de la actividad de allatotropina y variaciones diarias en la frecuencia cardiaca basal en machos adultos ayunados.}

Como primera aproximación al estudio de la actividad de AT sobre la frecuencia de contracciones del vaso dorsal y la tasa de contracciones peristálticas del buche, y teniendo en cuenta resultados previos obtenidos en nuestro laboratorio sobre la especie afín $T$. infestans, decidimos ensayar las dosis máximas previamente utilizadas $\left(10^{-9}\right.$ y $\left.10^{-6} \mathrm{M}\right)$. Los resultados muestran que, al igual que en $T$. infestans, AT no indujo aumentos estadísticamente significativos en la frecuencia cardíaca de insectos adultos que no hubieran recibido alimentación previa (Fig. 1A).

Durante el análisis, observamos la existencia de una variación en la frecuencia basal de los individuos, aparentemente asociada a fluctuaciones diarias. Con el objetivo de estudiar la misma, decidimos analizar la frecuencia de la aorta en condiciones basales (inyectados con solución salina) en insectos tratados durante la mañana (i.e. 09:00 a 13:00 hs) e individuos tratados durante la tarde (14:00 a 18:00 hs). Los resultados mostraron que la frecuencia basal fue diferente en ambos grupos analizados, siendo significativamente mayor en el grupo correspondiente al horario comprendido entre las 14:00 y 18:00 hs (Fig. 1B).

En función de estos resultados, y con el objetivo de descartar diferencias asociadas a variaciones diarias en la respuesta de los insectos, analizamos el afecto de AT $\left(10^{-6} \mathrm{M}\right)$ sobre la frecuencia cardíaca de insectos ayunados, discriminando según los dos períodos horarios señalados. Los resultados mostraron que AT no fue capaz de modificar significativamente la frecuencia de las contracciones de la aorta en ninguno de los dos momentos analizados, confirmando los resultados previamente descriptos en T. infestans (Fig. 1C). 

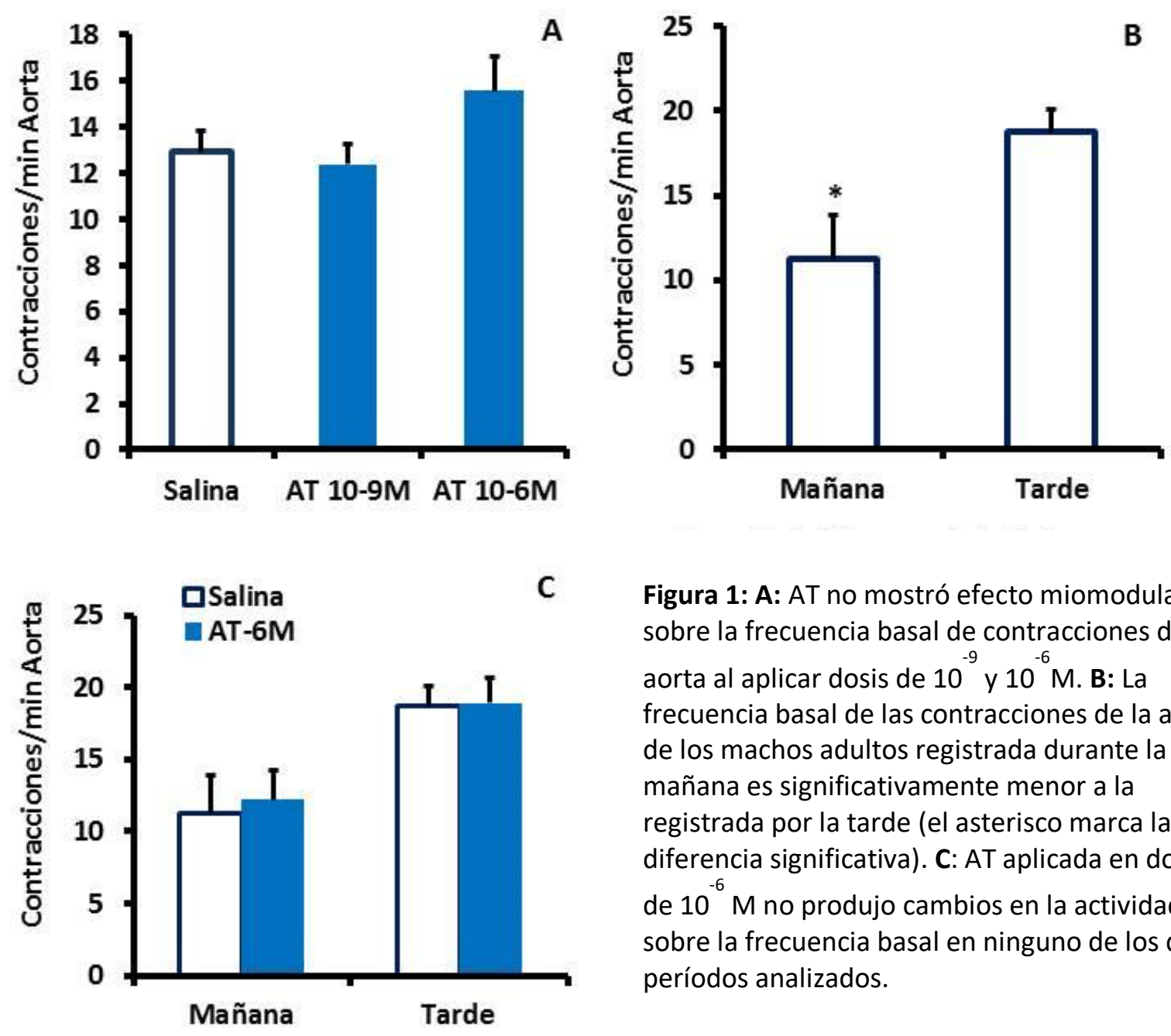

Figura 1: A: AT no mostró efecto miomodulador sobre la frecuencia basal de contracciones de la aorta al aplicar dosis de $10^{-9}$ y $10^{-6} \mathrm{M}$. B: La frecuencia basal de las contracciones de la aorta de los machos adultos registrada durante la mañana es significativamente menor a la registrada por la tarde (el asterisco marca la diferencia significativa). C: AT aplicada en dosis de $10^{-6} \mathrm{M}$ no produjo cambios en la actividad sobre la frecuencia basal en ninguno de los dos períodos analizados.

\subsubsection{Estudio del efecto mio-regulador de Allatotropina sobre la aorta y el digestivo medio anterior en presencia de serotonina en insectos ayunados.}

Anteriormente demostramos en $T$. infestans que AT es capaz de incrementar la frecuencia de contracciones de la aorta luego del tratamiento previo con serotonina (Sterkel et al., 2010). Con el fin de corroborar dicha actividad en $R$. prolixus decidimos ensayar la respuesta de la aorta ante AT previa estimulación con serotonina. Los resultados mostraron que al igual que en $T$. infestans, AT $\left(10^{-9} \mathrm{M}\right)$ generó un aumento significativo de la frecuencia (Fig. 2A). El efecto no fue evidente a nivel del digestivo medio anterior (Fig. 2B). 


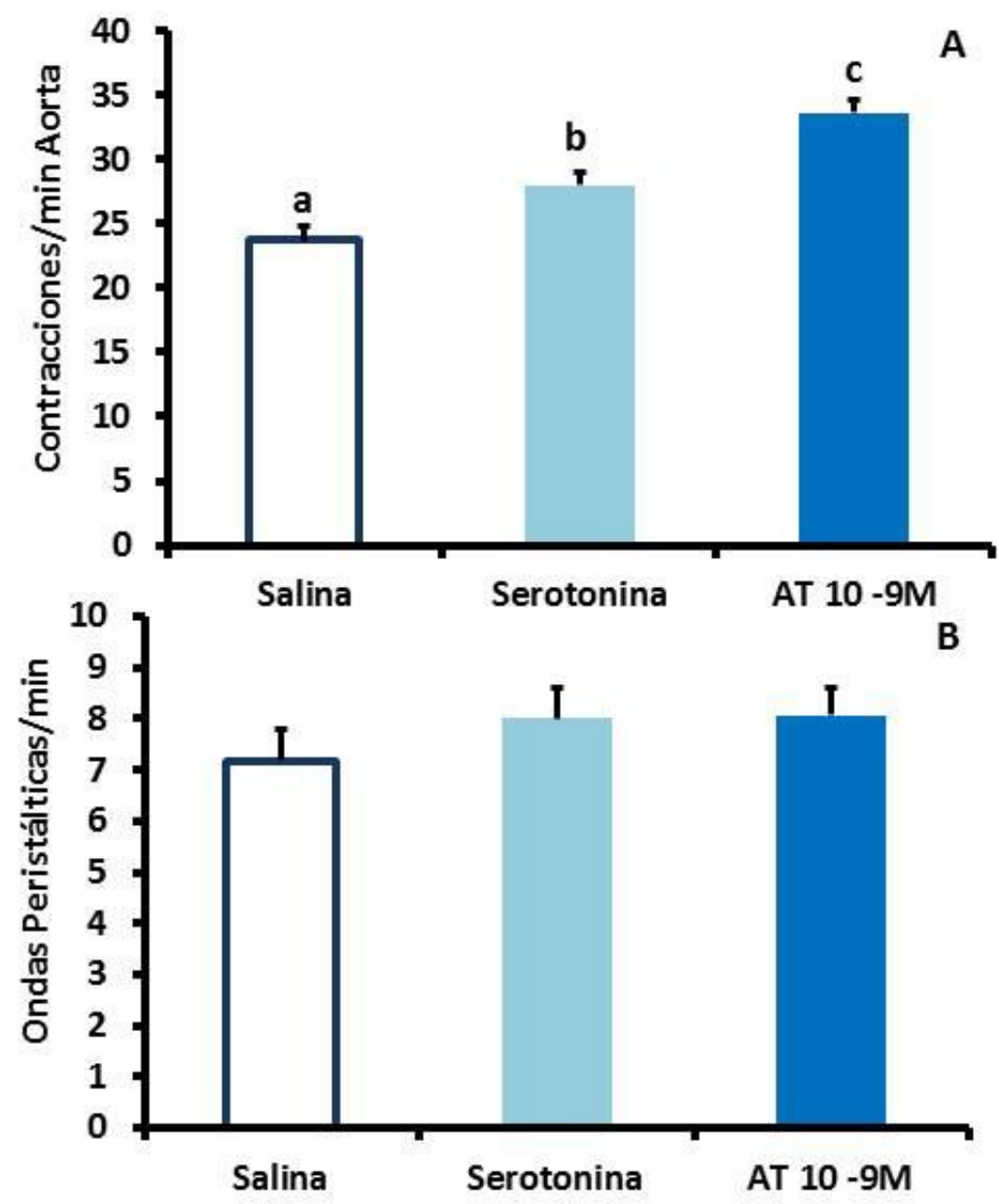

Figura 2: A: Actividad sinergística de AT en el incremento de la frecuencia de contracción de la aorta, inducida previamente por la serotonina $\left(10^{-9} \mathrm{M}\right)$. Las letras minúsculas marcan las diferencias significativas entre los tratamientos. B: La tasa de las ondas peristálticas del buche no fue modificada por la aplicación de serotonina o AT.

\subsubsection{Efecto de la administración a través de la ingesta de un antisuero anti-AT sobre} la frecuencia de contracciones de la aorta y la tasa de ondas peristálticas del buche durante la diuresis post-prandial.

Santini \& Ronderos (2007) demostraron que la inyección en el hemocele de un antisuero anti-AT previo a la alimentación genera una disminución significativa de la eliminación de orina en larvas del IV estadio de T. infestans, debido a la inhibición de las contracciones peristálticas del recto que son estimuladas por este péptido. Más recientemente, demostramos también que la administración con la ingesta de dicho antisuero genera un efecto similar en larvas del IV estadio de $R$. prolixus sugiriendo que, durante la ingesta, las inmunoglobulinas son capaces de atravesar la pared del buche manteniendo su 
actividad en el hemocele y bloqueando la eliminación de orina (Villalobos-Sambucaro et al., 2015a). Con el objeto de comprobar el efecto cardioacelerador de AT en condiciones fisiológicas, decidimos ensayar el bloqueo del efecto del péptido durante el proceso fisiológicamente crítico de la diuresis post-prandial. A tal fin, dos grupos de machos que no habían recibido alimentación en el estado adulto fueron alimentados con PBS (controles) o con PBS conteniendo antisuero anti-AT (1/100). El tratamiento control utilizando el antisuero preadsorbido con el péptido de referencia no fue incluido, dado que la especificidad del mismo en R. prolixus ya había sido comprobada anteriormente (Villalobos Sambucaro et al., 2015a). Luego de la alimentación se registró la frecuencia de contracciones de la aorta y la tasa de contracciones peristálticas del buche a los 15, 30, 45, 60, 120 y 240 minutos, período durante el cual la diuresis es máxima.

Los resultados demuestran que la frecuencia de la aorta, disminuyó significativamente durante el período analizado (Fig. 3A). El análisis de la respuesta a lo largo del experimento, mostró que el efecto fue máximo durante los primeros 60 minutos, disminuyendo posteriormente hasta observarse valores semejantes a los del grupo control (Fig. 3B). 


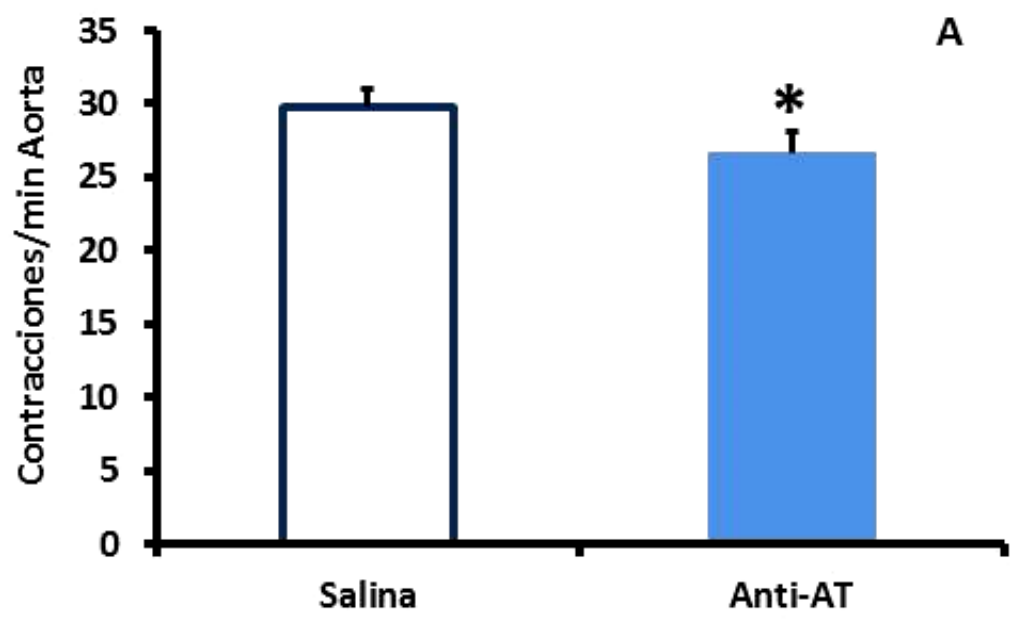

B

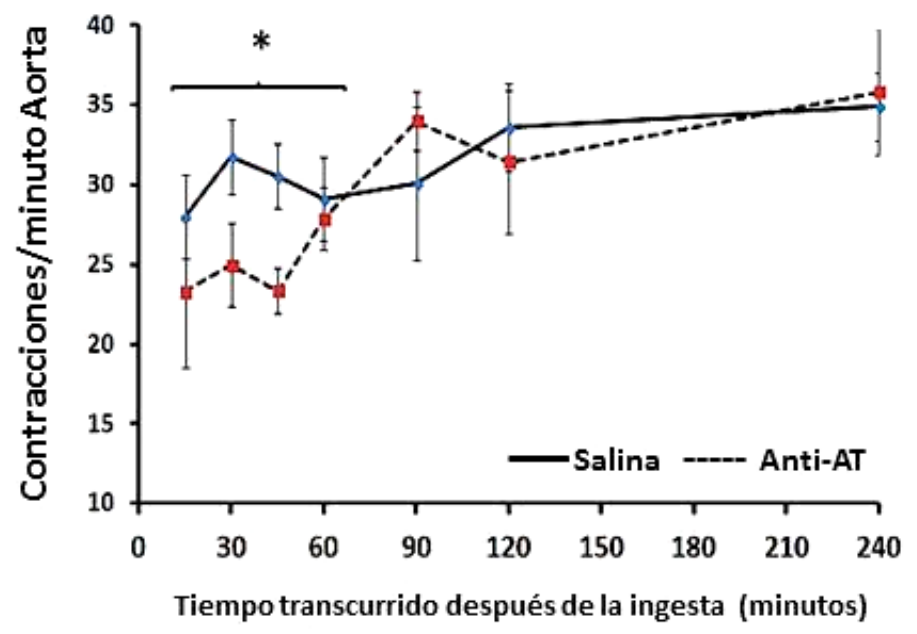

Figura 3: Disminución de la frecuencia de contracciones de la aorta después de la administración del antisuero anti- AT junto con el alimento. A: Comparación de la frecuencia de contracción de la aorta a lo largo de los primeros 90 minutos después de la ingesta en el alimentador artificial. B: Frecuencia de contracciones en cada momento registrado a lo largo de 240 minutos después de la ingesta de comida. Cada punto representa la media \pm error estándar. Los asteriscos representan diferencias estadísticamente significativas entre los tratamientos.

A diferencia de lo observado en insectos ayunados, la actividad del buche también disminuyó, sugiriendo que AT está involucrada en la modulación de la actividad peristáltica del buche durante la diuresis post-prandial (Fig. 4A). De modo similar a lo observado en la aorta, el efecto de la administración del antisuero no se mantuvo durante todo el período registrado, observándose diferencias significativas solo entre los 15 y 90 minutos luego de comenzado el registro (Fig. 4B). 

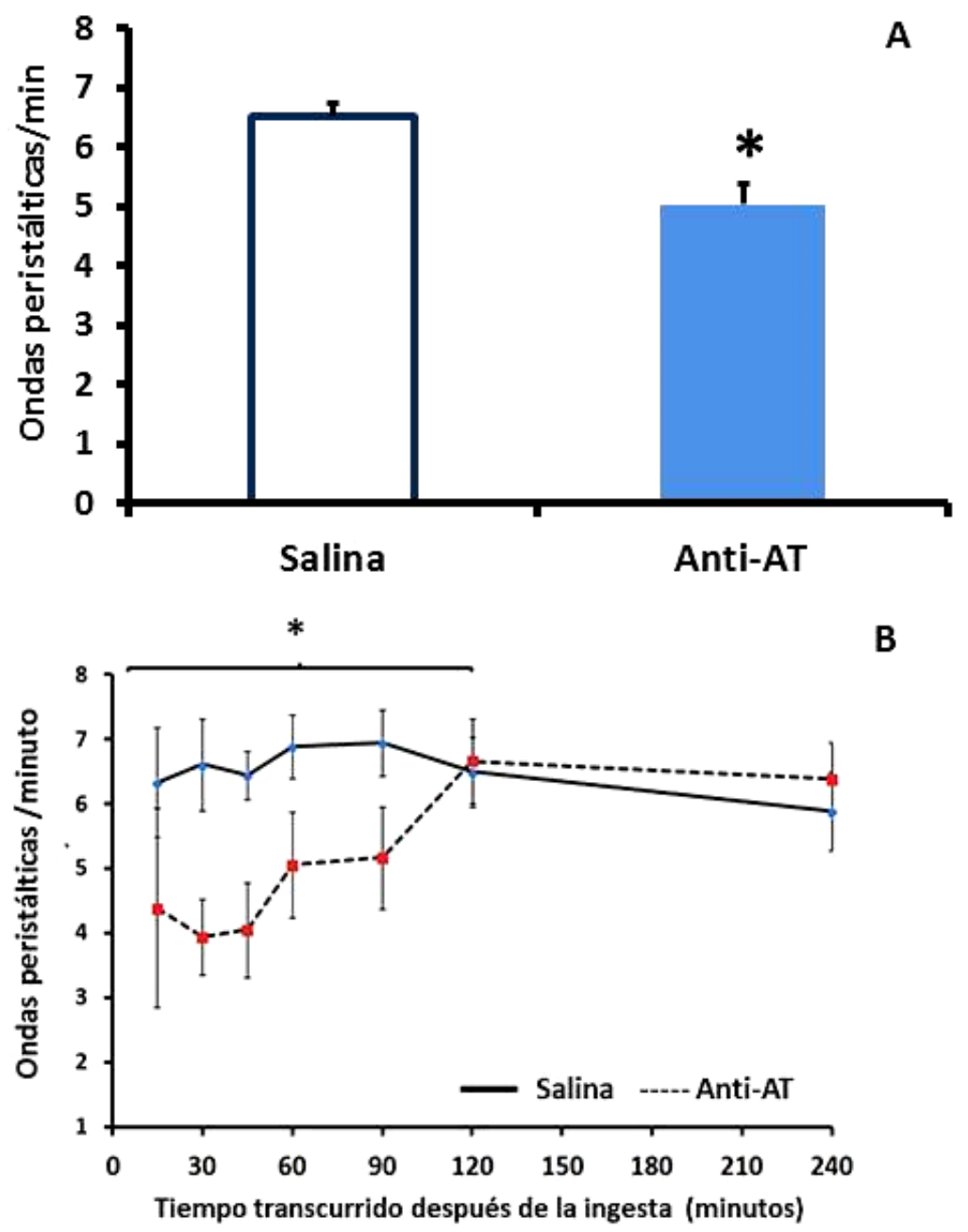

Figura 4: Disminución de la tasa de las ondas peristálticas del buche inducida por la administración del antisuero anti- AT junto con el alimento. A: Comparación de la frecuencia de las ondas peristálticas del buche a lo largo de los primeros 120 minutos luego de la ingesta. B: frecuencia de las ondas peristálticas registradas a lo largo de 240 minutos después de la ingesta. Cada punto representa la media \pm error estándar. Los asteriscos representan diferencias estadísticamente significativas entre los tratamientos.

\subsubsection{Estudio del efecto de Allatostatina-C sobre la actividad cardioaceleradora de serotonina/allatotropina en machos adultos sin alimentación previa.}

Ha sido demostrado que AST-C inhibe la síntesis de HJs en hembras adultas del mosquito Aedes aegypti (Li et al., 2004 y 2006; Nouzova et al., 2015). Se ha propuesto también que AST-C posee actividad mioinhibidora en el intestino anterior de Lacanobia oleracea (Lepidoptera: Noctuidae) (Duve et al., 2000; Matthews et al., 2007) y cardioinhibidora en $D$. melanogaster (Price et al., 2002). En función de estos hechos decidimos estudiar la probable 
existencia de un efecto similar sobre la actividad contráctil de la aorta y la frecuencia de ondas peristálticas del buche en $R$. prolixus.

Luego de la aplicación consecutiva de AT y serotonina, que genera un aumento máximo en la frecuencia de contracciones de la aorta, se administró AST-C $10^{-6} \mathrm{M}$. Los resultados mostraron que la frecuencia disminuyó significativamente después del tratamiento. (Fig. 5A, película suplementaria 1), no observándose cambios en la actividad a nivel del buche (Fig. 5B). Como se puede observar en la figura, la frecuencia de la aorta después del tratamiento con AST-C disminuyó a valores similares a los alcanzados luego del tratamiento con serotonina, manteniendo valores superiores a la frecuencia basal.
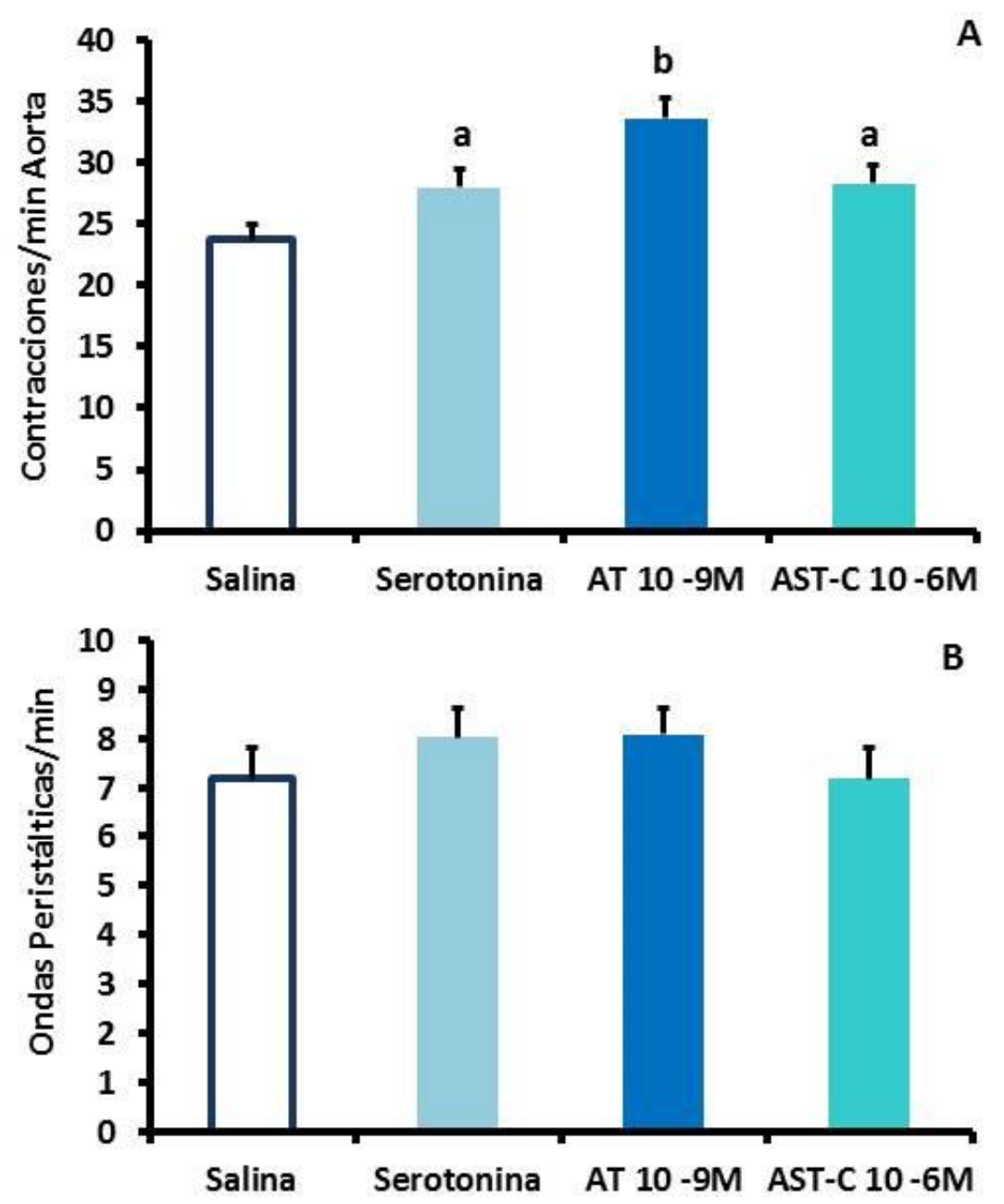

Figura 5: A: La aplicación de AST-C disminuyó la frecuencia de contracción de la aorta generada luego de la estimulación con serotonina $\left(10^{-9} \mathrm{M}\right)$ y AT. B: El número de ondas peristálticas del intestino medio anterior no se modificó durante el experimento. Las diferencias entre los tratamientos se señalan con letras minúsculas. 
Los resultados obtenidos sugieren que la frecuencia de contracción de la aorta en los individuos sometidos al tratamiento con AST-C disminuye a través de un mecanismo antagónico sobre el efecto sinérgico de AT en tejidos previamente expuestos a serotonina. Con el fin de analizar esta hipótesis, decidimos ensayar el efecto de AST-C sobre la frecuencia cardíaca de machos estimulados solo con serotonina. Los resultados mostraron que en los insectos tratados previamente con serotonina/AT, AST-C tuvo efecto sobre la actividad muscular de la aorta, disminuyendo significativamente la frecuencia de contracción durante los primeros 15 minutos del tratamiento (Fig. 6A), mientras que no se observaron diferencias significativas cuando el péptido fue aplicado luego del tratamiento de serotonina (Fig. 6B).
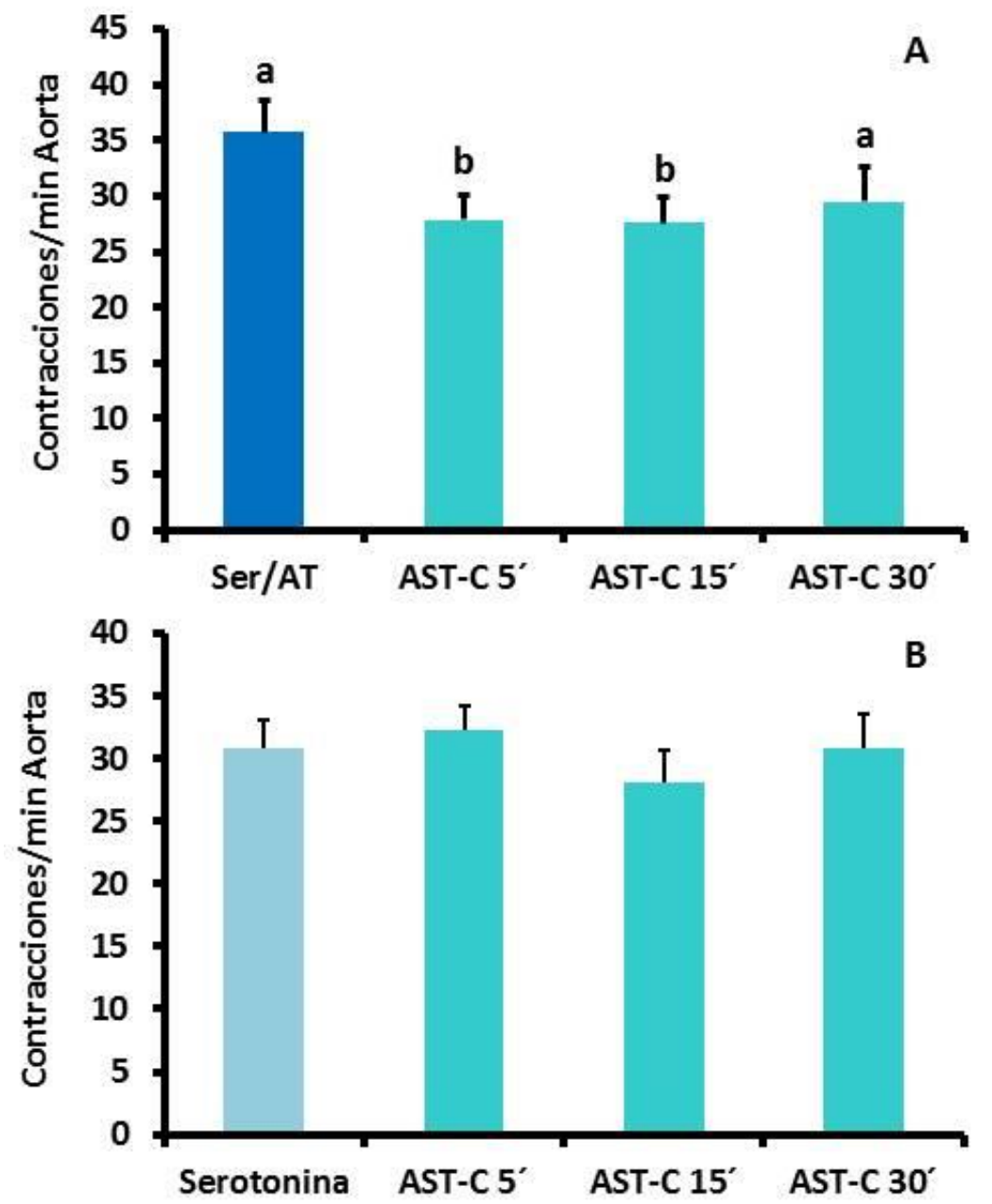

Figura 6: A: Efecto dependiente del tiempo de AST-C sobre la frecuencia de contracción de la aorta previamente estimulada con Serotonina /AT, donde AST-C presenta un efecto inhibidor significativo a los 5 y 15 minutos B: La dosis de AST-C aplicada luego del tratamiento de serotonina no tuvo efecto. Las diferencias entre los tratamientos se señalan con letras minúsculas. 


\subsubsection{Estudio del efecto mioinhibidor de Allatostatina-C sobre la frecuencia de} contracciones de la aorta y del digestivo medio anterior durante el periodo de diuresis post-prandial.

Una vez demostrado el efecto inhibidor de AST-C sobre la estimulación de la frecuencia cardiaca causada por serotonina/AT, decidimos ensayar el efecto de AST-C durante el desarrollo de un proceso fisiológico como lo es la diuresis post-prandial. A tal fin, analizamos la respuesta tanto del buche como de la aorta mediante dos diseños experimentales; en ambos casos los insectos recibieron alimento a repleción y fueron procesados de modo similar a los experimentos anteriores 45 minutos luego de la ingesta sanguínea. Un grupo de insectos fue tratado con la máxima dosis de AST-C $\left(10^{-6} \mathrm{M}\right)$, mientras que un segundo grupo fue tratado con dosis crecientes del péptido. Los resultados demostraron que el péptido mostró tener efecto inhibidor al ser suministrado en altas concentraciones inmediatamente después de haberse concretado la ingesta en ambos órganos (Fig. 7 A y B). La frecuencia de contracción de la aorta, así como la del buche disminuyó además en relación a la dosis aplicada (Fig. 7 C y D). En ambos órganos, la dosis mínima necesaria para generar una disminución significativa de la frecuencia fue de $10^{-10} \mathrm{M}$ alcanzando un efecto máximo en el vaso dorsal con $10^{-8} \mathrm{M}$. 

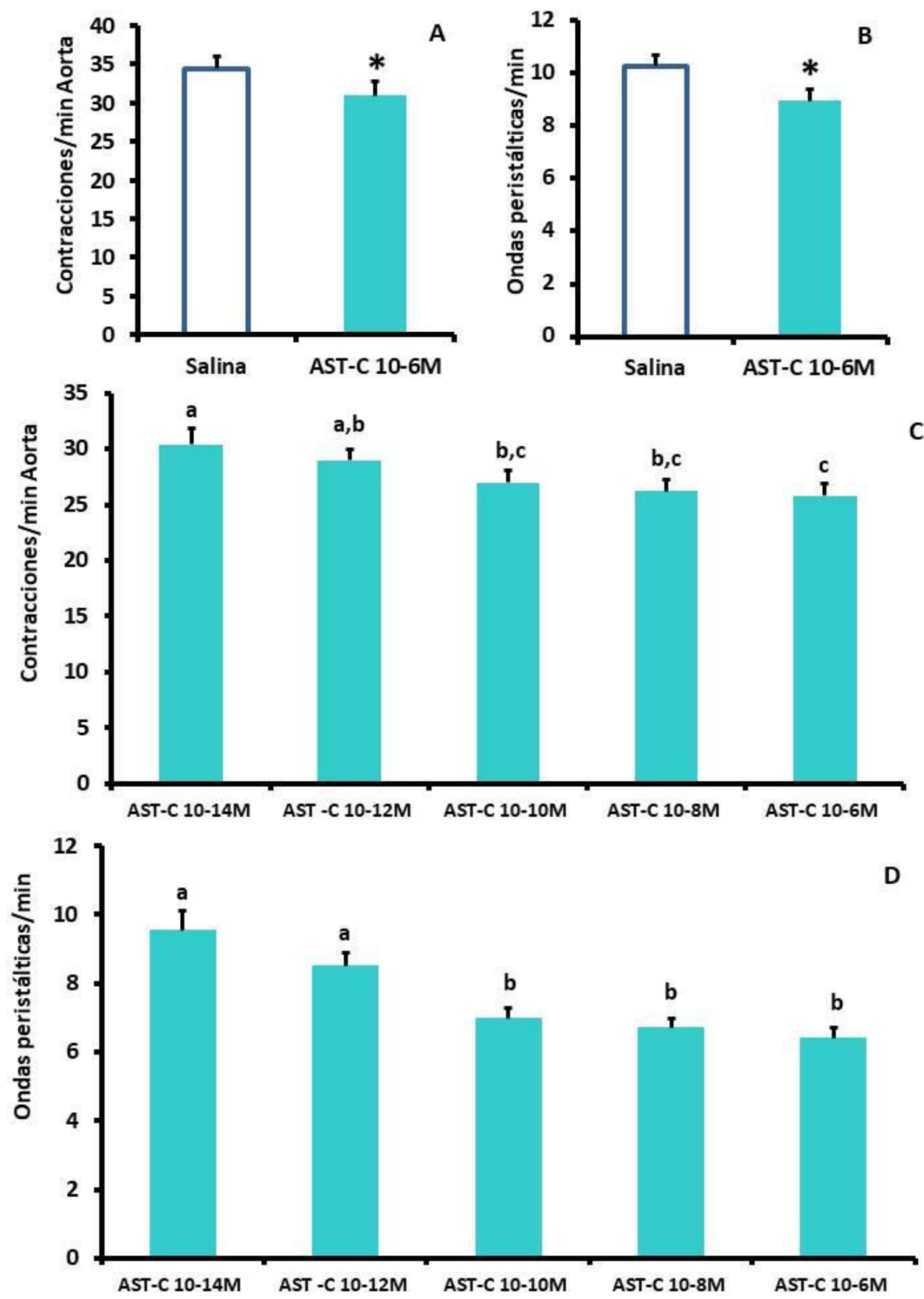

Figura 7: A y B: efecto de AST-C $10^{-6} \mathrm{M}$ luego de la ingesta sanguínea en la aorta y el buche. Los asteriscos señalan las diferencias significativas entre los tratamientos. C y D: efecto de dosis dependencia de AST-C sobre la frecuencia de contracciones de la aorta y el buche durante el proceso de diuresis post-prandial. Las diferencias entre los tratamientos se señalan con letras minúsculas.

Con el objeto de realizar una primera aproximación a la probable vía de acción de ASTC en R. prolixus, y dada la capacidad de AST-C de disminuir la estimulación de la frecuencia cardíaca generada por AT, decidimos analizar el efecto de la administración simultanea de AST- 
C y TG (un compuesto que inhibe la actividad de la ATPasa asociada a la re-captación de $\mathrm{Ca}^{+2}$ en el retículo endoplásmico liso) durante la diuresis post-ingesta. Los resultados mostraron que en presencia de TG, AST-C no produjo cambios significativos en la frecuencia de las contracciones de ninguno de los dos órganos en estudio, sugiriendo que la actividad del péptido está asociada a la disminución de $\mathrm{Ca}^{+2}$ citosólico mediada por la ATPasa del retículo endoplásmico liso (Fig. 8 A y B).
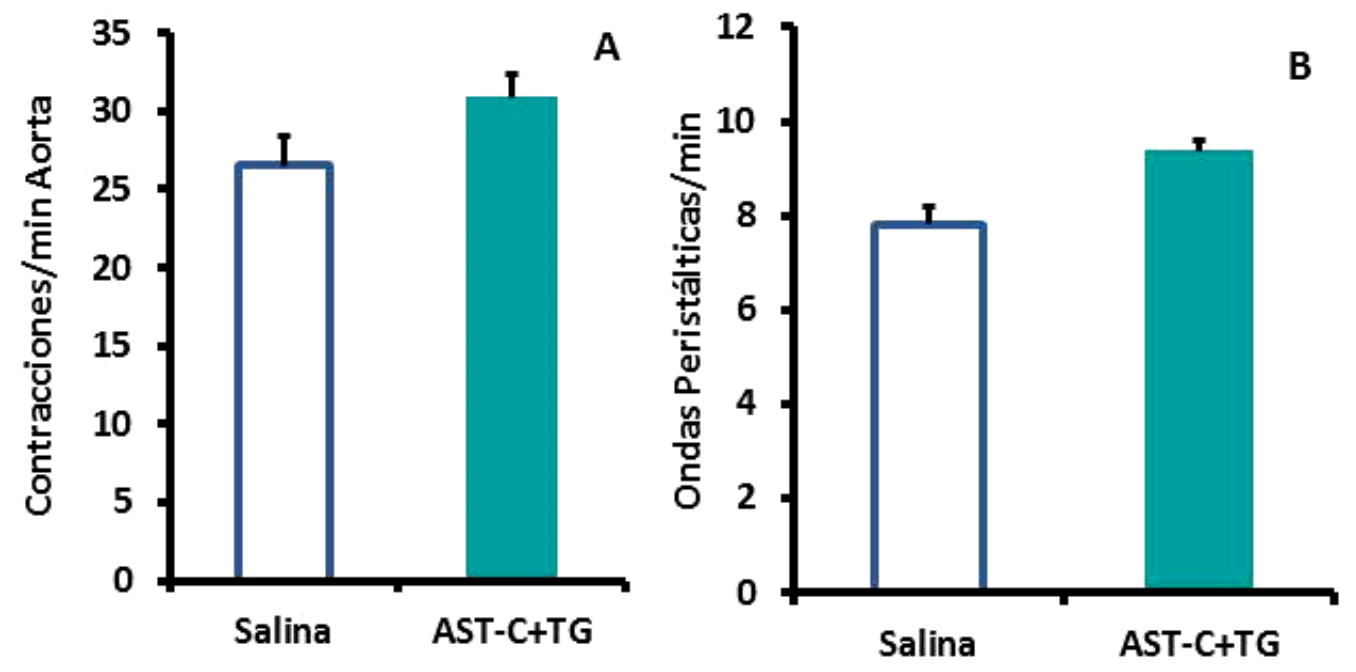

Figura 8: La frecuencia de contracción del vaso dorsal (A) y de las ondas peristálticas del buche (B) no fueron modificadas por la aplicación conjunta de AST-C $\left(10^{-6} \mathrm{M}\right)$ y TG $\left(10^{-6} \mathrm{M}\right)$ durante el momento fisiológico crítico de diuresis.

\section{2 ¿DÓNDE SE PRODUCE EL PÉPTIDO QUE MODULA LA ACTIVIDAD DE LA} AORTA Y EL BUCHE?: ANÁLISIS INMUNOHISTOQUÍMICO DE LA EXPRESIÓN DE ALLATOSTATINA-C MEDIANTE MICROSCOPÍA LASER DE BARRIDO CONFOCAL

Con el objeto de determinar la fuente de origen de AST-C, analizamos mediante inmunohistoquímica y LSCM la presencia del péptido en los órganos involucrados y en los ganglios ventrales. Las imágenes obtenidas mostraron la existencia de neuronas inmunoreactivas en los ganglios ventrales, y en células epiteliales del intestino medio anterior (Fig. 9 D-G). Respecto del buche, si bien no se encontró inervación, sí se observó la existencia de células inmuno-reactivas en el tejido epitelial, que podrían corresponder a células de tipo abierto (Fig. 9C). La marcación conjunta con faloidina, que pone en evidencia la presencia de Actina-F facilitando la observación del tejido muscular, mostró la colocalización del péptido 
con el tejido muscular, sugiriendo la existencia de un mecanismo de acción paracrina (Fig. 9C). Con respecto a la distribución de las neuronas AST-C positivas, se observó que las mismas se distribuyen simetrícamente a ambos lados de los ganglios subesofágico y protorácico (Fig. 9D), mostrando un claro patrón granular a nivel del citoplasma del soma neuronal (Fig. 9 E y F). El análisis de los nervios pertenecientes al GMT mostró la existencia de zonas de alta concentración del péptido que sugieren la existencia de sitios neurohemales desde donde podría ser secretado el péptido hacia la hemolinfa (Fig. 9G). Si bien no se observó la presencia de inervación a nivel del corazón y de la aorta, el análisis inmunohistoquímico a nivel del corazón demostró la presencia de una intensa inmunomarcación en la cavidad del mismo (Fig. 9A). La marcación conjunta con faloidina, mostró una marcada colocalización de la marcación correspondiente al péptido con el tejido muscular (Fig. 9A). Es importante remarcar la concentración de material inmuno-reactivo a nivel de los ostiolos sugiriendo el ingreso del péptido por vía hemolinfática (Fig. 9 A y B). La presencia de material inmuno-reactivo se manifestó además en los nefrocitos asociados a los músculos alares, lo que es un indicativo de la presencia del péptido en la hemolinfa (Fig. 9 A).

Figura 9: A: Corazón con inmunomarcación positiva para AST-C (verde) y faloidina (rojo). En la parte inferior izquierda de la imagen se observan un par de músculos alares junto con nefrocitos asociados (flecha blanca interrumpida). En el lateral derecho de la porción posterior del corazón se visualizan dos ostia, los cuales se observan en el detalle de la imagen B, (flechas blancas continuas). El límite de la cámara contráctil se delinea por paquetes de fibras musculares longitudinales (cabeza de flecha blanca). C: epitelio de la mucosa del buche donde se observa la colocalización (amarillo verdoso) de las células secretoras de AST-C de tipo abierto cargadas con el péptido (verde) y las fibras musculares (rojo). D: ganglios ventrales: GSE (derecha), GPT (izquierda) donde se observan cuerpos neuronales marcados específicamente para AST-C. Dichas neuronas se ven con detalle en las imágenes $\mathbf{E}$ y $\mathbf{F}$, observándose claramente la presencia de gránulos inmunomarcados. G: detalle de la salida de un nervio del GMT donde las flechas blancas señalan la existencia de marcación específica en el nervio. 


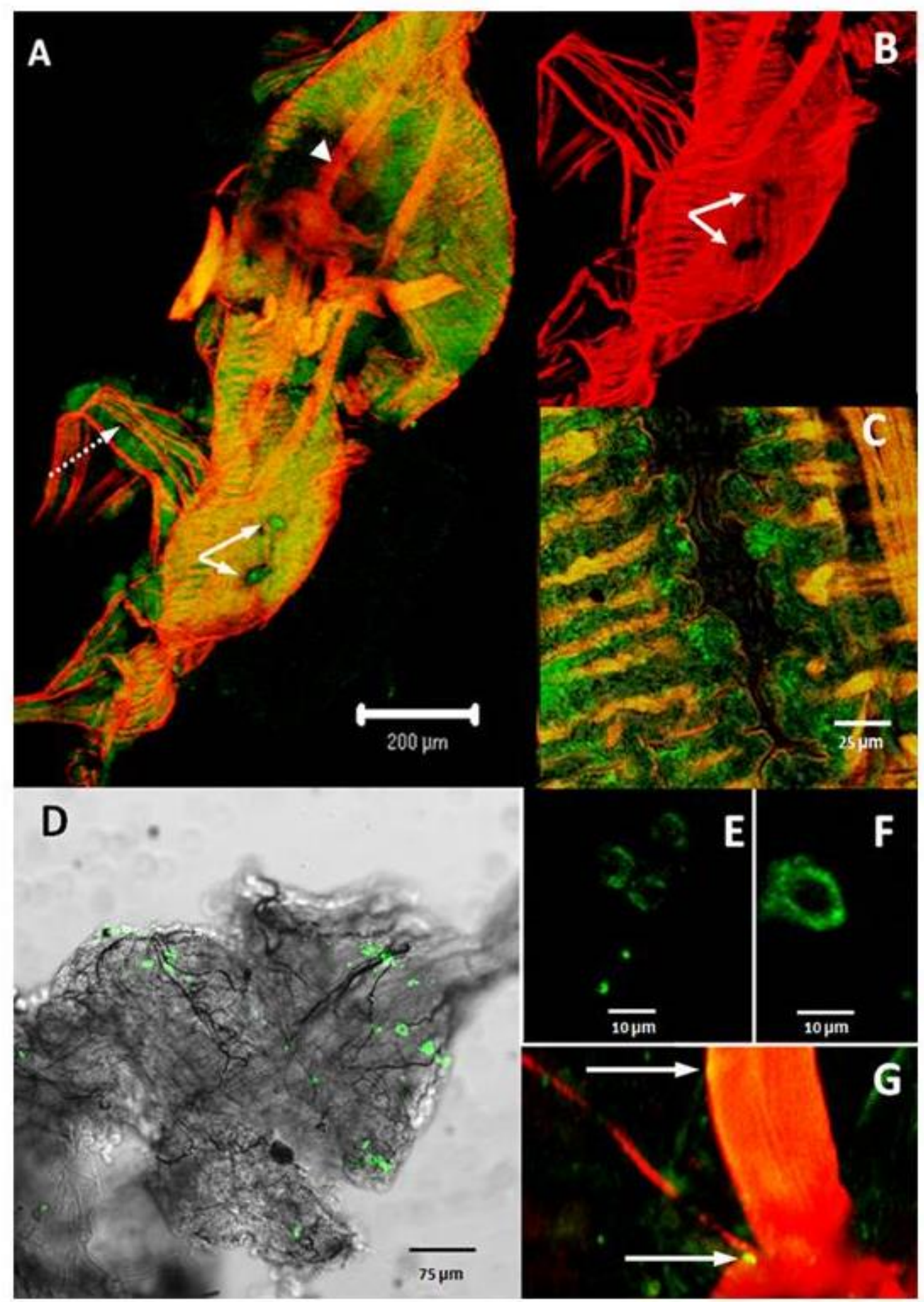




\subsection{PÉPTIDOS ALLATOREGULATORIOS COMO MIO-REGULADORES \\ EN EL SISTEMA REPRODUCTOR DE LA HEMBRA DE R. prolixus}

Como señalamos anteriormente, durante el ensayo de la actividad de AT sobre la frecuencia de contracciones de la aorta en hembras de $T$. infestans, se observó que en muchos individuos se produjo la deposición de huevos durante los momentos de máxima estimulación de la actividad muscular causada por el péptido (Sterkel et al., 2010). El sistema reproductor tiene un importante desarrollo de la musculatura en cada uno de los órganos que lo integran (Sedra \& Lange, 2014). El desarrollo del tejido muscular es relevante en cuanto al movimiento y desplazamiento de los ovocitos en desarrollo, así como en función del desplazamiento de espermatozoides hacia las espermatecas en momentos posteriores a la cópula, y desde las espermatecas hacia el útero para facilitar la fecundación de los ovocitos.

Con el objeto de estudiar la probable actividad de AT y AST-C como mio-reguladores de la musculatura asociada al sistema reproductor de la hembra, decidimos ensayar el efecto de AT sobre la frecuencia de contracciones de la musculatura del sistema reproductor en tres condiciones fisiológicas diferentes:

- Vírgenes ayunadas -HV-

- Copuladas no alimentadas -HC-

- Grávidas (copuladas) alimentadas -HG-

\subsubsection{Evaluación del efecto dosis dependiente de Allatotropina sobre el SRH.}

El análisis de los resultados, mostró que las HV no experimentaron cambios significativos en la frecuencia de contracciones en ninguno de los órganos analizados, con ninguna de las dosis ensayadas (Figs. 10-15). Con respecto a las HC y las HG, la respuesta fue diferente en cada uno de los órganos que conforman el sistema reproductor, dependiendo del estado reproductivo de los individuos. Los resultados se detallan a continuación.

Análisis de la frecuencia de contracción en los OVARIOS: la frecuencia basal de las HV fue menor a la registrada tanto en las HC como así también en las HG, mostrando éstas últimas la mayor frecuencia (Fig. 10A). Cuando se analizó el efecto del péptido con las diferentes dosis ensayadas, se observó además que las HV no mostraron cambios estadísticamente significativos con ninguna de las dosis aplicadas (Fig. 10B). Las HC mostraron un comportamiento dependiente de la dosis, alcanzando una frecuencia máxima con un rango de 
dosis que varió entre $10^{-12}$ y $10^{-8} \mathrm{M}$. Llamativamente, la dosis de $10^{-6} \mathrm{M}$, si bien causó un aumento significativo con respecto a los individuos en situación basal, el incremento fue menor a las dosis previas (Fig. 10B). La actividad de los ovarios de las HG mostró la mayor frecuencia de contracciones respecto a los otros estados fisiológicos estudiados, siendo la frecuencia observada en condición basal similar a la registrada con cualquiera de las dosis ensayadas (Fig. 10A), no mostrando AT efecto con ninguna de las dosis (Fig. 10B).
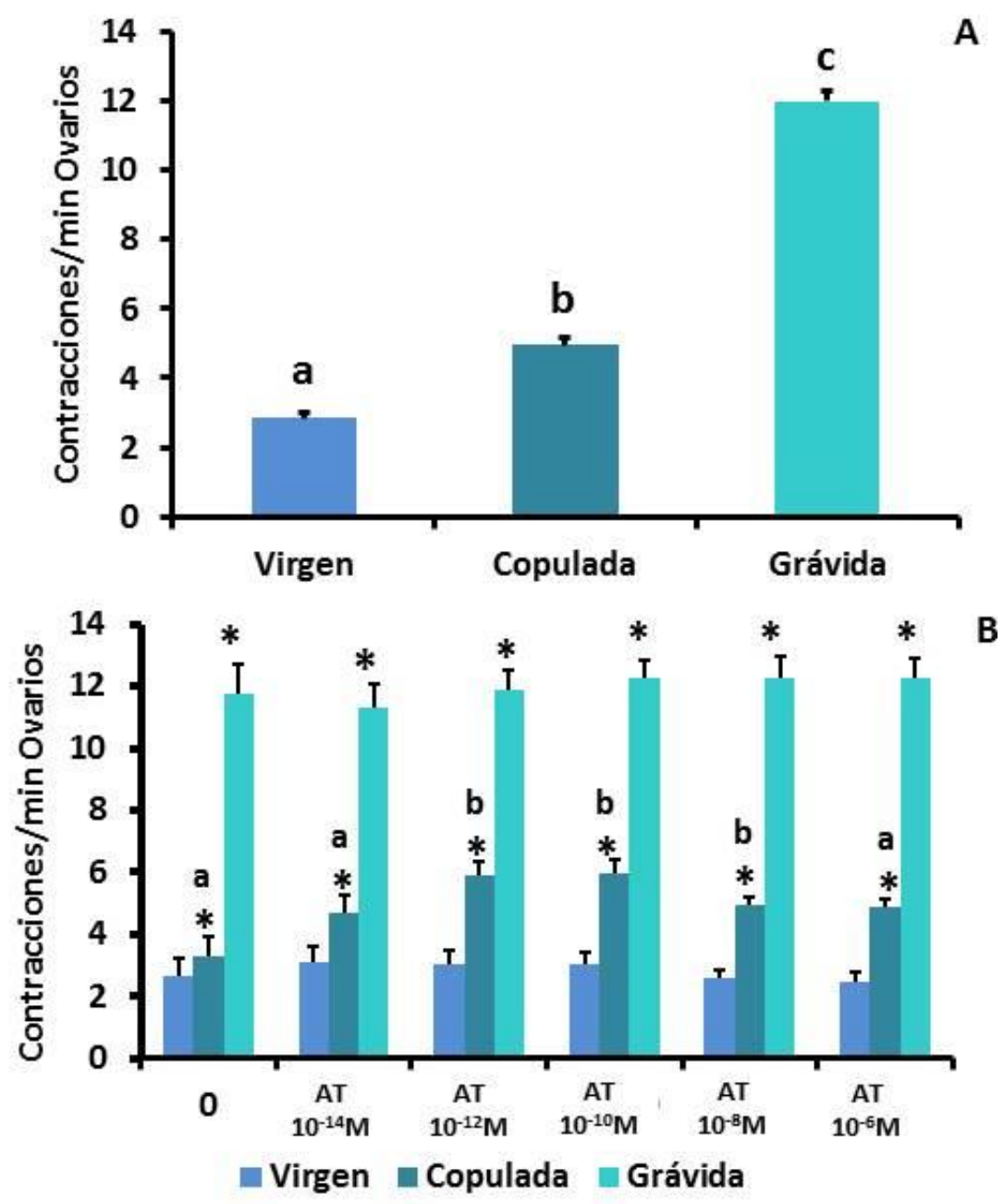

Figura 10: efecto dosis dependiente de Allatotropina en los OVARIOS. A: análisis comparativo de las frecuencias de contracción de los ovarios en los tres estados fisiológicos. Las diferencias significativas se señalan con letras minúsculas B: estudio de la dosis dependencia de AT en Ovarios en cada uno de los estados fisiológicos. Los asteriscos marcan las diferencias significativas que presentan los tratamientos realizados sobre HC y HG respecto a las HV. Las letras minúsculas marcan las diferencias significativas encontradas entre dosis.

Análisis de la frecuencia de contracción en los OVIDUCTOS: El análisis de los oviductos mostró actividad contráctil solo en las HC (Fig. 11A). El péptido presentó una actividad dosis 
dependiente mostrando un aumento de las contracciones a medida que aumentaba la concentración de AT, siendo significativo a partir de la dosis de $10^{-12} \mathrm{M}$, y alcanzando un máximo de $3,83 \pm 0,52$ contracciones/minuto con la dosis de $10^{-6} \mathrm{M}$ (Fig. 11B).

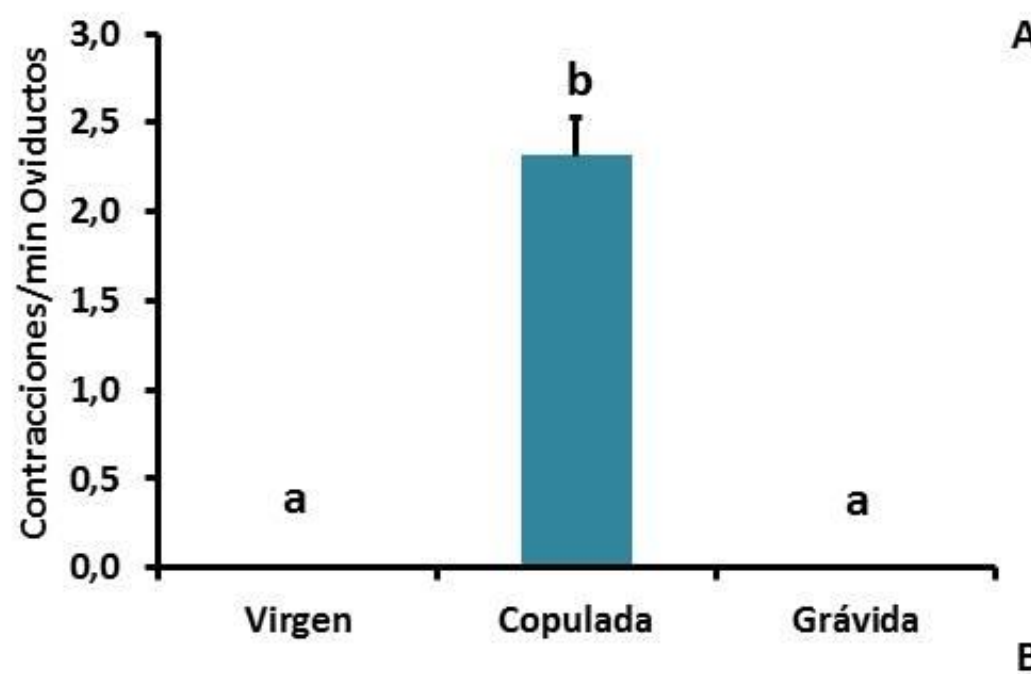

A

\section{B}

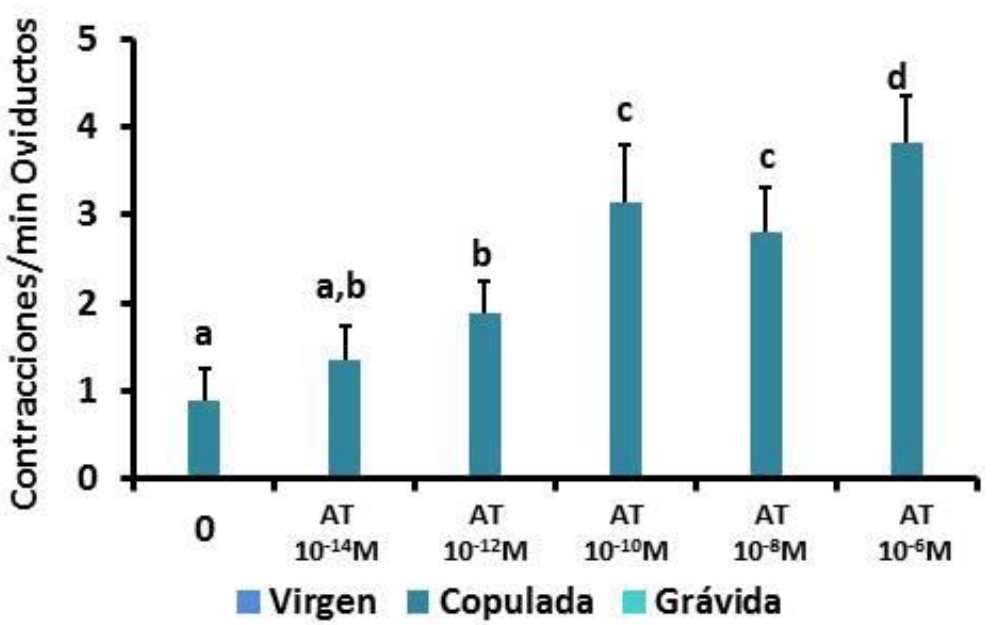

Figura 11: efecto dosis dependiente de Allatotropina en los OVIDUCTOS. A: Análisis comparativo de las frecuencias de contracción de los oviductos en los tres estados fisiológicos. Únicamente presentaron actividad los oviductos de las HC. Las diferencias significativas se señalan con letras minúsculas. B: Análisis de la dosis dependencia de AT en los oviductos de las HC. Las letras minúsculas marcan las diferencias significativas encontradas entre dosis.

Análisis de la frecuencia de contracción muscular en el ÚTERO: la actividad registrada en el útero, fue mayor tanto en las $\mathrm{HC}$ como en las $\mathrm{HG}$, respecto a la frecuencia promedio de las HV (Fig. 12A). La máxima actividad se observó en las HC, mostrando una frecuencia de contracción mayor respecto a las HV y HG (Fig. 12A). En cuanto a la respuesta en relación a la dosis, nuevamente se encontraron diferencias significativas en las $\mathrm{HC}$, a partir de la dosis de 
$10^{-12} \mathrm{M}$ alcanzando un máximo a una concentración de $10^{-6} \mathrm{M}$. La frecuencia máxima observada en las HG fue registrada en la dosis más alta ensayada. La actividad del útero no se vio modificada en las HV (Fig. 12B).

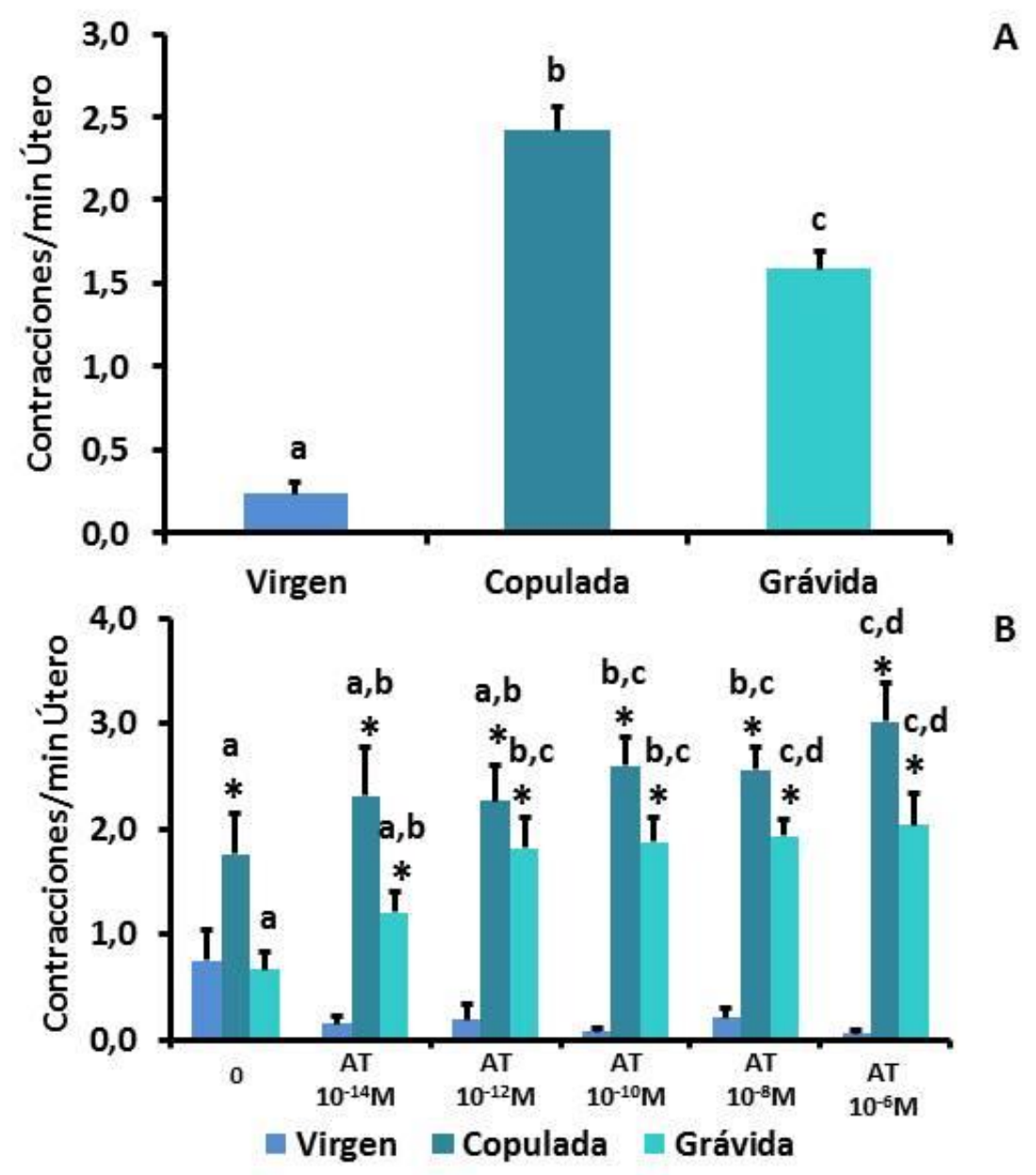

Figura 12: efecto dosis dependiente de Allatotropina en el ÚTERO. A: Análisis comparativo de las frecuencias de contracción del útero en los tres estados fisiológicos. Las diferencias significativas se señalan con letras minúsculas B: estudio de la dosis dependencia de AT en el útero en cada uno de los estados fisiológicos. Los asteriscos marcan las diferencias significativas que presentan los tratamientos realizados sobre HC y HG respecto a las HV. Las letras minúsculas marcan las diferencias significativas encontradas entre dosis para cada estado analizado.

\section{Análisis de la frecuencia de contracción en las ESPERMATECAS: Al igual que en los} órganos anteriormente descriptos, las HV no presentaron una actividad relevante a lo largo del experimento (Fig. $13 \mathrm{~A}$ y B). A diferencia de estas, tanto las HC como las HG mostraron actividad contráctil. Al igual que en el útero, la frecuencia de contracción fue mayor en las HC (Fig. 13A). En ambos estados se registró un efecto dosis dependiente en la respuesta al 
péptido. Mientras que las HG respondieron significativamente solo con las mayores concentraciones ensayadas $\left(10^{-8}\right.$ y $\left.10^{-6} \mathrm{M}\right)$, alcanzando una frecuencia máxima de $1,98 \pm 0,62$ contracciones/minuto, en las $\mathrm{HC}$ se observó un aumento significativo con la dosis de $10^{-12} \mathrm{M}$, llegando a un valor máximo de 4,87 $\pm 0,49$ durante el tratamiento con la dosis de $10^{-6} \mathrm{M}$ (Fig. 13B).
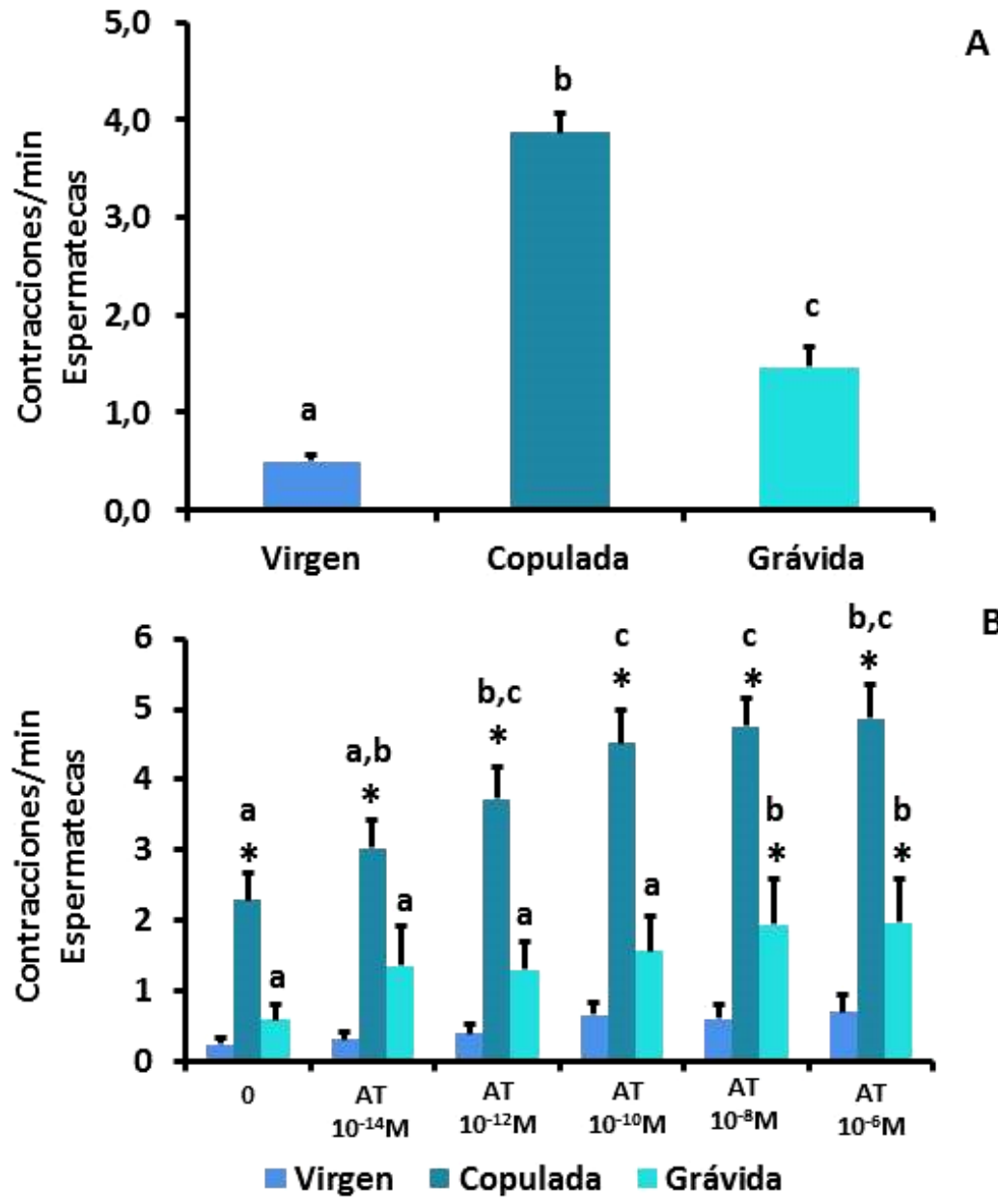

Figura 13: efecto dosis dependiente de Allatotropina en las ESPERMATECAS. A: Análisis comparativo de las frecuencias de contracción de las espermatecas en los tres estados fisiológicos. Las diferencias significativas se señalan con letras minúsculas B: estudio de la dosis dependencia de AT en las espermatecas en cada uno de los estados fisiológicos. Los asteriscos marcan las diferencias significativas que presentan los tratamientos realizados sobre HC respecto a las HV y HG. Las letras minúsculas marcan las diferencias significativas encontradas entre las distintas dosis para cada estado fisiológico analizado.

Análisis de la frecuencia de contracción en la BURSA: Con respecto a la bursa, sólo se observó un patrón de contracciones peristálticas en las HG (Fig. 14A). Si bien las frecuencias 
observadas fueron bajas, la actividad registrada mostró ser dosis-dependiente alcanzando una frecuencia máxima con $10^{-6} \mathrm{M}$ (Fig. 14B).
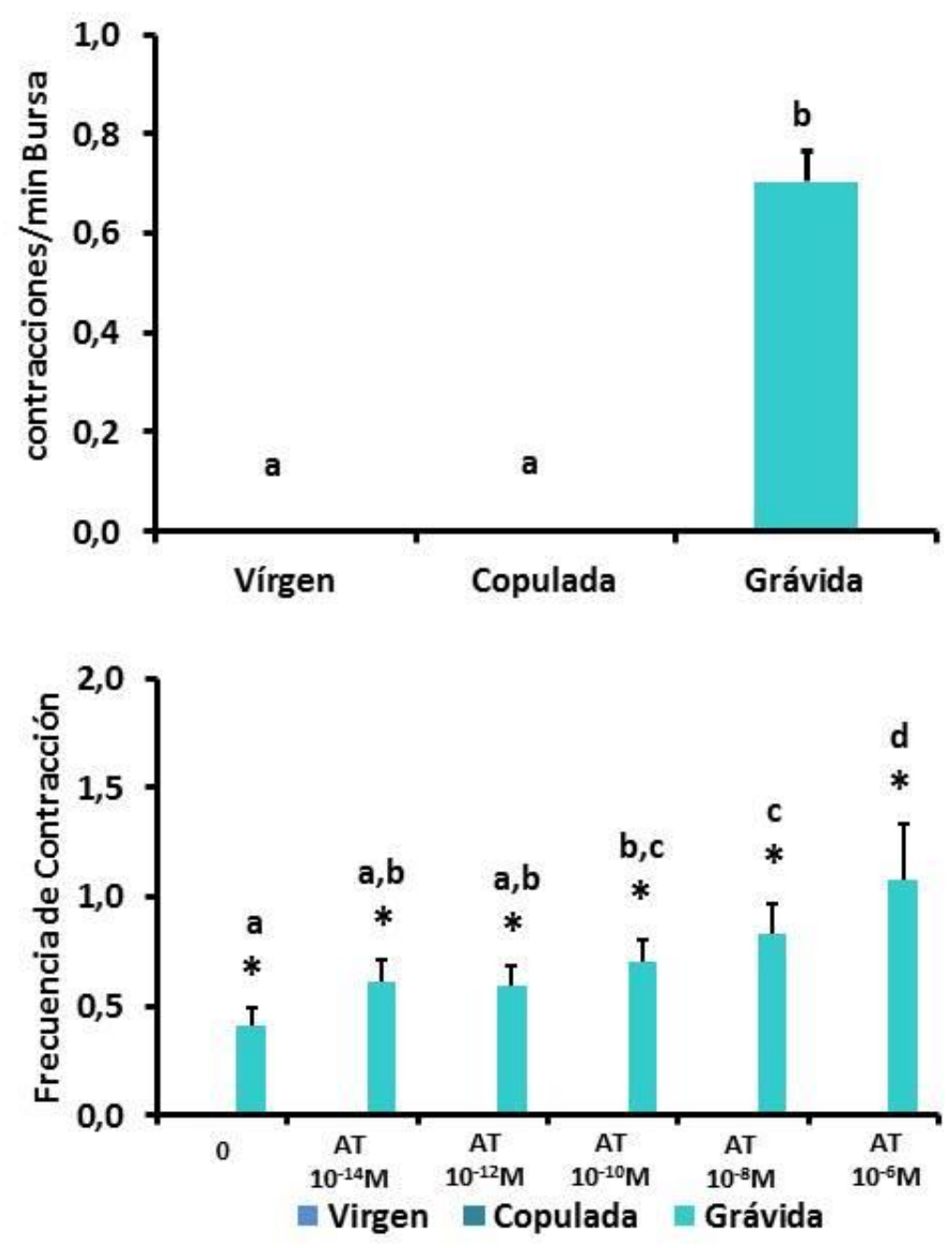

B

Figura 14: Efecto dosis dependiente de Allatotropina en la BURSA. A: Análisis comparativo de las frecuencias de contracción de la bursa en los tres estados fisiológicos. Las diferencias significativas se señalan con letras minúsculas. B: estudio de la dosis dependencia de AT en la bursa de las HG. Las letras minúsculas marcan las diferencias significativas encontradas entre las distintas dosis ensayadas.

\subsubsection{Evaluación del efecto de Allatostatina-C sobre el SRH.}

En función de los resultados obtenidos en el vaso dorsal y el tubo digestivo medio, decidimos analizar la existencia de un efecto similar de AST-C sobre la actividad muscular en el sistema reproductor de la hembra. Como primera aproximación a este análisis y con el objeto de ensayar la probable actividad mioinhibidora del péptido en una situación fisiológica, decidimos ensayar el efecto de AST-C sobre la frecuencia de contracción de la musculatura de 
los ovarios en hembras grávidas los que, como señalamos anteriormente, mostraron una actividad máxima en estado basal. Los datos obtenidos mostraron una disminución significativa de la frecuencia de contracción en un rango de dosis de $10^{-8}$ a $10^{-6} \mathrm{M}$ (Fig. 15A). Cuando se analizaron los resultados discriminando a lo largo del tiempo transcurrido luego de la aplicación de cada dosis, se observaron diferencias significativas respecto del tiempo de respuesta. De hecho, mientras que con la dosis de $10^{-10} \mathrm{M}$ el péptido comenzó a evidenciar su efecto a los 30 minutos del tratamiento, con las dosis más altas $\left(10^{-8} \mathrm{M}\right.$ y $\left.10^{-6} \mathrm{M}\right)$ la disminución de la actividad contráctil se hizo evidente a los 5 y 15 minutos (Fig. 15B).
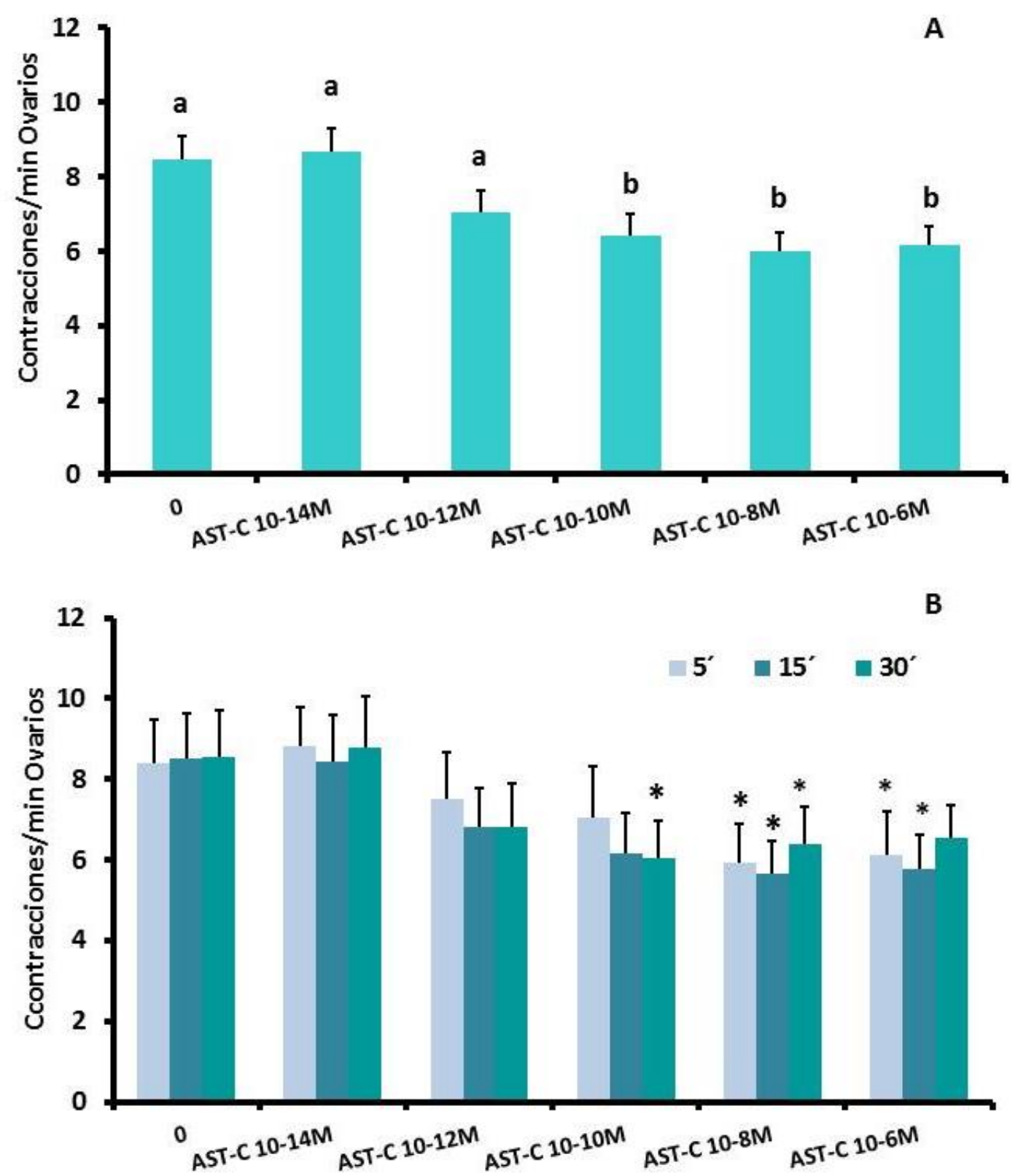

Figura 15: Análisis de la acción dosis dependiente de AST-C en los OVARIOS de HG. A: Cada barra representa al promedio de contracciones en cada dosis de AST-C. Las diferencias 
significativas que se encontraron entre las mismas se identifican con letras minúsculas. B: Análisis de cada dosis a través del tiempo. Los asteriscos marcan las diferencias significativas respecto al número de contracciones registradas en cada tiempo registrado.

\subsection{CARACTERIZACIÓN GENÓMICA Y EXPRESIÓN DE LOS}

\section{RECEPTORES DE MEMBRANA DE ALLATOTROPINA (RpATr) Y}

\section{ALLATOSTATINA C (RpAST-Cr)}

\subsubsection{Caracterización genómica y expresión de ATr}

Mediante el uso de los primers previamente descriptos se obtuvo una muestra correspondiente a 919 pares de bases. Una vez purificada y secuenciada, la secuencia de nucleótidos obtenida fue alineada con la secuencia correspondiente al receptor de $M$. sexta, revelando un alto grado de conservación entre las mismas (60\% de identidad y $74 \%$ de similitud). El análisis de la estructura genómica demostró que el gen está compuesto por cinco exones y cuatro intrones (Fig. 16B). La secuencia predice una proteína constituida por 334 aminoácidos que incluyen la porción correspondiente al amino y carboxilo terminal y los siete dominios de transmembrana característicos de los GPCRs. La figura 16 A muestra la secuencia genómica, la secuencia de la proteína predicha y la secuencia de la fracción del mRNA secuenciado. Ambas secuencias fueron anotadas en el Genbank e identificadas con los siguientes códigos: AHE41431.1 (secuencia peptídica), KF740716.1 (secuencia nucleotídica). La secuencia proteica presentó los siete dominios transmembrana característicos de los GPCR y el motivo DRWYAl en el sector citoplasmático del 3TM. Éste motivo de aminoácidos puede ser considerado como una característica distintiva de los receptores de la familia AT/Ox (Ronderos et al., 2016). 
$>$ Rp ATr protein sequence

MSDEDYLNMMTEHIFPTVYEWILGMHAVVFAVGLTGNFLVCLVVHRNPAMRTVTNYFIVNLAVADFL VILICLPPTLIWDTTETWFLGHVLCKLVLYFQTVSVAVSVLTLTFISLDRWYAICFPLKFKSTTSRAKTAILI IWIIALLYDIPELITLRTASRKKFHVETVLFTOCIASWDDVAERHYTTSKIVFLYLLPLTITSAAYFOIVRVL WKSDNIPGHRYQREVCYSGSSVDSRRYMAVSRGPTSGGTQAQIRSRRKAAKMLVCVVLMFALCYF PVHLLLSILRYTVDIPQNDITVALAMLSHWLCYANSATNPLIYNFMSGKSSITYPstop

$>$ Rp_ATr genomic sequence

ATGTCCGATGAAGACTATCTGAACATGATGACCGAGCATATATTCCCTACGGTATACGAATGGATAT TAATCGGCATGCACGCTGTAGTGTITGCGGTCGGATT GACTGGCAACTITCTAGTCTGTCTTGITG TTCATCGCAATCCGGCCATGAGAACCGTCACCAACTATITCATCGTGAATCTGGCTGTAGCGGATT TCTTAGTCATITTGATATGTCTACCGCCAACATTGATATGGGATACCACAGAAACATGGITTCTIGG ACATGTCCTCTGCAAATTAGTGCTCTAC $<$ pb > TITCAGACAGTGTCCGTAGCGGTCAGCGTGC TGACTCTTACATTCATATCATTAGATCGITGGTAT̈GCCATTTGCTTTCCATTAAAGTTCAAATCTACC ACATCTCGAGCTAAAACTGCCATACTAATCATCTGGATAATCGCATTGTTGTAC $<307$ pb > GAT ATTCCGGAGTTGATAACACTTCGTACAGCCAGTCGTAAGAAGTTCACGTGGAAACG GTACT GTT CACACAATGTATCGCCTCCTGGGACGATGTTGCCGAACGTCATTACACCACATCTAAAATTGTATT TITGTATTTACT GCCACTCACCATTACTTCTGCTGCTTACTITCAAATTGTCAGAGTCCTITGGAAG TCGGACAACATACCTGGCCATCGCTATCAGCGAGAAGTITGCTACATTTCAGGG $<1545 \mathrm{pb}>$ A GCAGTGTAGATTCTAGAAGATACATGGCTGTATCCAGAGGACCTACATCCGGTGG $\bar{C}$ ACACAGG̈CT CAAATAAGATCTCGCAGGAAAGCTGCCAAAATGTTGGTGTGTGTGGTATTAATGTTCGCACTCTG TIATITCCTGTACATCTGCTCAGTATTCTAAGA<_178_pb_>TATACTGTTGATATACCTCAAAAC GACATCACTGTAGCCCTGGCAATGCTTICACATTGGTTGTITATGCTAATTCGGCCACTAATCCT CTTATCTACAATTTTATGTCAGGTAAAAGTTCTATAACGTATCCATGA

\begin{abstract}
$>$ Rp ATr mRNA cloned
GATG̈ACCGAGCATNTATTCCNTACNGTATACGAATGGATATTAATCGGCATGCACGCTGTAGTGTI TGCGGTCGGATTGACTGGCAACTTICTAGTCTGTCTTGTTGTTCATCGCAATCCGGCCATGAGAA CCGTCACTAACTATTTCATCGTGAATCTGGCTGTAGCGGATTICTTAGTCATITTGATATGTCTACC GCCAACATTGATATGGGATACCACAGAAACATGGIICTTGGACATGTCCTCTGCAAATTAGTGCT CTACTTACAGACAGTGTCCGTAGCGGTCAGCGTGCTGACTCTTACATTCATATCATTAGATCGTTG GTATGCCATTTGCTTTCCATTAAAGTTCAAATCTACCACATCTCGAGCTAAAACTGCCATACTAATC ATCTGGATAATCGCATTGTTGTAC GATATTCCGGAGTTGATAACACTICGTACAGCCAGICGTAAG AAGTTCACGTGGAAACGGTACT GTTCACACAATGTATCGCCTCCTGGGACGATGITGCCGAACG TCATTACACCACATCTAAAATTGTATITITGTATTTACTGCCACTCACCATTACTTCTGCTGCTTACT TTCAAATTGTCAGAGTCCTITGGAAGTCGGACAACATACCTGGCCATCGCTATCAGCGAGAAGTT TGCTACATTTCAGGGAGCAGTGTAGATTCTAGAAGATACATGGCTGTATCCAGAGGACCTACATCC GGTGGCACACAGGCTCAAATAAGATCTCGCAGGAAAGCTGCCAAAATGITGGTGTGTGTGGTAT TAATGTICGCACTCTGTTATIITCCTGTACATCTGCTCAGTATTCTAAGATATACTGTTGATATACCTC AAAACGACATCACTGTAGCCCTGGCAATGCTTICACATTGGTTGTGTTATGCTAATTCGNCNC
\end{abstract}

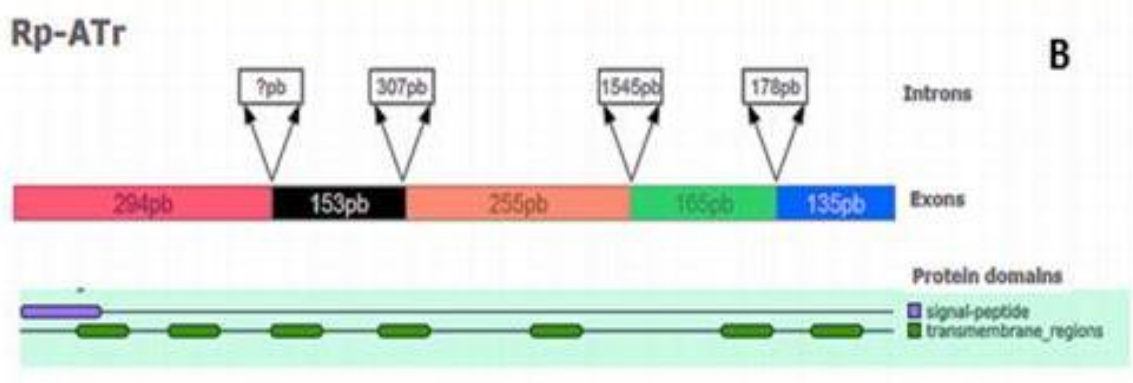

Figura 16: A secuencia proteica predicha de Rp-ATr a partir de la secuencia de mRNA clonada y de la secuencia genómica predicha por el genoma de $R$. prolixus. Las letras resaltadas corresponden a diferencias entre las secuencias predichas y la que se obtuvo por secuenciación. Cada color corresponde a un exón y los números entre signos <-> corresponde al número de pares de bases nucleotídicas que se encontrarían en los intrones. Los colores se respetan en el esquema señalado en $\mathbf{B}$. Además se muestra la predicción de la ubicación de la secuencia señal y de los dominios transmembrana. 
El análisis de las distintas muestras de cDNA mostró que el RpATr se expresa en el IV estadio larval, y en todos los órganos de insectos adultos analizados, incluyendo el intestino medio, el vaso dorsal y el sistema reproductor de la hembra (Fig. 17).

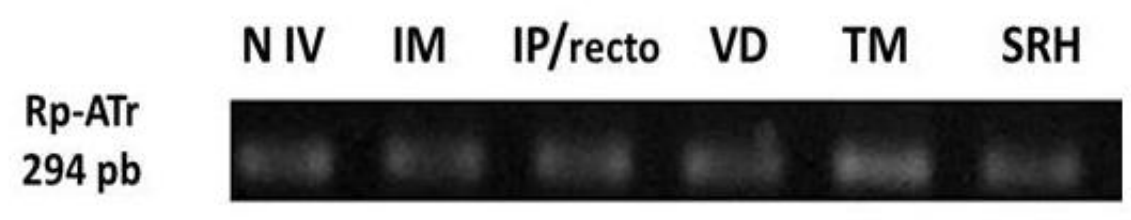

Figura 17: expresión del gen de Rp-ATr en los cDNA estudiados. N IV: cDNA de pool de insectos de IV estadio larval; IM: intestino medio; IP/recto: intestino posterior y recto; VD: Vaso dorsal; TM: tubos de Malpighi; SRH: Sistema reproductor de la hembra.

\subsubsection{Caracterización genómica y expresión de AST-Cr}

Mediante el uso de los primers previamente descriptos se obtuvo una muestra correspondiente a 517 pares de bases correspondiente a una secuencia parcial de receptor. Ésta y la secuencia de aminoácidos traducida fueron anotadas en el Genbank, identificadas con los siguientes códigos: AHE41430.1 (secuencia proteica), KF501574.1 (secuencia nucleotídica). La secuencia predicha para RpAST-Cr por el genoma se conforma de 1260 pares de bases, que codifican para una proteína de 419 aminoácidos. El análisis genómico reveló la ausencia de intrones. La proteína predicha presenta los siete dominios transmembrana característicos de la familia de GPCR (Fig. 18A). Se identificó además, la secuencia DRY en el segundo dominio intracelular asociado al 3TM (Fig. 19). Basado en las búsquedas de secuencias homólogas se encontró que la secuencia proteica de RpAST-Cr conserva las características típicas de los receptores tipo somatostatina, incluyendo varios sitios de glicosilación unidos a nitrógeno en el dominio $\mathrm{N}$-terminal y varios sitios probables de palmitolización, además de estar presente el patrón YSNSAMNPILYA en el 7TM considerado característico de este tipo de receptores (Fig. 19). 
$>$ Rp_AST-C protein sequence

MSKD̈TTVSWLADSLENGSIESLYNSSYGNETQFCGSTDQPTLHIFTQVLYAFVCIVGLLGNTLVIYVVL RFSKMQTVTNLYIVNLAVADECFLIGIPFLIATMSLQLWPFGNVMCKLYMASTSINQFTSSIFLTIMSAD RYVAVCHPITAPKMRTPFISKIVSLSAWTASAIFMIPIFMYANIMDDDQVKSCNILWPEGENLSGQTAFT LYSFVLGFAVPVVLIFCFYFMVIRKLQTVGPKNKSKEKKKSHRKVTKLVLTVITVYVLCWLPYWITQMA LIFTPPKQCQSKFTVTVFLFAGFFSYSNSAMNPILYAFLSDNFKKSFVKACTCAAGKEVNATLHLENSV FPRRTQRGGSERARAGKNRADHTDEGAETGPLVSRGEHSTTALTSRSNITVTSDTITPVKNGVKINL. TPTELstop

$>$ RP_AST-C genomic sequence ATGTCTAAGGATACCACAGTCAGCTGGTTGGCCGATTCTITAGAAAACGGTTCAATTGAATCTCTC TACAACTCATCATATGGTAACGAGACTCAGTTCTGTGGCAGTACAGATCAACCAACATTACACATAT TTACTCAAGTACTGTATGCGTTIGTTTGTATTGTCGGCCTGTTGGGCAATACATTAGTAATATATGTT GTACTGAGATTITCCAAAATGCAAACTGITACAAATITGTATATTGTAAATTTAGCTGTAGCCGATG AATGTTTCCTAATAGGTATACCATIITITAATAGCAACGATGAGCCTTCAATTATGGCCATTTGGTAAT GTAATGTGTAAATTGTACATGGCTTCAACAAGTATAAATCAATTTACTAGTAGTATATTITTAACCAT AATGAGTGCAGATCGTTATGTGGCTGTATGTCACCCGATAACGGCGCCCAAAATGAGGACACCTT TCATCTCGAAAATTGTATCGTTGAGCGCTTGGACGGCAAGTGCCATATTTATGATACCAATATTCAT GTATGCAAATATAATGGATGATGACCAGGTGAAAAGTTGTAATATACTITGGCCGGAAGGCGAAA ATCTAAGCGGCCAGACAGCGTITACATTGTACTCATTTGTATTGGGATTTGCTGTACCTGTGGTGT TAATATITTGTIITITTTCATGGTTATAAGAAAGTTACAAACAGTAGGACCAAAGAATAAATCAAA AGAGAAAAAGAAATCACATAGAAAAGTTACTAAATTAGTATTGACTGTAATAACAGTATACGIITG TGTTGGTTACCATATTGGATCACACAGATGGCGTTGATTITCACTCCGCCAAAACAGTGCCAATCA AAGTTCACTGTTACCGTATTCCTGTTTGCCGGATTCTTTAGCTATTCAAATTCAGCAATGAATCCAA TACTTIATGCATIIITAAGTGATAATTITAAGAAAAGTTITGTAAAAGCGTGCACTTGTGCTGCTGG TAAAGAAGTGAATGCCACTITACACTTAGAGAATAGTGTATTTCCCAGACGTACCCAGAGAGGCG GCTCTGAACGTGCCAGAGCTGGTAAAAATAGAGCCGACCATACAGACGAAGGTGCTGAAACTG GACCGTTGGTGAGCAGAGGTGAACATTCCACAACGGCGCTCACATCTAGGTCTAATATCACCGTC ACTAGTGATACTACAACTCCAGTCAAAAATGGAGTGAAAATTAATCTAACTCCAACTGAATTGTAA

$>$ Rp_AST-C mRNA cloned

TNGCTTGACCTGTGGTGTTAATATITTIITTATTTCATGGTTATAAGAAAGTTACAAACAGTAGG ACCAAAGAATAAATCAAAAGAGAAAAAGAAATCACATAGAAAAGTTACTAAATTAGTATTGACTGT AATAACAGTATACGTITIGTTIGGTTACCATATTGGATCACACAGATGGCGTTGATITTCACTCCG CCAAAACAGTGCCAATCAAAGTTCACTGTTACCGTATTCCTGTITGCCGGATTCTITAGCTATTCA AATTCAGCAATGAATCCAATACTTTATGCATITITAAGTGATAATTITAAGAAAAGTITTGTAAAAG CGTGCACTTGTGCTGCTGGTAAAGAAGTGAATGCCACTITACACTTAGAGAATAGTGTATTTCCC AGGCGTACCCAGAGAGGCGGCTCTGAACGTGCCAGAGCTGGTAAAAATAGAGCCGACCATACA GACGAAGGTGCTGAAACTGGACCGTTGGTGAGCAGAGGTGAACATTCCACA

\section{Rp-AST-C}

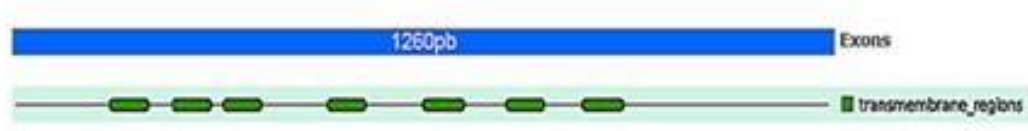

B

Figura 18. A: secuencia proteica predicha de Rp-ATr a partir de la secuencia de mRNA clonada y de la secuencia genómica predicha por el genoma de $R$. prolixus. La estructura del gen mostró que se compone de un único exón. Las letras resaltadas corresponden a diferencias entre las secuencias predichas y la que se obtuvo por secuenciación. B: esquema donde se muestra la predicción de la ubicación de los dominios transmembrana de la proteína. 


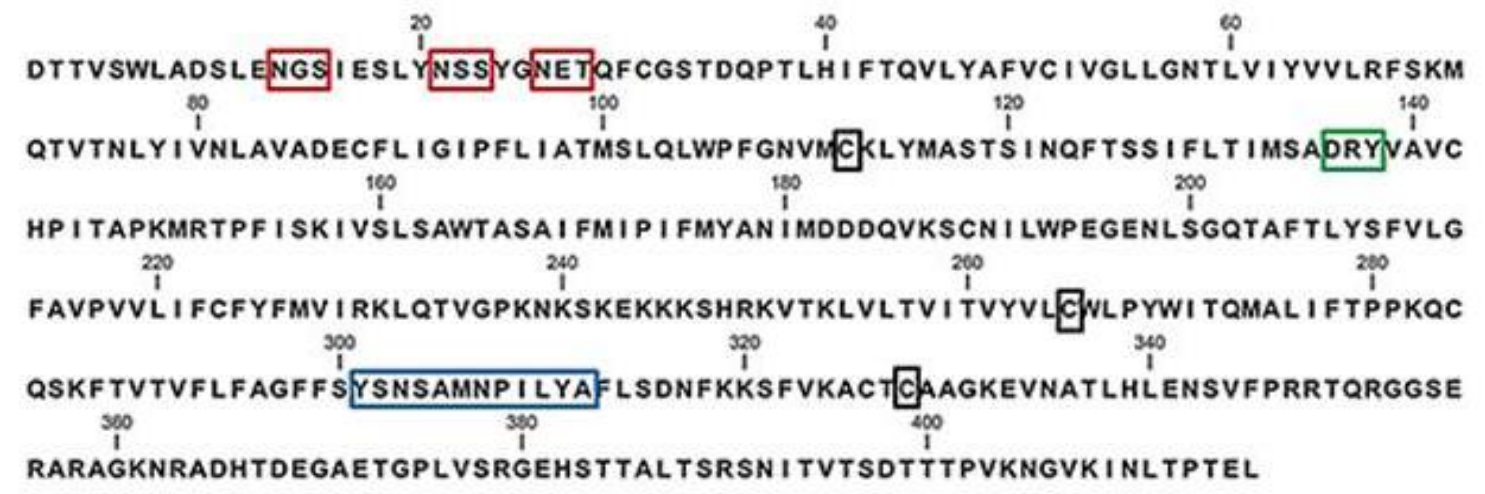

Figura 19: Análisis de las características de la secuencia proteica predicha para Rp-AST-Cr. En la misma se señalan sitios de glicosilación (cuadrados rojos) (predicho con http://www.cbs.dtu.dk/services/NetNGlyc/), residuos de cisteína que corresponden a sitios de palmitolización (cuadrados negros) (predicho con http://csspalm.biocuckoo.org/online.php), secuencias características de los GPCR tipo somatostatina (cuadros verde y azul).

El análisis de las distintas muestras de cDNA mostró que el RpAST-Cr se expresa en el IV estadio larval, y en todos los órganos de insectos adultos analizados, incluyendo el intestino medio, el vaso dorsal y el sistema reproductor de la hembra (Fig. 20).

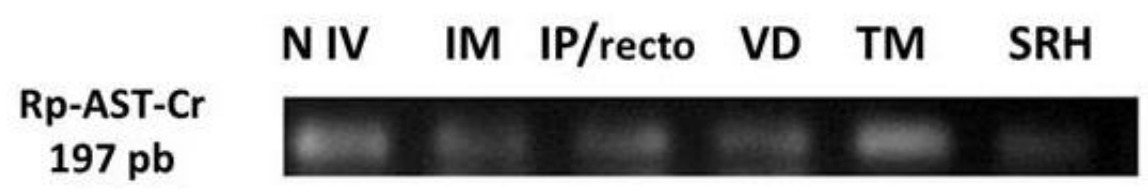

Figura 20: expresión del gen de Rp-AST-Cr en los CDNA estudiados. N IV: cDNA de pool de insectos de IV estadio larval; IM: intestino medio; IP/recto: intestino posterior y recto; VD: Vaso dorsal; TM: tubos de Malpighi; SRH: Sistema reproductor de la hembra.

\subsection{ANÁLISIS FILOGENÉTICOS DE LOS RECEPTORES DE ALLATOTROPINA Y ALLATOSTATINA-C}

Con el objetivo de estudiar las probables relaciones evolutivas de ATr y AST-Cr en insectos, se procedió con el análisis de alineamientos múltiples y la realización de árboles filogenéticos. 


\subsubsection{Búsqueda bioinformática de secuencias homólogas}

Las secuencias homólogas encontradas mediante búsquedas bioinformáticas fueron utilizadas para realizar alineamientos múltiples, por medio de los cuales se pudieron analizar e identificar las características propias de cada uno de los receptores en estudio. Solo fueron utilizadas aquellas secuencias que cumplían con los requisitos previamente detallados en M\&M. Las mismas se presentan ordenadas siguiendo la clasificación taxonómica conocida en las Tablas 1 y 2.

\begin{tabular}{|c|c|c|c|}
\hline & Especie & Nombre de la secuencia & $\begin{array}{c}\mathbf{N}^{\circ} \text { de indetificación del } \\
\text { Genbank }\end{array}$ \\
\hline 1 & Trachymyrmex septentrionalis & orexin receptor type 2 & KYN40586.1 \\
\hline 2 & Atta cephalotes & $\begin{array}{l}\text { orexin receptor type 1- } \\
\text { like }\end{array}$ & XP_012060050.1 \\
\hline 3 & Trachymyrmex cornetzi & orexin receptor type 2 & KYN10929.1 \\
\hline 4 & Acromyrmex echinatior & $\begin{array}{l}\text { orexin receptor type } 1 \text { - } \\
\text { like }\end{array}$ & XP_011049457.1 \\
\hline 5 & Atta colombica & orexin receptor type 2 & KYM82895.1 \\
\hline 6 & Trachymyrmex zeteki & orexin receptor type 2 & KYQ55426.1 \\
\hline 7 & Camponotus floridanus & $\begin{array}{l}\text { orexin receptor type 2- } \\
\text { like isoform X1 }\end{array}$ & XP_011268788.1 \\
\hline 8 & Camponotus floridanus & $\begin{array}{l}\text { orexin receptor type 2- } \\
\text { like isoform X2 }\end{array}$ & XP_011268789.1 \\
\hline 9 & Solenopsis invicta & $\begin{array}{l}\text { orexin receptor type 1- } \\
\text { like }\end{array}$ & XP_011162112.1 \\
\hline 10 & Pogonomyrmex barbatus & $\begin{array}{l}\text { orexin receptor type } 2- \\
\text { like }\end{array}$ & XP_011639561.1 \\
\hline 11 & Monomorium pharaonis & $\begin{array}{l}\text { orexin receptor type 2- } \\
\text { like isoform X1 }\end{array}$ & XP_012526141.1 \\
\hline 12 & Monomorium pharaonis & $\begin{array}{l}\text { orexin receptor type 2- } \\
\text { like isoform X2 }\end{array}$ & XP_012526146.1 \\
\hline 13 & Vollenhovia emeryi & $\begin{array}{l}\text { orexin receptor type 2- } \\
\text { like isoform X1 }\end{array}$ & XP_011866277.1nce: \\
\hline 14 & Vollenhovia emeryi & $\begin{array}{c}\text { orexin receptor type 2- } \\
\text { like isoform X2 }\end{array}$ & XP_011866284.1 \\
\hline 15 & Linepithema humile & $\begin{array}{l}\text { orexin receptor type } 2- \\
\text { like }\end{array}$ & XP_012221220.1 \\
\hline
\end{tabular}




\begin{tabular}{|c|c|c|c|}
\hline 16 & Cerapachys biroi & $\begin{array}{c}\text { orexin receptor type } 2 \\
\text { isoform } X 2\end{array}$ & XP_011343398.1 \\
\hline 17 & Cerapachys biroi & $\begin{array}{c}\text { orexin receptor type } 2 \\
\text { isoform X1 }\end{array}$ & XP_011343395.1 \\
\hline 18 & Cerapachys biroi & Orexin receptor type & EZA51412.1 \\
\hline 19 & Harpegnathos saltator & $\begin{array}{l}\text { orexin receptor type } 2- \\
\text { like }\end{array}$ & XP_011152030.1 \\
\hline 20 & Dinoponera quadriceps & $\begin{array}{l}\text { orexin receptor type } 2- \\
\text { like }\end{array}$ & XP_014485900.1 \\
\hline 21 & Megachile rotundata & $\begin{array}{c}\text { orexin receptor type 2- } \\
\text { like isoform X2 }\end{array}$ & XP_012152839.1 \\
\hline 22 & Megachile rotundata & $\begin{array}{l}\text { orexin receptor type 2- } \\
\text { like isoform X1 }\end{array}$ & XP_003708421.2 \\
\hline 23 & Megachile rotundata & $\begin{array}{c}\text { orexin receptor type 2- } \\
\text { like isoform X4 }\end{array}$ & XP_012152841.1 \\
\hline 24 & Habropoda laboriosa & $\begin{array}{c}\text { orexin receptor type } 2- \\
\text { like }\end{array}$ & XP_017798180.1 \\
\hline 25 & Ceratina calcarata & $\begin{array}{c}\text { orexin receptor type } 2- \\
\text { like }\end{array}$ & XP_017877907.1 \\
\hline 26 & Dufourea novaeangliae & $\begin{array}{l}\text { orexin receptor type 1- } \\
\text { like }\end{array}$ & XP_015430623.1 \\
\hline 27 & Bombus impatiens & $\begin{array}{c}\text { orexin receptor type 2- } \\
\text { like isoform X1 }\end{array}$ & XP_012236721.1 \\
\hline 28 & Bombus impatiens & $\begin{array}{c}\text { orexin receptor type 2- } \\
\text { like isoform X2 }\end{array}$ & XP_012236723.1 \\
\hline 29 & Bombus terrestris & $\begin{array}{l}\text { allatotropin receptor } \\
\text { precursor }\end{array}$ & NP_001291369.1 \\
\hline 30 & Bombus terrestris & $\begin{array}{l}\text { allatotropin receptor } \\
\text { isoform } \times 2\end{array}$ & XP_012174018.1 \\
\hline 31 & Melipona quadrifasciata & orexin receptor type 2 & KOX75334.1 \\
\hline 32 & Eufriesea mexicana & $\begin{array}{l}\text { orexin receptor type } 2- \\
\text { like }\end{array}$ & XP_017756699.1 \\
\hline 33 & Apis florea & $\begin{array}{c}\text { orexin receptor type 2- } \\
\text { like isoform X2 }\end{array}$ & XP_012342412.1 \\
\hline 34 & Apis florea & $\begin{array}{c}\text { orexin receptor type 2- } \\
\text { like isoform X1 }\end{array}$ & XP_003690070.1 \\
\hline 35 & Apis mellifera & $\begin{array}{l}\text { orexin receptor type 1- } \\
\text { like }\end{array}$ & XP_016767251.1 \\
\hline 36 & Apis cerana & $\begin{array}{c}\text { orexin receptor type } 2- \\
\text { like }\end{array}$ & XP_016919230.1 \\
\hline 37 & Apis dorsata & $\begin{array}{l}\text { orexin receptor type 2- } \\
\text { like isoform X2 }\end{array}$ & XP_006621949.1 \\
\hline 38 & Apis dorsata & $\begin{array}{c}\text { orexin receptor type 2- } \\
\text { like isoform X1 }\end{array}$ & XP_006621948.1 \\
\hline
\end{tabular}




\begin{tabular}{|c|c|c|c|}
\hline 39 & Polistes dominula & $\begin{array}{l}\text { orexin receptor type } 2- \\
\text { like }\end{array}$ & XP_015181013.1 \\
\hline 40 & Polistes dominula & $\begin{array}{l}\text { orexin receptor type } 2- \\
\text { like }\end{array}$ & XP_015181013.1 \\
\hline 41 & Polistes canadensis & $\begin{array}{c}\text { orexin receptor type 2- } \\
\text { like isoform X2 }\end{array}$ & XP_014604851.1 \\
\hline 42 & Polistes canadensis & $\begin{array}{c}\text { orexin receptor type 2- } \\
\text { like isoform X2 }\end{array}$ & XP_014604851.1 \\
\hline 43 & Orussus abietinus & $\begin{array}{c}\text { orexin receptor type } 2- \\
\text { like }\end{array}$ & XP_012286269.1 \\
\hline 44 & Athalia rosae & $\begin{array}{l}\text { orexin receptor type } 2 \text { - } \\
\text { like }\end{array}$ & XP_012253675.1 \\
\hline 45 & Neodiprion lecontei & $\begin{array}{c}\text { orexin receptor type } 2- \\
\text { like }\end{array}$ & XP_015522778.1 \\
\hline 46 & Cephus cinctus & $\begin{array}{l}\text { orexin receptor type } 2 \text { - } \\
\text { like isoform } X 1\end{array}$ & XP_015598582.1 \\
\hline 47 & Cephus cinctus & $\begin{array}{c}\text { orexin receptor type 2- } \\
\text { like isoform X2 }\end{array}$ & XP_015598583.1 \\
\hline 48 & Microplitis demolitor & $\begin{array}{c}\text { orexin receptor type } 1 \\
\text { isoform X1 }\end{array}$ & XP_008556466.1 \\
\hline 49 & Microplitis demolitor & $\begin{array}{c}\text { orexin receptor type } 1 \\
\text { isoform } X 2\end{array}$ & XP_008556467.1 \\
\hline 50 & Diachasma alloeum & $\begin{array}{l}\text { orexin receptor type } 2- \\
\text { like }\end{array}$ & XP_015108917.1 \\
\hline 51 & Fopius arisanus & $\begin{array}{l}\text { orexin receptor type 1- } \\
\text { like isoform X2 }\end{array}$ & XP_011309700.1 \\
\hline 52 & Fopius arisanus & $\begin{array}{c}\text { orexin receptor type 2- } \\
\text { like isoform X3 }\end{array}$ & XP_011309701.1 \\
\hline 53 & Fopius arisanus & $\begin{array}{l}\text { orexin receptor type 1- } \\
\text { like isoform X1 }\end{array}$ & XP_011309698.1 \\
\hline 54 & Copidosoma floridanum & $\begin{array}{l}\text { orexin receptor type 1- } \\
\text { like }\end{array}$ & XP_014213261.1 \\
\hline 55 & Trichogramma pretiosum & $\begin{array}{l}\text { orexin receptor type 1- } \\
\text { like }\end{array}$ & XP_014229577.1 \\
\hline 56 & Nasonia vitripennis & $\begin{array}{l}\text { orexin receptor type 1- } \\
\text { like isoform X1 }\end{array}$ & XP_001604582.2 \\
\hline 57 & Nasonia vitripennis & $\begin{array}{l}\text { orexin receptor type 2- } \\
\text { like isoform X2 }\end{array}$ & XP_008217710.1 \\
\hline 58 & Nicrophorus vespilloides & $\begin{array}{l}\text { orexin receptor type } 2 \text { - } \\
\text { like }\end{array}$ & XP_017784249.1 \\
\hline 59 & Nicrophorus vespilloides & $\begin{array}{l}\text { orexin receptor type } 2 \text { - } \\
\text { like }\end{array}$ & XP_017780791.1 \\
\hline 60 & Tribolium castaneum & $\begin{array}{c}\text { Orexin receptor type 2- } \\
\text { like Protein }\end{array}$ & EEZ99337.2 \\
\hline
\end{tabular}




\begin{tabular}{|c|c|c|c|}
\hline 61 & Tribolium castaneum & $\begin{array}{c}\text { orexin receptor type } 1 \\
\text { isoform } X 2\end{array}$ & XP_008199736.1 \\
\hline 62 & Graphocephala atropunctata & $\begin{array}{c}\text { hypothetical protein } \\
\text { g.5050 }\end{array}$ & JAT14796.1 \\
\hline 63 & Homalodisca liturata & $\begin{array}{c}\text { hypothetical protein } \\
\text { g. } 27627\end{array}$ & JAS97347.1 \\
\hline 64 & Clastoptera arizonana & $\begin{array}{c}\text { hypothetical protein } \\
\text { g.20635 }\end{array}$ & JAS06979.1 \\
\hline 65 & Cimex lectularius & $\begin{array}{c}\text { orexin receptor type } 2- \\
\text { like }\end{array}$ & XP_014244153.1 \\
\hline 66 & Rhodnius prolixus & $\begin{array}{c}\text { allatotropin receptor, } \\
\text { partial }\end{array}$ & AHE41431.1 \\
\hline 67 & Nilaparvata lugens & neuropeptide GPCR A16 & BAO01066.1 \\
\hline 68 & Schistocerca gregaria & allatotropin receptor & AEX08666.2 \\
\hline 69 & Aedes aegypti & NPYLR4 & AGX85002.1 \\
\hline 70 & Aedes aegypti & allatotropin receptor & AEN03789.1 \\
\hline 71 & Papilio xuthus & $\begin{array}{l}\text { orexin receptor type 1- } \\
\text { like }\end{array}$ & XP_013174428.1 \\
\hline 72 & Papilio machaon & $\begin{array}{l}\text { orexin receptor type 1- } \\
\text { like }\end{array}$ & XP_014355752.1 \\
\hline 73 & Papilio machaon & orexin receptor type 2 & KPJ20254.1 \\
\hline 74 & Bombyx mori & $\begin{array}{c}\text { neuropeptide receptor A5 } \\
\text { precursor }\end{array}$ & NP_001127740.1 \\
\hline 75 & Amyelois transitella & $\begin{array}{c}\text { orexin receptor type } 1, \\
\text { partial }\end{array}$ & XP_013193322.1 \\
\hline 76 & Chilo suppressalis & neuropeptide receptor $A 5$ & ALM88300.1 \\
\hline 77 & Plutella xylostella & $\begin{array}{l}\text { orexin receptor type 1- } \\
\text { like }\end{array}$ & XP_011557993.1 \\
\hline 78 & Papilio machaon & Orexin receptor type 2 & KPJ20251.1 \\
\hline 79 & Papilio machaon & $\begin{array}{l}\text { orexin receptor type 1- } \\
\text { like }\end{array}$ & XP_014355832.1 \\
\hline 80 & Papilio xuthus & $\begin{array}{l}\text { orexin receptor type } 1 \text { - } \\
\text { like }\end{array}$ & XP_013176423.1 \\
\hline 81 & Chilo suppressalis & $\begin{array}{c}\text { neuropeptide receptor } \\
\text { A16 }\end{array}$ & ALM88312.1 \\
\hline 82 & Bombyx mori & $\begin{array}{c}\text { neuropeptide receptor } \\
\text { A16 }\end{array}$ & NP_001127714.1 \\
\hline 83 & Danaus plexippus & $\begin{array}{l}\text { neuropeptide receptor } \\
\text { A16 }\end{array}$ & EHJ74388.1 \\
\hline 84 & Manduca sexta & allatotropin receptor & ADX66344.1 \\
\hline 85 & Helicoverpa armigera armigera & allatotropin receptor & AIT70966.1 \\
\hline
\end{tabular}


Tabla 2: secuencias homólogas de receptores tipo somatostatina/AST-C en insectos. Las mismas están ordenadas por orden sistemático los cuales se indican con líneas de colores recuadrando las grillas. Azul: orden Himenóptera; Rojo: orden Coleóptera; Verde: orden Hemíptera; Violeta: orden Díptera; Amarillo: orden Lepidóptera.

\begin{tabular}{|c|c|c|c|}
\hline & Especie & Nombre de la secuencia & $\begin{array}{l}N^{\circ} \text { de indetificación } \\
\text { del Genbank }\end{array}$ \\
\hline 1 & Apis mellifera & somatostatin receptor type 2 & XP_006560939.1 \\
\hline 2 & Apis dorsata & somatostatin receptor type 2 -like & XP_006616354.1 \\
\hline 3 & Apis florea & somatostatin receptor type 2 -like & XP_003698610.1 \\
\hline 4 & Bombus terrestris & somatostatin receptor type 2 -like & XP_003394391.1 \\
\hline 5 & Bombus impatiens & somatostatin receptor type 2 -like & XP_003486456.1 \\
\hline 6 & Megachile rotundata & somatostatin receptor type 2-like & XP_003706519.1 \\
\hline 7 & Microplitis demolitor & somatostatin receptor type 2 -like & XP_008548803.1 \\
\hline 8 & Solenopsis invicta & $\begin{array}{c}\text { hypothetical protein SINV_02583, } \\
\text { partial }\end{array}$ & EFZ10721.1 \\
\hline 9 & Harpegnathos saltator & Somatostatin receptor type 1 & EFN80627.1 \\
\hline 10 & Camponotus floridanus & Somatostatin receptor type 2 & EFN69671.1 \\
\hline 11 & Nasonia vitripennis & somatostatin receptor type 2 -like & XP_001600654.2 \\
\hline 12 & Nilaparvata lugens & neuropeptide GPCR A1 & BA001050.1 \\
\hline 13 & Rhodnius prolixus & allatostatin C receptor, partial & AHE41430.1 \\
\hline 14 & Acyrthosiphon pisum & somatostatin receptor type 5 & XP_001950448.2 \\
\hline 15 & Tribolium castaneum & $\begin{array}{l}\text { allatostatin C-like G protein- } \\
\text { coupled receptor }\end{array}$ & DAA64491.1 \\
\hline 16 & Bombyx mori & neuropeptide receptor $\mathrm{A} 1$ & NP_001127736.1 \\
\hline 17 & Danaus plexippus & neuropeptide receptor $A 1$ & EHJ63490.1 \\
\hline 18 & Manduca sexta & allatostatin receptor & ADX66345.1 \\
\hline 19 & Aedes aegypti & somatostatin receptor & XP_001662510.1 \\
\hline 20 & Culex quinquefasciatus & somatostatin receptor type 5 & XP_001854846.1 \\
\hline 21 & Anopheles & somatostatin receptor type 5 & ETN66881.1 \\
\hline 22 & Ceratitis capitata & somatostatin receptor type 5 & XP 012155565.1 \\
\hline 23 & Musca domestica & somatostatin receptor type 5 & XP_005179255.1 \\
\hline 24 & Drosophila. mojavensis & uncharacterized protein & XP_002008619.1 \\
\hline
\end{tabular}




\begin{tabular}{|c|c|c|c|}
\hline & & Dmoj_GI11711 & \\
\hline 25 & Drosophila pseudoobscura & $\begin{array}{c}\text { uncharacterized protein } \\
\text { Dpse_GA12470 }\end{array}$ & XP_001353984.2 \\
\hline 26 & Drosophila sechellia & GM14937 & XP_002042582.1 \\
\hline 27 & Drosophila yakuba & $\begin{array}{c}\text { uncharacterized protein } \\
\text { Dyak_GE22071 }\end{array}$ & XP_002094901.1 \\
\hline 28 & Drosophila erecta & $\begin{array}{c}\text { uncharacterized protein } \\
\text { Dere_GG15739 }\end{array}$ & XP_001972840.1 \\
\hline
\end{tabular}

La búsqueda en bases de datos de las secuencias homólogas para ambos receptores arrojó como resultado numerosas secuencias relacionadas con los receptores de orexina en el caso de ATr, y receptores relacionados con los de somatostatina siendo estos homólogos a AST-Cr. Las secuencias pertenecientes al género Drosophila tenidas en cuenta, aun no se les ha asignado un nombre que haga referencia a receptores AST-Cr/Somatostatina, pero en el análisis de búsqueda de homólogos éstas secuencias coincidían con altos porcentajes de identidad y similitud.

El alineamiento realizado con las secuencias homólogas correspondientes a ATr mostró un alto grado de conservación entre las mismas. En la figura 21 se resalta la presencia de la secuencia de aminoácidos DRW, propia de los receptores de Orexina /AT, además de la secuencia de aminoácidos PLIYTNFMS ubicada en el 7TM, también altamente conservada. De igual manera se procedió con el análisis de las secuencias homólogas de Somatostatina/AST-Cr en insectos, cuyo alineamiento presentó un alto grado de conservación entre las mismas. Fue identificado el motivo $\underline{\mathrm{DRY}}$ en el segundo loop intracelular, asociado al dominio 3TM, propio de los GPCRs, además de la secuencia YSNSAMNPILYA que identifica al 7TM, altamente conservado en todas las secuencias homólogas (Fig. 22). 


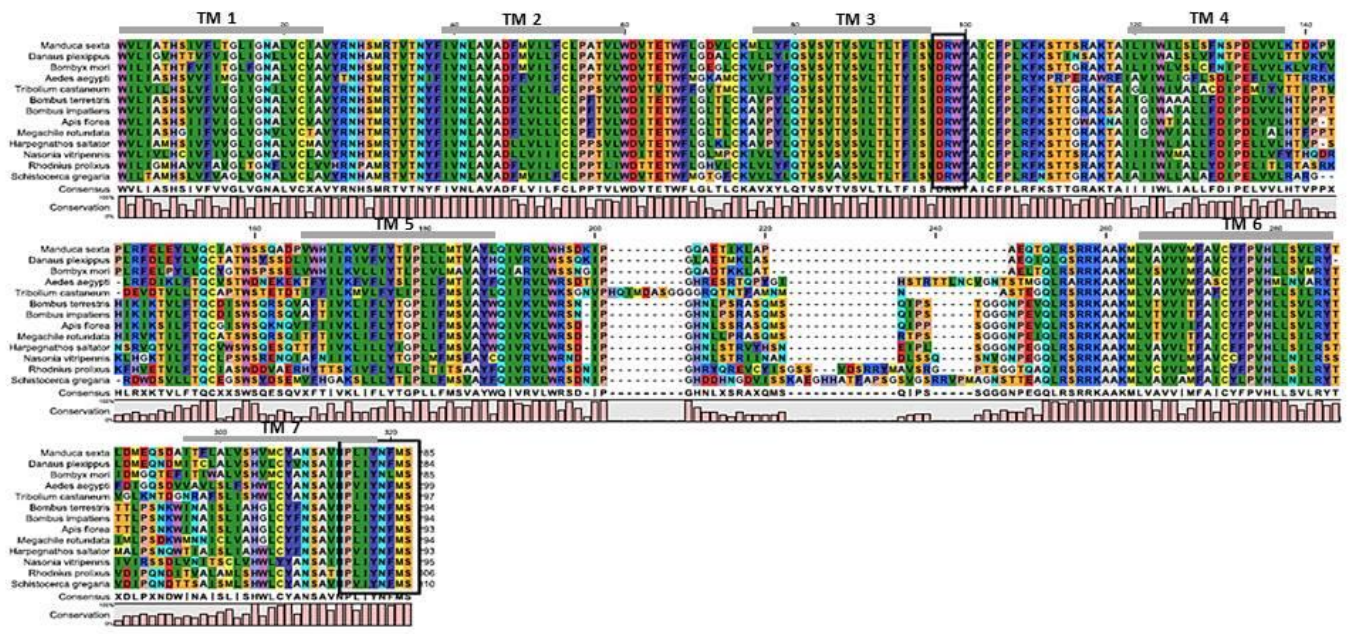

Figura 21: Alineamiento múltiple de secuencias homólogas seleccionadas de Orexina/ATr, realizado con el software Clustal W. En el mismo se observa el alto grado de similitud e identidad entre los aminoácidos de cada secuencia. Los recuadros negros resaltan la presencia de la secuencia de aminoácidos DRW, propia de los receptores de Orexina /AT, y la secuencia de aminoácidos PLIYTNFMS ubicada en el 7TM (ver figura suplementaria en PDF para mayor definición en sección “Anexo").

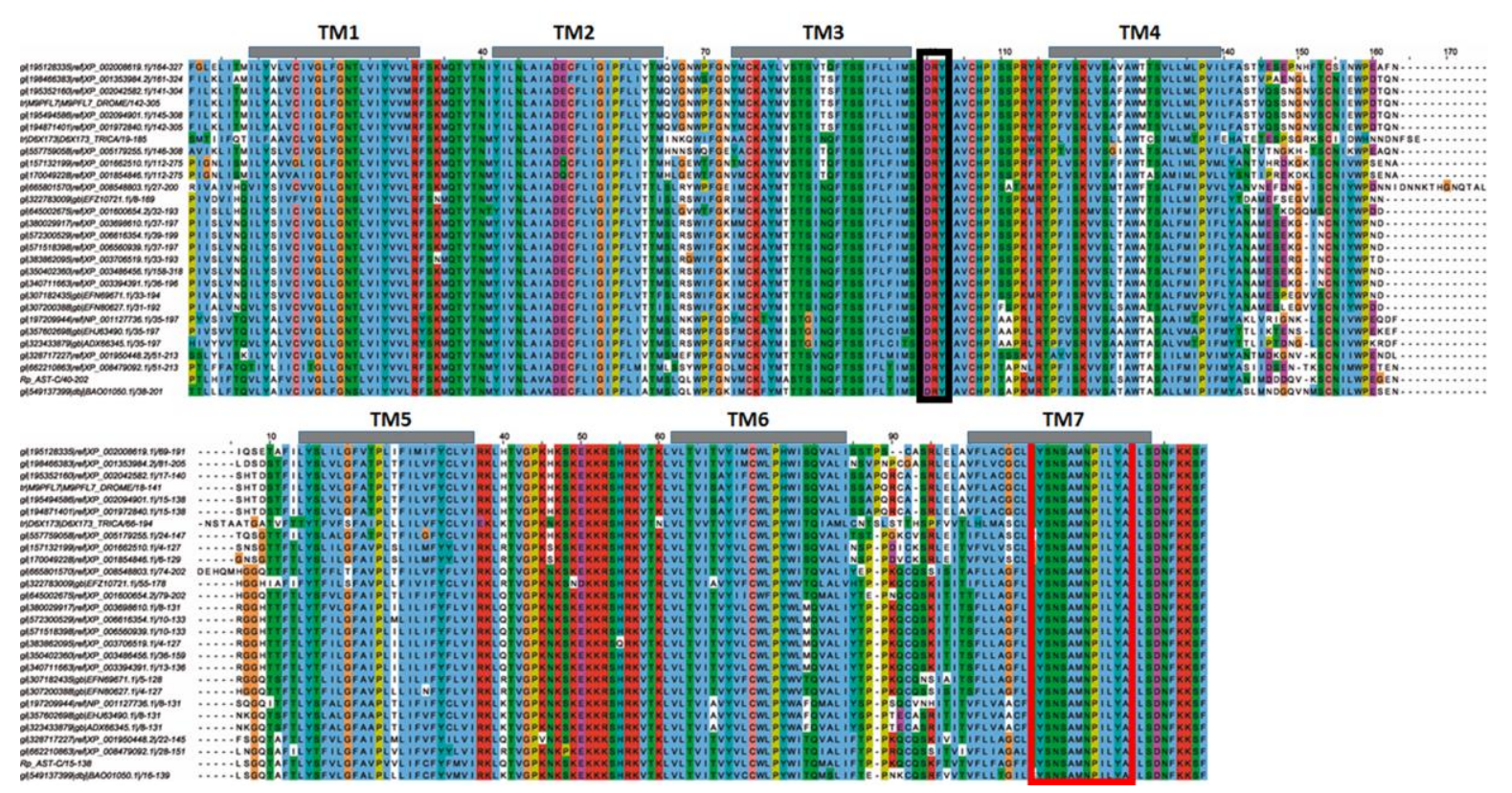

Figura 22: Alineamiento múltiple de secuencias homólogas seleccionadas de Serotonina/AST$\mathrm{Cr}$, realizado con el software Clustal W. El mismo presentó un alto grado de conservación entre las secuencias de aminoácidos. El recuadro negro resalta la presencia del motivo $\underline{D R Y}$ mientras que el recuadro color rojo la secuencia YSNSAMNPILYA que identifica al 7TM, altamente conservado en todas las secuencias homólogas (ver figura suplementaria en PDF para mayor definición en sección "Anexo"). 


\subsubsection{Construcción de los árboles filogenéticos}

Como resultado del alineamiento múltiple de las secuencias proteicas de Orexina/ATr de insectos se obtuvo un árbol filogenético el cual se ordenó en dos grandes grupos: uno contiene a todas las secuencias del orden Hymenóptera, mientras que la otra rama agrupa a los órdenes Coleóptera, Hemíptera, Díptera y Lepidóptera. A su vez, el orden Coleóptera se ubicó independientemente de los otros 3 clados. La rama que sostiene a los grupos restantes ubica en una misma llave a los dípteros y lepidópteros, y estos a su vez se relacionaron como grupo hermano de los hemípteros, donde se ubicó la secuencia Rp-ATr (Fig. 23).

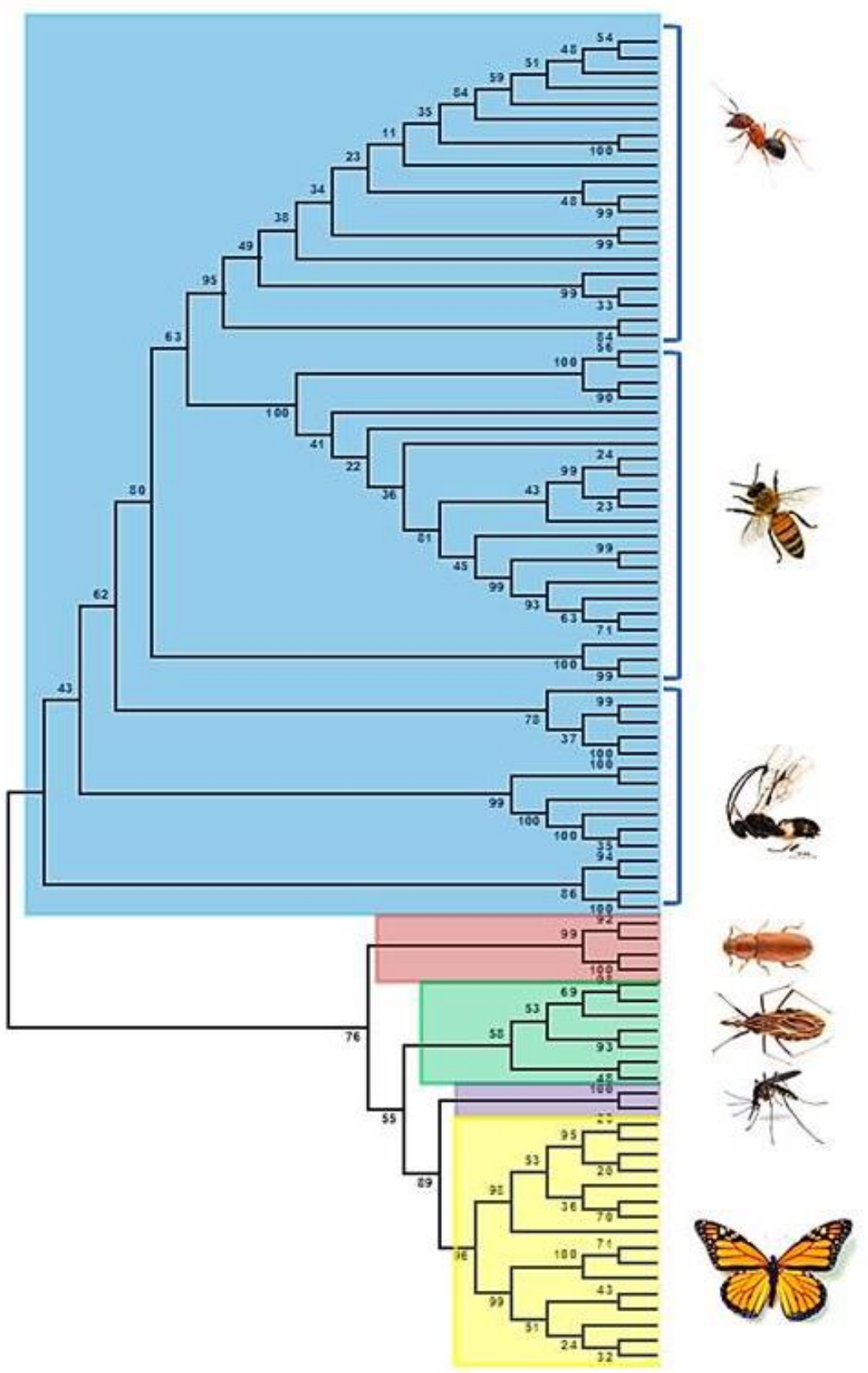


Figura 23: árbol filogenético de los receptores tipo Orexina/AT de insectos. El mismo fue inferido utilizando el método de Máxima verosimilitud (el cual utiliza la matriz JTT), basado en el modelo de corrección de Poisson. El porcentaje replicas (1000 bootstrap) se muestran en las ramas. Los análisis se realizaron con MEGA 6.06. Cada orden taxonómico se destaca en colores: Azul: orden Himenóptera; Rojo: orden Coleóptera; Verde: orden Hemíptera; Violeta: orden Díptera; Amarillo: orden Lepidóptera. El orden de aparición de cada secuencia en el árbol filogenético corresponde al orden de numeración de la tabla 1.

Con la misma metodología que se analizaron las probables relaciones filogenéticas de ATr se construyó el correspondiente árbol para Somatostatina/AST-Cr. Las secuencias ingresadas en el análisis se dividieron en dos clados, por un lado se agruparon todas aquellas pertenecientes al orden Díptera, mientras que en el otro grupo se ubicaron los himenópteros, hemípteros, coleópteros y lepidópteros. El análisis filogenético ubicó al orden Himenóptera como grupo hermano del orden Hemíptera, ambos relacionados con los coleópteros. El orden Lepidóptera, a su vez, se asoció con estos tres últimos (Fig. 24).

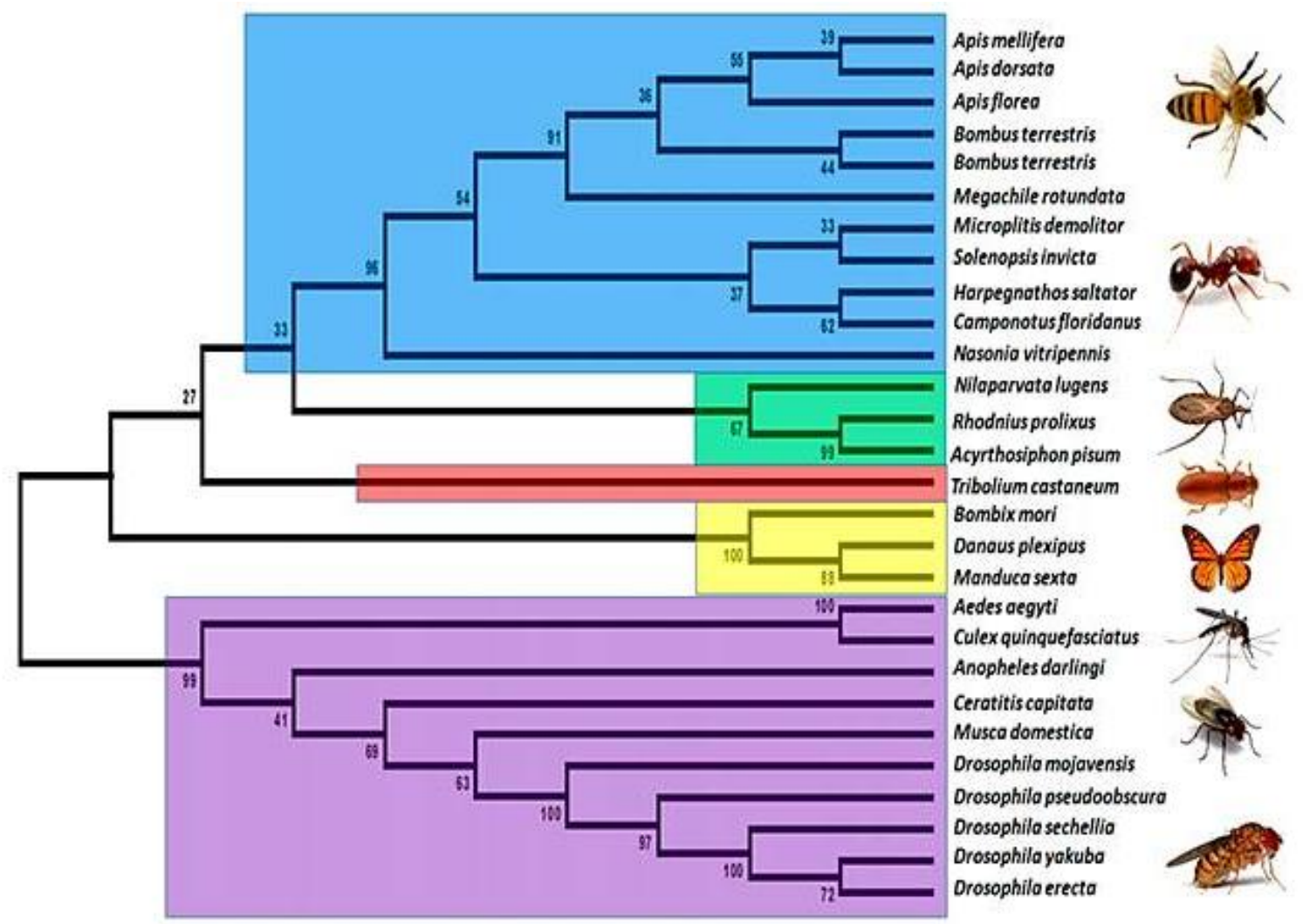

Figura 24: árbol filogenético que representa las probables relaciones evolutivas entre los receptores tipo Somatostatina/AST-C. El mismo fue inferido utilizando el método de Máxima verosimilitud (el cual utiliza la matriz JTT), basado en el modelo de corrección de Poisson. El porcentaje replicas (1000 bootstrap) se muestran en las ramas. Los análisis se realizaron con MEGA 6.06. Cada orden taxonómico se destaca en colores: Azul: orden Himenóptera; Rojo: 
orden Coleóptera; Verde: orden Hemíptera; Violeta: orden Díptera; Amarillo: orden Lepidóptera. La historia evolutiva se dedujo mediante el método de máxima verosimilitud, el cual utiliza la matriz JTT. 
Discusión 
Allatotropina y Allatostatina- $C$, dos neuropéptidos originalmente aislados en base a su función como reguladores de la síntesis de HJs han demostrado ser pleiotrópicos presentando, entre otras funciones, la capacidad de modular la musculatura visceral. Esta función ha sido estudiada a nivel del sistema digestivo y circulatorio en insectos como lepidópteros, blatodeos y dípteros (Veenstra et al., 1994; Duve et al., 1999; Duve et al., 2000; Rudwall et al., 2000; Koladich et al., 2002; Price et al., 2002; Matthews et al., 2007). En insectos triatominos se ha observado la actividad mioestimuladora de AT sobre dichos sistemas. Durante la ingesta, estos insectos incorporan una gran cantidad de sangre con cada ciclo alimenticio, que puede llegar a más de 10 veces su peso original en los estadios larvales (Buxton, 1930). Dada la gran cantidad de sangre incorporada y el desbalance hídrico-mineral que esto conlleva, los insectos comienzan inmediatamente el proceso de diuresis. Este evento fisiológico crítico se mantiene a tasas máximas hasta tres horas posteriores a la ingesta y se encuentra regulado por hormonas diuréticas y antidiuréticas, las cuales modulan la actividad de los TMs (Beyenbach, 2003; Coast \& Garside, 2005). Si bien los mecanismos que controlan la actividad de los TMs durante la diuresis post-prandial han sido ampliamente estudiados (Wigglesworth, 1931; Ramsay, 1952; Maddrell, 1969; Maddrell \& Phillips, 1975; Maddrell, 1978; O’Donnell \& Spring, 2000), los mecanismos endocrinos que modulan el proceso de recirculación de la hemolinfa durante la diuresis han recibido menor atención. En este sentido, es importante destacar que para favorecer el acceso de neurohormonas como la serotonina a los TMs, y facilitar los procesos de eliminación de la orina, es necesario aumentar la frecuencia cardiaca, que propulsa la hemolinfa en sentido posteroanterior y las contracciones peristálticas del buche que facilita la circulación de la hemolinfa en sentido anteroposterior (Maddrell, 1964). Nuestro laboratorio ha demostrado en la especie afín T. infestans, que el neuropéptido AT aumenta la frecuencia de contracciones del VD cuando este se encuentra previamente estimulado por la serotonina, impulsando la hemolinfa en sentido posteroanterior (Sterkel et al., 2010). Además, AT incrementa las contracciones peristálticas del buche para impulsar la hemolinfa en sentido anteroposterior (Sterkel et al., 2010). Este fenómeno se encuentra asociado a la actividad de AT como mio-regulador de las contracciones peristálticas del recto, favoreciendo la eliminación de orina durante la diuresis post-ingesta (Santini \& Ronderos, 2007), siendo secretada por vía endocrina desde los TMs (Santini \& Ronderos, 2009 a y b). Hemos demostrado además, que el péptido está presente en axones que inervan a la aorta, señalando la existencia de una vía nerviosa. Además, AT sería liberado, también por células de origen epitelial, como las células de tipo abierto presentes en el epitelio del buche, que actuarían por vía paracrina (Riccillo \& Ronderos, 2010; Sterkel et al., 2010) y por los túbulos de Malpighi que participarían por vía endocrina (Santini \& Ronderos, 2007, 2009 a y b). 
Masood \& Orchard (2014), propusieron que las actividades descriptas en T. infestans no estarían presentes en $R$. prolixus. Más allá de que analizaron la actividad de AT sobre insectos que no habían sido alimentados, y sin tratamiento conjunto con serotonina, lo que hace que estos experimentos no sean comparables a los realizados en $T$. infestans, estos autores refieren a la existencia de material inmuno-reactivo para un anticuerpo anti-AT en axones que inervan tanto el VD como el buche y el digestivo posterior, no pudiendo explicar el porqué de la presencia del péptido. Con el objeto de aclarar esta controversia entre la probable actividad especie-específica de AT entre estas dos especies de insectos triatominos, decidimos analizar el comportamiento del VD y el buche en machos adultos de $R$. prolixus. En este sentido, nuestros experimentos demuestran que al igual que en $T$. infestans, la musculatura asociada a la pared del VD responde a AT cuando los insectos son previamente estimulados con serotonina, reproduciendo el efecto previamente demostrado en $T$. infestans y justificando la presencia de axones inmuno-reactivos a nivel de estos órganos, descripta por Masood \& Orchard (2014) en R. prolixus y previamente demostrada en T. infestans (Riccillo \& Ronderos, 2010; Sterkel et al., 2010). Nuestros resultados demuestran que efectivamente, por sí misma, AT no afectaría la actividad de la aorta, sino que estimularía la frecuencia de contracción del VD en presencia de serotonina, siendo un factor sinérgico en la regulación de la frecuencia del VD. Este tipo de fenómeno relacionado a la actividad de la serotonina, ha sido previamente demostrado en otros grupos de insectos. En efecto, la existencia de un efecto sinérgico entre serotonina y FMRFamidas fue también descripto en la aorta de la mosca de la fruta $D$. melanogaster donde, de modo similar, la FMRFamida no demostró tener efecto sobre la frecuencia basal, pero al ser aplicada junto con la serotonina, el número de contracciones de este órgano se incrementó significativamente (Nichols, 2006).

Se ha documentado previamente la existencia de patrones circadianos en triatominos relacionados a la secreción de hormonas o neurosecreciones con el propósito de modular fenómenos fisiológicos, tales como el control de la actividad y comportamiento diario de larvas y adultos (Steel \& Vafopoulou, 2006; Vafopoulou et al., 2010), así como el control de puesta de los huevos (Ampleford \& Davey, 1989; Cardinal-Aucoin et al., 2013; Vafopoulou et al., 2012). De hecho, en T. infestans, los niveles de AT en el intestino medio y en los TMs varían a lo largo de un período de 24 horas, alcanzando su mayor concentración horas previas del comienzo del período de oscuridad donde los insectos preparan su sistema para la búsqueda de alimento (Santini \& Ronderos, 2009a). En el análisis de nuestros resultados, observamos una marcada variación de la frecuencia basal de las contracciones de la aorta de $R$. prolixus, mostrando frecuencias máximas durante la tarde, cuando los insectos se estarían preparando para la 
ingesta de sangre. Es importante señalar que AT no demostró efecto sobre la actividad basal en ninguna de las dos situaciones.

Como se explicó previamente, la principal vía de transmisión de la enfermedad de Chagas se produce cuando los insectos se alimentan, liberando durante el proceso de diuresis post-ingesta junto con la orina y las heces la forma infectante de $T$. cruzi. Dada la relevancia que AT presenta como modulador de la velocidad de circulación de la hemolinfa durante la diuresis, la posibilidad de alterar su actividad durante este proceso podría abrir la discusión al desarrollo de métodos alternativos de control de la transmisión de esta enfermedad. Santini \& Ronderos (2007) demostraron en larvas de $T$. infestans que la inyección de un antisuero antiAT en el hemocele, previo a la alimentación, provoca una disminución significativa de la eliminación de orina durante las dos primeras horas posteriores a la ingesta. Más recientemente, nuestro laboratorio demostró la existencia de un fenómeno similar en larvas de $4^{\text {to }}$ estadio de R. prolixus (Villalobos Sambucaro et al., 2015), corroborando el efecto de AT sobre la actividad del tubo digestivo posterior. A diferencia de lo realizado en $T$. infestans, en esta ocasión, el anticuerpo fue administrado por vía digestiva demostrando que las inmunoglobulinas de vertebrados pueden atravesar la pared del tubo digestivo manteniendo su actividad. La capacidad que poseen los anticuerpos de atravesar la pared del tubo digestivo y ser activos en la hemolinfa fue evidenciada previamente en otras especies de insectos, como en la mosca Haematobia irritans exigua (Allingham et al., 1992) pero no había sido ensayada previamente en triatominos. La administración de antisuero anti-AT con el alimento a insectos adultos provocó una disminución significativa de la frecuencia de contracción de la aorta, corroborando el efecto cardioacelerador del péptido. En este ensayo se observó además, que la tasa de contracciones peristálticas del buche también disminuyó. Teniendo en cuenta que la aplicación conjunta de AT y serotonina no generó ningún efecto en el buche, es probable que el péptido esté interactuando con otros miomoduladores no ensayados sobre la regulación de la actividad contráctil de la musculatura en el tubo digestivo medio. De hecho, ha sido demostrado que la proctolina incrementa la actividad contráctil del digestivo medio anterior en $R$. prolixus (Orchard et al., 2011). En referencia a la transmisión vectorial de la enfermedad de Chagas, el bloqueo de la actividad del péptido AT en un periodo vital para los insectos hematófagos resulta relevante en base a la importancia sanitaria. La disminución de la actividad contráctil, tanto del VD como del buche, conlleva a la disminución de la recirculación de la hemolinfa, alterando la formación de orina por los TMs. Este hecho, sumado a la disminución de la eliminación de orina debido al bloqueo de la actividad del tubo digestivo posterior (Santini \& Ronderos, 2007; Villatobos et al., 2015), resultaría en un retraso en la 
liberación de formas infectantes del parásito causante de la enfermedad sobre el huesped, proporcionando nuevas aproximaciones para abordar potenciales estrategias de control de la enfermedad de Chagas.

Al igual que AT, AST-C fue originalmente caracterizada por su función relacionada con la actividad de la CA, actuando como inhibidora de la síntesis de HJs en algunos grupos de insectos holometábolos como dípteros y lepidópteros (Kramer et al., 1991; Li et al., 2004). Como hemos señalado, se ha observado además que este péptido tiene un efecto mioinhibidor sobre la musculatura visceral de L. oleracea (Duve et al., 2000; Matthews et al., 2007) y se ha propuesto también, que presenta un efecto cardioinhibidor en $D$. melanogaster (Price et al., 2002). Los datos obtenidos mediante el análisis de AST-C sobre la frecuencia de contracciones de la aorta de machos ayunados de R. prolixus, demostraron la existencia del efecto mioinhibitorio de la hormona. De modo significativo, el tratamiento con AST-C en insectos estimulados por serotonina/AT generó una disminución de la frecuencia de contracción del VD que no alcanzó valores basales, siendo la tasa registrada similar a la observada luego de la estimulación con serotonina, sugiriendo una acción antagonista sobre la actividad de AT, sin alterar la capacidad estimuladora de la serotonina. De hecho, cuando la misma dosis de AST-C fue ensayada en individuos estimulados solamente con serotonina, la frecuencia de contracción no disminuyó.

Si bien la actividad de estos péptidos ha sido estudiada en numerosas especies pertenecientes a distintos grupos de insectos, y han sido descriptas múltiples funciones para ambos, el modo de acción de los mismos no ha sido analizado en detalle, a excepción de los estudios realizados por Rachinsky y colaboradores que sugieren que AT, del mismo modo que orexina en vertebrados, induce un incremento del $\mathrm{Ca}^{2+}$ citosólico (Rachinsky et al., 2003; Wu et al., 2013). Estudios recientes llevados a cabo sobre Hydra sp (Cnidaria: Hydrozoa) donde se ensayó el efecto de nifedipina (un bloqueante de los canales de calcio) sobre la actividad contráctil del hipostoma inducida por AT, sugieren, además, que la actividad del péptido estaría modulada por el ingreso de $\mathrm{Ca}^{2+}$ extracelular (Alzugaray et al., 2017). Respecto al modo de acción de AST-C, si bien no existen a la fecha estudios en insectos, se sabe que el receptor de la misma es homólogo del receptor de somatostatina de vertebrados (Auerswald et al., 2001). Este péptido, originalmente caracterizado por su actividad como inhibidor de la secreción de la hormona de crecimiento en estos organismos, actúa principalmente causando una reducción de la disponibilidad del $\mathrm{Ca}^{2+}$ citosólico (Barbieri et al., 2013; Farrell et al., 2014; Patel, 1999). Sobre la base de esta información, y como una primera aproximación a la probable vía de acción de AST-C en nuestro modelo de estudio, decidimos ensayar el efecto 
del péptido en presencia de tapsigargina (un compuesto que inhibe la recaptación del ion calcio hacia el retículo sarcoplásmico), sobre la frecuencia cardiaca y la tasa de contracciones peristálticas del buche durante el proceso de diuresis post-ingesta. Los resultados mostraron que en presencia de tapsigargina, AST-C no generó efecto sobre ninguna de las dos variables analizadas, sugiriendo que la actividad del péptido está asociada a la disminución de los niveles de $\mathrm{Ca}^{2+}$ citosólico.

Los ensayos realizados durante la diuresis post-prandial, AST-C mostró ser mioinhibidora, reduciendo tanto, la tasa de contracción de la aorta, así como las ondas peristálticas del buche. Estos resultados sugieren que el péptido estaría implicada en la regulación de la recirculación de la hemolinfa durante este proceso, cuando la serotonina y la AT son fisiológicamente activas, modulando tanto la dirección posteroanterior (dado por la actividad del VD) como el sentido de circulación anteroposterior del flujo de la hemolinfa.

En base a los resultados obtenidos, AT y AST-C modularían la actividad del tejido muscular en los sistemas de órganos analizados en insectos machos de la especie $R$. prolixus. Si bien se ha documentado la existencia de la co-localización de estos péptidos en el ganglio frontal de lepidópteros, cuyos nervios llegan a este sector del tubo digestivo y modularía su actividad mediante estos neuropéptidos (Duve et al., 2000; Duve \& Thorpe, 2005), nuestros resultados representan el primer registro de la existencia de un efecto antagónico entre estos neuropéptidos implicados en la mio-regulación.

El análisis inmunohistoquímico mediante microscopía de barrido laser confocal reveló datos sobre la probable fuente de síntesis de AST-C en relación con la regulación de laactividad del VD y del buche. Las imágenes de los ganglios ventrales evidencian somasneuronales marcados positivamente para AST-C. Así como se observó en escarabajos de laespecie $T$. castaneum (Audsley et al., 2013) y en mosquitos de las especies A. aegypti y An.albimanus, (Hernández-Martínez et al., 2005) la cantidad de somas inmunomarcados no fuenumerosa. Asimismo, las células presentan una disposición simétrica en la periferia de losganglios. Los mismos, además de desempeñar su función como neuromoduladores en elsistema nervioso constituyen órganos neurohemales, es decir, que hormonas secretadas porlas neuronas son liberadas hacia la hemolinfa.

El VD no se encuentra inervado por axones que contengan el péptido, caso contrario a lo observado en estudios sobre la distribución de AT, donde se identificaron axones inmunoreactivos inervando el VD de R. prolixus y T. infestans (Sterkel et al., 2010; Masood \& Orchard, 2014). En el interior del corazón se evidenció inmunomarcación específica para AST-C 
colocalizando con fibras musculares. La presencia del péptido en los nefrocitos asociados a los músculos alares, así como la intensa marcación en las aberturas del corazón por donde ingresa la hemolinfa (ostiolos), sugiere que el péptido está circulando en la hemolinfa y modifica la actividad contráctil del corazón por vía neuroendocrina.

En el epitelio de revestimiento del buche se encuentran células endocrinas denominadas "de tipo abierto". Las mismas tienen forma de botella y se extienden desde la lámina basal hasta el lumen del intestino medio, y su citoplasma contiene gránulos de secreción. El dominio apical de las células de tipo abierto está en contacto con el lumen del órgano siendo capaz de detectar cambios en el contenido del mismo. Este tipo de células secretoras, representa una forma de integrar los sistemas digestivo y endocrino en los insectos, evaluando la calidad del alimento y transmitiendo la información a otras células por vía endocrina o paracrina (Klowden, 2013). Mediante el estudio inmunohistoquímico del epitelio del buche de insectos machos de $R$. prolixus, fueron identificadas células con gránulos inmunopositivos para AST-C. Las mismas se encuentran asociadas a fibras musculares que producen las ondas peristálticas de la pared del órgano. Esto se deduce a partir de la colocalización de los colores rojo ( $\beta$-actina de las fibras musculares) y verde (péptido AST-C) que en microscopía de fluorescencia se observa en color amarillo, por lo que probablemente el péptido tenga un accionar de tipo paracrino sobre la musculatura. Un sistema similar fue previamente descripto en $T$. infestans en relación a AT (Riccillo \& Ronderos, 2010; Sterkel et al., 2010). La presencia del péptido en células epiteliales del intestino medio fue descripta también en $T$. castaneum, aunque en este caso, no tendría acciones mio-reguladoras a nivel del tubo digestivo y estaría implicado en la estimulación de la secreción de proteasas hacia la luz del mismo (Audsley et al., 2013).

Con respecto al sistema reproductor de la hembra, trabajos previos en donde se evaluó la variación de la frecuencia basal de contracción de los ovarios a lo largo del ciclo gonadotrófico en $R$. prolixus, demostraron que la cópula y la ingesta sanguínea activan la síntesis y secreción a nivel del protocerebro, de compuestos con actividad miotrópica, que modularían los movimientos de contracción de estos órganos (Kriger \& Davey, 1982; Kriger \& Davey, 1984; Davey \& Kriger, 1985). En efecto, la presencia de este tipo de factores asociados a la actividad contráctil de la musculatura en el SRH de $R$. prolixus, originalmente denominados como Hormona Miotrópica de la Ovulación, fue previamente propuesta (Davey \& Krieger, 1984; Krieger and Davey, 1983). Más recientemente, se demostró además, que el neuropéptido proctolina y péptidos de tipo FMRFamida modulan positivamente la actividad contráctil espontanea del sistema reproductor en hembras no alimentadas, aunque los autores 
no especifican si las hembras utilizadas eran vírgenes o habían sido copuladas (Lange, 1990; Sedra \& Lange, 2014; Sevala et al., 1992).

Investigadores de nuestro laboratorio observaron previamente, mientras era evaluado el efecto de AT sobre la frecuencia de contracción de la aorta, que algunas hembras de $T$. infestans llevaban a cabo la postura de huevos durante la estimulación con el péptido (Sterkel et al., 2010). Es así que surgieron diferentes preguntas acerca de que si en este proceso estaría participando AT sobre la musculatura del sistema reproductor de la hembra en los insectos triatominos, facilitando los movimientos de las paredes de los órganos durante la oviposición. Habiendo evaluado las implicancias que tiene no solo AT, sino también AST-C sobre las contracciones musculares en el sistema digestivo y el sistema circulatorio en un momento crítico como es la diuresis post-prandial en insectos machos de $R$. prolixus, fue de interés para nosotros profundizar la caracterización funcional de los mismo sobre el sistema reproductor de las hembras de esta especie. El diseño experimental planteado es novedoso en varios sentidos: es el primer registro de la actividad de AT y AST-C que se realiza discriminando su accionar en cada uno de los órganos. Además, se tuvo en cuenta, y de manera rigurosa, el estado fisiológico y reproductivo de la hembra para realizar los experimentos. En otros estudios, tanto en insectos triatominos como en otros grupos, no se detallan con precisión en qué condiciones nutricias se encontraban los insectos al momento de realizarse los experimentos, o si las hembras habían sido copuladas, o incluso la edad de las mismas (Lange, 1990; Paemen et al., 1991; Wagner et al., 1993; Chiang, 2010; Orchard et al., 2011; Audsley et al., 2013; Sedra \& Lange, 2014; Sedra et al., 2015). Sin embargo, nosotros tomamos como relevantes estas variables por lo que el diseño experimental fue significativo para el estudio de estos péptidos.

Nuestros resultados demuestran que la actividad mio-reguladora de AT sobre el SRH se encuentra condicionada por la cópula y la ingesta sanguínea, no observándose actividad en ninguno de los órganos, en hembras que no fueron copuladas. El comportamiento de los órganos bajo los efectos de AT puede observarse claramente en la película suplementaria $\mathrm{N}^{\circ} 2$, donde se muestra comparativamente una hembra ayunada virgen, en contraste con un insecto ayunado copulado, durante el mismo tratamiento. Efectivamente, AT no fue capaz de estimular la musculatura de ningún órgano en aquellas hembras que se encontraban ayunadas y vírgenes (película suplementaria $\mathrm{N}^{\circ} 2$ ).

A diferencia de estas últimas, sí se observaron respuestas dependientes de las dosis en el SRH, tanto en individuos copulados ayunados como en las hembras grávidas. Los resultados mostraron además, que cada uno de los órganos respondió de manera diferencial, 
dependiendo del estatus reproductivo del insecto. En el siguiente esquema se resumen las distintas respuestas de cada órgano ante la presencia de AT.

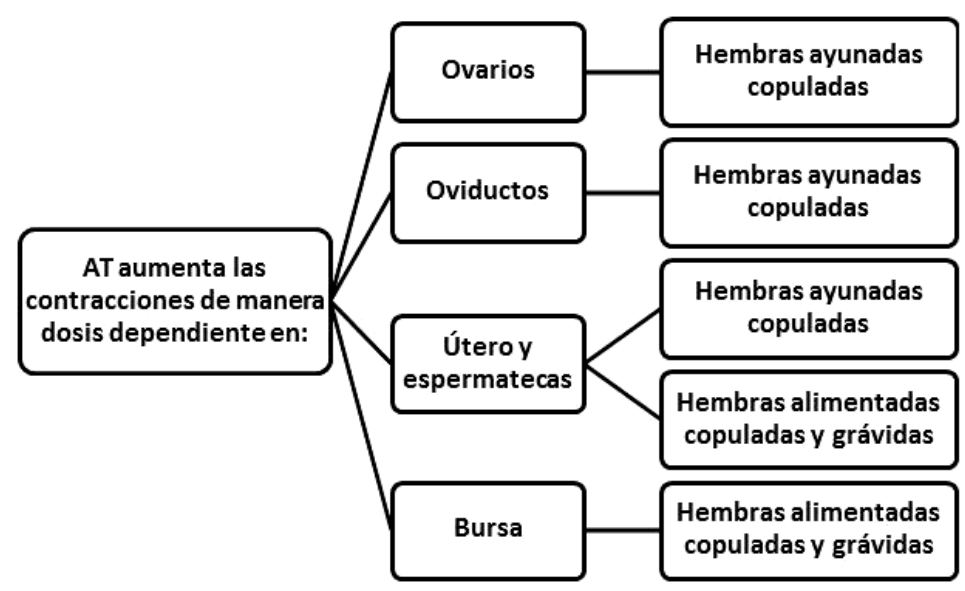

Es interesante destacar, que los movimientos en estado basal y la respuesta de cada órgano al péptido variaron dependiendo de las condiciones fisiológicas a lo largo del ciclo reproductivo. De hecho, a excepción de la bursa que no mostró un patrón claro de contracciones salvo en las hembras grávidas, la respuesta de los ovarios, oviductos, espermatecas y útero fue mayor en las hembras copuladas no alimentadas (ovarios previtelogenéticos). Llamativamente, si bien los ovarios de las hembras que se encontraban en esta condición fisiológica respondieron positivamente ante las dosis crecientes, observamos una disminución en las número de contracciones de dichos órganos en el registro de la dosis más alta de AT $\left(10^{-6} \mathrm{M}\right)$. Ésta disminución en la frecuencia de los ovarios registrada durante este tratamiento podría deberse a un aumento en la duración de la contracción.

Luego de la cópula, los movimientos en cada sector del SRH tienen como finalidad movilizar los espermatozoides libres en el tracto genital hacia su lugar de almacenamiento en las espermatecas. Por otro lado, una vez maduros los ovocitos, los mismos son liberados hacia el oviducto común en el momento en que el huevo debe ser fertilizado. En este sentido, el aumento de las contracciones de la musculatura asociada a los ovarios en las hembras copuladas ayunadas, que genera contracciones peristálticas con sentido anteroposterior, evitaría que los espermatozoides liberados luego de la cópula sean movilizados más allá del útero, en el cual abren las espermatecas. Asimismo, luego de la cópula, las contracciones espasmódicas de los oviductos, junto con los movimientos del útero y de las espermatecas, ejercerían una presión negativa que facilita el desplazamiento de los espermatozoides hacia estas últimas. Por otro lado, si bien no hemos podido registrar un patrón definido de la actividad de la bursa luego de la cópula, se ha propuesto que la misma sufre movimientos del 
sector posterior que evitarían que el líquido seminal liberado en ella se pierda a través de la abertura genital (Davey, 1958). Estudios realizados sobre la variación de la tasa de contracciones espontáneas de las espermatecas a lo largo del ciclo gonadotrófico de $R$. prolixus, demostró que la misma es mayor en hembras copuladas que en las vírgenes, y que además estaría controlada por el sistema neuroendocrino y por factores sintetizados por la glándula opaca del sistema reproductor del macho (Davey, 1958; Kuster \& Davey, 1986). La cópula podría, no solo incrementar la frecuencia de contracciones espontáneas de las espermatecas, sino que sensibilizaría a las fibras musculares, de manera similar a lo observado en el útero, haciéndolos más susceptibles a la presencia del péptido. En este sentido, nuestros resultados demuestran que AT estaría involucrada en la coordinación de los movimientos asociados al traslado y almacenamiento de los espermatozoides en momentos posteriores a la cópula.

La frecuencia basal de los ovarios en las hembras grávidas se encuentra elevada sugiriendo una actividad máxima, y no fue afectada por el tratamiento con AT. Tampoco fue posible registrar cambios en la frecuencia de contracción en los oviductos bajo estas condiciones fisiológicas, ya que en su mayoría se encontraban con huevos en su interior. Es conocido el accionar de otros péptidos mioestimuladores sobre los oviductos en $R$. prolixus como la proctolina (Lange, 1990) y FMRFamida (Sedra \& Lange, 2014). En otros grupos de insectos como L. migratoria y L. maderae AT modificó las contracciones espontáneas de los oviductos de manera positiva así como el péptido cardioactivo de crustáceos (Paemen et al., 1991; Donini et al., 2001). Es probable que AT provoque cambios en el tono y la amplitud de las fibras musculares de estos órganos en $R$. prolixus para direccionar los huevos hacia el útero, al igual que en L. migratoria y L. maderae, pero con la metodología que utilizamos esto no ha sido percibido.

Respecto de la importancia de la cópula en el cambio de respuesta del SRH, si bien estudios realizados en diferentes especies de insectos holometábolos sugieren que AT no estaría presente en el líquido seminal ingresado con el espermatóforo (Dottorini et al., 2007; Avila et al., 2011; South et al., 2011; Azevedo et al., 2012; Baldini et al., 2012; Wei et al., 2015), Paemen y colaboradores demostraron que las glándulas accesorias del sistema reproductor del macho de L. migratoria producen AT, proponiendo que el péptido sería ingresado a la hembra durante la cópula, modificando el comportamiento de la musculatura del SRH (Paemen et al., 1999). 
El incremento de la tasa de contracción del útero y de las espermatecas fue dependiente de la dosis en las hembras grávidas, aunque los valores observados fueron menores a los registrados en las hembras copuladas. Estudios sobre la variación diaria a lo largo del ciclo gonadotrófico de las hembras de $R$. prolixus muestran que la frecuencia de contracción disminuye los días próximos a la puesta de los huevos (Kuster \& Davey, 1986). Esto podría deberse a que la liberación de los espermatozoides, el pasaje de los huevos y su puesta son controlados por movimientos más pausados y precisos de la pared del SRH. AT podría estar vinculada con el control de estos movimientos junto con otros péptidos como la proctolina y la FMRFamida (Kuster \& Davey, 1986; Lange, 1990; Sevala et al., 1992). De hecho, se ha demostrado que las espermatecas se encuentran invervadas por axones que transportan dichas neurohormonas (Lange 1990; Sedra \& Lange, 2014). Por otro lado, la liberación de los mismos podría estar controlada mediante otros mecanismos que garanticen su presencia en el momento en el que el huevo se encuentre el útero. Recientemente se ha estudiado la existencia de una vía neuronal que controla la eyección y el almacenamiento del esperma en hembras de D. melanogaster. Esto sería regulado por la hormona diurética 44 sintetizada por neuronas del cerebro, en cuya ausencia se ve alterada la liberación de los espermatozoides hacia el útero (Lee et al., 2015). Para esclarecer si efectivamente AT pudiera ser sintetizada por las glándulas accesorias del macho, realizamos una primera aproximación mediante inmunohistoquímica y microscopia de barrido laser confocal, pero no pudimos observar la presencia del péptido. Si bien no podemos descartar hasta el momento que AT sea secretada por el sistema reproductor del macho durante algún período fisiológico específico que no hemos tenido en cuenta, quizás el péptido sea producido por la hembra, siendo estimulada su secreción como consecuencia de la cópula.

La última porción conductora del SRH, la bursa, mostró movimientos erráticos durante los tratamientos realizados sobre las hembras ayunadas vírgenes y copuladas. Dicha actividad descripta por Chiang \& O’Donnell (2009), no pudo ser registrada durante los tratamientos ya que no era posible reconocer un patrón identificable que pudiera ser contabilizado mediante la metodología aquí presentada. Por otro lado, en las hembras grávidas fue identificado un claro cambio en el comportamiento de la pared muscular de la bursa, donde se reconocieron y contabilizaron contracciones peristálticas en el momento cercano a la oviposición, las cuales se direccionan hacia el aparato ovopositor (dirección anteroposterior). AT demostró tener actividad sobre las fibras musculares de este órgano, incrementando la frecuencia de las ondas peristálticas de manera dosis dependiente. Las contracciones espontáneas de la bursa están descriptas como débiles, en comparación con otros órganos del sistema, y espaciadas en el 
tiempo, durando cada una de ellas entre 30 y 60 segundos (Sedra \& Lange, 2014). Es por ello que el registro en número de las mismas es bajo. Además, la ovisiposición per se respondería a un control circadiano en las hembras de $R$. prolixus, donde el mayor número de huevos son puestos durante la noche, posiblemente controlado por el sistema neuroendocrino (Ampleford \& Davey, 1989). Sería factible que en ese momento se registre una frecuencia aún mayor de las ondas peristálticas de la bursa por la actividad de AT. Este órgano no solo parece ser susceptible a AT, sino que también responde aumentando su tono basal de manera dosis dependiente ante la aplicación de FMRFamida (Sedra \& Lange, 2014).

Sin dudas, la cópula y la ingesta son eventos que modifican la fisiología de los órganos que componen el sistema reproductor de las hembras de $R$. prolixus. Además, condicionan el inicio de la vitelogénesis, el desarrollo de los ovocitos, así como su viabilidad (Lutz \& Huebner, 1980; Davey et al., 1986; Davey \& Singleton, 1989). Se ha registrado en hembras de $D$. melanogaster, que la cópula intervendría en la remodelación del tejido muscular de los oviductos. Utilizando microscopía electrónica y de barrido confocal, se identificaron cambios en el tejido tales como diferenciación de las uniones celulares, remodelación de la matriz extracelular, aumento de la formación de miofibrillas así como de inervación en la pared de los oviductos (Kapelnikov et al., 2008). Si algo similar ocurriese en el SRH de R. prolixus, sería una de las explicaciones por las cuales el tejido muscular respondería ante la presencia de AT. Otra posibilidad que explicaría el accionar diferencial de AT sobre los órganos del SRH sería que a causa del estímulo de la cópula se genere un aumento en la expresión de su receptor. Como primera aproximación para responder esta hipótesis, decidimos cuantificar la expresión del mismo, mediante PCR cuantitativa. Para ello se utilizó como moldes de la reacción cDNA del sistema reproductor completo perteneciente a hembras ayunadas, vírgenes y copuladas. Los resultados no mostraron diferencias significativas en la presencia del receptor entre ninguna de las tres condiciones analizadas (datos no presentados). Como se detalló anteriormente, cada uno de los órganos respondió de manera diferente ante la presencia del péptido. Es por ello que proponemos continuar investigando mediante esta técnica, incluyendo esta última variable, pero analizando de manera individual cada órgano, es decir, obteniendo el cDNA de cada uno de ellos en cada circunstancia analizada.

La actividad mioinhibitora de AST-C fue evaluada sobre el SRH grávidas. Si bien la frecuencia de contracción de todos los órganos fue registrada (datos no presentados), únicamente observamos cambios estadísticamente significativos a nivel de los ovarios, cuya frecuencia basal, que se encontraba a valores máximos, disminuyó significativamente durante el registro. Ha sido previamente reportado por otros autores que otras neurohormonas, como 
el péptido mioinhibidor tipo 4 y la AST-A tipo 2, modulan negativamente los oviductos de hembras de $R$. prolixus in vitro (Sedra et al., 2015), mostrando incluso, que el primero se encuentra presente en nervios que llegan a la pared tanto de los oviductos como del útero (Lange et al., 2012) por lo que AST-C podría estar interactuando con dichos péptidos en los mecanismos que modulan negativamente las contracciones en otros órganos del sistema reproductor de la hembra. El análisis de AST-C como péptido mioinhibidor a nivel del sistema reproductor no ha sido analizado exhaustivamente en ninguna especie de insectos. En $T$. castaneum, el ensayo de AST-C como péptido mioinhibidor en oviductos aislados no produjo resultados (Audsley et al., 2013). Por otro lado, en el lepidóptero S. frugiperda, se demostró que los genes tanto de AST-C como el de AT, se expresan a nivel de los sistemasreproductores de machos y hembras, donde los autores proponen que cumplirían funcionesmio-reguladoras (Abdel-latief et al., 2004). Recientemente, ha sido comunicado también, quelainhibición de la actividad de neuronas productoras de AST-C produce una disminución de lapuesta de huevos en D. melanogaster (Zhang \& Kim, 2016).

Con el objeto de corroborar la actividad fisiológica de los dos péptidos analizados, realizamos la caracterización genómica de los mismos en $R$. prolixus, y analizamos la expresión de los receptores de AT y AST-C, corroborando que los mismos se encuentran expresados en los sistemas analizados a lo largo de este trabajo.

Mediante los alineamientos múltiples, observamos que Rp-ATr y Rp-AST-Cr comparten un alto grado de similitud con los receptores de otros insectos pertenecientes a especies de holometábolos y hemimetábolos (Vuerinckx et al., 2011; Horodyski et al., 2011; Nouzova et al., 2012; Verlinden et al., 2013; Lismont et al., 2015).

Respecto de Rp-ATr, el alineamiento múltiple obtenido muestra un alto grado de conservación del dominio 7TM (YAN-SCAN $[V / I / T]$ P). Esta secuencia de aminoácidos es considerada un patrón que identifica a los receptores de orexina (Voisin et al., 2003). Esta secuencia no solo se encuentra conservada en insectos sino también en organismo ancestrales como los cnidarios (Alzugaray et al., 2013; Alzugaray \& Ronderos, 2017). Mediante análisis bioinformáticos de más de 200 secuencias de receptores orexina/AT, que representan a todos los Metazoa, se observó que la secuencia asociada a 3TM (DRWYAI) se encuentra altamente conservada, desde el Phyllum Placozoa hasta el Phyllum Chordata, y podría ser considerado como una secuencia que represente a esta familia de receptores (Ronderos et al., 2016). Esta misma secuencia se encontró totalmente conservada en nuestro análisis. Aunque AT y orexina no están estructuralmente relacionadas, es interesante que ambos péptidos estén implicados 
en la regulación de eventos que tienen lugar durante la alimentación, concluyendo que probablemente sus receptores comparten un ancestro común (Alzugaray et al., 2013; Alzugaray \& Ronderos, 2017).

De igual manera, se analizó la secuencia del RpAST-Cr, el cual muestra todas las características de la familia de receptores de la somatostatina/AST-C, incluyendo la secuencia altamente conservada del dominio 7TM (YSNSAMNPILYA), patrón que identifica a esta familia (Mayoral et al., 2010; Olias et al., 2004). Tanto el patrón distintivo de este dominio y la secuencia $D R Y$ ubicada en el segundo dominio intracelular, se encuentran conservados en las secuencias de insectos homólogas utilizadas en el alineamiento múltiple. La caracterización genómica de AST-Cr ya había sido descripta en otros insectos holometábolos, como $D$. melanogaster, B. mori, A. aegypti, T. castaneum (Yamanaka et al., 2008; Kreienkamp et al., 2002; Mayoral et al., 2010; Audsley et al., 2013). Hay evidencias de que probablemente este receptor se origine tempranamente en la evolución, ya que la secuencia de aminoácidos del dominio 7TM de insectos comparte un alto porcentaje de identidad y similitud con organismos ancestrales como los cnidarios (Alzugaray et al., 2016). 
Conclusiones y Perspectivas futuras 
Los resultados obtenidos a partir de nuestras investigaciones aportan conocimientos en cuanto a la caracterización genómica y funcional de dos neuropéptidos pleiotrópicos, Allatotropina y Allatostatina-C, y su actividad como mio-reguladores en el insecto vector del Mal de Chagas, Rhodnius prolixus. Los mismos han demostrado su capacidad de estimular o inhibir la musculatura visceral en momentos críticos de su biología, como lo son los procesos de diuresis post ingesta, el proceso de vitelogénesis y la puesta de huevos. En este trabajo no solo se recurrió al desarrollo de ensayos experimentales, sino que además realizamos aportes sobre la caracterización genómica de los receptores de ambos péptidos, utilizando diferentes metodologías del campo de la biología molecular.

Ambas neurohormonas mostraron estar implicadas en la actividad muscular del tubo digestivo medio anterior (buche) y de la aorta durante la diuresis post ingesta, proceso importante de comprender ya que es allí donde se produce la transmisión del parásito $T$. cruzi al humano y a los organismos que actúan como reservorio del mismo. Demostramos que AT y AST-C se encuentran regulando de manera conjunta la actividad muscular de los sistemas en estudio, donde AST-C antagoniza el efecto estimulador de AT; reafirmando además, el efecto sinergístico de este último sobre la serotonina, a nivel de la actividad del vaso dorsal. De este modo, podemos sugerir que AT actúa incrementando la velocidad de circulación de la hemolinfa tanto en sentido anteroposterior (aumentando la tasa de contracciones peristálticas del buche), como en sentido posteroanterior a través del incremento de la frecuencia de contracciones del vaso dorsal, facilitando de este modo la distribución de neurohormonas que modulan la producción de orina a nivel de los túbulos de Malpighi y el funcionamiento de los mismos.

Siendo un objetivo primario en este trabajo profundizar los conocimientos sobre la actividad miomoduladora de ambos péptidos, nuevamente, AT y AST-C demostraron ser capaces de regular la frecuencia de contracción de la musculatura de cada uno de los órganos del SRH, siendo su accionar claramente dependiente del periodo gonadotrófico, pudiendo estar implicados en los mecanismos de control de almacenamiento y liberación de los espermatozoides así como de la movilización de los ovocitos en desarrollo.

A raíz de la caracterización funcional de AT y AST-C llevada a cabo en el presente estudio, nos es de interés conocer los mecanismos de acción por los cuales estos péptidos intervienen como miomoduladores. Conocer la distribución de la expresión de RpATr y RpASTCr y contribuir con conocimientos sobre la caracterización genómica de los mismos, abre las puertas para continuar con la caracterización funcional en profundidad. Esto puede realizarse 
mediante el silenciamiento de la expresión de los receptores, lo cual facilitaría el análisis de sus funciones asociadas a los péptidos. Es sumamente interesante abordar la caracterización funcional de los GPCRs por ser considerados como potenciales alternativas para desarrollar nuevos agentes selectivos para el control de plagas.

AT y AST-C, fueron caracterizados en primera instancia por tener la capacidad de regular la síntesis de hormonas juveniles a nivel de la corpora allata en insectos. Sin embargo, la función de estimular o inhibir la producción de esta hormona sería una función derivada en este grupo de organismos, mientras que se ha propuesto que su función ancestral estaría asociada a la regulación de la actividad de la musculatura visceral asociada a los movimientos relacionados con la ingesta. En organismos como la Hydra sp., se ha comprobado la presencia de AT y AST-C, así como sus funciones regulando los movimientos que se llevan a cabo durante el momento de la alimentación. Recientemente, se han profundizado los estudios sobre los mecanismos de regulación del $\mathrm{Ca}^{+2}$ que provocarían estos péptidos sobre esta especie, en dicho momento. El uso de tapsigargina nos ha permitido comenzar a comprender los probables mecanismos de la regulación de segundos mensajeros, como el $\mathrm{Ca}^{+2}$, en presencia de AST-C en el VD y el buche. Con el objeto de progresar sobre la caracterización de la cascada de señales que se activarían en presencia de AT y AST-C en las células musculares del VD, proponemos realizar experimentos fisiológicos para aproximarnos a comprender los mecanismos que utiliza AT sobre la mioestimulación de este órgano, cuyo protagonismo en la recirculación de la hemolinfa es primordial. Es por ello que presentamos un proyecto de investigación para llevar a cabo en una etapa post doctoral, cuyo principal objetivo es analizar la importancia de los niveles de $\mathrm{Ca}^{+2}$ citosólico como mediador de la respuesta de los tejidos involucrados en el accionar del péptido AT. Planteamos el uso de diferentes compuesto que bloquean el accionar de los canales que permiten el ingreso y egreso del ion $\mathrm{Ca}^{+2}$ en el citoplasma de las células. Nuevamente, proponemos utilizar el mismo modelo experimental utilizando machos adultos, cuya frecuencia de contracción de la aorta es claramente modulada por las hormonas en estudio, que además se encuentra ya estandarizado en nuestro laboratorio. En consecuencia, será de utilidad para estudiar los mecanismos de regulación en pos de producir información de alta calidad que abrirán las puertas para el desarrollo de nuevos análisis, como la caracterización genómica y funcional de los distintos tipos de proteínas involucradas en el metabolismo de $\mathrm{Ca}^{+2}$ durante la contracción muscular.

En base a los resultados obtenidos en este trabajo de investigación se abren nuevos interrogantes, permitiéndonos plantear perspectivas a futuro, no sólo en cuanto al estudio de los mecanismos de regulación de segundos mensajeros en presencia de los péptidos, sino 
también en cuanto a la probable interacción de AT y AST-C con otros neuropéptidos a nivel del sistema reproductor de la hembra. Algunos autores han propuesto que ciertos componentes sintetizados en las glándulas accesorias del macho son los responsables de las modificaciones que suceden, no solo a nivel comportamental de la hembra, sino también en cuanto a cambios del control neuroendocrino (Kuster \& Davey, 1986; Gillott, 2003; Ravi Ram et al., 2005; Dottorini et al., 2007). A raíz de estos compuestos se activaría la síntesis de ciertos péptidos, como la FMRFamida en $R$. prolixus, al cual se le adjudica la activación de la movilidad de los ovarios (Kriger \& Davey, 1982). Investigaciones realizadas en dípteros proponen que el mecanismo de la cópula per se desencadenaría también cambios en la fisiología de la hembra (Abraham et al., 2014). Teniendo en cuenta que la actividad de AT y AST-C dependen del status reproductivo modulado por la cópula y la ingesta de alimento, sería interesante abrir nuevas líneas de investigación abocadas en estudiar la probable existencia de una interacción funcional entre los neuropéptidos aquí estudiados y otros, como la FMRFamida, sobre la actividad muscular de este sistema en relación a su fisiología reproductiva.

En resumen, así como en los años '30, R. prolixus continúa siendo fuente de estudios fehacientes para comprender la fisiología de insectos, los cuales pueden derivarse a otros organismos no relacionados directamente como lo son los Cnidarios. Utilizando de manera conjunta distintas metodologías, como la experimentación, la bioinformática y la biología molecular hemos realizado un estudio sobre la caracterización funcional de dos neurohormonas pleiotrópicas. La expresión de sus receptores en órganos donde cumplen su rol como miomoduladores confirman este accionar en procesos vitales como los es la ingesta y la reproducción. Relacionando los resultados aquí presentados nos permite formular nuevas preguntas sobre aquello que desencadenan distintos eventos en la biología de los insectos (la cópula y la ingesta de alimento), así como los mecanismos que regulan estos péptidos en el metabolismo de las células. 


\section{BIBLIOGRAFÍA}

Abdel-latief, M., Meyering-Vos, M., Hoffmann, K.H., 2004. Expression and localization of the Spodoptera frugiperda allatotropin (Spofr-AT) and allatostatin (Spofr-AS) genes. Arch. Insect Biochem. Physiol. 55, 188-199.

Abdel-Latief, M., Meyering-Vos, M., Hoffmann, K.H., 2003. Molecular characterisation of cDNAs from the fall armyworm Spodoptera frugiperda encoding Manduca sexta allatotropin and allatostatin preprohormone peptides. Insect Biochem. Mol. Biol. 33, 467-476.

Abraham, S., Nuñez-Beverido, N., Contreras-Navarro, Y., Pérez-Staples, D., 2014. Female receptivity in Anastrepha ludens (Diptera: Tephritidae) is not modulated by male accessory gland products. J. Insect Physiol. 70, 41-48.

Adami, M.L., Damborenea, C., Ronderos, J.R., 2012. An allatotropin-like neuropeptide in Mesostoma ehrenbergii (Rhabdocoela, Platyhelminthes). Zoomorphology 131, 1-9.

Adami, M.L., Damborenea, C., Ronderos, J.R., 2011. Expression of a neuropeptide similar to allatotropin in free living turbellaria (platyhelminthes). Tissue Cell 43, 377-383.

Ahn, S.-J., Martin, R., Rao, S., Choi, M.-Y., 2017. Neuropeptides predicted from the transcriptome analysis of the gray garden slug Deroceras reticulatum. Peptides 93, 51-65.

Allingham, P.G., Kerlin, R.L., Tellam, R.L., Briscoe, S.J., Standfast, H.A., 1992. Passage of host immunoglobulin across the mid-gut epithelium into the haemolymph of blood-fed buffalo flies Haematobia irritans exigua. J. Insect Physiol. 38, 9-17.

Alzugaray, M.E., Adami, M.L., Diambra, L.A., Hernandez-Martinez, S., Damborenea, C., Noriega, F.G., Ronderos, J.R., 2013. Allatotropin: an ancestral myotropic neuropeptide involved in feeding. PLoS One 8, e77520.

Alzugaray, M.E., Hernández-martínez, S., Rafael, J., 2016. Somatostatin signaling system as an ancestral mechanism : Myoregulatory activity of an Allatostatin-C peptide in Hydra. Peptides 82, 67-75.

Alzugaray, M.E., Ronderos, J.R., 2017. Allatoregulatory-like systems and changes in cytosolic $\mathrm{Ca}^{2+}$ modulate feeding behavior in Hydra. Gen. Comp. Endocrinol. En prensa. 
Ampleford, E.J., Davey, K.G., 1989. Egg laying in the insect Rhodnius is timed in a circadian fashion. J. Insect Physiol. 35, 183-187.

Atella, G.C., Gondim, K.C., Machado, E.A., Medeiros, M.N., Masuda, H., 2005. Oogenesis and egg development in triatomines: a biochemical approach. An. Acad. Bras. Cienc. 77, 405430.

Audsley, N., Jensen, D., Schooley, D. a., 2013. Signal transduction for Schistocerca gregaria ion transport peptide is mediated via both cyclic AMP and cyclic GMP. Peptides 41, 74-80.

Audsley, N., Vandersmissen, H.P., Weaver, R., Dani, P., Matthews, J., Down, R., Vuerinckx, K., Kim, Y.-J., Vanden Broeck, J., 2013. Characterisation and tissue distribution of the PISCF allatostatin receptor in the red flour beetle, Tribolium castaneum. Insect Biochem. Mol. Biol. 43, 65-74.

Audsley, N., Weaver, R.J., 2009. Neuropeptides associated with the regulation of feeding in insects. Gen. Comp. Endocrinol. 162, 93-104.

Audsley, N., Weaver, R.J., Edwards, J.P., 2000. Juvenile hormone biosynthesis by corpora allata of larval tomato moth, Lacanobia oleracea, and regulation by Manduca sexta allatostatin and allatotropin. Insect Biochem. Mol. Biol. 30, 681-689.

Avila, F.W., Sirot, L.K., LaFlamme, B. a, Rubinstein, C.D., Wolfner, M.F., 2011. Insect seminal fluid proteins: identification and function. Annu. Rev. Entomol. 56, 21-40.

Baldini, F., Gabrieli, P., Rogers, D.W., Catteruccia, F., 2012. Function and composition of male accessory gland secretions in Anopheles gambiae: a comparison with other insect vectors of infectious diseases. Pathog. Glob. Health 106, 82-93.

Barrett, F.M., 1982. Absorption of fluid from the anterior midgut in Rhodnius. J. Insect Physiol. 28, 335-341.

Bendena, W.G., Donly, B.C., Tobe, S.S., 1999. Allatostatins: a growing family of neuropeptides with structural and functional diversity. Annu. New York Acad. Sci. 897, 311-329.

Bendena, W.G., Tobe, S.S., 2012. Families of allatoregulator sequences : a 2011 perspective. Can. J. Zoll. 90, 521-544.

Beyenbach, K.W., 2003. Transport mechanisms of diuresis in Malpighian tubules of insects. J. Exp. Biol. 206, 3845-3856. 
Burgos, M.H., Gutiérrez, L.S., 1976. The intestine of Triatoma infestans. I. Cytology of the midgut. J. Ultrasructure Res. 57, 1-9.

Burgos, L.S., Gutierrez, M.H., 1978. The Intestine of Triatoma infestans II. The surface coat of the midgut. J. Ultrasructure Res. 63, 244-251.

Buxton, P.A., 1930. The Biology of a Blood-sucking Bug, Rhodnius prolixus. Ecol. Entomol. 78, 227-256.

Caers, J., Verlinden, H., Zels, S., Vandersmissen, H.P., Vuerinckx, K., Schoofs, L., 2012. More than two decades of research on insect neuropeptide GPCRs: an overview. Front. Endocrinol. (Lausanne). 3, 151.

Cardinal-Aucoin, M., Rapp, N., Steel, C.G.H., 2013. Circadian regulation of hemolymph and ovarian ecdysteroids during egg development in the insect Rhodnius prolixus (Hemiptera). Comp. Biochem. Physiol. Part A. 166, 503-509.

Chiang, R., Chiang, J., Hoogendoorn, H., Lima, M., 2013. Exploring the role of Rhodtestolin, a cardio-inhibitor from the testes of Rhodnius prolixus, in relation to the structure and function of reproductive organs in insect vectors of Chagas disease. Insects 4, 593-608.

Chiang, R.G., 2010. Functional anatomy of the vagina muscles in the adult western conifer seed bug, Leptoglossus occidentalis (Heteroptera: Coreidae), and its implication for the egg laying behaviour in insects. Arthropod Struct. Dev. 39, 261-7.

Chiang, R.G., Chiang, J.A., Davey, K.G., 1992. A sensorory input inhibiting heart rate in an insect, Rhodnius prolixus. Experientia 48, 1122-1125.

Chiang, R.G., Chiang, J. a, Davey, K.G., 1990. Morphology of the dorsal vessel in the abdomen of the blood-feeding insect Rhodnius prolixus. J. Morphol. 204, 9-23.

Chiang, R.G., Chiang, J. a, Sarquis, O., Lima, M.M., 2012. Morphology of reproductive accessory glands in eight species of blood-feeding Hemiptera (Hemiptera, Reduviidae) insect vectors of Chagas disease. Acta Trop. 122, 196-204.

Chiang, R.G., O'Donnell, M.J., 2009. Functional anatomy of vagina muscles in the blood-feeding insect, Rhodnius prolixus. Arthropod Struct. Dev. 38, 499-507.

Christie, A.E., 2014. Peptide discovery in the ectoparasitic crustacean Argulus siamensis: Identification of the first neuropeptides from a member of the Branchiura. Gen. Comp. 
Endocrinol. 204, 114-125.

Clynen, E., Huybrechts, J., Verleyen, P., De Loof, A., Schoofs, L., 2006. Annotation of novel neuropeptide precursors in the migratory locust based on transcript screening of a public EST database and mass spectrometry. BMC Genomics 7, 201.

Coast, G.M., Garside, C.S., 2005. Neuropeptide control of fluid balance in insects. Annu. New York Acad. Sci. 1040, 1-8.

Dasari, S., Cooper, R., 2006. Direct influence of serotonin on the larval heart of Drosophila melanogaster. J. Comp. Physiol B 176, 349-357.

Davey, K., 2007. The interaction of feeding and mating in the hormonal control of egg production in Rhodnius prolixus. J. Insect Physiol. 53, 208-215.

Davey, K., 1959. Spermatophore production in Rhodnius prolixus. Q. J. Microsc. Sci. 100, 221230.

Davey, K.G., 1993. Hormonal Integration of Egg Production in Rhodnius prolixus. Am. Zool. 33, 397-402.

Davey, K.G., 1967. Some Consequences of copulation Rhodnius prolixus. J. Insect Physiol. 13, 1629-1636.

Davey, K.G., 1958. The migration of spermatozoa in the female of Rhodnius prolixus Stal. J Exp Biol 35, 694-701.

Davey, K.G., Kriger, F.L., 1985. Variations during the gonotrophic cycle in the titer of the myotropic ovulation hormone and the response of the ovarian muscles in Rhodnius prolixus. Gen. Comp. Endocrinol. 58, 452-457.

Davey, K.G., Maimets, I.K., Ruegg, R.P., 1986. The relationship between crop size and egg production in Rhodnius prolixus. Can. J. Zool. 64, 2654-2657.

Davey, K.G., Singleton, D.M., 1989. Activation of egg production and the corpus allatum without feeding in the adult female of the insect Rhodnius prolixus. Invertebr. Reprod. Dev. 16, 131-134.

Davey, K.G., Webster, G.F., 1967. The structure and secretion of the spermatheca of Rhodnius prolixus Stäl: a Histochemical Study. Can. J. Zool. 45, 653-659. 
de la Vega, G.J., Medone, P., Ceccarelli, S., Rabinovich, J., Schilman, P.E., 2015. Geographical distribution, climatic variability and thermo-tolerance of Chagas disease vectors. Ecography (Cop.). 38, 851-860.

Donini, a, Agricola, H., Lange, A., 2001. Crustacean cardioactive peptide is a modulator of oviduct contractions in Locusta migratoria. J. Insect Physiol. 47, 277-285.

Dottorini, T., Nicolaides, L., Ranson, H., Rogers, D.W., Crisanti, A., Catteruccia, F., 2007. A genome-wide analysis in Anopheles gambiae mosquitoes reveals 46 male accessory gland genes, possible modulators of female behavior. Proc. Natl. Acad. Sci. U. S. A. 104, 1621516220.

Dubrovsky, E.B., 2005. Hormonal cross talk in insect development. Trends Endocrinol. Metab. $16,6-11$.

Duve, H., Audsley, N., Weaver, R.J., Thorpe, A., 2000. Triple co-localisation of two types of allatostatin and an allatotropin in the frontal ganglion of the lepidopteran Lacanobia oleracea (Noctuidae): Innervation and action on the foregut. Cell Tissue Res. 300, 153163.

Duve, H., East, P.D., Thorpe, A., 1999. Regulation of lepidopteran foregut movement by allatostatins and allatotropin from the frontal ganglion. J. Comp. Neurol. 413, 405-416.

Duve, H., Thorpe, A., 2005. Neuropeptide co-localisation in the lepidopteran frontal ganglion studied by electron-microscopic gold-labelling immunocytochemistry. Cell Tissue Res. 320, 187-199.

Friedel, T., Gillott, C., 1976. Male Accessory Gland substance of Melanoplus sanguinipes: An oviposition stimulant under the control of the Corpus Allatum. J. Insect Physiol. 22, 489495.

Fusca, D., Schachtner, J., Kloppenburg, P., 2015. Colocalization of allatotropin and tachykininrelated peptides with classical transmitters in physiologically distinct subtypes of olfactory local interneurons in the cockroach (Periplaneta americana). J. Comp. Neurol. $523,1569-1586$.

Gillott, C., 2003. Male accessory gland secretions: modulators of female reproductive physiology and behavior. Annu. Rev. Entomol. 48, 163-84.

Gold, S.M.W., Davey, K.G., 1989. The Effect of Juvenile Hormone on protein synthesis in the 
transparent accessory gland of male Rhodnius prolixus. Insect Biochem. 19, 139-143.

Gonzalez, R., Orchard, I., 2009. Physiological activity of neuropeptide F on the hindgut of the blood-feeding hemipteran, Rhodnius prolixus. J. Insect Sci. 9, 1-14.

Goodman, W.G., Cusson, M., 2012. 8 - The Juvenile Hormones, in: Insect Endocrinology. Elsevier, pp. 310-365.

Hashimoto, K., Schofield, C.J., 2012. Elimination of Rhodnius prolixus in Central America. Parasit. Vectors 5.

Hauser, F., Neupert, S., Williamson, M., Predel, R., Tanaka, Y., Grimmelikhuijzen, C.J.P., 2010. Genomics and peptidomics of neuropeptides and protein hormones present in the parasitic wasp Nasonia vitripennis. J. Proteome Res. 9, 5296-5310.

Henikoff, S., Henikoff, J.G., 1992. Amino acid substitution matrices from protein blocks. Proc. Natl. Acad. Sci. U. S. A. 89, 10915-10919.

Hernández-Martínez, S., Li, Y., Lanz-Mendoza, H., Rodríguez, M.H., Noriega, F.G., 2005. Immunostaining for allatotropin and allatostatin-A and -C in the mosquitoes Aedes aegypti and Anopheles albimanus. Cell Tissue Res. 321, 105-113.

Hernández-Martínez, S., Sanchez-Zavaleta, M., Brito, K., Herrera-Ortiz, A., Ons, S., Noriega, F.G., 2017. Allatotropin: A pleiotropic neuropeptide that elicits mosquito immune responses. PLoS One 12, 1-21.

Hertel, W., Pass, G., 2002. An evolutionary treatment of the morphology and physiology of circulatory organs in insects. Comp. Biochem. Physiol. - A Mol. Integr. Physiol. 133, 555575.

Hewes, R.S., Taghert, P.H., 2001. Neuropeptides and neuropeptide receptors in the Drosophila melanogaster genome. Genome Res. 11, 1126-1142.

Hillyer, J.F., Estévez-Lao, T.Y., Mirzai, H.E., 2015. The neurotransmitters serotonin and glutamate accelerate the heart rate of the mosquito Anopheles gambiae. Comp. Biochem. Physiol. Part A Mol. Integr. Physiol. 188, 49-57.

Homberg, U., Reischig, T., Stengl, M., 2003. Neural organization of the circadian system of the cockroach Leucophaea maderae. Chronobiol. Int. 20, 577-591.

Horodyski, F.M., Verlinden, H., Filkin, N., Vandersmissen, H.P., Fleury, C., Reynolds, S.E., Kai, Z., 
Broeck, J. Vanden, 2011. Isolation and functional characterization of an allatotropin receptor from Manduca sexta. Insect Biochem. Mol. Biol. 41, 804-814.

Huebner, E., Anderson, E., 1972. A cytological study of the ovary. II. Oocyte differentiation. J. Morph 137, 385-416.

Hummon, A.B., Richmond, T. a, Verleyen, P., Baggerman, G., Huybrechts, J., Ewing, M. a, Vierstraete, E., Rodriguez-Zas, S.L., Schoofs, L., Robinson, G.E., Sweedler, J. V, 2006. From the genome to the proteome: uncovering peptides in the Apis brain. Science (80-. ). 314, 647-649.

Huser, A., Eschment, M., Güllü, N., Collins, K.A.N., Böpple, K., Pankevych, L., Rolsing, E., Thum, A.S., 2017. Anatomy and behavioral function of serotonin receptors in Drosophila melanogaster larvae. PLoS One 12, e0181865.

Insausti, T.C., 1994. Nervous system of Triatoma infestans. J. Morphol. 121, 343-359.

Jansons, I.S., Cusson, M., McNeil, J.N., Tobe, S.S., Bendena, W.G., 1996. Molecular characterization of a cDNA from Pseudaletia unipuncta encoding the Manduca sexta allatostatin peptide (Mas-AST). Insect Biochem. Mol. Biol. 26, 767-773.

Kapelnikov, A., Rivlin, P.K., Hoy, R.R., Heifetz, Y., 2008. Tissue remodeling: a mating-induced differentiation program for the Drosophila oviduct. BMC Dev. Biol. 8, 114.

Kastin, A.J., 2013. Handbook of Biologically Active Peptides, Elsevier. ed. San Diego. EEUU.

Kataoka, H., Troetschler, R.G., Li, J.P., Kramer, S.J., Carney, R.L., Schooley, D. a., 1989. Isolation and identification of a diuretic hormone from the tobacco hornworm, Manduca sexta. Proc. Natl. Acad. Sci. U. S. A. 86, 2976-2980.

Kierszenbaum, A.F., Gottlieb, C.A., Budzko, D.B., 1981. Antibody-independent, natural resistance of birds to Trypanosoma cruzi infection. J. Parasitol. 67, 656-660.

Klowden, M.J., 2013. Physiological Systems in Insects, 3 edition. ed. Elsevier, Burlington USA.

Koladich, P.M., Cusson, M., Bendena, W.G., Tobe, S.S., McNeil, J.N., 2002. Cardioacceleratory effects of Manduca sexta allatotropin in the true armyworm moth, Pseudaletia unipuncta. Peptides 23, 645-651.

Körner, M., Reubi, J.C., 2013. Handbook of Biologically Active Peptides, Handbook of Biologically Active Peptides. 
Koziol, U., Koziol, M., Preza, M., Costábile, A., Brehm, K., Castillo, E., 2016. De novo discovery of neuropeptides in the genomes of parasitic flatworms using a novel comparative approach. Int. J. Parasitol. 46, 709-721.

Kramer, S.J., Toschi, A., Miller, C. a, Kataoka, H., Quistad, G.B., Li, J.P., Carney, R.L., Schooley, D. a, 1991. Identification of an allatostatin from the tobacco hornworm Manduca sexta. Proc. Natl. Acad. Sci. U. S. A. 88, 9458-9462.

Kreienkamp, H.J., Larusson, H.J., Witte, I., Roeder, T., Birgül, N., Hönck, H.H., Harder, S., Ellinghausen, G., Buck, F., Richter, D., 2002. Functional annotation of two orphan Gprotein-coupled receptors, drostar1 and -2, from Drosophila melanogaster and their ligands by reverse pharmacology. J. Biol. Chem. 277, 39937-39943.

Kriger, F.L., Davey, K.G., 1984. Identified neurosecretory cells in the brain of female Rhodnius prolixus contain a myotropic peptide. Can. J. Zool. 62, 3-6.

Kriger, F.L., Davey, K.G., 1982. Ovarian motility in mated Rhodnius prolixus requires an intact cerebral neurosecretory system. Gen. Comp. Endocrinol. 48, 130-134.

Kuster, J.E., Davey, K.G., 1986. Mode of action of cerebral neurosecretory cells on the function of the spermatheca in Rhodnius prolixus. Int. J. Invertebr. Reprod. Dev. 10, 59-69.

Lange, A.B., 2009. The female reproductive system and control of oviposition in Locusta migratoria. Can. J. Zool. 87, 649-661.

Lange, A.B., 1990. The presence of proctolin in the reproductive system of Rhodnius prolixus. J. Insect Physiol. 36, 345-351.

Lange, A.B., Alim, U., Vandersmissen, H.P., Mizoguchi, A., Vanden Broeck, J., Orchard, I., 2012. The distribution and physiological effects of the myoinhibiting peptides in the kissing bug, Rhodnius prolixus. Front. Neurosci. 6, 98.

Lee, D., Taufique, H., da Silva, R., Lange, A.B., 2012. An unusual myosuppressin from the bloodfeeding bug Rhodnius prolixus. J. Exp. Biol. 215, 2088-2095.

Lee, D.H., Lange, A.B., 2011. Crustacean cardioactive peptide in the Chagas' disease vector, Rhodnius prolixus: presence, distribution and physiological effects. Gen. Comp. Endocrinol. 174, 36-43.

Lee, K.-M., Daubnerová, I., Isaac, R.E., Zhang, C., Choi, S., Chung, J., Kim, Y.-J., 2015. A neuronal 
pathway that controls sperm ejection and storage in female Drosophila. Curr. Biol. 25, 790-797.

Lee, K.Y., Horodyski, F.M., Chamberlin, M.E., 1998. Inhibition of midgut ion transport by allatotropin (Mas-AT) and Manduca FLRFamides in the tobacco hornworm Manduca sexta. J. Exp. Biol. 201, 3067-3074.

Li, B., Predel, R., Neupert, S., Hauser, F., Tanaka, Y., Cazzamali, G., Williamson, M., Arakane, Y., Verleyen, P., Schoofs, L., Schachtner, J., Grimmelikhuijzen, C.J.P., Park, Y., 2008. Genomics, transcriptomics, and peptidomics of neuropeptides and protein hormones in the red flour beetle Tribolium castaneum. Genome Res. 18, 113-122.

Li, Y., Hernandez-Martinez, S., Fernandez, F., Mayoral, J.G., Topalis, P., Priestap, H., Perez, M., Navare, A., Noriega, F.G., 2006. Biochemical, molecular, and functional characterization of PISCF-allatostatin, a regulator of juvenile hormone biosynthesis in the mosquito Aedes aegypti. J. Biol. Chem. 281, 34048-55.

Li, Y., Hernandez-Martinez, S., Noriega, F.G., 2004. Inhibition of juvenile hormone biosynthesis in mosquitoes: Effect of allatostatic head factors, PISCF- and YXFGL-amide-allatostatins. Regul. Pept. 118, 175-182.

Li, Y., Unnithan, G.C., Veenstra, J. a, Feyereisen, R., Noriega, F.G., 2003. Stimulation of JH biosynthesis by the corpora allata of adult female Aedes aegypti in vitro: effect of farnesoic acid and Aedes allatotropin. J. Exp. Biol. 206, 1825-1832.

Lismont, E., Vleugels, R., Marchal, E., Badisco, L., Van Wielendaele, P., Lenaerts, C., Zels, S., Tobe, S.S., Vanden Broeck, J., Verlinden, H., 2015. Molecular cloning and characterization of the allatotropin precursor and receptor in the desert locust, Schistocerca gregaria. Front. Neurosci. 9, 1-14.

Lococo, D., Huebner, E., 1980. The ultrastructure of the female accessory-gland, the cement gland, in the insect Rhodnius prolixus. Tissue Cell 12, 557-580.

Lung, O., Wolfner, M.F., 1999. Drosophila seminal fluid proteins enter the circulatory system of the mated female fly by crossing the posterior vaginal wall. Insect Biochem. Mol. Biol. 29, 1043-1052.

Lutz, A., Huebner, E., 1980. Development and cellular differentiation of an insect telotrophic ovary (Rhodnius prolixus). Tissue cell 12, 773-794. 
Lwalaba, D., Hoffmann, K.H., Woodring, J., 2010. Control of the release of digestive enzymes in the larvae of the fall armyworm, Spodoptera frugiperda. Arch. Insect Biochem. Physiol. 73, 14-29.

Maddrell, S.H., O'Donnell, M.J., Caffrey, R., 1993. The regulation of haemolymph potassium activity during initiation and maintenance of diuresis in fed Rhodnius prolixus. J. Exp. Biol. $177,273-285$.

Maddrell, S.H.P., 1963. Excretion in the Blood-Sucking Bug, Rhodnius Prolixus Stäl. I. The control of diuresis. J. Exp. Biol 40, 247-256.

Maddrell, S.H.P., 1964a. Excretion in the blood-sucking bug Rhodnius prolixus Stal. II. The normal course of diuresis and the effect of temperature. J. Exp. Biol. 41, 163-176.

Maddrell, S.H.P., 1964b. Excretion in the Blood-Sucking Bug, Rhodnius Prolixus Stäl. III. The control of the release of the Diuretic Hormone. J. Exp. Biol 41, 459-472.

Maddrell, S.H.P., 1966a. The site of release of the Diuretic Hormone in Rhodnius - A New Neurohaemal System in Insects. J. Exp. Biol. 45, 499-508.

Maddrell, S.H.P., 1966b. Nervous control of the mechanical properties of the abdominal wall at feeding in Rhodnius. J. Exp. Biol. 44, 59-68.

Maddrell S H P, 1978. Physiological discontinuity in an epithelium with an apparently uniform structure. J. Exp. Biol. 75, 133-146.

Masood, M., Orchard, I., 2014. Molecular characterization and possible biological roles of allatotropin in Rhodnius prolixus. Peptides 53, 159-71.

Matthews, H.J., Audsley, N., Weaver, R.J., 2007. Interactions between allatostatins and allatotropin on spontaneous contractions of the foregut of larval Lacanobia oleracea. J. Insect Physiol. 53, 75-83.

Matthews, H.J., Audsley, N., Weaver, R.J., 2006. Alanine substitution and deletion analogues of Manduca sexta allatostatin: Structure-activity relationship on the spontaneous contractions of the foregut of larval Lacanobia oleracea. J. Insect Physiol. 52, 128-135.

Mayoral, J.G., Nouzova, M., Brockhoff, A., Goodwin, M., Hernandez-Martinez, S., Richter, D., Meyerhof, W., Noriega, F.G., 2010. Allatostatin-C receptors in mosquitoes. Peptides 31, 442-450. 
Medone, P., Ceccarelli, S., Parham, P.E., Figuera, A., Rabinovich, J.E., 2015. The impact of climate change on the geographical distribution of two vectors of Chagas disease : implications for the force of infection. Philos. Trans. R. Soc. Lond. B. Biol. Sci. 370, 20130560.

Mesquita, R.D., Vionette-Amaral, R.J., Lowenberger, C., Rivera-Pomar, R., Monteiro, F. A., Minx, P., Spieth, J., Carvalho, A.B., Panzera, F., Lawson, D., Torres, A.Q., Ribeiro, J.M., Sorgine, M.H., Waterhouse, R.M., Montague, M.J., Abad-Franch, F., Alves- Bezerra, M., Amaral, L.R., Araujo, H.M., Araujo, R.N., Aravind, L., Atella, G.C., Azambuja, P., Berni, M., Bittencourt-Cunha, P.R., Braz, G.R., Calderon-Fernandez, G., Carareto, C.M., Christensen, M.B., Costa, I.R., Costa, S.G.,Dansa, M., Daumas- Filho, C.R., De-Paula, I.F., Dias, F.A., Dimopoulos, G., Emrich, S.J., Esponda- Behrens, N., Fampa, P., Fernandez-Medina, R.D., da Fonseca, R.N., Fontenele, M., Fronick, C., Fulton, L.A., Gandara, A.C., Garcia, E.S., Genta, F.A., Giraldo-Calderon, G.I., Gomes, B., Gondim, K.C., Granzotto, A., Guarneri, A.A., Guigo, R., Harry, M., Hughes, D.S., Jablonka, W., Jacquin-Joly, E., Juarez, M.P., Koerich, L.B., Latorre- Estivalis, J.M., Lavore, A., Lawrence, G.G., Lazoski, C., Lazzari, C.R., Lopes, R.R., Lorenzo, M.G., Lugon, M.D., Majerowicz, D., Marcet, P.L., Mariotti, M., Masuda, H., Megy, K., Melo, A.C., Missirlis, F., Mota, T., Noriega, F.G., Nouzova, M., Nunes, R.D., Oliveira, R.L., Oliveira-Silveira, G., Ons, S., Pagola, L., Paiva-Silva, G.O., Pascual, A., Pavan, M.G., Pedrini, N., Peixoto, A.A., Pereira, M.H., Pike, A., Polycarpo, C., Prosdocimi, F., Ribeiro-Rodrigues, R., Robertson, H.M., Salerno, A. P., Salmon, D., Santesmasses, D., Schama, R., Seabra-Junior, E.S., Silva-Cardoso, L., Silva-Neto, M.A., Souza-Gomes, M., Sterkel, M., Taracena, M.L., Tojo, M., Tu, Z. J., Tubio, J.M., Ursic-Bedoya, R., Venancio, T.M., Walter-Nuno, A.B., Wilson, D., Warren, W.C., Wilson, R.K., Huebner, E., Dotson, E.M., Oliveira, P.L., 2015. Genome of Rhodnius prolixus, an insect vector of Chagas disease, reveals unique adaptations to hematophagy and parasite infection. Proc. Natl. Acad. Sci. USA 112, 14936-14941.

Neckameyer, W.S., 2010. A trophic role for serotonin in the development of a simple feeding circuit. Dev. Neurosci. 32, 217-237.

Nichols, R., 2006. FMRFamide-related peptides and serotonin regulate Drosophila melanogaster heart rate: Mechanisms and structure requirements. Peptides 27, 11301137.

Noriega, F.G., 2014. Juvenile hormone biosynthesis in insects: what is new, what do we know, and what questions remain. Int Sch Res Not. 967361. 
Noriega, F.G., 1992. Autogeny in three species of triatominae: Rhodnius prolixus, Triatoma rubrovaria, and Triatoma infestans. J. Med.entolmol 29, 273-277.

Nouzova, M., Brockhoff, A., Mayoral, J.G., Goodwin, M., Meyerhof, W., Noriega, F.G., 2012. Functional characterization of an allatotropin receptor expressed in the corpora allata of mosquitoes. Peptides 34, 201-208.

Nouzova, M., Rivera-Perez, C., Noriega, F.G., 2015. Allatostatin-C reversibly blocks the transport of citrate out of the mitochondria and inhibits juvenile hormone synthesis in mosquitoes. Insect Biochem. Mol. Biol. 57, 20-26.

Núñez J.A., Lazzari, C.R., 1990. Rearing of Triatoma infestans Klug (Heteroptera, Reduviidae) in the ab- sence of a live host. I. Some factors affecting the artificial feeding. J. Appl. Ent. 109, 87-92.

O'Donnell, M.J., Spring, J.H., 2000. Modes of control of insect Malpighian tubules: Synergism, antagonism, cooperation and autonomous regulation. J. Insect Physiol. 46, 107-117.

Olias, G., Viollet, C., Kusserow, H., Epelbaum, J., Meyerhof, W., 2004. Regulation and function of somatostatin receptors. J. Neurochem. 89, 1057-1091.

Oliveira, M.F., Silva, J.R., Dansa-Petretski, M., De Souza, W., Braga, C.M.S., Masuda, H., Oliveira, P.L., 2000. Haemozoin formation in the midgut of the blood-sucking insect Rhodnius prolixus. FEBS Lett. 477, 95-98.

Ons, S., Sterkel, M., Diambra, L., Urlaub, H., Rivera-Pomar, R., 2011. Neuropeptide precursor gene discovery in the Chagas disease vector Rhodnius prolixus. Insect Mol. Biol. 20, 2944.

Orchard, I., 2006. Serotonin: a coordinator of feeding-related physiological events in the bloodgorging bug, Rhodnius prolixus. Comp. Biochem. Physiol. A. Mol. Integr. Physiol. 144, 316-324.

Orchard, I., Lee, D.H., da Silva, R., Lange, A.B., 2011. The proctolin gene and biological effects of proctolin in the blood-feeding bug, Rhodnius prolixus. Front. Endocrinol. (Lausanne). 2.

Paemen, L., Tips, A., Schoofs, L., Proost, P., Van Damme, J., De Loof, A., 1991. Lom-AGmyotropin: a novel myotropic peptide from the male accessory glands of Locusta migratoria. Peptides 12, 7-10. 
Patel, H., Orchard, I., Veenstra, J. a, Lange, a B., 2014. The distribution and physiological effects of three evolutionarily and sequence-related neuropeptides in Rhodnius prolixus: Adipokinetic hormone, corazonin and adipokinetic hormone/corazonin-related peptide. Gen. Comp. Endocrinol. 195, 1-8.

Petri, B., Homberg, U., Loesel, R., Stengl, M., 2002. Evidence for a role of GABA and Masallatotropin in photic entrainment of the circadian clock of the cockroach Leucophaea maderae. J. Exp. Biol. 205, 1459-1469.

Price, M.D., Merte, J., Nichols, R., Koladich, P.M., Tobe, S.S., Bendena, W.G., 2002. Drosophila melanogaster flatline encodes a myotropin orthologue to Manduca sexta allatostatin. Peptides 23, 787-94.

Rachinsky, A., Srinivasan, A., Ramaswamy, S.B., 2003. Regulation of Juvenile Hormone biosynthesis in Heliothis virescens by Manduca sexta allatotropin. Arch. Insect Biochem. Physiol. 54, 121-133.

Rachinsky, a, Feldlaufer, M.F., 2000. Responsiveness of honey bee (Apis mellifera L.) corpora allata to allatoregulatory peptides from four insect species. J. Insect Physiol. 46, 41-46.

Ramsay, J.A., 1952. Ramsay, J.A., 1952. The excretion of sodium and potassium by the Malpighian tubules. J Exp Biol 29, 110-126.

Ravi Ram, K., Ji, S., Wolfner, M.F., 2005. Fates and targets of male accessory gland proteins in mated female Drosophila melanogaster. Insect Biochem. Mol. Biol. 35, 1059-1071.

Ribeiro, J.M.C., Genta, F.A., Sorgine, M.H.F., Logullo, R., Mesquita, R.D., Paiva-Silva, G.O., Majerowicz, D., Medeiros, M., Koerich, L., Terra, W.R., Ferreira, C., Pimentel, A.C., Bisch, P.M., Leite, D.C., Diniz, M.M.P., Junior, J.L. da S.G. V., Da Silva, M.L., Araujo, R.N., Gandara, A.C.P., Brosson, S., Salmon, D., Bousbata, S., González-Caballero, N., Silber, A.M., Alves-Bezerra, M., Gondim, K.C., Silva-Neto, M.A.C., Atella, G.C., Araujo, H., Dias, F.A., Polycarpo, C., Vionette-Amaral, R.J., Fampa, P., Melo, A.C.A., Tanaka, A.S., Balczun, C., Oliveira, J.H.M., Gonçalves, R.L.S., Lazoski, C., Rivera-Pomar, R., Diambra, L., Schaub, G.A., Garcia, E.S., Azambuja, P., Braz, G.R.C., Oliveira, P.L., 2014. An Insight into the transcriptome of the digestive tract of the bloodsucking bug, Rhodnius prolixus. PLoS Negl. Trop. Dis. 8.

Riccillo, F.L., Ronderos, J.R., 2010. Allatotropin expression during the development of the fourth instar larvae of the kissing-bug Triatoma infestans (Klug). Tissue Cell 42, 355-359. 
Ronderos, J.R., 2009. Changes in the corpora allata and epidermal proliferation along the fourth instar of the Chagas disease vector Triatoma infestans. Biocell 33, 149-154.

Rosenbaum, D.M., Rasmussen, S.G.F., Kobilka, B.K., 2009. The structure and function of Gprotein-coupled receptors. Nature 459, 356-363.

Rudwall, A.J., Sliwowska, J., Nässel, D.R., 2000. Allatotropin-like neuropeptide in the cockroach abdominal nervous system: Myotropic actions, sexually dimorphic distribution and colocalization with serotonin. J. Comp. Neurol. 428, 159-173.

Santini, M.S., Ronderos, J.R., 2009a. Allatotropin-like peptide in Malpighian tubules: Insect renal tubules as an autonomous endocrine organ. Gen. Comp. Endocrinol. 160, 243-249.

Santini, M.S., Ronderos, J.R., 2009b. Daily variation of an allatotropin-like peptide in the Chagas disease vector Triatoma infestans (Klug). Biol. Rhythm Res. 40, 299-306.

Santini, M.S., Ronderos, J.R., 2007. Allatotropin-like peptide released by Malpighian tubules induces hindgut activity associated with diuresis in the Chagas disease vector Triatoma infestans (Klug). J. Exp. Biol. 210, 1986-1991.

Sarkar, N.R.S., Tobe, S.S., Orchard, I., 2003. The distribution and effects of Dippu-allatostatinlike peptides in the blood-feeding bug, Rhodnius prolixus. Peptides 24, 1553-1562.

Schoofs, L., Holman, G.M., Hayes, T.K., Nachman, R.J., De Loof, A., 1991. Isolation, identification and synthesis of Locusta myoinhibiting peptide (LOM-MIP), a novel biologically active neuropeptide from Locusta migratoria. Regul. Pept. 36, 111-119.

Sedra, L., Haddad, A.S., Lange, A.B., 2015. Myoinhibitors controlling oviduct contraction within the female blood-gorging insect, Rhodnius prolixus. Gen. Comp. Endocrinol. 211, 62-68.

Sedra, L., Lange, A.B., 2014. The female reproductive system of the kissing bug, Rhodnius prolixus: Arrangements of muscles, distribution and myoactivity of two endogenous FMRFamide-like peptides. Peptides 53, 140-147.

Sevala, V.L., Sevala, V.M., Davey, K.G., Loughton, B.G., 1992. A FMRFamide-like peptide is associated with the myotropic ovulation hormone in Rhodnius prolixus. Arch. Insect Biochem. Physiol. 20, 193-203.

Sheng, Z., Ma, L., Cao, M.X., Li, S., Jiang, R.J., 2007. Biochemical and molecular characterization of allatotropin and allatostatin from the Eri silkworm, Samia cynthia ricini. Insect 
Biochem. Mol. Biol. 37, 90-96.

Stay, B., 2000. A review of the role of neurosecretion in the control of Juvenile Hormone synthesis: a tribute to Berta Scharrer. Insect Biochem. Mol. Biol. 30, 653-62.

Stay, B., Tobe, S.S., 2007. The role of allatostatins in Juvenile Hormone synthesis in insects and crustaceans. Annu. Rev. Entomol. 52, 277-299.

Steel, C.G.H., Vafopoulou, X., 2006. Circadian orchestration of developmental hormones in the insect, Rhodnius prolixus. Comp. Biochem. Physiol. - A Mol. Integr. Physiol. 144, 351-364.

Sterkel, M., Riccillo, F.L., Ronderos, J.R., 2010. Cardioacceleratory and myostimulatory activity of allatotropin in Triatoma infestans. Comp. Biochem. Physiol. - A Mol. Integr. Physiol. $155,371-377$.

Sterkel, M., Urlaub, H., Rivera-Pomar, R., Ons, S., 2011. Functional proteomics of neuropeptidome dynamics during the feeding process of Rhodnius prolixus. J. Proteome Res. 10, 3363-3371.

Tamura, K., Stecher, G., Peterson, D., Filipski, A., Kumar, S., 2013. MEGA6: Molecular evolutionary genetics analysis version 6.0. Mol. Biol. Evol. 30, 2725-2729.

Taylor;, P.A., Bhatt, T.R., Horodyski, F.M., 1996. Molecular characterization and expression analysis of Manduca sexta Allatotropin. Eur. J. Biochem 239, 588-596.

Te Brugge, V., lanowski, J.P., Orchard, I., 2009. Biological activity of diuretic factors on the anterior midgut of the blood-feeding bug, Rhodnius prolixus. Gen. Comp. Endocrinol. 162, 105-112.

Terra, W.R., 2001. The origin and functions of the insect peritrophic membrane and peritrophic gel. Arch. Insect Biochem. Physiol. 47, 47-61.

Tobe, S.S., Stay, B., 1985. Structure and Regulation of the Corpus Allatum. Adv. In Insect Phys. $18,305-432$.

Vafopoulou, X., Cardinal-Aucoin, M., Steel, C.G.H., 2012. Rhythmic release of prothoracicotropic hormone from the brain of an adult insect during egg development. Comp. Biochem. Physiol. A. Mol. Integr. Physiol. 161, 193-200.

Vafopoulou, X., Terry, K.L., Steel, C.G.H., 2010. The circadian timing system in the brain of the fifth larval instar of Rhodnius prolixus (Hemiptera). J. Comp. Neurol. 518, 1264-1282. 
Veenstra, J. a., 2009. Allatostatin C and its paralog allatostatin double C: The arthropod somatostatins. Insect Biochem. Mol. Biol. 39, 161-170.

Veenstra, J. a, Lehman, H.K., Davis, N.T., 1994. Allatotropin is a cardioacceleratory peptide in Manduca sexta. J. Exp. Biol. 188, 347-354.

Veenstra, J. a, Rodriguez, L., Weaver, R.J., 2012. Allatotropin, leucokinin and AKH in honey bees and other Hymenoptera. Peptides 35, 122-30.

Verlinden, H., Gijbels, M., Lismont, E., Lenaerts, C., Vanden Broeck, J., Marchal, E., 2015. The pleiotropic allatoregulatory neuropeptides and their receptors: A mini-review. J. Insect Physiol. 80, 2-14.

Verlinden, H., Lismont, E., Bil, M., Urlacher, E., Mercer, A., Vanden Broeck, J., Huybrechts, R., 2013. Characterization of a functional allatotropin receptor in the bumblebee, Bombus terrestris (Hymenoptera, Apidae). Gen. Comp. Endocrinol. 193, 193-200.

Verlinden, H., Vleugels, R., Zels, S., Dillen, S., Lenaerts, C., Spit, J., Broeck, J. Vanden, Physiology, M.D., Leuven, K.U., 2014. Receptors for neuronal or endocrine signaling molecules as potential targets for the control of insect pests, in: Cohen, E. (Ed.), Advances in Insect Physiology Part II. Elsevier, Oxford, pp. 167-305.

Villalobos-Sambucaro, M.J., Lorenzo-Figueiras, A.N., Riccillo, F.L., Diambra, L.A., Noriega, F.G., Ronderos, J.R., 2015a. Allatotropin modulates myostimulatory and cardioacceleratory activities in Rhodnius prolixus (Stal). PLoS One 10, 1-14.

Villalobos-Sambucaro, M.J., Riccillo, F.L., Calderón-Fernández, G.M., Sterkel, M., Diambra, L.A., Ronderos, J.R., 2015b. Genomic and functional characterization of a methoprene-tolerant gene in the kissing-bug Rhodnius prolixus. Gen. Comp. Endocrinol. 216, 1-8.

Vleugels, R., Verlinden, H., Broeck, J. Vanden, 2015. Serotonin, serotonin receptors and their actions in insects. Neurotransmitter 2, 1-14.

Voisin, T., Rouet-Benzineb, P., Reuter, N., Laburthe, M., 2003. Orexins and their receptors: structural aspects and role in peripheral tissues. Cell. Mol. Life Sci. 60, 72-87.

Vuerinckx, K., Verlinden, H., Lindemans, M., Broeck, J. Vanden, Huybrechts, R., 2011. Characterization of an allatotropin-like peptide receptor in the red flour beetle, Tribolium castaneum. Insect Biochem. Mol. Biol. 41, 815-822. 
Wagner, R.M., Woods, C.W., Hayes, J.A., Kochansky, J.P., Hill, J.C., Fraser, B.A., 1993. Isolation and identification of a novel peptide from the accessory sex gland of the female house fly, Musca domestica. Biochem. Biophys. Res. Commun.

Waterhouse, A.M., Procter, J.B., Martin, D.M. a, Clamp, M., Barton, G.J., 2009. Jalview Version 2--a multiple sequence alignment editor and analysis workbench. Bioinformatics 25 , 1189-91.

Wigglesworth, V., 1936. The function of the Corpus Allatum in the growth and reproduction of Rhodnius prolixus (Hemiptera). Q. J. Microsc. Sci. 79, 91-123.

Wigglesworth, V.B., 1943. The fate of haemoglobin in Rhodnius prolixus (Hemiptera) and other blood-sucking arthropods. Proc. R. Soc. Lond. B 131, 313-339.

Wigglesworth, V.B., 1934. The physiology of ecdysis in Rhodnius prolixus (Hemiptera). II. Factors controlling moulting and 'metamorphosis'. Q. J. Microsc. Sci. 191-222.

Wigglesworth, V.B., 1931. The Physiology of Excretion in a Blood Sucking Insect, Rhodnius prolixus (Hemiptera, Reduviidae). II. Anatomy and Histology of the Excretory System. J Exp Biol 8, 428-442.

Williamson, M., Lenz, C., Winther, a M., Nässel, D.R., Grimmelikhuijzen, C.J., 2001. Molecular cloning, genomic organization, and expression of a C-type (Manduca sexta-type) allatostatin preprohormone from Drosophila melanogaster. Biochem. Biophys. Res. Commun. 282, 124-30.

Woodhead, A.P., Stay, B., Seidel, S.L., Khan, M. a, Tobe, S.S., 1989. Primary structure of four allatostatins: neuropeptide inhibitors of juvenile hormone synthesis. Proc. Natl. Acad. Sci. U.S. A. $86,5997-6001$.

Wurden, S., Homberg, U., 1995. Immunocytochemical mapping of serotonin and neuropeptides in the accessory medulla of the locust, Schistocerca gregaria. J. Comp. Neurol. 362, 305-319.

Yamanaka, N., Yamamoto, S., Žitňan, D., Watanabe, K., Kawada, T., Satake, H., Kaneko, Y., Hiruma, K., Tanaka, Y., Shinoda, T., Kataoka, H., 2008. Neuropeptide receptor transcriptome reveals unidentified neuroendocrine pathways. PLoS One 3, 1-12.

Yuan, Q., Lin, F., Zheng, X., Sehgal, A., 2005. Serotonin modulates circadian entrainment in Drosophila. Neuron 47, 115-127. 
Zandawala, M., Orchard, I., 2013. Post-feeding physiology in Rhodnius prolixus: the possible role of FGLamide-related allatostatins. Gen. Comp. Endocrinol. 194, 311-317.

Zhang, C., Kim, Y.J., 2016. Reproductive functions of allatostatin-C in Drosophila melanogaster. 28th Conference of European Comparative Endocrinologists.

Zhu, J., Noriega, F.G., 2016. The role of Juvenile Hormone in mosquito development and reproduction, in: Advances in Insect Physiology. pp. 93-13. 


\section{PROTOCOLOS Y SOLUCIONES}

Solución salina de $\boldsymbol{R}$. prolixus (Maddrell et al., 1993)

Composición estándar (mmol I-1): $\mathrm{NaCl}, 129 ; \mathrm{KCl}, 8.6 ; \mathrm{CaCl}_{2}, 2.0 ; \mathrm{MgCl}_{2}, 8.5 ; \mathrm{NaHCO}_{3}, 10.2$; $\mathrm{NaH}_{2} \mathrm{PO}_{4}$, 4.3; Hepes, 8.6; glucosa, 20; pH ajustado a 7.0 con $\mathrm{NaOH}$. La solución fue adaptada omitiendo el compuesto Hepes.

\begin{tabular}{cccc}
\hline Reactivo & mmol & Gramos & Peso molecular \\
\hline $\mathbf{N a C l}$ & 129 & 7,537 & $58,43 \mathrm{~g}$ \\
$\mathbf{K C l}$ & 8.6 & 0,64 & $74,56 \mathrm{~g}$ \\
$\mathrm{CaCl}_{2}$ & 2.0 & 0,294 & $147 \mathrm{~g}$ (dihidrato) $\mathrm{CaCl}_{2} 2 \mathrm{H}_{2} \mathrm{O}$ \\
$\mathbf{M g C l}_{\mathbf{2}}$ & 8.5 & 1,73 & $203,31 \mathrm{~g}(6-\mathrm{hidrato})$ \\
$\mathrm{NaHCO}_{3}$ & 10.2 & 0,856 & $84,01 \mathrm{~g}$ \\
$\mathrm{NaH}_{\mathbf{2}} \mathbf{P O}_{4}$ & 4.3 & 0,671 & $156,01 \mathrm{~g}$ \\
glucose $^{\mathbf{H}}$ & 20 & 3,60 & $180,16 \mathrm{~g}$ \\
\hline $\mathbf{H}_{\mathbf{2}} \mathbf{O}$ & & $1000 \mathrm{ml}$ & \\
\hline
\end{tabular}

Preparación de las dosis de las neurohormonas: las dosis correspondientes a serotonina, AT y AST-C utilizadas en los experimentos fueron diluidas en solución salina de $R$. prolixus.

Solución RNA later (500ml) (US Patent 6.204.375)

Soluciones stock y reactivos: EDTA 0,5 M disódico, dihidratado $(9,305 \mathrm{gr} / 50 \mathrm{ml}, \mathrm{pH}$ a 8,0 con $\mathrm{NaOH}$ agitar); $1 \mathrm{M}$ de sal trisódica de citrato sódico, dihidrato (14,7 gr / $50 \mathrm{ml}$, agitar para disolver); Sulfato amónico, en polvo. Agua destilada estéril.

Preparación: en un vaso de precipitado, colocar $20 \mathrm{ml}$ de EDTA 0,5 M, 12,5 ml de Citrato de Sodio 1M, Sulfato de Amonio 35 gr y 467,5 ml de agua destilada estéril, agitar sobre un agitador de placa caliente hasta que el Sulfato de Amonio se disuelva completamente. Dejar enfriar, ajustar el pH de la solución a pH 5,2 usando $\mathrm{H}_{2} \mathrm{SO}_{4} 1 \mathrm{M}$. Transferir a una botella de rosca y almacenar a temperatura ambiente o refrigerada.

Formol buffer 4\% (pH = 7) (1Litro): $100 \mathrm{ml}$ de formol puro; 4 gr fosfato monobásico de sodio $\left(\mathrm{NaH}_{2} \mathrm{PO}_{4}\right), 6,5 \mathrm{gr}$ fosfato dibásico de sodio $\left(\mathrm{Na}_{2} \mathrm{HPO}_{4}\right)$ y $900 \mathrm{ml}$ de agua destilada.

Solución buffer forfato, PBS $(\mathrm{pH}=7.4,1 \mathrm{X}): 0,20 \mathrm{gr}$ fosfato monobásico de potasio $\left(\mathrm{KH}_{2} \mathrm{PO}_{4}\right)$, 1,44gr fosfato dibásico de sodio $\left(\mathrm{Na}_{2} \mathrm{HPO}_{4}\right), 8,06 \mathrm{gr}$ cloruro de sodio (CINa), 0,22 gr cloruro de potasio (CIK), $1000 \mathrm{ml}$ de agua destilada.

Precipitación de ADN a partir del producto de PCR (Acetato de Sodio-etanol): en un tubo Eppendorf, colocar el volumen del producto de PCR y agregarle 0,1 volúmenes de acetato de sodio 3M, mezclar bien por pipeteo y agitar con vortex 1 o 2 minutos. Luego, agregar 2,5 volúmenes de etanol absoluto, agitar con vortex 3 minutos y colocar en el freezer a $-80{ }^{\circ} \mathrm{C} 1$ hora ó a $-20^{\circ} \mathrm{C} 24$ hs. Transcurrido este tiempo, centrifugar 30 minutos a temperatura ambiente y descartar el sobrenadante. Lavar el pellet con $400 \mu \mathrm{l}$ de etanol $70 \%$, dos veces, suavemente para evitar que el pellet se despegue de la base del tubo. Retirar suavemente el 
etanol y evaporar el resto en estufa a $37^{\circ} \mathrm{C}$ durante 20 a 30 minutos. Resuspender DNA precipitado, el pellet, en 10-15 $\mu \mathrm{l}$ de agua destilada esterilizada.

Purificación de ADN a partir de un gel de agarosa con lana de vidrio (guata): sembrar en un gel de agarosa $1 \%$ la cantidad de producto de PCR deseada y proceder con la corrida electroforética a 90-100 volts. Detener la corriente cuando sea necesario y cortar el taco de agarosa con la banda de interés a purificar, rápidamente en el transiluminador (utilizar gafas y guantes). Colocar el taco en un tubo Eppendorf de $0,5 \mathrm{ml}$ con lana de vidrio autoclavada cuyo extremo ha sido perforado, y tapar. Colocar este tubo dentro del otro de 1,5 $\mathrm{ml}$ estéril. Centrifugar a $14000 \mathrm{rpm}$ durante 2 minutos. Al filtrado recogido en el tubo inferior agregar 0,1 volúmenes $(10 \%)$ de cloruro de litio ( $\mathrm{LiCl} 8 \mathrm{M})$ y agitar con vortex 1,5 minutos. Luego agregar 2,5 ó 3 volúmenes de etanol absoluto (100\%) refrigerado y agitar con vortex 3 minutos. Colocar a $-80^{\circ} \mathrm{C}$ durante 30 minutos. Centrifugar 30 minutos a 14000 rpm y descartar el sobrenadante. Lavar suavemente el pellet resultante con $400 \mu \mathrm{l}$ de etanol $70 \%$ refrigerado. Volver a centrifugar 10 minutos a 14000rpm y descartar el sobrenadante. Secar el pellet a $37^{\circ} \mathrm{C}$, sin secar demasiado, aproximadamente 10 minutos, hasta que el aroma a etanol se haya evaporado. Resuspender el DNA precipitado en $15 \mu \mathrm{l}$ de agua destilada esterilizada.

Buffer TBE 5X (Stock) para preparación de geles de agarosa (1Litro): 54 gr de TRIS base, 27,5 gr de ácido bórico, $20 \mathrm{ml}$ de 0,5X EDTA ( $\mathrm{pH}=8,0)$, completar 1 litro de agua de destilada. Se guarda un frasco color caramelo y se esteriliza mediante autoclave. Para preparar gel de agarosa se utiliza TBE 0,5X (100 ml de TBE $5 \mathrm{X}$ se mezclan con 1 litro de agua destilada esterilizada).

Gel de Agarosa 1\%: Para las cubas de acrílico que hemos utilizado se prepara 1gr de agarosa con $100 \mathrm{ml}$ de TBE $0,5 \mathrm{X}$ en un matraz de Erlenmeyer, y se calienta suavemente en microondas hasta que se disuelve la agarosa. Se agrega $1 \mu \mathrm{l}$ de bromuro de etidio. Colocar el peine correspondiente para la siembra del producto de PCR y volcar en la cuba en una superficie nivelada y dejar solidificar.

\section{Extracción de RNA en columnas (QIAGEN 74903):}

Importante: todos los elementos a utilizar durante este procedimiento deben estar esterilizados en autoclave. La superficie de trabajo, las micropipetas deben ser esterilizadas con una solución de inhibidora de enzimas de RNA (RNAsa ZAP-AMBION cat: AM9780). Trabajar con guantes de látex, lavarlos periódicamente con alcohol $70 \%$ y cambiarlos. Todos los pasos a seguir deber realizarse en hielo.

El tejido a procesar debe estar conservado en RNAlater. Este kit comercial requiere para garantizar la eficacia de la extracción una cantidad máxima de material de $30 \mathrm{mg}$.

Materiales:

- Ultracentrífuga (ThermoFisher Scientific)

- NanoDrop 2000c (ThermoFisher Scientific)

- Cuba de Electroforesis, fuente de poder, transiluminador.

- Rotor para homogenizar

- Betamercaptoetanol 
- Alcohol $100 \%$ y $70 \%$ (diluido en agua destilada estéril)

- $\quad$ Kit comercial de DNAasa (Qiagen cat:79254)

- Micropipetas automáticas

- Tips

- Tubos Eppendorf

- Homogenizadores de vidrio y embolo de teflón

- Cuchara, espátula y pinza (que quepan en el homogenizador)

- Columnas de extracción y de colecta (provistas por el kit)

1. Disrupción y homogenización del tejido: se realiza de manera simultánea con cada tejido por separado. Bajo campana, se prepara previamente por cada muestra a procesar, una solución de buffer de lisis RLT (suministrado por el kit) (600 $\mu$ l) al cual se le agregan $10 \mu \mathrm{l}$ de $\beta$-mercaptoetanol ( $\beta-\mathrm{ME})$. Con pinzas y/o cuchara traspasar el material biológico con la menor cantidad posible de RNAlater al tubo homogenizador. Colocar primero $400 \mu \mathrm{l}$ de la solución de buffer RLT con $\beta$-ME y homogenizar con el rotor a máxima velocidad, moviendo cuidadosamente el mismo para que el émbolo triture todo el tejido. Verter el homogenato en un tubo Eppendorf y colocarlo en hielo. Utilizar el resto de la solución para bañar y enjuagar el émbolo, activar el rotor suavemente. Esto se vierte con el resto del homogenato.

2. Centrifugar el lisado durante 3 minutos a máxima velocidad. Retirar cuidadosamente el sobrenadante con micropipeta y transferirlo a un nuevo tubo de Eppendorf y colocarlo en hielo. Éste sobrenadante es el que se utilizará en los próximos pasos.

3. Al sobrenadante obtenido añadir 1 volumen de etanol $70 \%$, mezclar inmediatamente por pipeteo suave. No centrifugar. Nota: El volumen de lisado puede ser inferior a $600 \mu \mathrm{l}$ debido a pérdida durante la homogeneización y centrifugación. Puede visualizarse material precipitado después de la adición de etanol, esto no afecta el procedimiento.

4. Transferir hasta $700 \mu \mathrm{l}$ de la muestra, a una columna de centrifuga RNeasy colocada en un tubo de colecta de $2 \mathrm{ml}$ (suministrado por el kit), cerrar la tapa suavemente, y centrifugar durante 15 segundos a 8000 x g (10.000 rpm). El líquido obtenido en el tubo de colecta se descarta y mediante golpeteos sobre un papel secante se eliminan las gotas que quedan sobre las paredes del tubo, el cual se vuelve a utilizar en el siguiente paso. Si el volumen de muestra excede de $700 \mu \mathrm{l}$, centrifugar las alícuotas sucesivas en la misma columna, desechando el efluido del tubo de colecta.

5. Digestión opcional de DNasa en la columna (Qiagen cat:79254): para preparar y alicuotar la enzima para su almacenamiento se siguieron las instrucciones que provee el kit. La enzima es muy susceptible a la desnaturalización mecánica por lo que no debe agitarse con vortex si no mediante pipeteo suave. En todo momento debe mantenerse en hielo. Procedimiento:

a. Añadir $350 \mu \mathrm{l}$ de la solución buffer RW1 a la columna que contiene la muestra. Cerrar cuidadosamente la tapa y centrifugar durante 15 segundos a 8000 x g (10.000 rpm) para lavar la membrana de la columna de centrifugado. Descartar el flujo. Reutilizar el tubo de colecta en el paso D4.

b. Añadir la solución de DNasa I ( $80 \mu \mathrm{l}$ ) directamente sobre la a la membrana de la columna e incubar 15 minutos a temperatura ambiente. 
c. Añadir $350 \mu$ de la solución buffer RW1 a la columna. Cerrar cuidadosamente la tapa y centrifugar durante 15 segundos a $8000 \mathrm{~g}$ (10.000 rpm). Descartar el efluido.

6. Lavar la membrana de la columna. Añadir $500 \mu \mathrm{l}$ de solución buffer RPE a la columna de centrifugado, cerrar la tapa suavemente y centrifugar durante 2 minutos 8000 g (10.000 $\mathrm{rpm})$. Durante este paso se eliminan los restos de etanol para que no interfieran en la pureza de la extracción.

7. Elución final: Colocar la columna en un nuevo tubo de colecta $1,5 \mathrm{ml}$ (Eppendorfsuministrado). Añadir $50 \mu \mathrm{l}$ de agua RNasa free (suministrado) directamente sobre la membrana de la columna, cerrar la tapa suavemente y centrifugar durante 1 minuto a $8.000 \mathrm{~g}$ (10.000 rpm) para eluir el RNA. Hacer una primera contabilización de la concentración del RNA obtenido con NanoDrop. Si la solución obtenida está demasiado concentrada, repetir la elución con $50 \mu \mathrm{l}$ de agua RNasa free. La concentración final debe ser próxima a $2 \mu \mathrm{g} / \mu \mathrm{l}$.

8. Calidad del RNA: se realiza un gel de agarosa $1 \%$ con agua destilada, $1 \mu \mathrm{l}$ de bromuro de etidio. la agarosa en estado líquido de vuelca en una cama de acrílico con un peine cuyas superficies fuero cuidadosamente lavadas con RNA zap. Tanto el gen de agarosa como la corrida electroforética se realizan con buffer TBE $1 \mathrm{X}$ estéril. La muestra a evaluar se siembra con loading buffer. Al revelar el gel deben aparecen las bandas correspondientes a los RNA ribosómicos.

\section{Síntesis de DNA complemantario (CDNA) a partir de RNA mensajero}

Para la obtención de cDNA que se utilizará como molde en las reacciones de PCR se utilizó el kit comercial RevertAid First Strand cDNA Synthesis Kit (Cat: \#K1621- Thermo Scientific). Para obtener el mismo se siguió el protocolo recomendado por el kit. Los productos obtenidos fueron cuantificados mediante el uso de NanoDrop 2000c (ThermoFisher Scientific), con el fin de conocer la concentración de cada uno de ellos.

Recomendaciones para trabajar sugeridas en el protocolo del kit: se debe evitar la contaminación por ribonucleasa. Para ello se deben usar guantes descartables durante todo el procedimiento. Utilizar RNAasa Zap sobre todas las superficies de trabajo y esterilizar el material plástico (tips, tubos Eppendorf). El producto obtenido debe almacenarse a $-20^{\circ} \mathrm{C}$.

\section{Protocolo para realizar la reacción de PCR cualitativa}

Los CDNA obtenidos se utilizaron como molde de DNA para realizar las reacciones de PCR cualitativa (Polymerase Chain Reaction).

Materiales:

- Ultracentrífuga (ThermoFisher Scientific)

- NanoDrop 2000c (ThermoFisher Scientific)

- Termocicladora (ThermoFisher Scientific)

- Cuba de Electroforesis, fuente de poder, transiluminador. 
- Vortex

- $\quad$ Alcohol 70\% (diluido en agua destilada estéril)

- Kit comercial de la enzima Taq Polimerasa (Cat \#EA0101/ PB-L)

- Micropipetas automáticas

- Tips

- Tubos Eppendorf

- $\quad$ dNTP kit comercial (PB-L) diluido a la concentración de 2mM

- Primers específicos $1 \mu \mathrm{M}$ (Eurofin), diluidos según especificaciones del comerciante

- $\quad$ Agua destilada estéril

- cDNA (molde)

- Loadding buffer

- $\quad$ Marcador de peso molecular de DNA (100 pb-1000pb)

- Agarosa ultra pura

- Bromuro de etidio

Recomendaciones de trabajo: mantener los reactivos en hielo y agitarlos en vortex antes de usar. Utilizar guantes durante todo el procedimiento y limpiar las superficies de trabajo con alcohol 70\%. La enzima Taq Polimerasa debe ser utilizada inmediatamente luego de ser extraída del freezer, por lo que es recomendable agregarla a la mezcla en último lugar, para volver a guardarla rápidamente; debe mezclarse mediante pipeteo suave.

Procedimiento: colocar en un tubo Eppendorf los reactivos en el siguiente orden para obtener un volumen final de $50 \mu$ l en la reacción.

\begin{tabular}{|c|c|}
\hline Reactivos & \\
\hline Buffer 10X & $5 \mu l$ \\
\hline $\mathrm{MgCl}_{2} 50 \mathrm{nM}$ & $2 \mu l$ \\
\hline dNTP 2 mM & $1 \mu \mathrm{l}$ (de cada uno) \\
\hline Primers $1 \mu \mathrm{M}$ & $1 \mu \mathrm{l}$ (de cada uno) \\
\hline Molde (hasta $1 \mu \mathrm{g}$ ) & $1 \mu l$ \\
\hline Taq polimerasa & $0,5 \mu l$ \\
\hline Agua & $\begin{array}{c}\text { Cantidad necesaria para } \\
\text { completar el total del } \\
\text { volumen de } 50 \mu l\end{array}$ \\
\hline
\end{tabular}

Una vez listo los tubos con los reactivos, mezclar mediante pipeteo y centrifugarlos brevemente para asegurar que los mismos se ubiquen en el fondo del tubo. Colocarlos en la termocicladora según el programa detallado en M\&M.

Finalizada la reacción, se verifica la expresión de la amplificación del gen en estudio mediante la electroforesis de un gel de agarosa (1\%), donde una muestra del producto de PCR $(5 \mu l)$ se siembra en el mismo, mezclado previamente con $1-2 \mu l$ de loadding buffer, para que 
precipite el DNA. Además, en una calle del gel debe sembrarse una muestra del marcador de peso molecular como referencia.

Luego de ser verificada la expresión del gen de interés, se procede a la cuantificación del producto de PCR mediante el unos de NanoDrop 2000c (ThermoFisher Scientific). Finalmente, se llevará a cabo la secuenciación del DNA clonado. La muestra es procesada según las indicaciones del prestador del servicio de secuenciación (INTA). 
Estadística: Tablas de Análisis de la Varianza de cada uno de los gráficos analizados en la sección "Resultados" de este trabajo.

\begin{tabular}{|c|c|c|c|c|c|}
\hline Fig. 1 A & $\begin{array}{c}\text { Suma de } \\
\text { Cuadrados }\end{array}$ & $\begin{array}{c}\text { Grados de } \\
\text { Libertad }\end{array}$ & $\begin{array}{c}\text { Suma de los } \\
\text { Cuadrados } \\
\text { Medios }\end{array}$ & $\begin{array}{c}\text { Valor del } \\
\text { estadístico F }\end{array}$ & $\begin{array}{c}\text { Valor de la } \\
\text { probabilidad } \\
\text { "p" }\end{array}$ \\
\hline Intercepción & 12934,11 & 1 & 12934,11 & 391,6140 & $\mathbf{0 , 0 0 0 0 0 0}$ \\
\hline Dosis & 115,90 & 2 & 57,95 & 1,7545 & 0,180618 \\
\hline Tiempo & 27,40 & 2 & 13,70 & 0,4147 & 0,662145 \\
\hline Dosis*Tiempo & 19,53 & 4 & 4,88 & 0,1478 & 0,963377 \\
\hline Error & 2278,91 & 69 & 33,03 & & \\
\cline { 1 - 3 }
\end{tabular}

\begin{tabular}{|c|c|c|c|c|c|}
\hline Fig. 1 B y C & $\begin{array}{c}\text { Suma de } \\
\text { Cuadrados }\end{array}$ & $\begin{array}{c}\text { Grados de } \\
\text { Libertad }\end{array}$ & $\begin{array}{c}\text { Suma de los } \\
\text { Cuadrados } \\
\text { Medios }\end{array}$ & $\begin{array}{c}\text { Valor del } \\
\text { estadístico F }\end{array}$ & $\begin{array}{c}\text { Valor de la } \\
\text { probabilidad } \\
\text { "p" }\end{array}$ \\
\hline Intercepción & 8392,596 & 1 & 8392,596 & 202,7137 & $\mathbf{0 , 0 0 0 0 0 0}$ \\
\hline Momento del día & 452,744 & 1 & 452,744 & 10,9355 & $\mathbf{0 , 0 0 2 9 6 2}$ \\
\hline Dosis & 2,966 & 1 & 2,966 & 0,0716 & 0,791248 \\
\hline Tiempo & 45,414 & 2 & 22,707 & 0,5485 & 0,584913 \\
\hline Hora*Dosis & 1,633 & 1 & 1,633 & 0,0394 & 0,844259 \\
\hline Hora*Tiempo & 32,969 & 2 & 16,485 & 0,3982 & 0,675905 \\
\hline Dosis*Tiempo & 18,451 & 2 & 9,225 & 0,2228 & 0,801890 \\
\hline Hora*Dosis*Tiempo & 35,932 & 2 & 17,966 & 0,4339 & 0,652929 \\
\hline Error & 993,630 & 24 & 41,401 & & \\
\hline
\end{tabular}

\begin{tabular}{|c|c|c|c|c|c|}
\hline Fig. 2 A & $\begin{array}{c}\text { Suma de } \\
\text { Cuadrados }\end{array}$ & $\begin{array}{c}\text { Grados de } \\
\text { Libertad }\end{array}$ & $\begin{array}{c}\text { Suma de los } \\
\text { Cuadrados } \\
\text { Medios }\end{array}$ & $\begin{array}{c}\text { Valor del } \\
\text { estadístico F }\end{array}$ & $\begin{array}{c}\text { Valor de la } \\
\text { probabilidad } \\
\text { "p" }\end{array}$ \\
\hline Intercepción & 43671,71 & 1 & 43671,71 & 1197,052 & $\mathbf{0 , 0 0 0 0 0 0}$ \\
\hline Dosis & 889,51 & 2 & 444,76 & 12,191 & $\mathbf{0 , 0 0 0 0 5 9}$ \\
\hline Tiempo & 291,18 & 2 & 145,59 & 3,991 & $\mathbf{0 , 0 2 5 3 8 3}$ \\
\hline Dosis*Tiempo & 14,22 & 4 & 3,55 & 0,097 & 0,982757 \\
\hline Error & 1641,72 & 45 & 36,48 & \multicolumn{1}{|c}{} \\
\cline { 1 - 3 }
\end{tabular}

\begin{tabular}{|c|c|c|c|c|c|}
\hline Fig 2 B & $\begin{array}{c}\text { Suma de } \\
\text { Cuadrados }\end{array}$ & $\begin{array}{c}\text { Grados de } \\
\text { Libertad }\end{array}$ & $\begin{array}{c}\text { Suma de los } \\
\text { Cuadrados } \\
\text { Medios }\end{array}$ & $\begin{array}{c}\text { Valor del } \\
\text { estadístico F }\end{array}$ & $\begin{array}{c}\text { Valor de la } \\
\text { probabilidad } \\
\text { "p" }\end{array}$ \\
\hline Intercepción & 3251,130 & 1 & 3251,130 & 502,7200 & $\mathbf{0 , 0 0 0 0 0 0}$ \\
\hline Dosis & 8,926 & 2 & 4,463 & 0,6901 & 0,506752 \\
\hline Tiempo & 1,444 & 2 & 0,722 & 0,1117 & 0,894580 \\
\hline Dosis*Tiempo & 14,259 & 4 & 3,565 & 0,5512 & 0,699083 \\
\hline Error & 291,019 & 45 & 6,467 & \multicolumn{1}{|l}{} \\
\cline { 1 - 3 }
\end{tabular}




\begin{tabular}{|c|c|c|c|c|c|}
\hline Fig. 3 A & $\begin{array}{c}\text { Suma de } \\
\text { Cuadrados }\end{array}$ & $\begin{array}{c}\text { Grados de } \\
\text { Libertad }\end{array}$ & $\begin{array}{c}\text { Suma de los } \\
\text { Cuadrados } \\
\text { Medios }\end{array}$ & $\begin{array}{c}\text { Valor del } \\
\text { estadístico F }\end{array}$ & $\begin{array}{c}\text { Valor de la } \\
\text { probabilidad } \\
\text { "p" }\end{array}$ \\
\hline Intercepción & 35934,26 & 1 & 35934,26 & 819,3257 & $\mathbf{0 , 0 0 0 0 0 0}$ \\
\hline Tratamiento & 300,00 & 1 & 300,00 & 6,8402 & $\mathbf{0 , 0 1 2 5 1 0}$ \\
\hline Tiempo & 65,24 & 3 & 21,75 & 0,4958 & 0,687229 \\
\hline Tratamiento*Tiempo & 67,94 & 3 & 22,65 & 0,5164 & 0,673373 \\
\hline Error & 1754,33 & 40 & 43,86 & & \\
\cline { 1 - 3 } & & &
\end{tabular}

\begin{tabular}{|c|c|c|c|c|c|}
\hline Fig. 4 A & $\begin{array}{c}\text { Suma de } \\
\text { Cuadrados }\end{array}$ & $\begin{array}{c}\text { Grados de } \\
\text { Libertad }\end{array}$ & $\begin{array}{c}\text { Suma de los } \\
\text { Cuadrados } \\
\text { Medios }\end{array}$ & $\begin{array}{c}\text { Valor del } \\
\text { estadístico F }\end{array}$ & $\begin{array}{c}\text { Valor de la } \\
\text { probabilidad } \\
\text { "p" }\end{array}$ \\
\hline Intercepción & 2384,335 & 1 & 2384,335 & 670,4196 & $\mathbf{0 , 0 0 0 0 0 0}$ \\
\hline Tratamiento & 55,125 & 1 & 55,125 & 15,4999 & $\mathbf{0 , 0 0 0 2 1 7}$ \\
\hline Tiempo & 18,100 & 5 & 3,620 & 1,0179 & 0,415251 \\
\hline Tratamiento*Tiempo & 14,273 & 5 & 2,855 & 0,8027 & 0,552237 \\
\hline Error & 213,389 & 60 & 3,556 & & \\
\cline { 1 - 3 } & & &
\end{tabular}

\begin{tabular}{|c|c|c|c|c|c|}
\hline Fig. 5 A & $\begin{array}{c}\text { Suma de } \\
\text { Cuadrados }\end{array}$ & $\begin{array}{c}\text { Grados de } \\
\text { Libertad }\end{array}$ & $\begin{array}{c}\text { Suma de los } \\
\text { Cuadrados } \\
\text { Medios }\end{array}$ & $\begin{array}{c}\text { Valor del } \\
\text { estadístico F }\end{array}$ & $\begin{array}{c}\text { Valor de la } \\
\text { probabilidad } \\
\text { "p" }\end{array}$ \\
\hline Intercepción & 58102,62 & 1 & 58102,62 & 1555,446 & $\mathbf{0 , 0 0 0 0 0 0}$ \\
\hline Dosis & 889,72 & 3 & 296,57 & 7,939 & $\mathbf{0 , 0 0 0 1 5 3}$ \\
\hline Tiempo & 261,38 & 2 & 130,69 & 3,499 & $\mathbf{0 , 0 3 6 5 4 3}$ \\
\hline Dosis*Tiempo & 56,80 & 6 & 9,47 & 0,253 & 0,956028 \\
\hline Error & 2241,26 & 60 & 37,35 & & \\
\cline { 1 - 3 } & & &
\end{tabular}

\begin{tabular}{|c|c|c|c|c|c|}
\hline Fig 5 B & $\begin{array}{c}\text { Suma de } \\
\text { Cuadrados }\end{array}$ & $\begin{array}{c}\text { Grados de } \\
\text { Libertad }\end{array}$ & $\begin{array}{c}\text { Suma de los } \\
\text { Cuadrados } \\
\text { Medios }\end{array}$ & $\begin{array}{c}\text { Valor del } \\
\text { estadístico F }\end{array}$ & $\begin{array}{c}\text { Valor de la } \\
\text { probabilidad } \\
\text { "p" }\end{array}$ \\
\hline Intercepción & 4175,965 & 1 & 4175,965 & 625,0346 & $\mathbf{0 , 0 0 0 0 0 0}$ \\
\hline Dosis & 13,375 & 3 & 4,458 & 0,6673 & 0,575427 \\
\hline Tiempo & 8,799 & 2 & 4,400 & 0,6585 & 0,521317 \\
\hline Dosis*Tiempo & 21,769 & 6 & 3,628 & 0,5430 & 0,773368 \\
\hline Error & 400,870 & 60 & 6,681 & & \\
\cline { 1 - 3 }
\end{tabular}

\begin{tabular}{|c|c|c|c|c|c|}
\hline Fig. 6 A & $\begin{array}{c}\text { Suma de } \\
\text { Cuadrados }\end{array}$ & $\begin{array}{c}\text { Grados de } \\
\text { Libertad }\end{array}$ & $\begin{array}{c}\text { Suma de los } \\
\text { Cuadrados } \\
\text { Medios }\end{array}$ & $\begin{array}{c}\text { Valor del } \\
\text { estadístico F }\end{array}$ & $\begin{array}{c}\text { Valor de la } \\
\text { probabilidad } \\
\text { "p" }\end{array}$ \\
\hline Intercepción & 34534,03 & 1 & 34534,03 & 771,5611 & $\mathbf{0 , 0 0 0 0 0 0}$ \\
\hline Ser/AT- AST-C & 254,23 & 1 & 254,23 & 5,6799 & $\mathbf{0 , 0 2 3 6 9 2}$ \\
\hline Tiempo & 54,69 & 2 & 27,34 & 0,6109 & 0,549483 \\
\hline Ser/AT- AST-C*Tiempo & 13,08 & 2 & 6,54 & 0,1461 & 0,864665 \\
\hline Error & 1342,76 & 30 & 44,76 & & \\
\cline { 1 - 3 } & & &
\end{tabular}




\begin{tabular}{|c|c|c|c|c|c|}
\hline Fig. 6 B & $\begin{array}{c}\text { Suma de } \\
\text { Cuadrados }\end{array}$ & $\begin{array}{c}\text { Grados de } \\
\text { Libertad }\end{array}$ & $\begin{array}{c}\text { Suma de los } \\
\text { Cuadrados } \\
\text { Medios }\end{array}$ & $\begin{array}{c}\text { Valor del } \\
\text { estadístico F }\end{array}$ & $\begin{array}{c}\text { Valor de la } \\
\text { probabilidad } \\
\text { "p" }\end{array}$ \\
\hline Intercepción & 33876,54 & 1 & 33876,54 & 482,9723 & $\mathbf{0 , 0 0 0 0 0 0}$ \\
\hline Ser- AST-C & 176,77 & 2 & 88,39 & 1,2601 & 0,293434 \\
\hline Tiempo & 9,47 & 2 & 4,74 & 0,0675 & 0,934792 \\
\hline Ser- AST-C*Teimpo & 135,15 & 4 & 33,79 & 0,4817 & 0,748988 \\
\hline Error & 3156,38 & 45 & 70,14 & & \\
\cline { 1 - 3 } & &
\end{tabular}

\begin{tabular}{|c|c|c|c|c|c|}
\hline Fig. 7 A & $\begin{array}{c}\text { Suma de } \\
\text { Cuadrados }\end{array}$ & $\begin{array}{c}\text { Grados de } \\
\text { Libertad }\end{array}$ & $\begin{array}{c}\text { Suma de los } \\
\text { Cuadrados } \\
\text { Medios }\end{array}$ & $\begin{array}{c}\text { Valor del } \\
\text { estadístico F }\end{array}$ & $\begin{array}{c}\text { Valor de la } \\
\text { probabilidad } \\
\text { "p" }\end{array}$ \\
\hline Intercepción & 30634,73 & 1 & 30634,73 & 634,4539 & $\mathbf{0 , 0 0 0 0 0 0}$ \\
\hline Dosis & 213,33 & 1 & 213,33 & 4,4182 & $\mathbf{0 , 0 4 6 2 3 5}$ \\
\hline Tiempo & 149,79 & 2 & 74,89 & 1,5510 & 0,232542 \\
\hline Dosis*Tiempo & 15,09 & 2 & 7,54 & 0,1562 & 0,856210 \\
\hline Error & 1158,84 & 24 & 48,29 & & \\
\cline { 1 - 3 } & &
\end{tabular}

\begin{tabular}{|c|c|c|c|c|c|}
\hline Fig. 7 B & $\begin{array}{c}\text { Suma de } \\
\text { Cuadrados }\end{array}$ & $\begin{array}{c}\text { Grados de } \\
\text { Libertad }\end{array}$ & $\begin{array}{c}\text { Suma de los } \\
\text { Cuadrados } \\
\text { Medios }\end{array}$ & $\begin{array}{c}\text { Valor del } \\
\text { estadístico F }\end{array}$ & $\begin{array}{c}\text { Valor de la } \\
\text { probabilidad } \\
\text { "p" }\end{array}$ \\
\hline Intercepción & 2771,204 & 1 & 2771,204 & 1012,483 & $\mathbf{0 , 0 0 0 0 0 0}$ \\
\hline Dosis & 12,893 & 1 & 12,893 & 4,710 & $\mathbf{0 , 0 4 0 1 0 0}$ \\
\hline Tiempo & 6,719 & 2 & 3,359 & 1,227 & 0,310819 \\
\hline Dosis*Tiempo & 3,607 & 2 & 1,804 & 0,659 & 0,526481 \\
\hline Error & 65,689 & 24 & 2,737 & & \\
\cline { 1 - 3 } & & &
\end{tabular}

\begin{tabular}{|c|c|c|c|c|c|}
\hline Fig. 7 C & $\begin{array}{c}\text { Suma de } \\
\text { Cuadrados }\end{array}$ & $\begin{array}{c}\text { Grados de } \\
\text { Libertad }\end{array}$ & $\begin{array}{c}\text { Suma de los } \\
\text { Cuadrados } \\
\text { Medios }\end{array}$ & $\begin{array}{c}\text { Valor del } \\
\text { estadístico F }\end{array}$ & $\begin{array}{c}\text { Valor de la } \\
\text { probabilidad } \\
\text { "p" }\end{array}$ \\
\hline Dosis & 429,50 & 5 & 85,90 & 2,600 & $\mathbf{0 , 0 2 9 1 9 5}$ \\
\hline Tiempo & 92,37 & 2 & 46,18 & 1,398 & 0,251555 \\
\hline Dosis*Tiempo & 232,38 & 10 & 23,24 & 0,703 & 0,719480 \\
\hline Error & 3568,13 & 108 & 33,04 & & \\
\cline { 1 - 3 } & &
\end{tabular}

\begin{tabular}{|c|c|c|c|c|c|}
\hline Fig. 7 D & $\begin{array}{c}\text { Suma de } \\
\text { Cuadrados }\end{array}$ & $\begin{array}{c}\text { Grados de } \\
\text { Libertad }\end{array}$ & $\begin{array}{c}\text { Suma de los } \\
\text { Cuadrados } \\
\text { Medios }\end{array}$ & $\begin{array}{c}\text { Valor del } \\
\text { estadístico F }\end{array}$ & $\begin{array}{c}\text { Valor de la } \\
\text { probabilidad } \\
\text { "p" }\end{array}$ \\
\hline Dosis & 180,650 & 5 & 36,130 & 9,615 & $\mathbf{0 , 0 0 0 0 0 0}$ \\
\hline Tiempo & 4,658 & 2 & 2,329 & 0,620 & 0,539977 \\
\hline Dosis*Tiempo & 15,014 & 10 & 1,501 & 0,400 & 0,944278 \\
\hline Error & 405,841 & 108 & 3,758 & & \\
\cline { 1 - 3 } & &
\end{tabular}




\begin{tabular}{|c|c|c|c|c|c|}
\hline Fig. 8 A & $\begin{array}{c}\text { Suma de } \\
\text { Cuadrados }\end{array}$ & $\begin{array}{c}\text { Grados de } \\
\text { Libertad }\end{array}$ & $\begin{array}{c}\text { Suma de los } \\
\text { Cuadrados } \\
\text { Medios }\end{array}$ & $\begin{array}{c}\text { Valor del } \\
\text { estadístico F }\end{array}$ & $\begin{array}{c}\text { Valor de la } \\
\text { probabilidad } \\
\text { "p" }\end{array}$ \\
\hline Intercepción & 39502,69 & 1 & 39502,69 & 635,0367 & $\mathbf{0 , 0 0 0 0 0 0}$ \\
\hline Dosis & 229,69 & 1 & 229,69 & 3,6924 & 0,061464 \\
\hline Tiempo & 321,06 & 2 & 160,53 & 2,5806 & 0,087690 \\
\hline Dosis*Tiempo & 36,50 & 2 & 18,25 & 0,2934 & 0,747252 \\
\hline Error & 2612,63 & 42 & 62,21 & & \\
\cline { 1 - 3 } & &
\end{tabular}

\begin{tabular}{|c|c|c|c|c|c|}
\hline Fig. 8 B & $\begin{array}{c}\text { Suma de } \\
\text { Cuadrados }\end{array}$ & $\begin{array}{c}\text { Grados de } \\
\text { Libertad }\end{array}$ & $\begin{array}{c}\text { Suma de los } \\
\text { Cuadrados } \\
\text { Medios }\end{array}$ & $\begin{array}{c}\text { Valor del } \\
\text { estadístico F }\end{array}$ & $\begin{array}{c}\text { Valor de la } \\
\text { probabilidad } \\
\text { "p" }\end{array}$ \\
\hline Intercepción & 3547,787 & 1 & 3547,787 & 1848,468 & $\mathbf{0 , 0 0 0 0 0 0}$ \\
\hline Dosis & 29,037 & 1 & 29,037 & 15,129 & $\mathbf{0 , 0 0 0 3 5 2}$ \\
\hline Tiempo & 23,949 & 2 & 11,975 & 6,239 & $\mathbf{0 , 0 0 4 2 4 2}$ \\
\hline Dosis*Tiempo & 1,282 & 2 & 0,641 & 0,334 & 0,717882 \\
\hline Error & 80,611 & 42 & 1,919 & & \\
\cline { 1 - 3 } & &
\end{tabular}

\begin{tabular}{|c|c|c|c|c|c|}
\hline $\begin{array}{l}\text { Fig. } 10 \text { B: Ovarios } \\
\text { Hembras Vírgenes }\end{array}$ & $\begin{array}{l}\text { Suma de } \\
\text { Cuadrados }\end{array}$ & $\begin{array}{l}\text { Grados de } \\
\text { Libertad }\end{array}$ & $\begin{array}{c}\text { Suma de los } \\
\text { Cuadrados } \\
\text { Medios }\end{array}$ & $\begin{array}{c}\text { Valor del } \\
\text { estadístico F }\end{array}$ & $\begin{array}{c}\text { Valor de la } \\
\text { probabilidad } \\
\text { "p" }\end{array}$ \\
\hline Intercepción & 1294,840 & 1 & 1294,840 & 245,1409 & 0,000000 \\
\hline Dosis & 10,282 & 5 & 2,056 & 0,3893 & 0,855530 \\
\hline Tiempo & 0,731 & 2 & 0,366 & 0,0692 & 0,933131 \\
\hline Dosis*Tiempo & 4,203 & 10 & 0,420 & 0,0796 & 0,999933 \\
\hline Error & 760,611 & 144 & 5,282 & & \\
\hline $\begin{array}{l}\text { Fig. } 10 \text { B: Ovarios } \\
\text { Hembras Copuladas }\end{array}$ & $\begin{array}{l}\text { Suma de } \\
\text { Cuadrados }\end{array}$ & $\begin{array}{l}\text { Grados de } \\
\text { Libertad }\end{array}$ & $\begin{array}{c}\text { Suma de los } \\
\text { Cuadrados } \\
\text { Medios }\end{array}$ & $\begin{array}{c}\text { Valor del } \\
\text { estadístico F }\end{array}$ & $\begin{array}{c}\text { Valor de la } \\
\text { probabilidad } \\
\text { "p" }\end{array}$ \\
\hline Intercepción & 2608,385 & 1 & 2608,385 & 604,9576 & 0,000000 \\
\hline Dosis & 86,292 & 5 & 17,258 & 4,0027 & 0,002539 \\
\hline Tiempo & 1,927 & 2 & 0,963 & 0,2234 & 0,800215 \\
\hline Dosis*Tiempo & 16,585 & 10 & 1,659 & 0,3847 & 0,950334 \\
\hline Error & 383,740 & 89 & 4,312 & & \\
\hline $\begin{array}{l}\text { Fig. } 10 \text { B: Ovarios } \\
\text { Hembras Grávidas }\end{array}$ & $\begin{array}{l}\text { Suma de } \\
\text { Cuadrados }\end{array}$ & $\begin{array}{l}\text { Grados de } \\
\text { Libertad }\end{array}$ & $\begin{array}{c}\text { Suma de los } \\
\text { Cuadrados } \\
\text { Medios }\end{array}$ & $\begin{array}{c}\text { Valor del } \\
\text { estadístico F }\end{array}$ & $\begin{array}{c}\text { Valor de la } \\
\text { probabilidad } \\
\text { "p" }\end{array}$ \\
\hline Intercepción & 15448,17 & 1 & 15448,17 & 1522,234 & 0,000000 \\
\hline Dosis & 13,46 & 5 & 2,69 & 0,265 & 0,930909 \\
\hline Tiempo & 16,55 & 2 & 8,28 & 0,815 & 0,445671 \\
\hline Dosis*Tiempo & 18,35 & 10 & 1,83 & 0,181 & 0,997250 \\
\hline Error & 913,35 & 90 & 10,15 & & \\
\hline
\end{tabular}




\begin{tabular}{|c|c|c|c|c|c|}
\hline Fig. 11: Oviductos & $\begin{array}{c}\text { Suma de } \\
\text { Cuadrados }\end{array}$ & $\begin{array}{c}\text { Grados de } \\
\text { Libertad }\end{array}$ & $\begin{array}{c}\text { Suma de los } \\
\text { Cuadrados } \\
\text { Medios }\end{array}$ & $\begin{array}{c}\text { Valor del } \\
\text { estadístico F }\end{array}$ & $\begin{array}{c}\text { Valor de la } \\
\text { probabilidad } \\
\text { "p" }\end{array}$ \\
\hline Intercepción & 578,1588 & 1 & 578,1588 & 128,3326 & $\mathbf{0 , 0 0 0 0 0 0}$ \\
\hline Dosis & 115,4582 & 5 & 23,0916 & 5,1256 & $\mathbf{0 , 0 0 0 3 5 4}$ \\
\hline Tiempo & 1,2755 & 2 & 0,6377 & 0,1416 & 0,868201 \\
\hline Dosis*Tiempo & 19,0755 & 10 & 1,9075 & 0,4234 & 0,931775 \\
\hline Error & 400,9593 & 89 & 4,5052 & & \\
\cline { 1 - 3 } & &
\end{tabular}

\begin{tabular}{|c|c|c|c|c|c|}
\hline Fig. 12 A: Útero & $\begin{array}{c}\text { Suma de } \\
\text { Cuadrados }\end{array}$ & $\begin{array}{c}\text { Grados de } \\
\text { Libertad }\end{array}$ & $\begin{array}{c}\text { Suma de los } \\
\text { Cuadrados } \\
\text { Medios }\end{array}$ & $\begin{array}{c}\text { Valor del } \\
\text { estadístico F }\end{array}$ & $\begin{array}{c}\text { Valor de la } \\
\text { probabilidad } \\
\text { "p" }\end{array}$ \\
\hline Intercepción & 727,9939 & 1 & 727,9939 & 633,6333 & $\mathbf{0 , 0 0 0 0 0 0}$ \\
\hline Estado & 325,5767 & 2 & 162,7883 & 141,6882 & $\mathbf{0 , 0 0 0 0 0 0}$ \\
\hline Dosis & 16,8402 & 5 & 3,3680 & 2,9315 & $\mathbf{0 , 0 1 3 1 1 6}$ \\
\hline Estado*Dosis & 41,4224 & 10 & 4,1422 & 3,6053 & $\mathbf{0 , 0 0 0 1 3 8}$ \\
\hline Error & 413,6111 & 360 & 1,1489 & & \\
\cline { 1 - 3 } & & &
\end{tabular}

\begin{tabular}{|c|c|c|c|c|c|}
\hline $\begin{array}{l}\text { Fig. } 12 \text { B: Útero } \\
\text { Hembras Vírgenes }\end{array}$ & $\begin{array}{l}\text { Suma de } \\
\text { Cuadrados }\end{array}$ & $\begin{array}{l}\text { Grados de } \\
\text { Libertad }\end{array}$ & $\begin{array}{c}\text { Suma de los } \\
\text { Cuadrados } \\
\text { Medios }\end{array}$ & $\begin{array}{c}\text { Valor del } \\
\text { estadístico F }\end{array}$ & $\begin{array}{c}\text { Valor de la } \\
\text { probabilidad } \\
\text { "p" }\end{array}$ \\
\hline Intercepción & 9,07064 & 1 & 9,070645 & 15,88112 & 0,000107 \\
\hline Dosis & 9,16392 & 5 & 1,832785 & 3,20889 & 0,008899 \\
\hline Tiempo & 2,00137 & 2 & 1,000686 & 1,75203 & 0,177098 \\
\hline Dosis*Tiempo & 4,96159 & 10 & 0,496159 & 0,86869 & 0,564017 \\
\hline Error & 82,24691 & 144 & 0,571159 & & \\
\hline $\begin{array}{c}\text { Fig. } 12 \text { B: Útero } \\
\text { Hembras Copuladas }\end{array}$ & $\begin{array}{l}\text { Suma de } \\
\text { Cuadrados }\end{array}$ & $\begin{array}{l}\text { Grados de } \\
\text { Libertad }\end{array}$ & $\begin{array}{c}\text { Suma de los } \\
\text { Cuadrados } \\
\text { Medios }\end{array}$ & $\begin{array}{c}\text { Valor del } \\
\text { estadístico F }\end{array}$ & $\begin{array}{c}\text { Valor de la } \\
\text { probabilidad } \\
\text { "p" }\end{array}$ \\
\hline Intercepción & 75,57427 & 1 & 75,57427 & 891,2049 & 0,000000 \\
\hline Dosis & 1,18517 & 5 & 0,23703 & 2,7952 & 0,021539 \\
\hline Tiempo & 0,19584 & 2 & 0,09792 & 1,1547 & 0,319777 \\
\hline Dosis*Tiempo & 0,27341 & 10 & 0,02734 & 0,3224 & 0,973260 \\
\hline Error & 7,63201 & 90 & 0,08480 & & \\
\hline $\begin{array}{l}\text { Fig. } 12 \text { B: Útero } \\
\text { Hembras Grávidas }\end{array}$ & $\begin{array}{l}\text { Suma de } \\
\text { Cuadrados }\end{array}$ & $\begin{array}{l}\text { Grados de } \\
\text { Libertad }\end{array}$ & $\begin{array}{c}\text { Suma de los } \\
\text { Cuadrados } \\
\text { Medios }\end{array}$ & $\begin{array}{c}\text { Valor del } \\
\text { estadístico F }\end{array}$ & $\begin{array}{c}\text { Valor de la } \\
\text { probabilidad } \\
\text { "p" }\end{array}$ \\
\hline Intercepción & 271,8066 & 1 & 271,8066 & 264,8316 & 0,000000 \\
\hline Dosis & 25,9835 & 5 & 5,1967 & 5,0634 & 0,000390 \\
\hline Tiempo & 1,4835 & 2 & 0,7418 & 0,7227 & 0,488219 \\
\hline Dosis*Tiempo & 7,2449 & 10 & 0,7245 & 0,7059 & 0,716665 \\
\hline Error & 92,3704 & 90 & 1,0263 & & \\
\hline
\end{tabular}




\begin{tabular}{|c|c|c|c|c|c|}
\hline Fig. 13 A: Espermatecas & $\begin{array}{c}\text { Suma de } \\
\text { Cuadrados }\end{array}$ & $\begin{array}{c}\text { Grados de } \\
\text { Libertad }\end{array}$ & $\begin{array}{c}\text { Suma de los } \\
\text { Cuadrados } \\
\text { Medios }\end{array}$ & $\begin{array}{c}\text { Valor del } \\
\text { estadístico F }\end{array}$ & $\begin{array}{c}\text { Valor de la } \\
\text { probabilidad } \\
\text { "p" }\end{array}$ \\
\hline Intercepción & 1374,724 & 1 & 1374,724 & 532,4753 & $\mathbf{0 , 0 0 0 0 0 0}$ \\
\hline Estado & 747,765 & 2 & 373,882 & 144,8168 & $\mathbf{0 , 0 0 0 0 0 0}$ \\
\hline Dosis & 99,412 & 5 & 19,882 & 7,7011 & $\mathbf{0 , 0 0 0 0 0 1}$ \\
\hline Estado*Dosis & 41,581 & 10 & 4,158 & 1,6106 & 0,101666 \\
\hline Error & 929,434 & 360 & 2,582 & &
\end{tabular}

\begin{tabular}{|c|c|c|c|c|c|}
\hline $\begin{array}{l}\text { Fig. } 13 \text { B: Espermatecas } \\
\text { Hembras Vírgenes }\end{array}$ & $\begin{array}{l}\text { Suma de } \\
\text { Cuadrados }\end{array}$ & $\begin{array}{l}\text { Grados de } \\
\text { Libertad }\end{array}$ & $\begin{array}{c}\text { Suma de los } \\
\text { Cuadrados } \\
\text { Medios }\end{array}$ & $\begin{array}{c}\text { Valor del } \\
\text { estadístico F }\end{array}$ & $\begin{array}{c}\text { Valor de la } \\
\text { probabilidad } \\
\text { "p" }\end{array}$ \\
\hline Intercepción & 39,8361 & 1 & 39,83608 & 55,65980 & 0,000000 \\
\hline Dosis & 5,2051 & 5 & 1,04102 & 1,45453 & 0,208425 \\
\hline Tiempo & 0,1248 & 2 & 0,06241 & 0,08721 & 0,916536 \\
\hline Dosis*Tiempo & 1,6612 & 10 & 0,16612 & 0,23210 & 0,992688 \\
\hline Error & 103,0617 & 144 & 0,71571 & & \\
\hline $\begin{array}{l}\text { Fig. } 13 \text { B: Espermatecas } \\
\text { Hembras Copuladas }\end{array}$ & $\begin{array}{l}\text { Suma de } \\
\text { Cuadrados }\end{array}$ & $\begin{array}{l}\text { Grados de } \\
\text { Libertad }\end{array}$ & $\begin{array}{c}\text { Suma de los } \\
\text { Cuadrados } \\
\text { Medios }\end{array}$ & $\begin{array}{c}\text { Valor del } \\
\text { estadístico F }\end{array}$ & $\begin{array}{c}\text { Valor de la } \\
\text { probabilidad } \\
\text { "p" }\end{array}$ \\
\hline Intercepción & 1589,845 & 1 & 1589,845 & 423,5945 & 0,000000 \\
\hline Dosis & 94,276 & 5 & 18,855 & 5,0237 & 0,000423 \\
\hline Tiempo & 1,443 & 2 & 0,722 & 0,1923 & 0,825425 \\
\hline Dosis*Tiempo & 7,013 & 10 & 0,701 & 0,1868 & 0,996841 \\
\hline Error & 334,037 & 89 & 3,753 & & \\
\hline
\end{tabular}

\begin{tabular}{|c|c|c|c|c|c|}
\hline Fig. 14: Bursa & $\begin{array}{c}\text { Suma de } \\
\text { Cuadrados }\end{array}$ & $\begin{array}{c}\text { Grados de } \\
\text { Libertad }\end{array}$ & $\begin{array}{c}\text { Suma de los } \\
\text { Cuadrados } \\
\text { Medios }\end{array}$ & $\begin{array}{c}\text { Valor del } \\
\text { estadístico F }\end{array}$ & $\begin{array}{c}\text { Valor de la } \\
\text { probabilidad } \\
\text { "p" }\end{array}$ \\
\hline Intercepción & 53,48148 & 1 & 53,48148 & 141,7230 & $\mathbf{0 , 0 0 0 0 0 0}$ \\
\hline Dosis & 4,72840 & 5 & 0,94568 & 2,5060 & $\mathbf{0 , 0 3 5 8 5 5}$ \\
\hline Tiempo & 1,35185 & 2 & 0,67593 & 1,7912 & 0,172659 \\
\hline Dosis*Tiempo & 1,58642 & 10 & 0,15864 & 0,4204 & 0,933387 \\
\hline Error & 33,96296 & 90 & 0,37737 & & \\
\cline { 1 - 3 } & &
\end{tabular}

\begin{tabular}{|c|c|c|c|c|c|}
\hline Fig. 15 A: Ovarios & $\begin{array}{c}\text { Suma de } \\
\text { Cuadrados }\end{array}$ & $\begin{array}{c}\text { Grados de } \\
\text { Libertad }\end{array}$ & $\begin{array}{c}\text { Suma de los } \\
\text { Cuadrados } \\
\text { Medios }\end{array}$ & $\begin{array}{c}\text { Valor del } \\
\text { estadístico F }\end{array}$ & $\begin{array}{c}\text { Valor de la } \\
\text { probabilidad } \\
\text { "p" }\end{array}$ \\
\hline Intercepción & 5494,569 & 1 & 5494,569 & 852,4150 & $\mathbf{0 , 0 0 0 0 0 0}$ \\
\hline Dosis & 125,771 & 5 & 25,154 & 3,9024 & $\mathbf{0 , 0 0 3 0 1 3}$ \\
\hline Tiempo & 3,193 & 2 & 1,597 & 0,2477 & 0,781117 \\
\hline Dosis*Tiempo & 6,226 & 10 & 0,623 & 0,0966 & 0,999826 \\
\hline Error & 580,130 & 90 & 6,446 & & \\
\cline { 1 - 3 } & &
\end{tabular}




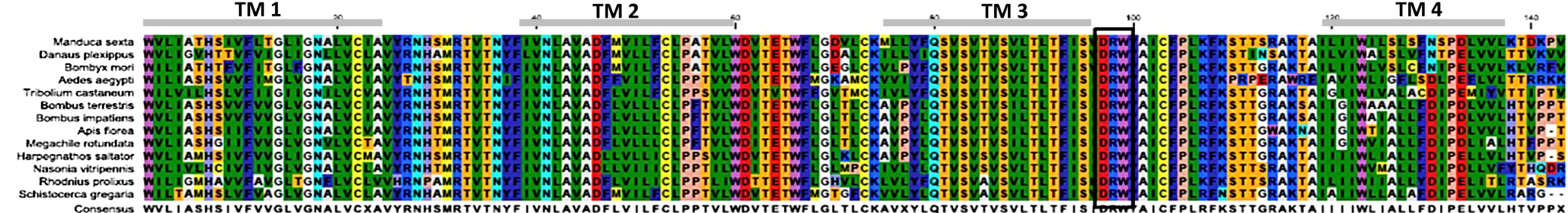

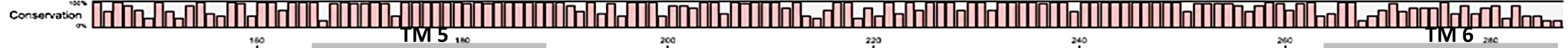
100 ind

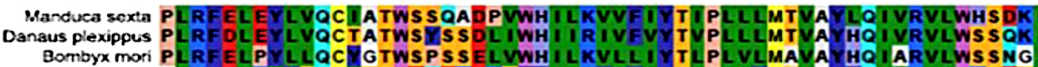

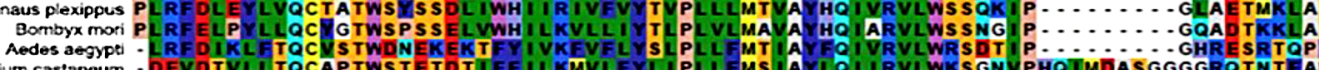

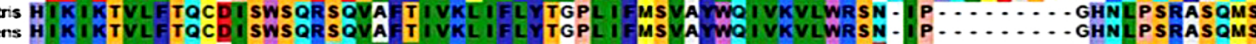
TQCGI SWSQKNQVIT

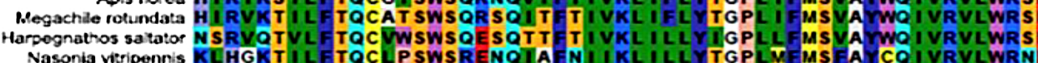

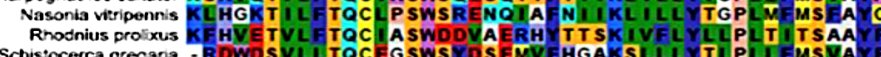
GHNLPRASOMS

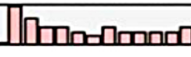
חח SGGGNPEGQLRSRKAAKMLVAVVIMFAICYFPVHLLSVLRY

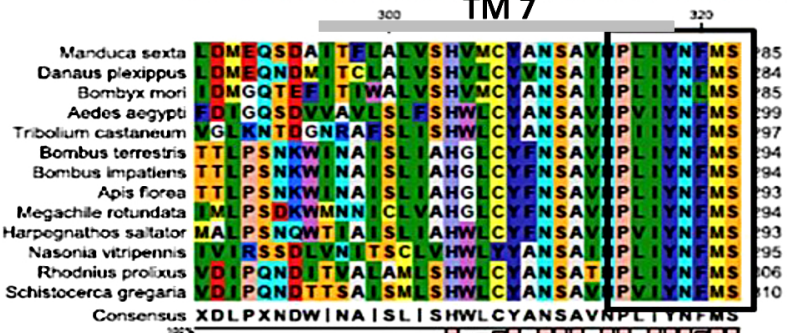

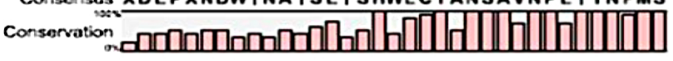


